MARCIO NIEBLAS ZAPATER

\title{
ANÁLISE TÉCNICO-ECONÔMICA DA INTRODUÇÃO DE SERVIÇOS IPTV POR OPERADORAS DE TELECOMƯNICAÇÕES
}

Dissertação apresentada à Escola Politécnica da Universidade de São Paulo para obtenção do título de Mestre em Engenharia Elétrica

São Paulo 
MARCIO NIEBLAS ZAPATER

\section{ANÁLISE TÉCNICO-ECONÔMICA DA INTRODUÇÃO DE SERVIÇOS IPTV POR OPERADORAS DE TELECOMƯNICAÇÕES}

Dissertação apresentada à Escola Politécnica da Universidade de São Paulo para obtenção do título de Mestre em Engenharia Elétrica

Área de Concentração:

Sistemas Digitais

Orientadora:

Profa. Dra. Graça Bressan

São Paulo 


\section{AGRADECIMENTOS}

Aos meus familiares e, em especial, aos meus pais por todo incentivo, apoio e compreensão que foram determinantes para a realização deste trabalho.

À minha orientadora Graça Bressan pela paciência, compreensão, dedicação, confiança, e intervenções certeiras.

Aos professores Tereza Cristina e Wilson Ruggiero, que participaram do exame de qualificação, pelas preciosas sugestões e contribuições para o encaminhamento do trabalho.

Ao professor Moacyr Martucci Jr. pelo incentivo e aconselhamento em iniciar o programa de mestrado.

Aos professores Denis Gabos e Regina Melo Silveira pelo apoio e colaboração

À Promon e à sua Diretoria por todo suporte, incentivo, compreensão e flexibilidade que viabilizaram a realização deste trabalho.

Aos amigos da Promon: Alex Paulino, Fábio Jardim, Lucas Pinz, Guilherme Tuche, Júlio Levy, Luiz Faro, Fábio Damasceno, Orlando Bugbil, Moisés Lopes, Danilo Cardoso, José Ricardo, Eduardo Harada, Eduardo Caraver, Cristina Miyata e Antonio Cruz pela amizade, paciência e cooperação; Eduardo Cardoso, Rodrigo Parreira, Mário Ripper, Carlos Pingarilho e Jorge Leonel pelo apoio, incentivo e compreensão.

Aos amigos da Cisco Systems, Rodrigo Uchoa, Mauro Amorim e Rodrigo Linhares, e da UTStarcom, Fausto e Gustavo, por todo seu apoio e disposição em colaborar com o trabalho.

A todos os colegas, pesquisadores e professores do LARC e do PCS e, em especial, a Ana Maria, Christiane Meiler, e Raoni pela amizade, colaboração e incentivo.

A todos os amigos e familiares que não foram citados e que, direta ou indiretamente, contribuíram para a realização deste trabalho. 


\section{RESUMO}

A evolução do portfolio de serviços das operadoras em direção a ofertas convergentes que combinam serviços de voz, dados e vídeo é uma tendência do setor de telecomunicações. É neste contexto que o conceito de Internet Protocol Television (IPTV) ganha um papel relevante, pois permite às operadoras oferecerem serviços de vídeo utilizando como base uma infra-estrutura de rede convergente baseada em Internet Protocol (IP).

Entretanto, existem diversos desafios relacionados à introdução de serviços IPTV. A nova realidade que inclui os serviços de vídeo apresenta um patamar de complexidade superior ao dos serviços já conhecidos. No que diz respeito à tecnologia, existem questões que permeiam desde a adaptação da infra-estrutura de rede e sistemas existentes até a implantação de plataformas de vídeo, até então não usuais no ambiente das operadoras.

Neste cenário de complexidade, a metodologia de análise técnico-econômica proposta neste trabalho se torna útil para suportar a tomada de decisão relacionada à introdução de serviços IPTV. A metodologia proposta visa gerar subsídios para a identificação das condições em que se verifica a viabilidade econômica do serviço tendo em vista aspectos relacionados ao próprio serviço e a arquitetura tecnológica que o suporta.

Para isto, a metodologia abrange as seguintes atividades: definição do serviço; mapeamento de seus requisitos; análise da arquitetura tecnológica existente; delineamento e dimensionamento da arquitetura tecnológica que suportará os novos serviços; modelagem econômica; análise de sensibilidade e cenários; e, por fim, análise dos resultados. Além da proposição da metodologia de análise, este trabalho inclui a aplicação da metodologia proposta em um caso de referência representativo da realidade de uma operadora de telecomunicações.

Palavras-chave: Análise técnico-econômica. IPTV. Sistemas multimídia. Telecomunicações. Redes e comunicação de dados. 


\begin{abstract}
The evolution towards integrated service offerings that combine voice, video and data is a key trend for telecommunications service providers. IP-based technology plays an important role on this scenario by enabling the delivery of video over a multiservice IP network, a service commonly known as Internet Protocol Television (IPTV).

There are many challenges to a large scale roll out of IPTV services, though. When compared to traditional voice and data services, video services introduce a higher level of complexity to the service providers' environment. The technology issues related to IPTV range from the upgrade of the existing networks and systems to the deployment of new technology platforms oriented to video services delivery, which are not common in a service provider's technology architecture.

Within this context, the techno-economic analysis methodology presented in this work aims to support the decision process underlying the IPTV services launch by a telecommunications service provider. The proposed methodology leads to the identification of economic feasibility conditions associated to relevant services aspects and required technology infrastructure alternatives.

The methodology encompasses the main following activities: services definition; services' requirements identification; analysis of the existing technology architecture; design and dimensioning of the new technology infrastructure that will support the services; economic analysis; sensitivity and scenario analysis. Besides the methodology proposition, this work includes a case study illustrating its application to a fictional service provider.
\end{abstract}

Keywords: Techno-economic Analysis. Methodology. IPTV. Multimedia Systems. Telecommunications. Data network communications. 


\section{LISTA DE FIGURAS}

Figura 1 - Processo de Desenvolvimento de Produtos e Serviços ...........................24

Figura 2 - Dimensões de análise de serviços de telecomunicações .......................25

Figura 3 - Dimensões de análise pertinentes à metodologia proposta ....................26

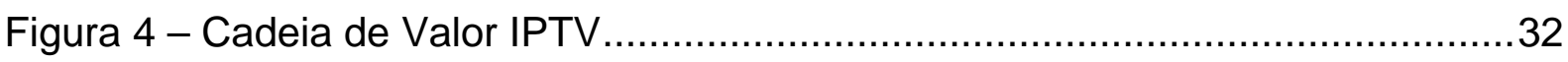

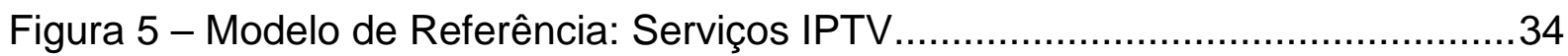

Figura 6 - Arquitetura de referência IPTV: Segmentos ............................................39

Figura 7 - Arquitetura de referência NGN: Camadas .......................................... 41

Figura 8 - Modelo de referência: arquitetura tecnológica de IPTV..........................43

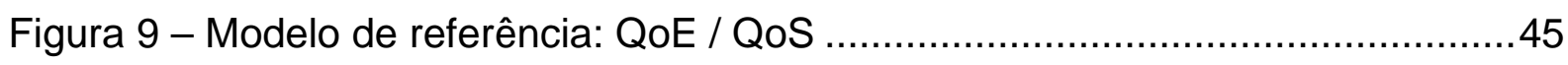

Figura 10 - Curva típica de popularidade de conteúdo de vídeo ..............................55

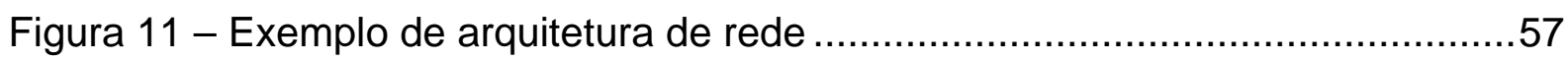

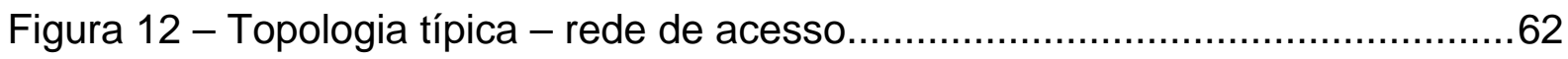

Figura 13 - Distribuição geográfica - rede de acesso ........................................62

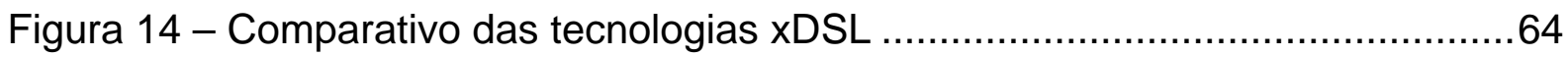

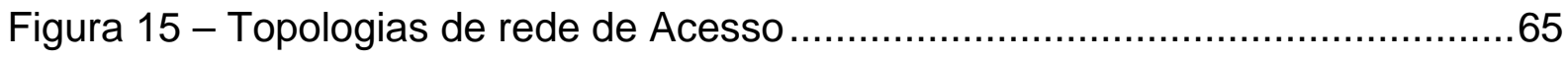

Figura 16 - Topologias de rede de acesso FTTH .............................................66

Figura 17 - Pilha de protocolos para transporte multimídia ......................................69

Figura 18 - Ganhos com utilização de distribuição multicast ..................................70

Figura 19 - Exemplo de atraso de mudança de canal .........................................77

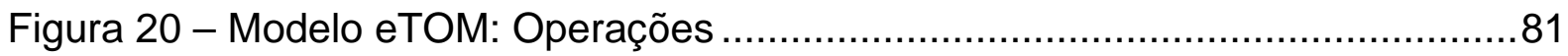

Figura 21 - Exemplo de arquitetura típica de OSS/BSS .....................................82

Figura 22 - Sistema integrado de gerenciamento - IPTV .........................................

Figura 23 - Metodologia de análise técnico-econômica de referência........................91

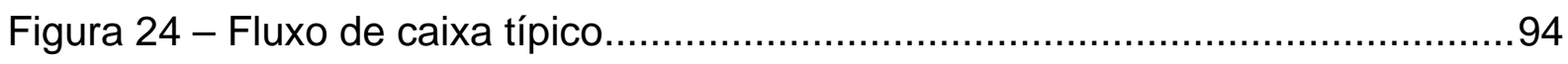

Figura 25 - Metodologia de análise técnico-econômica proposta..........................108

Figura 26 - Definição de objetivos e escopo de análise ......................................109

Figura 27 - Etapa de Modelagem de Serviços e Arquitetura Tecnológica................111

Figura 28 - Etapa de Definição dos Serviços .........................................................112

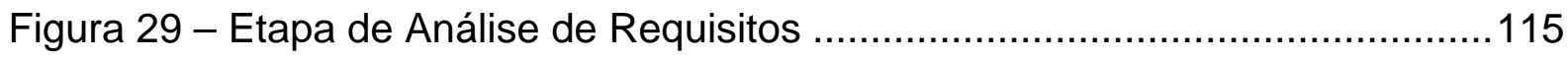

Figura 30 - Etapa de Análise da Arquitetura Tecnológica Atual ...........................120

Figura 31 - Etapa de Definição da Arquitetura Tecnológica .................................124 
Figura 32 - Etapa de Análise e Dimensionamento - Serviço ...............................125

Figura 33 - Etapa de Análise e Dimensionamento - Rede ....................................132

Figura 34 - Etapa de Análise e Dimensionamento - Gerenciamento .....................143

Figura 35 - Etapa de Validação da Arquitetura Tecnológica e Dimensionamento.. 145

Figura 36 - Etapa de Definição dos Cenários de Serviços e Tecnologia.................146

Figura 37 - Etapa de Modelagem Econômica.................................................148

Figura 38 - Etapas de Análise de Sensibilidade / Cenários e Resultados ..............149

Figura 39 - Metodologia de análise técnico-econômica detalhada ........................150

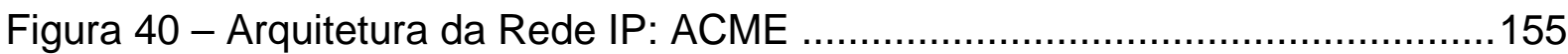

Figura 41 - Arquitetura da solução de IPTV - ACME .......................................157

Figura 42 - Tráfego IPTV: Serviço VOD …………......................................161

Figura 43 - Tráfego IPTV: Serviço broadcast ...................................................161

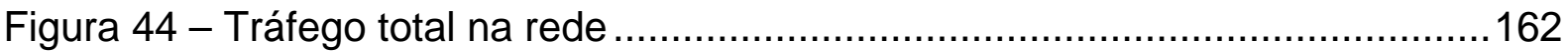

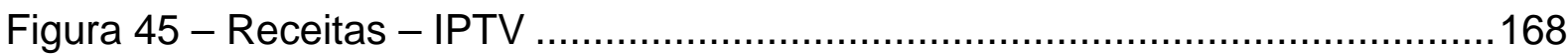

Figura 46 - Custos e despesas operacionais - IPTV........................................168

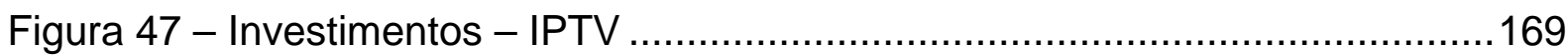

Figura 48 - Investimento médio por assinante - IPTV .......................................170

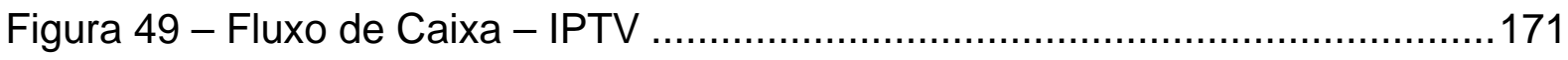

Figura 50 - Posicionamento da ACME na Cadeia de Valor .................................200

Figura 51 - Evolução de Assinantes Internet Banda Larga e IPTV - ACME ...........202

Figura 52 - Topologia do núcleo da Rede IP - ACME..........................................208

Figura 53 - Estrutura típica de um PoP de núcleo da Rede IP ............................210

Figura 54 - Topologia típica da rede de agregação - ACME ..................................213

Figura 55 - Topologia da rede de acesso ACME............................................214

Figura 56 - Distribuição geográfica da rede de acesso - ACME ...........................215

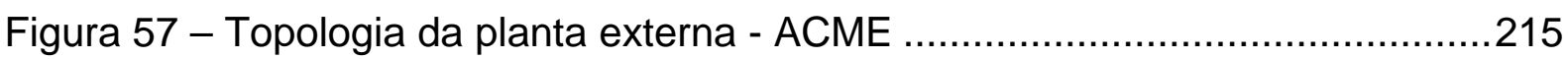

Figura 58 - Projeção de Evolução de Tráfego - ACME.......................................220

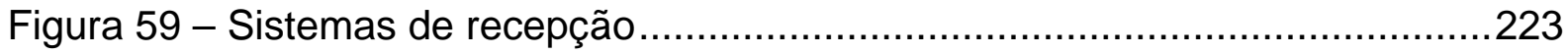

Figura 60 - Sistemas de processamento e codificação ........................................225

Figura 61 - Perfil de tráfego VOD no núcleo da rede.......................................232

Figura 62 - Perfil de tráfego VOD nas redes de agregação...................................232

Figura 63 - Quantidade de set-top boxes por tipo ………...............................234

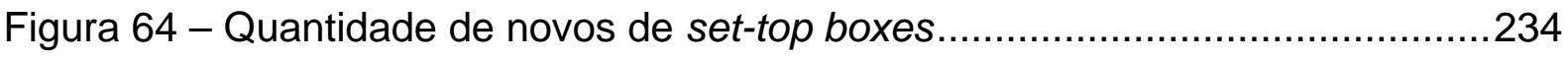

Figura 65 - Largura de banda no acesso por quantidade de pontos .....................236 
Figura 66 - Rede de Acesso ACME - FTTN: ADSL2 + ..................................238

Figura 67 - Rede de Acesso ACME - FTTCab: VDSL2 ……...........................239

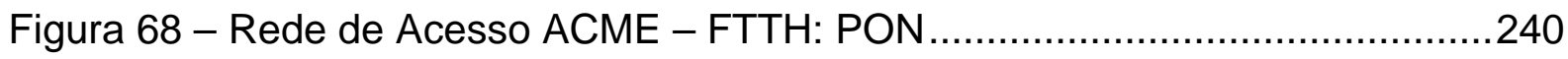

Figura 69 - Rede de Acesso ACME - FTTH: Ethernet estrela ativa .....................240

Figura 70 - Rede de Acesso ACME - FTTH: Ethernet ponto-a-ponto ...................241

Figura 71 - Tráfego total nas redes de agregação............................................248

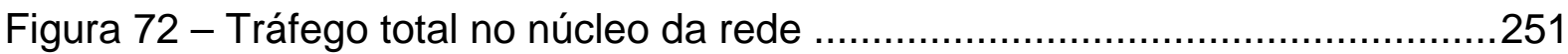

Figura 73 - Investimentos - serviço IPTV (grandes blocos) ……........................257

Figura 74 - Investimentos em Plataforma de Serviço - serviço IPTV .......................258

Figura 75 - Investimentos em Rede - serviço IPTV ..........................................259

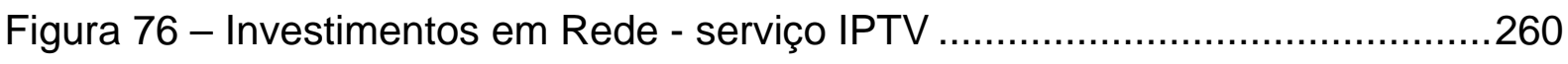

Figura 77 - Fluxo de Caixa Acumulado - cenários de adoção do serviço ...............264

Figura 78 - Investimento por assinante - cenários de adoção do serviço ...............265

Figura 79 - Investimento por assinante - adoção conservadora ............................266

Figura 80 - Fluxo de Caixa Acumulado - cenários de adoção de HDTV .................267

Figura 81 - Investimento por assinante - cenários de adoção de HDTV .................268

Figura 82 - Receita por Assinante - cenários de adoção de HDTV ......................268

Figura 83 - Fluxo de Caixa Acumulado - cenários de adoção de VOD....................270

Figura 84 - Investimento por assinante - cenários de adoção de VOD..................271

Figura 85 - Receita por Assinante - cenários de adoção de VOD .........................271

Figura 86 - Fluxo de Caixa Acumulado - cenários de oferta set-top box ...............273

Figura 87 - Investimento por assinante - cenários de oferta set-top box ...............274

Figura 88 - Fluxo de Caixa Acumulado - cenários de distribuição de conteúdo ....276

Figura 89 - Investimento por assinante - cenários de distribuição de conteúdo ...277

Figura 90 - Fluxo de Caixa Acumulado - cenários de tecnologia de acesso .........279

Figura 91 - Investimento por assinante - cenários de tecnologia de acesso .........280

Figura 92 - Fluxo de Caixa Acumulado - cenários de preço do serviço ..................282

Figura 93 - Fluxo de Caixa Acumulado - cenários de custo de conteúdo ...............284

Figura 94 - Fluxo de Caixa Acumulado - cenários de investimento .......................285

Figura 95 - Fluxo de Caixa Acumulado - cenários de taxa de desconto .................286 


\section{LISTA DE TABELAS}

Tabela 1 - Comparativo entre formatos: Analógico x SDTV x HDTV.......................36

Tabela 2 - Comparativo entre Codificadores ...........................................................51

Tabela 3 - Comparativo de banda necessária no acesso.......................................61

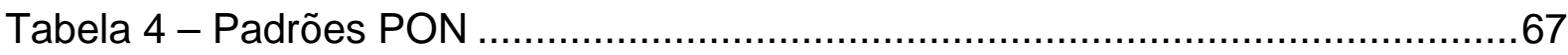

Tabela 5 - Exemplos de parâmetros de qualidade de transporte ………………...76

Tabela 6 - Projetos envolvendo análise técnico-econômica em telecomunicações .90

Tabela 7 - Principais requisitos de Serviço - Exemplos .......................................118

Tabela 8 - Cenários de Serviços e Tecnologia - IPTV ACME.................................166

Tabela 9 - Indicadores econômicos - cenário base ...............................................171

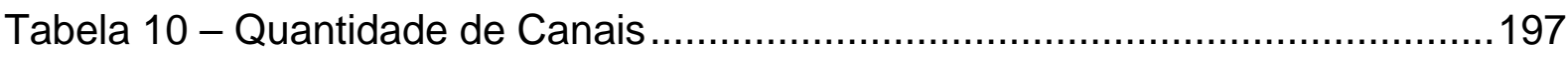

Tabela 11 - Características dos cenários - SDTV e HDTV ..................................203

Tabela 12 - Características dos cenários - VOD e broadcast.................................204

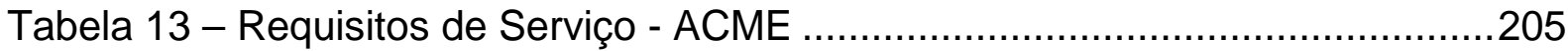

Tabela 14 - Serviços suportados e tráfego gerado ............................................207

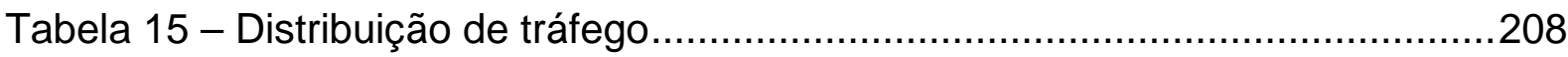

Tabela 16 - Matriz de tráfego no núcleo da rede .............................................209

Tabela 17 - Distribuição de tráfego - Redes de Agregação ..................................212

Tabela 18 - Distribuição de elementos de rede ..............................................217

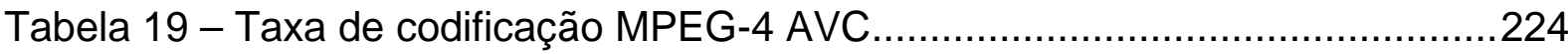

Tabela 20 - Dimensionamento - Servidores de Vídeo ........................................230

Tabela 21 - Quantidade de portas instaladas por tecnologia de acesso ................243

Tabela 22 - Dimensionamento Acesso - Cobertura de uma central ......................244

Tabela 23 - Tráfego de vídeo na agregação - VOD...........................................247

Tabela 24 - Tráfego de vídeo na agregação - broadcast.......................................247

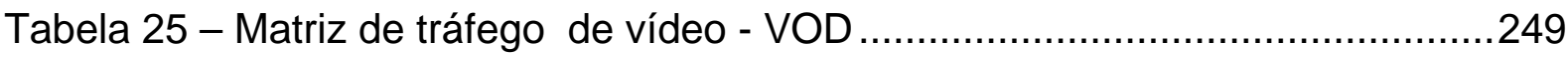

Tabela 26 - Matriz de tráfego de vídeo - broadcast ..........................................250

Tabela 27 - Premissas de Operação e Manutenção de Rede e Sistemas ..............255

Tabela 28 - Premissas de manutenção relacionada ao cliente .............................255

Tabela 29 - Cálculo do Fluxo de Caixa do Projeto ...............................................262

Tabela 30 - Indicadores econômicos - cenários de adoção do serviço ..................264

Tabela 31 - Indicadores econômicos - cenários de adoção de HDTV ....................267 
Tabela 32 - Indicadores econômicos - cenários de adoção de VOD ......................270

Tabela 33 - Indicadores econômicos - cenários de oferta set-top box...................274

Tabela 34 - Indicadores econômicos - cenários de distribuição de conteúdo........276

Tabela 35 - Indicadores econômicos - cenários de tecnologia de acesso ..............279

Tabela 36 - Indicadores econômicos - cenários de preço do serviço ......................283

Tabela 37 - Indicadores econômicos - cenários de custo de conteúdo ..................284

Tabela 38 - Indicadores econômicos - cenários de investimento ...........................285

Tabela 39 - Indicadores econômicos - cenários de taxa de desconto ....................287 


\section{LISTA DE ABREVIATURAS}

ACTS Advanced Communications Technologies and Services

ADSL Asymmetric Digital Subscriber Line

API Application Programming Interface

APON ATM PON

ATIS Alliance for Telecommunications Industry Solutions

ATM Asynchronous Transfer Mode

AVC Advanced Video Coding

BPON Broadband PON

B-RAS Broadband Remote Access Server

BSSR Broadband Service Switch Router

BSS Business Support Systems

CAPEX Capital Expenditure

CAS Conditional Access Systems

CBT Core Based Trees

CDN Content Delivery Network

CPE Customer Premises Equipment

co Central Office

CoS Class of Service

DG Distribuidor Geral

DiffServ Differentiated Services

DLNA Digital Living Network Alliance

DNG Delivery Network Gateway

DRM Digital Rights Management

DSCP Differentiated Services Code Point 
DSL Digital Subscriber Line

DSLAM DSL Access Multiplexer

DTT Digital Terrestrial Television

DVB Digital Video Broadcast

DVD Digital Versatile Disc

DVR Digital Video Recorder

DVMRP Distance Vector Multicast Routing Protocol

DWDM Dense Wavelength Division Multiplexing

ECOSYS Techno-ECOnomics of integrated communication SYStems and services

EPON Ethernet PON

EPG Eletronic Program Guide

EoMPLS Ethernet over MPLS

eTOM Enhanced Telecommunications Operations Model

ETSI European Telecommunications Standards Institute

EXP Experimental Field

FR Full Reference

FTTCab Fiber to the cabinet

FTTCurb Fiber to the curb

FTTH Fiber to the home

FTTN Fiber to the node

FTTP Fiber to the premises

GMPLS Generalized Multiprotocol Label Switching

GPON Gigabit PON

GOP Group of Pictures

HD High Definition

HDTV High Definition Television 
HGI Home Gateway Institute

HTML HyperText Markup Language

H-VPLS Hierarchical VPLS

IDS Intrusion Detection System

IPS Intrusion Prevention System

IGMP Internet Group Management Protocol

IMS IP Multimedia Subsystem

IntServ Integrated Services

IIF IPTV Interoperability Forum

IP Internet Protocol

IPTV Internet Protocol Television

IRD Integrated Receiver Decoder

IRT Integrated Receiver Transcoder

ISO International Standards Organization

IST Information Society Technologies

ITU International Telecommunication Union

LSP Label Switched Path

MACRS Modified Accelerated Cost Recovery

MBGP Multicast Border Gateway Protocol

MDI Media Delivery Index

MMOG Massively Multiplayer Online Games

MPEG Moving Picture Experts Group

MPLS Multiprotocol Label Switching

MPQM Moving Picture Quality Metrics

MOS Mean Opinion Score

MOSPF Multicast Open Shortest Path First 
MAN Metropolitan Area Network

MSAP Multiservice Access Platform

MSDP Multicast Source-Discovery Protocol

MSE Mean Square Error

NGN Next Generation Network

NPVR Network Personal Video Recorder

NR No Reference

OA\&M Operation, Administration and Maintenance

OLT Optical Line Termination

ONT Optical Network Terminal

ONU Optical Network Unit

OPEX Operating Expenditure

OPTIMUM OPTImised architectures for MUItiMedia networks and services

OSS Operation Support Systems

PC Personal Computer

P2P Point-to-point

PIM-DM Protocol-Independent Multicast - Dense Mode

PIM-SM Protocol-Independent Multicast - Sparse Mode

PIM-SSM Protocol-Independent Multicast - Specific Source Mode

PNSR Peak Signal-to-Noise ratio

PON Passive Optical Network

PVR Personal Video Recorder

QoS Quality of Service

QoE Quality of Experience

RACE Research in Advance Communications in Europe

RF Rádio-freqüência 
RN Remote Node

RP Rendezvous Point

RR Reduced Reference

RSTP Rapid Spanning Tree Protocol

RSVP Resource Reservation Protocol

RTP Real Time Protocol

RTCP Real Time Control Protocol

RTSP Real Time Streaming Protocol

SD Standard Definition

SDH Synchronous Digital Hierarchy

SDK Software Development Kit

SDP Service Delivery Platform

SD Standard Definition

SDTV Standard Definition Television

SHE Super Head-End

SLM Service Level Management

SMPTE Society of Motion Picture and Television Engineers

SONET Synchronous Optical Network

STB Set-top box

STP Spanning Tree Protocol

TCP Transmission Control Protocol

ToS Type of Service

UDP User Datagram Protocol

VDSL Very-high-bit-rate Digital Subscriber Line

VOD Video on Demand

VOIP Voice over IP 


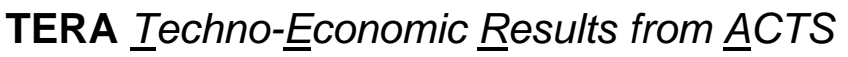

TIR Taxa Interna de Retorno

TITAN $\underline{T}$ ool for Introduction scenario and Iechnical evaluation for $\underline{\text { Access }}$ Network

TMF TeleManagement Forum

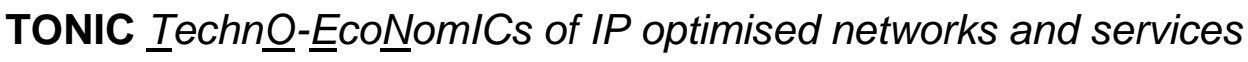

TS Transport Stream

TV Televisão

UPnP Universal Plug and Play Forum

URD Unidade Receptora Decodificadora

USTA United States Telecom Association

VLAN Virtual Local Area Network

VHO Video Hub Office

VPL Valor Presente Líquido

VPLS Virtual Private Label Switching

VPN Virtual Private Network

VSo Video Serving Office

WACC Weighted Average Cost of Capital

WAN Wide Area Network

WM9 Windows Media 9 


\section{SUMÁRIO}

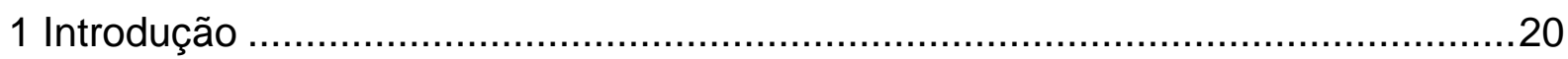

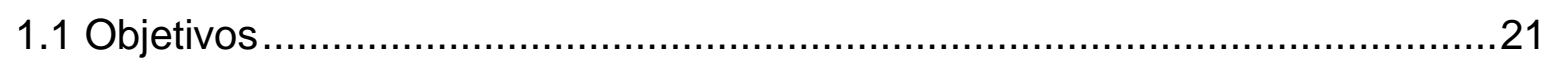

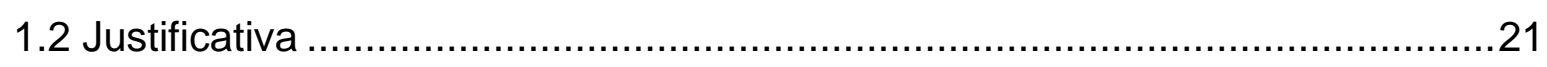

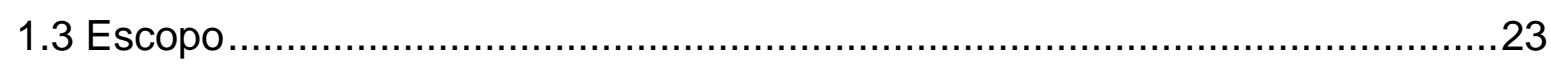

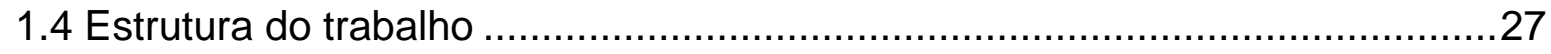

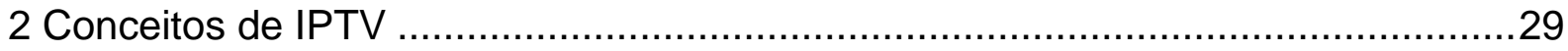

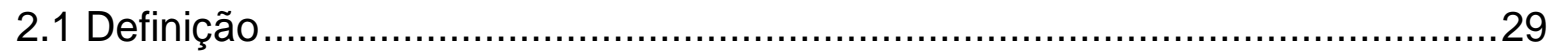

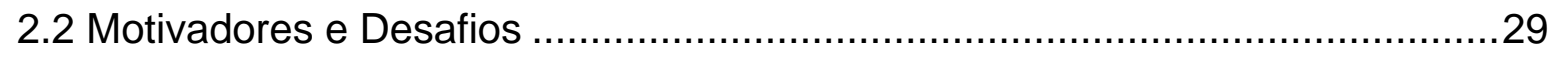

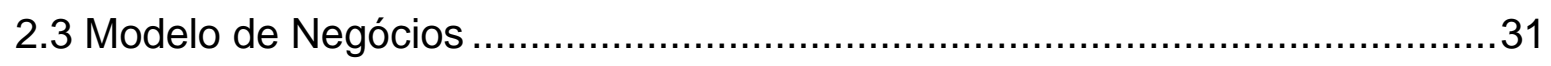

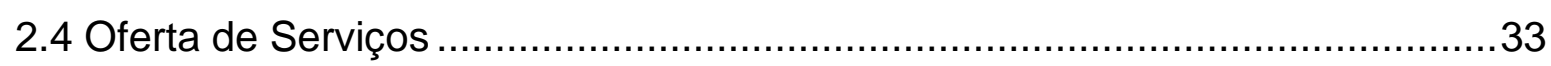

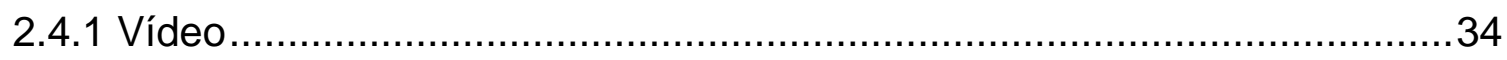

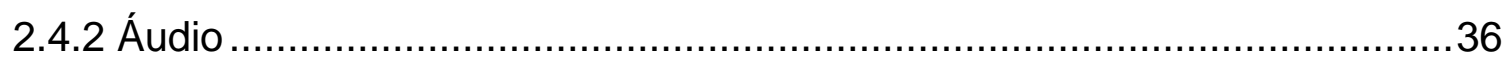

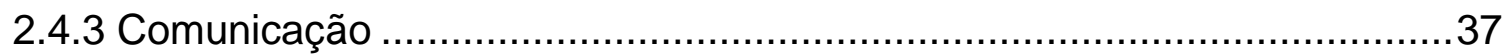

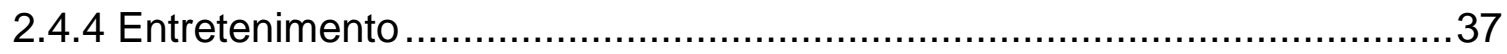

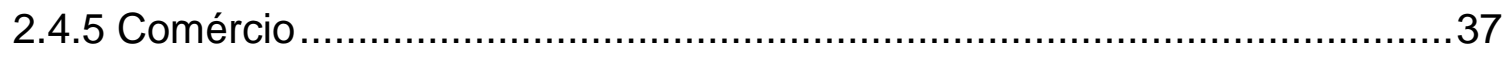

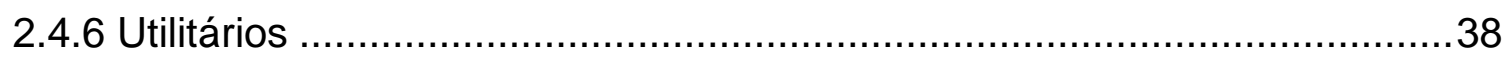

2.5 Modelos de Referência de Arquitetura Tecnológica .......................................38

2.5.1 Modelo de referência em Segmentos...................................................38

2.5.2 Modelo de referência em Camadas ....................................................40

2.5.3 Modelo de referência: Segmento x Camadas .......................................42

2.6 Quality of Experience e Serviços IPTV ....................................................43

2.6.1 Conceito de Quality of Experience ................................................. 43

2.6.2 Modelo integrado de Quality of Experience......................................... 45

2.6.3 Quality of Experience e a Arquitetura Tecnológica ...............................48

2.7 Infra-estrutura de Serviço ............................................................ 49

2.7.1 Sistemas de Head-end .......................................................... 49

2.7.2 Middleware ................................................................................... 51

2.7.3 Digital Rights Management ...................................................... 53

2.7.4 Servidores de Vídeo................................................................. 54

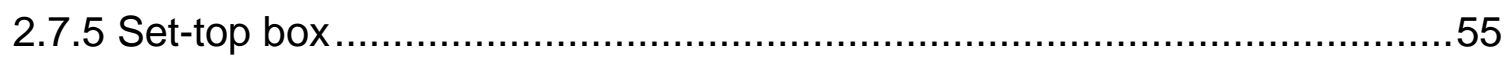




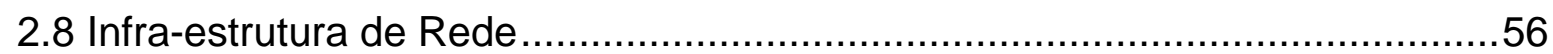

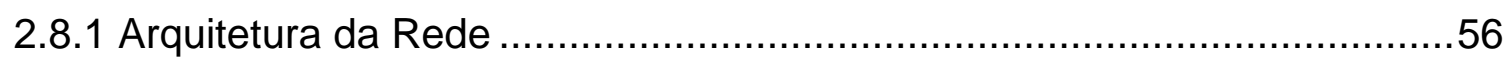

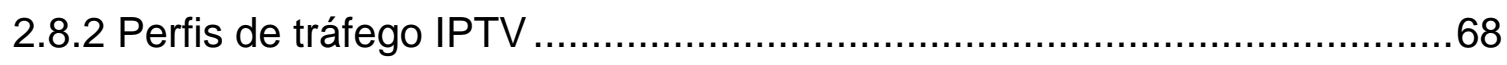

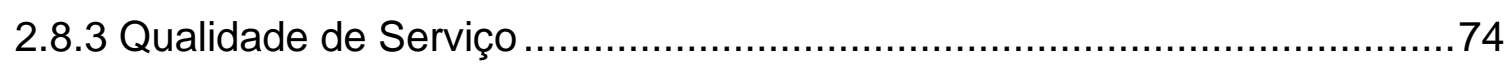

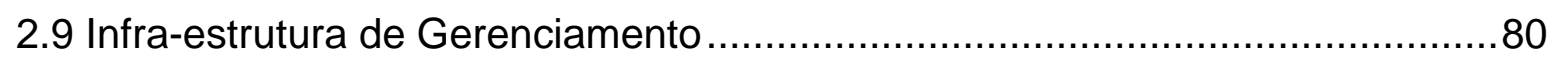

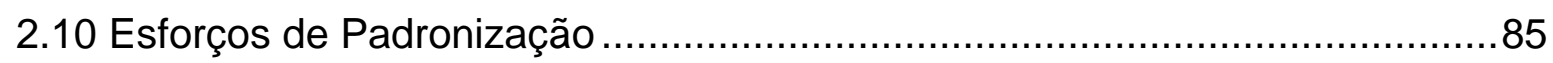

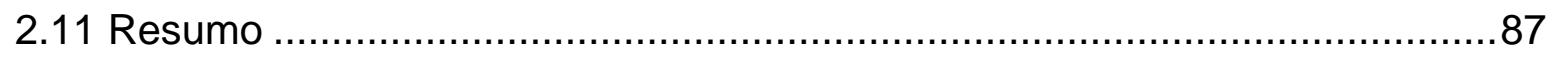

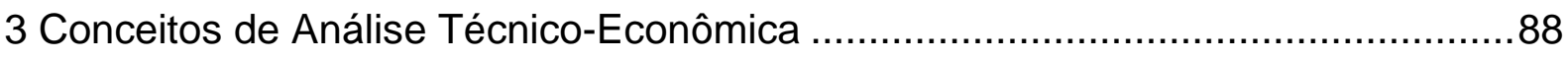

3.1 Metodologias de Análise Técnico-Econômica de referência.............................88

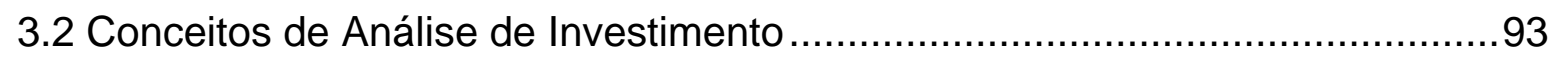

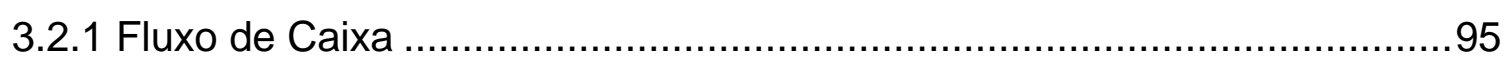

3.2.2 Taxa Mínima de Atratividade...............................................................98

3.2.3 Métodos de Análise de Investimento....................................................100

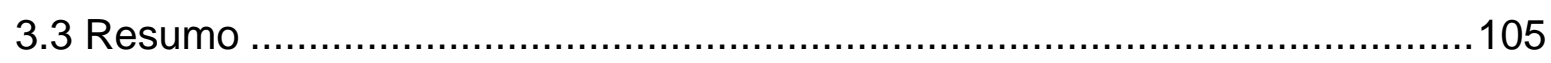

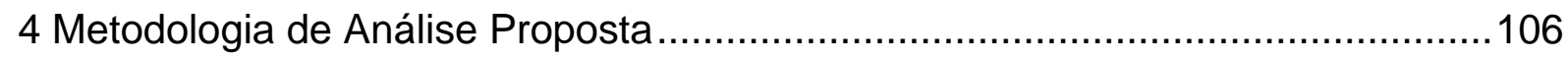

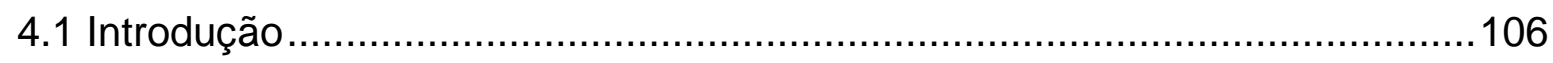

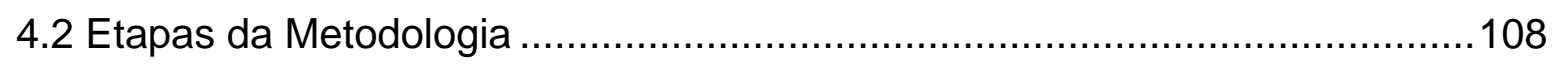

4.2.1 Definição de Objetivos e Escopo da Análise ..........................................108

4.2.2 Modelagem de Serviços e Arquitetura Tecnológica ...............................110

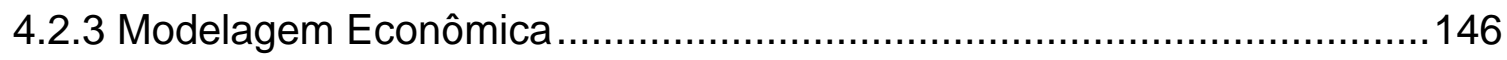

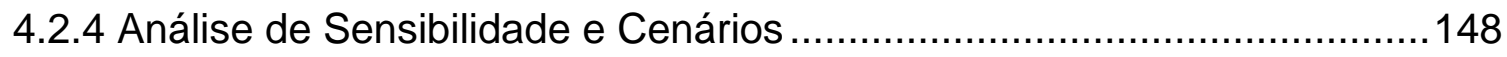

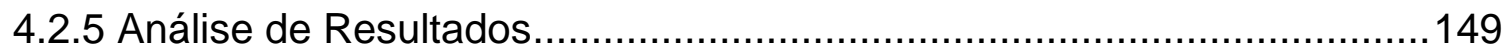

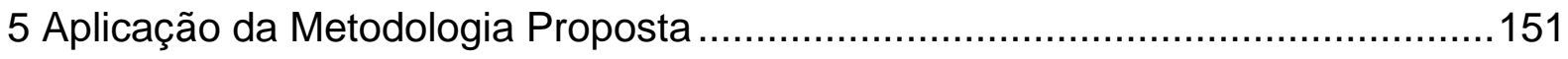

5.1 Etapas da Metodologia e Resultados .....................................................151

5.1.1 Definição de Objetivos e Escopo da Análise ..........................................151

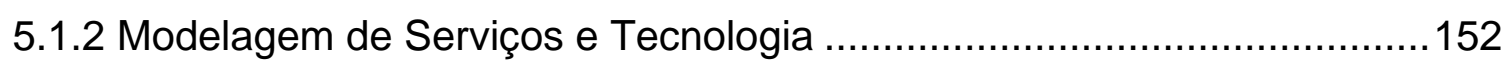

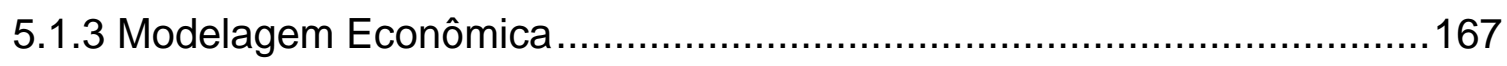

5.1.4 Análise de Sensibilidade e Cenários ................................................... 172

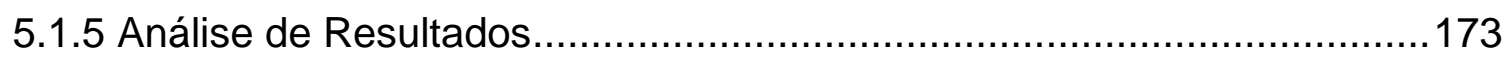

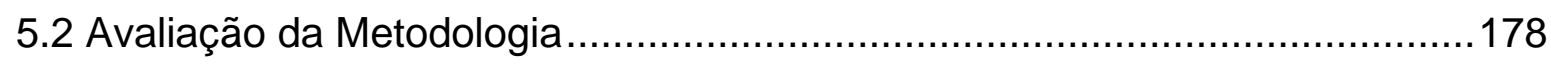

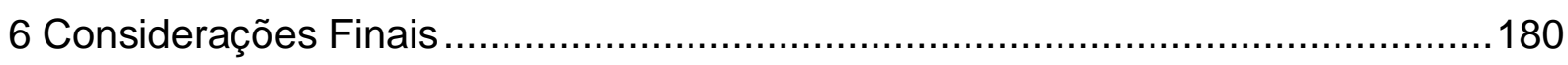

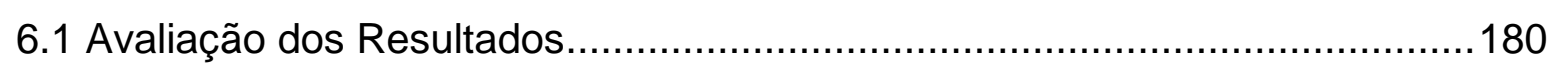

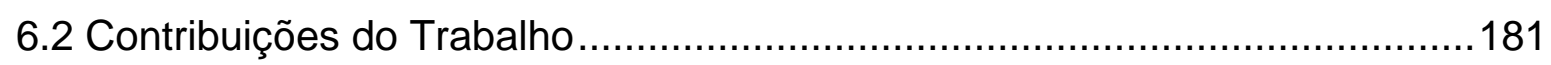

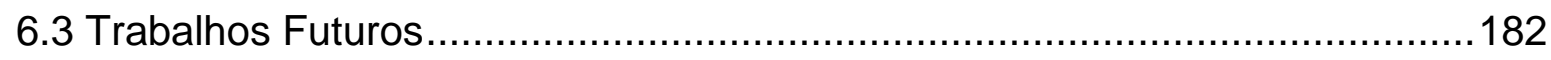


Lista de Referências. 183

Apêndice A - Arquitetura de Redes de Agregação ..........................................188

A.1 Inteligência Centralizada e Distribuída .......................................................188

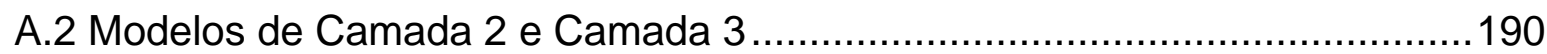

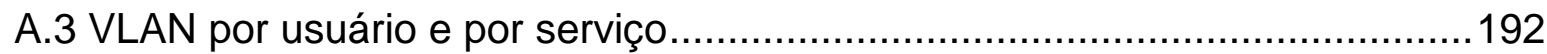

Apêndice B - Informações Complementares à Aplicação da Metodologia ..............194

B.1 Definição de Objetivos e Escopo da Análise ................................................194

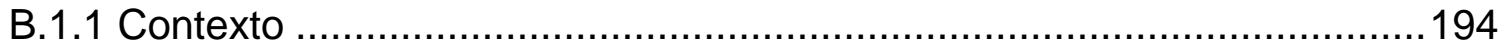

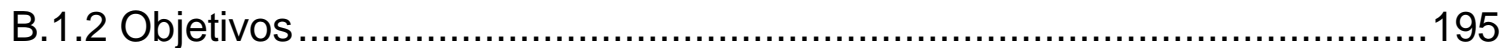

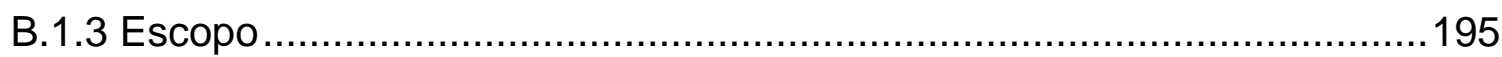

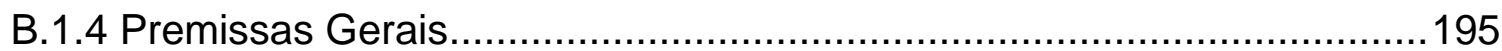

B.2 Modelagem de Serviços e Tecnologia......................................................196

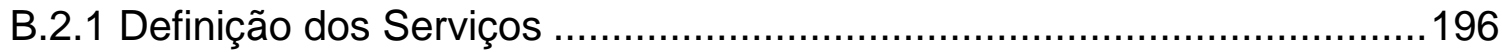

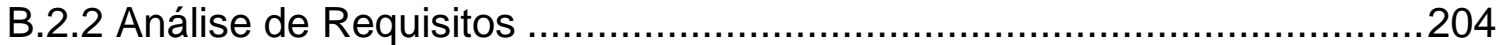

B.2.3 Análise da Arquitetura Tecnológica Atual ...........................................206

B.2.4 Definição e Dimensionamento da Arquitetura Tecnológica .....................221

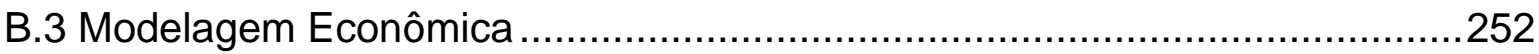

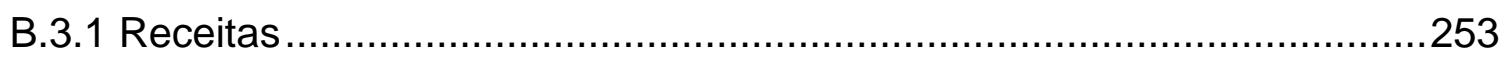

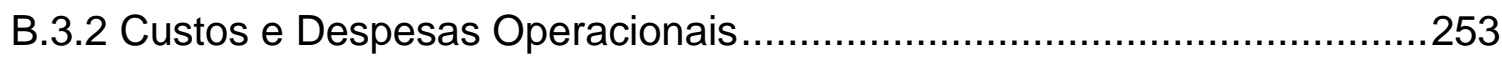

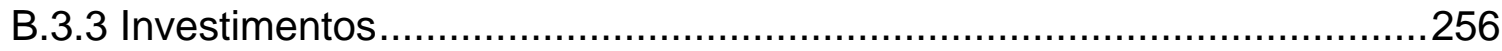

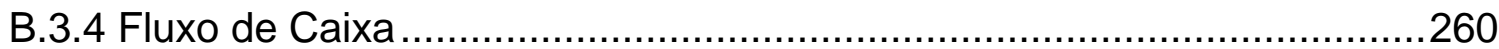

B.4 Análise de Sensibilidade e Cenários .......................................................263

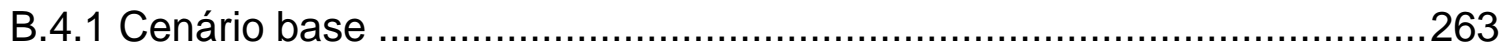

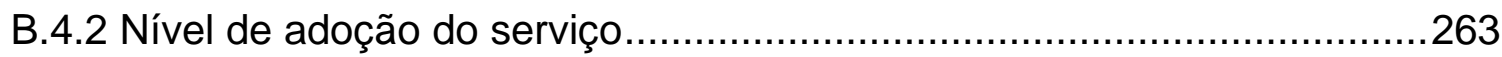

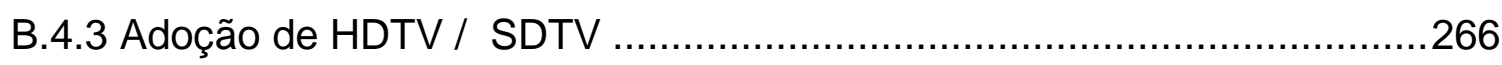

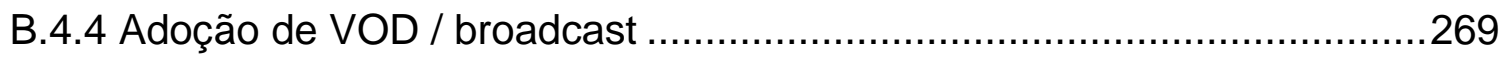

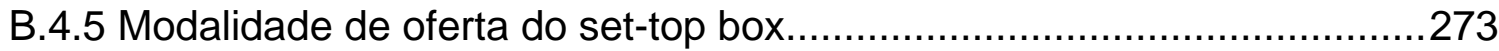

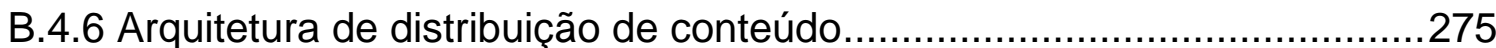

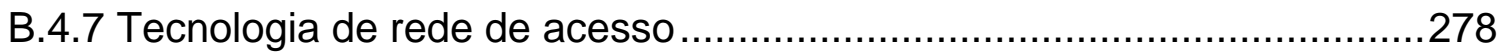

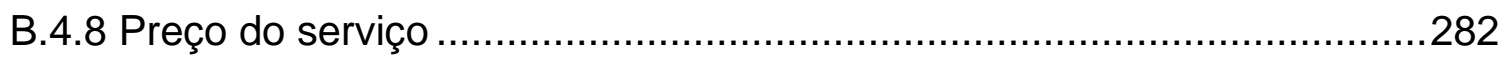

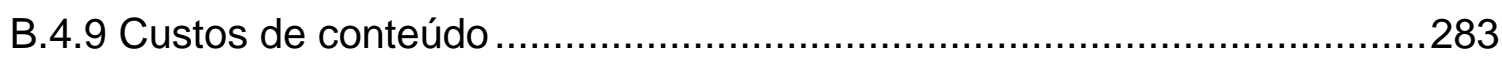

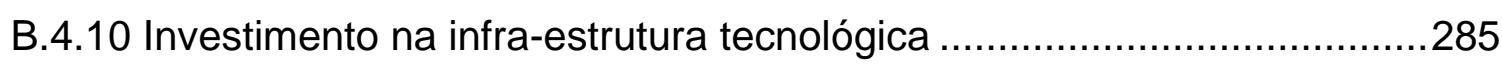

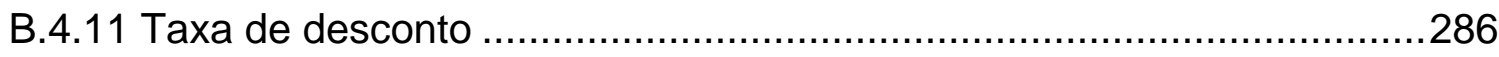




\section{INTRODUÇÃO}

Mesmo após os avanços crescentes na indústria de telecomunicações, a televisão ainda continua sendo o meio de comunicação mais eficiente para educar, informar e entreter públicos de massa. Os televisores ainda representam os aparelhos eletrônicos domésticos mais populares ao redor do mundo. Desde a sua massificação na metade da década de 50, avanços não faltaram à TV (1): a evolução para TV em cores, a invenção do controle remoto, até os mais recentes avanços rumo à digitalização do sinal e High Definition Television (HDTV).

A mais recente novidade neste meio é o conceito de Internet Protocol Television (IPTV) que é, em grande parte, viabilizado pela difusão do Internet Protocol (IP) e a evolução das plataformas que permitem a oferta de serviços de transmissão de vídeo utilizando uma infra-estrutura IP convergente. A combinação do binômio IP+TV é expressão do conceito da convergência multimídia: voz, vídeo e dados (2). Muitas vezes confundido com o serviço de Internet TV em que se utiliza o PC conectado à Internet pública para assistir programas e canais de TV, o serviço IPTV permite o uso de uma rede banda larga para entregar conteúdo de TV com garantia de qualidade de serviço e potencialmente acrescido de serviços interativos (3).

Os serviços IPTV se aproveitam da capacidade e da natureza bidirecional das redes banda larga para oferecer uma grande dose de interatividade e atender à crescente sofisticação dos requisitos dos assinantes (1). Assinantes estes que buscam cada vez mais serviços individualizados e personalizados que os permitam escolher o que e quando assistir, em contraposição à menor flexibilidade inerente ao formato convencional de serviços de broadcast oferecidos hoje (2). Vídeo sob demanda também conhecidos como Video on Demand (VOD), gravação seletiva de conteúdo e aplicações interativas como os jogos online figuram na lista de alguns serviços IPTV (4) que ilustram as tendências de consumo permeado por maior poder conferido ao usuário final.

O advento de IPTV abre novas oportunidades de negócio às operadoras de telecomunicações (4)(5) que agora, pelo menos em tese, tem elementos em mãos para colocar em prática uma oferta Triple Play (voz + acesso à Internet banda larga + TV) ou até Quadruple Play (Triple Play + celular). O acesso banda larga se torna o 
veículo não apenas para acessar a Internet e fazer chamadas utilizando voz sobre IP (voice over ip - VoIP), mas também para assistir TV. Ou seja, ele passa a ser o meio de transporte de inúmeros serviços digitais para uma residência, viabilizando o que se denomina digital home convergence. Em contrapartida, existem diversos desafios concretos para que os serviços IPTV se tornem realidade para uma operadora. Entre eles estão: definição do modelo de negócios, aspectos tecnológicos, operacionais e regulatórios (3)(5).

\subsection{OBJETIVOS}

O objetivo deste trabalho é apresentar, com base em conhecimentos práticos e teóricos, uma metodologia para análise técnica e econômica da introdução de serviços IPTV em operadoras de telecomunicações. Além de apresentar a metodologia de análise, este trabalho tem por objetivo ilustrar sua aplicação através de um estudo de caso. A metodologia proposta fornece os subsídios necessários para identificar o impacto na infra-estrutura existente; delinear a infra-estrutura tecnológica que suporta o serviço em toda a sua extensão; e verificar as condições em que este serviço se viabiliza economicamente.

A metodologia serve de base para que uma operadora de telecomunicações possa avaliar e planejar de maneira estruturada e sistematizada a introdução do serviço IPTV em seu ambiente. Em especial, os responsáveis pelo planejamento da arquitetura tecnológica de uma operadora constituem o público-alvo deste trabalho, em conjunto com os responsáveis pela especificação do serviço que será oferecido ao cliente final. Em geral, nas operadoras, essas funções são realizadas pelas áreas de Engenharia e Marketing, respectivamente.

\subsection{JUSTIFICATIVA}

A convergência de televisão e telefonia vem se mostrando uma tendência no setor de telecomunicações. Essa convergência se materializa nos serviços IPTV. Embora 
o conceito de transmitir vídeo sobre IP não seja novo e já tenham ocorrido diversas tentativas de torná-lo um serviço para o usuário final, apenas recentemente essa tendência se expressa de forma tão clara (6). Os principais motivadores dessa tendência tem sido, por um lado, a pressão mercadológica das operadoras de telecomunicações para encontrarem novas fontes de receita e protegerem seu mercado. Por outro lado, a eliminação gradual das barreiras tecnológicas contribuiu para a consolidação dessa tendência (5).

A constatação dessa tendência se dá pelo movimento das grandes operadoras de telecomunicações do mundo nesse sentido (4). A lista das operadoras ao redor do mundo que estão testando a tecnologia ou lançaram serviços em escala comercial é bastante extensa (7). Na Europa, Telefônica (Espanha), France Telecom (França), Telecom Itália (Itália), FastWeb (Itália), Britsh Telecom (Reino Unido), Belgacom (Bélgica), TeliaSonera (Suécia) e Swisscom (Suiça) são exemplos de operadoras em estágios variados de teste ou implementação comercial. Nos Estados Unidos, as principais operadoras, Verizon, SBC e BellSouth, também já se movimentaram neste sentido. Na Ásia, operadoras como PCCW (Hong Kong), Chungwa (China), Yahoo!Broadband (Japão) já oferecem comercialmente o serviço. No Brasil, grandes operadoras do cenário nacional - Telefônica, Oi e Brasil Telecom - já anunciaram testes da tecnologia e planejam a oferta desses serviços no futuro próximo (8).

Apesar desse movimento massivo das operadoras rumo ao IPTV, existem diversos desafios para transformar os testes em serviços de grande escala da mesma forma que os serviços de telefonia e acesso à Internet atualmente. Esses desafios recaem no campo regulatório, na formatação do modelo de negócios, nos processos operacionais, na viabilidade econômica e também na frente tecnológica (3). A introdução desses serviços traz novos elementos que não são tradicionais à realidade das operadoras habituadas a prestarem serviços de voz e, mais recentemente, serviços de dados de alta velocidade em maior intensidade. A nova realidade que inclui os serviços de vídeo apresenta um patamar de complexidade superior ao dos serviços já conhecidos. Em particular, no que tange à tecnologia (6), existem questões que permeiam desde a adaptação da infra-estrutura de rede e sistemas de suporte até a implementação de novas plataformas não usuais ao ambiente tecnológico das operadoras como, por exemplo, a recepção de vídeo, sua 
codificação, armazenamento, distribuição, e a proteção dos direitos autorais do conteúdo contra eventual pirataria ou reprodução ilegal.

Neste contexto de complexidade (6), acredita-se que uma metodologia estruturada para realizar a análise técnico-econômica da introdução do serviço IPTV se torna útil, em especial, para as equipes de Engenharia de operadoras de telecomunicações. Essas equipes possuem o árduo desafio de delinear uma arquitetura tecnológica adequada e flexível capaz de suportar a introdução de novos serviços de maneira pouco traumática e ao mesmo tempo visam à minimização de investimentos e de custos operacionais associados às plataformas tecnológicas. Este trabalho também possui utilidade para a área de Marketing responsável pela especificação do serviço que será ofertado, na medida em que se faz necessária uma visão integrada do serviço e do que as plataformas tecnológicas são capazes de oferecer e, em especial, como tais plataformas influem na viabilidade econômica da oferta.

A principal justificativa desse trabalho reside na inexistência de uma metodologia dessa natureza específica para IPTV. A aplicação da metodologia proposta nesse trabalho a uma situação real visa gerar subsídios claros aos tomadores de decisão para que determinem as plataformas tecnológicas que melhor suportarão o serviço, baseados em uma análise técnico-econômica de sua viabilidade.

\subsection{ESCOPO}

O escopo deste trabalho abrange:

- Especificação da uma metodologia para a análise técnico-econômica da introdução de serviços IPTV em uma operadora de telecomunicações;

- Aplicação da metodologia a um caso de referência;

- Avaliação dos resultados da aplicação da metodologia.

A metodologia proposta nesse trabalho se situa na etapa inicial do ciclo de desenvolvimento de produtos de uma operadora de telecomunicações. Segundo Cooper, o processo de desenvolvimento de produtos pode ser caracterizado por 
uma seqüência de estágios e decisões ${ }^{1}$. Este processo de desenvolvimento é amplamente utilizado na indústria de telecomunicações (10) e define diversos estágios discretos em que são realizadas análises e coletadas as informações necessárias para levar o processo adiante ou não. A metodologia a ser proposta neste trabalho visa suportar o estágio de Análise Detalhada a respeito do novo serviço e oferece subsídios para o estágio posterior que compreende o seu Desenvolvimento propriamente dito.

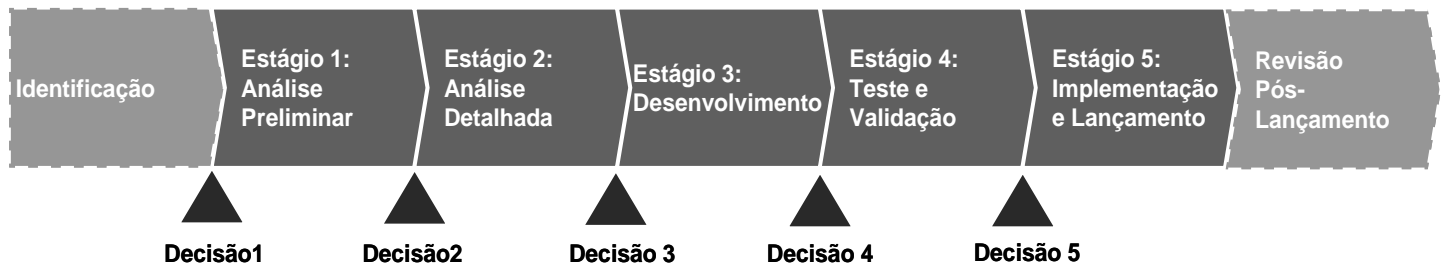

Figura 1 - Processo de Desenvolvimento de Produtos e Serviços (fonte: adaptado de Cooper (9))

O processo de desenvolvimento de produtos delineado por Cooper está apresentado na Figura 1 e detalhado brevemente a seguir (9).

- Estágio 1 - Análise Preliminar: nesta etapa é realizada uma rápida investigação a respeito da atratividade e viabilidade do serviço.

- Estágio 2 - Análise Detalhada: esta etapa é orientada à confecção de um Business Case do serviço, demonstrando sua viabilidade. Compreende avaliações do produto em suas diversas dimensões: mercado, tecnologia, operações e econômica, e a elaboração de um plano de desenvolvimento.

- Estágio 3 - Desenvolvimento: compreende o desenvolvimento do serviço propriamente dito, em que são elaborados os planos de marketing, o projeto tecnológico detalhado e a análise de processos para suportar o serviço.

- Estágio 4 - Teste e Validação: é a etapa da verificação e validação do serviço proposto através de testes e pilotos com funcionários e clientes selecionados. O resultado desta etapa é o serviço testado e especificado para o seu lançamento.

- Estágio 5 - Implementação e Lançamento: ocorre a implementação do serviço em larga escala. Todos s planos elaborados nos estágios anteriores

\footnotetext{
${ }^{1}$ O processo de desenvolvimento de produtos proposto por Cooper é conhecido como Stage-gate (9)
} 
são colocados em prática e o serviço é lançado no mercado. Esta etapa vem acompanhada do monitoramento e ajustes no serviço pós-lançamento.

A análise da introdução de um novo serviço de telecomunicações tradicionalmente leva em conta cinco dimensões (9)(11) conforme ilustrado na Figura 2.

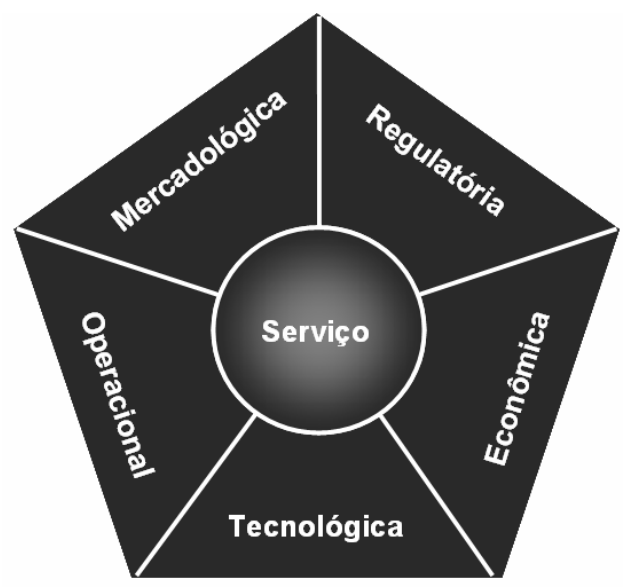

Figura 2 - Dimensões de análise de serviços de telecomunicações

A seguir, cada uma das dimensões da Figura 2 é brevemente descrita:

- Mercadológica (Marketing): nesta dimensão são avaliadas as questões pertinentes ao ambiente de negócios em que o serviço se insere. São analisadas questões como a dinâmica do mercado, incluindo as dimensões de oferta e a demanda. A análise da oferta passa pela identificação da dinâmica competitiva da indústria, da concorrência e os detalhes específicos do serviço em questão. Já a análise da demanda trata de questões relacionadas às características de consumo do usuário final, desde seus requisitos, seu comportamento até a estimativa do mercado potencial. A conjugação das dimensões oferta versus demanda permite analisar o serviço sob a perspectiva de marketing, identificando desde potenciais modelos de negócios até o espectro possível da oferta de acordo com as condições mercadológicas.

- Regulatória: considerando a natureza fortemente regulada do setor de telecomunicações, as questões regulatórias se colocam como relevantes na introdução do serviço. Nesta dimensão, é analisado se o serviço desenhado em questão está de acordo com o arcabouço regulatório do mercado em que a operadora atua. 
- Operacional: é a dimensão que avalia o impacto do novo serviço nos processos de negócio e de suporte da operadora de telecomunicações. A avaliação da introdução do novo serviço requer o mapeamento dos processos que o suportam de maneira fim-a-fim de maneira a identificar as adaptações necessárias nos processos existentes.

- Tecnológica: nesta dimensão são avaliadas as questões de cunho tecnológico que se colocam relevantes para a prestação do serviço. Ou seja, nesta dimensão, os requisitos do serviço identificados na dimensão de marketing são transpostos para as arquiteturas tecnológicas necessárias para a prestação do serviço.

- Econômica: esta é a dimensão que valida ou não o sentido econômico do lançamento do serviço. Esta dimensão possui uma forte relação com as demais. É nela que se verifica se o serviço definido com as condições de contorno das frentes de Marketing, Operações, Tecnologia e Regulatório, é economicamente viável, ou seja, se ele cria valor para a operadora.

A metodologia proposta nesse trabalho focaliza duas das dimensões apresentadas: Tecnológica e Econômica conforme ilustrado na Figura 3.

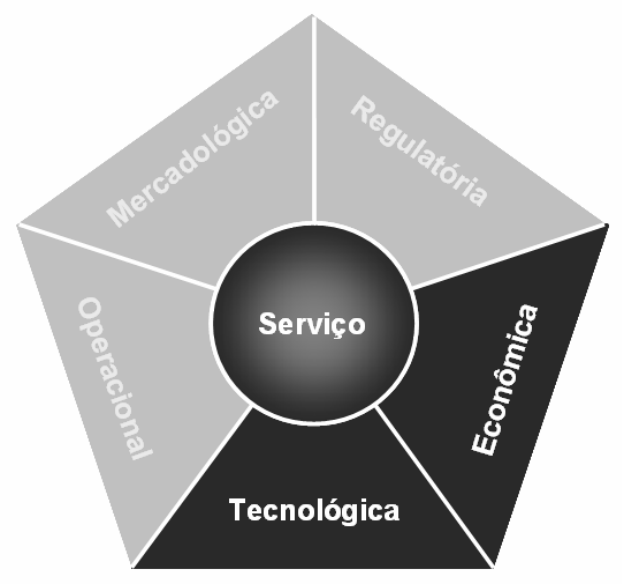

Figura 3 - Dimensões de análise pertinentes à metodologia proposta

A metodologia delineia, portanto, as principais etapas para se avaliar a introdução de serviços IPTV nas duas vertentes:

- Tecnológica: considerações sobre o impacto dos novos serviços na arquitetura tecnológica da operadora, identificação dos requisitos de infraestrutura tecnológica para suportar o serviço, da necessidade de adaptação da 
infra-estrutura, e das alternativas plausíveis considerando os benefícios e desvantagens de cada uma.

- Econômica: arcabouço para criação da modelagem econômica que permita a avaliação da viabilidade do novo serviço, e permita identificar em quais condições a viabilidade se verifica. Este modelo possui grande conexão com a vertente de tecnologia, pois a infra-estrutura tecnológica possui grande influência na viabilidade econômica de um novo serviço de telecomunicações.

Desta forma, para elaboração da metodologia, são assumidas premissas referentes às dimensões de Mercado, Regulatório e Operações que impactam diretamente as duas dimensões que compõem o objeto de estudo deste trabalho.

\subsection{ESTRUTURA DO TRABALHO}

O documento da dissertação de mestrado está organizado em cinco capítulos. O capítulo 1 possui um caráter introdutório. Os capítulos 2 e 3 visam fornecer a base de conceituação teórica para o leitor. Os capítulos 4 e 5 constituem a proposição da metodologia de análise técnico-econômica proposta e a sua aplicação, respectivamente. $O$ capítulo 6 corresponde às considerações finais sobre o trabalho.

A descrição do conteúdo dos capítulos encontra-se detalhada a seguir:

- Capítulo 1 - Introdução: neste capítulo é apresentada uma introdução à dissertação, delineando brevemente o cenário em que está inserida, principais motivações para seu desenvolvimento, seu escopo e a estrutura do trabalho.

- Capítulo 2 - Conceitos de IPTV: neste capítulo são introduzidos os conceitos básicos relacionados ao tema de IPTV. O capítulo explora desde os motivadores de negócio para a oferta de serviços IPTV, descreve a cadeia de valor em que estão inseridos, delineia os serviços que compõem a oferta $e$ qual a infra-estrutura tecnológica que suporta os serviços. A conceituação de IPTV é realizada neste capítulo sob a perspectiva de uma operadora de telecomunicações e como o serviço impacta seu ambiente. 
- Capítulo 3 - Conceitos de Análise Técnico-Econômica: neste capítulo são apresentados os conceitos básicos de análise técnico-econômica. Este capítulo inclui a descrição de metodologias de referência de análise técnicoeconômica da introdução de um novo serviço ou tecnologia que são utilizadas como base do trabalho. Além disso, são detalhados os métodos para realizar a análise de investimentos associados a um projeto.

- Capítulo 4 - Metodologia de Análise Proposta: neste capítulo é apresentada a metodologia proposta para a análise técnico-econômica da introdução de serviços IPTV por uma operadora de telecomunicações. A metodologia é descrita de maneira geral e, em seguida, cada uma de suas etapas é detalhada. $O$ detalhamento de cada etapa ocorre com a definição das entradas, saídas e das atividades necessárias.

- Capítulo 5 - Aplicação da Metodologia Proposta: neste capítulo a metodologia proposta é aplicada a um caso de referência que reflete uma situação hipotética. Após a aplicação da metodologia e das considerações sobre o caso em específico, é realizada uma avaliação da metodologia frente aos objetivos a que se propõe e os resultados obtidos.

- Capítulo 6 - Considerações Finais: neste último capítulo são avaliadas as principais contribuições deste trabalho de mestrado e as perspectivas de sua continuidade através do desenvolvimento de trabalhos futuros.

- Lista de Referências: nesta seção, é apresentada a bibliografia utilizada ao longo do trabalho.

- Apêndice A - Arquitetura de Redes de Agregação: no Apêndice A estão descritos conceitos complementares relacionados à implementação da arquitetura de rede de agregação que impactam o serviço IPTV.

- Apêndice B - Informações Complementares à Aplicação da Metodologia: no Apêndice $B$ constam informações complementares à aplicação da metodologia ao caso de referência como, por exemplo, detalhes das premissas consideradas, arquitetura tecnológica, entre outros. 


\section{CONCEITOS DE IPTV}

\subsection{DEFINIÇÃO}

O termo Internet Protocol Television (IPTV) em essência denota a entrega de conteúdo de televisão para o usuário final utilizando o transporte sobre uma rede IP (12). Entretanto, esta definição é bastante abrangente e inclui diversas interpretações. A primeira delas é a realização de download ou streaming de vídeo da Internet visualizados no PC, também conhecida como Internet TV (3). Esta definição pressupõe o tráfego de conteúdo através da Internet pública, sem garantia de qualidade de serviço. Uma segunda interpretação do termo IPTV consiste na oferta de serviços de TV pelas operadoras de telecomunicações utilizando uma plataforma IP convergente de maneira que estes serviços sejam comparáveis aos oferecidos pelas operadoras de TV a cabo e TV via satélite. Ou seja, uma oferta com qualidade de serviço garantida e ambiente controlado (5). $\mathrm{Na}$ indústria de telecomunicações, o termo IPTV remete imediatamente a essa última definição e, por vezes, é também referido como TelcoTV ou até TV over Broadband (4). É essa definição que serve de base para o desenvolvimento desse trabalho.

\subsection{MOTIVADORES E DESAFIOS}

São diversos os motivadores da adoção de serviços IPTV pelas operadoras (3)(4)(5):

- Busca por novas fontes de receita devido à estagnação e erosão das receitas de comunicação de voz.

- Competição das operadoras de TV cabo oferecendo serviços de voz integrados com vídeo e banda larga, também conhecidos como triple play. 
- Diferenciação da concorrência através da oferta de serviços integrados (vídeo + voz + dados), alavancando maior potencial de fidelização de clientes existentes e a captura de novos clientes.

- O serviço IPTV possui diversos diferenciais em relação aos serviços de TV existentes. Além de suas funções básicas de TV broadcast e vídeo sob demanda, o serviço IPTV oferece o nível de interatividade que seus concorrentes não conseguem alcançar devido às suas limitações, pois ele se utiliza de redes banda larga bidirecionais com grande capacidade de transmissão e canal de retorno. A interatividade que motivou grande parte do sucesso da Internet é agora transportada para um outro meio, a televisão. Diversos serviços podem ser oferecidos utilizando uma plataforma de IPTV conforme ilustrado no item 2.4

- A gradual eliminação de barreiras tecnológicas como, por exemplo, a evolução das tecnologias de acesso banda larga oferecendo maior capacidade de transmissão, otimização dos algoritmos de compressão e viabilização de soluções de proteção de conteúdo.

- Convergência de serviços e redes utilizando IP como viabilizador da convergência é uma tendência da indústria. As grandes operadoras no cenário de telecomunicações vêm evoluindo suas redes de maneira que tenham uma rede IP multisserviços que possa disponibilizar serviços para uma diversidade de meios de acesso (fixo e móvel). Além dos benefícios do ponto de vista de serviços, a convergência traz ganhos operacionais e redução de custos na medida em que vem acompanhada da simplificação das redes e habilita a conseqüente otimização dos processos e investimentos.

Entretanto, para obter sucesso em uma oferta de IPTV, a operadora também deve sobrepassar diversos desafios que se colocam no seu caminho (3)(5)(6):

- Definir o modelo de negócio, os atributos de serviço e a estratégia comercial vencedora para atender às necessidades do usuário e superar as ofertas já estabelecidas no mercado (TV a Cabo e Satélite).

- Desenvolver bons relacionamentos com os provedores e agregadores de conteúdo visando à oferta de programação diferenciada e de qualidade, e 
estabelecer acordos de remuneração que Ihes permitam patamares saudáveis de rentabilidade.

- Explorar os aspectos interativos do serviço, alavancando a vantagem competitiva tecnológica sobre os concorrentes tradicionais.

- Adquirir expertise em novas áreas que não Ihe são familiares, sobretudo aquelas voltadas para aquisição, manipulação e gestão de conteúdo.

- Enquadrar os serviços IPTV e demais serviços convergentes no arcabouço legal e regulatório locais. Nos países em que isso representa um entrave, é necessário fomentar o debate sobre os trade-offs associados a potenciais ajustes no modelo que permitiriam a oferta de tais serviços e, conseqüentemente, a promoção de um cenário mais competitivo.

- Implementar uma arquitetura de serviços sólida e escalável, num cenário em que as tecnologias ainda estão em processo de amadurecimento e em que não existem padrões consolidados.

- Avaliar o impacto dos novos serviços sobre a infra-estrutura tecnológica desde as redes e plataformas de serviços, passando pela adequação dos sistemas de gerenciamento. Avaliar as alternativas tecnológicas e o impacto de cada uma na viabilidade econômica do serviço é fundamental para promover a evolução tecnológica.

\subsection{MODELO DE NEGÓCIOS}

O modelo de negócios de IPTV se baseia na cadeia de valor apresentada na Figura 4, na qual estão representadas as atividades em cada elo e os principais papéis dos atores em cada etapa (13)(14)(15). 


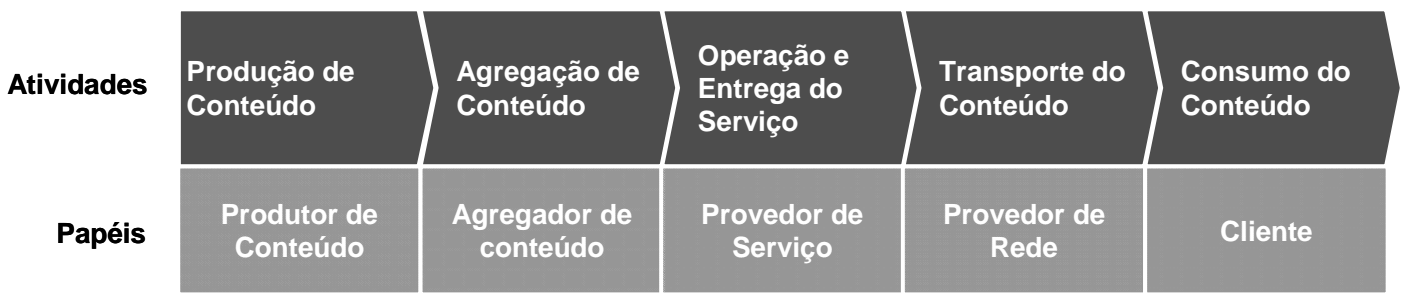

Figura 4 - Cadeia de Valor IPTV

- Produção de conteúdo: aqui se incluem todos os produtores de conteúdo (ex.: estúdios, produtores independentes) que licenciam ou vendem seu conteúdo para terceiros.

- Agregação de conteúdo: os agregadores empacotam e formatam o conteúdo de fontes de terceiros, entregando aos provedores de serviços grades de pacotes com diversos canais e conteúdo sob demanda.

- Operação e entrega do serviço: o provedor de serviço (utilizando a plataforma de IPTV) processa o conteúdo de diversas fontes (agregadores de conteúdo ou direto dos provedores), e entrega o conteúdo através de uma rede IP para o cliente final.

- Transporte do conteúdo: o provedor de rede recebe o conteúdo processado pelo provedor de serviço e distribui para o cliente final. A rede de transporte entrega o conteúdo ao assinante da mesma forma que o recebeu, de maneira transparente, podendo utilizar Content Delivery Networks (CDNs) para armazenar o conteúdo mais próximo do usuário e, assim, melhorar a sua experiência.

- Consumo de conteúdo: o cliente final que assina o serviço fecha a cadeia de valor consumindo o conteúdo e pagando por ele.

Vale notar que os elos da cadeia de Provedor de Serviço e Provedor de Rede estão separados, pois a natureza de suas atividades é bastante distinta. Mas na prática, estes dois papéis constituem, em geral, uma mesma entidade, a operadora de telecomunicações. Ela atua de forma integrada oferecendo o serviço e o transporte do conteúdo de maneira verticalizada. 


\subsection{OFERTA DE SERVIÇOS}

Antes do detalhamento das plataformas tecnológicas que suportam uma oferta de IPTV, é importante compreender o conjunto de serviços que compõem essa oferta. A oferta de IPTV vai além dos serviços tradicionais de vídeo, trazendo a interatividade da Internet ao alcance da TV e permitindo a integração de outros diversos serviços como, por exemplo, serviços de comunicação.

É uma tendência que a oferta de IPTV deve começar pelos serviços tradicionais de vídeo em broadcast ou sob demanda e evolua a partir daí em nível de sofisticação e escala. Devido ao estágio ainda inicial desse tipo de oferta ao redor do mundo, a definição de muitos serviços ainda é nebulosa e deve se esclarecer na medida em que a infra-estrutura é implementada e a oferta ganha volume (4).

Os serviços que compõem uma oferta de IPTV são comuns na literatura identificada sobre o assunto (5)(12)(13). Uma taxonomia dos serviços pode ser definida nas seguintes categorias: vídeo, áudio, comunicação, entretenimento, comércio e utilitários. A seguir, o modelo de referência de serviços IPTV está apresentado na Figura 5 e descritos na seqüência. 


\begin{tabular}{|c|c|c|}
\hline Video & Comunicação & Entretenimento \\
\hline \multirow{3}{*}{$\begin{array}{l}\text { - Broadcast de Vídeo } \\
\text { - Live TV } \\
\text { - Pay per view } \\
\text { - Vídeo Armazenado } \\
\text { - VOD / nVOD / sVOD } \\
\text { - Time-shifted TV } \\
\text { - PVR/ NPVR }\end{array}$} & \multirow{5}{*}{$\begin{array}{l}\text { - Telefonia } \\
\text { - Video Telefonia } \\
\text { - Video Conferência } \\
\text { - Video Mail } \\
\text { - Voice Mail Integrado } \\
\text { - Identificador de chamadas } \\
\text { - SMS / MMS } \\
\text { - Serviço de Diretório } \\
\text { - Internet } \\
\text { - TV Web Browsing / Walled } \\
\text { Garden } \\
\text { - TV Instant Messaging / Chat } \\
\text { - TV e-mail } \\
\text { - Serviços de informação / alertas }\end{array}$} & $\begin{array}{l}\text { - Jogos } \\
\text { - Apostas } \\
\text { - Karaoke }\end{array}$ \\
\hline & & Comércio \\
\hline & & $\begin{array}{l}\text { - T-commerce } \\
\text { - Propaganda direcionada / interativa / } \\
\text { personalizada }\end{array}$ \\
\hline Áudio & & Utilitários \\
\hline $\begin{array}{l}\text { - Broadcast de música } \\
\text { - Música sob demanda }\end{array}$ & & $\begin{array}{l}\text { - Monitoramento de vídeo / Segurança } \\
\text { - Automação residencial } \\
\text { - E-learning }\end{array}$ \\
\hline
\end{tabular}

Figura 5 - Modelo de Referência: Serviços IPTV

\subsubsection{Vídeo}

Os serviços de vídeo (4) englobam duas grandes categorias - broadcast e vídeo armazenado. O serviço de broadcast é o tradicional existente na TV aberta ou TV paga, baseado em canais e grades de programação. Esse serviço constitui a base de um serviço de TV.

Os serviços de vídeo armazenado assumem diversas variantes e possuem grande potencial de diferenciação em relação às ofertas tradicionais de TV. Serviços dessa natureza trazem uma experiência de personalização muito rica ao usuário, permitindo que ele assista o conteúdo de sua preferência na sua melhor disponibilidade de tempo. Oferecem aos usuários a possibilidade de controlar o conteúdo armazenado assim como controlam seus aparelhos de DVD ou vídeocassete, incluindo funções como play, stop, rewind, fast forward. Exemplos de modalidades de serviços nesta categoria incluem:

- Video on Demand (VOD): usuário pode selecionar o conteúdo que deseja assistir de uma lista que inclui filmes, documentários, entre outros programas. Existem diversas variações de modalidades do serviço como, por exemplo:, near VOD (NVOD) em que existem horários pré-definidos (ex.: meia em meia hora) para início da exibição de um determinado conteúdo; subscription VOD (SVOD) em que o usuário paga uma assinatura que lhe dá direito a consumir 
uma quantidade de títulos determinada; free VOD (FVOD) em que o usuário possui acesso gratuito a conteúdo sob demanda; e o VOD propriamente dito em que, tradicionalmente, o usuário paga por transação.

- Virtual Channels: são uma variação dos serviços NVOD em que a operadora cria canais virtuais para exibir conteúdos selecionados. Por exemplo, é possível criar canais virtuais temáticos onde são exibidos filmes de um determinado gênero sequencialmente.

- Time-shifted TV: enquanto o usuário assiste um conteúdo broadcast, possui a facilidade de retroceder no tempo como se tivesse utilizando um vídeo cassete e depois continua a seguir o conteúdo de acordo com a transmissão original.

- Personal Video Recorder (PVR) ou Digital Video Recorder (DVR): facilidade que permite ao usuário armazenar um conteúdo desejado de acordo com regras pré-estabelecidas de Digital Rights Management (DRM). A facilidade é análoga a de um vídeo-cassete. O conteúdo pode ficar armazenado localmente no Customer Premises Equipment (CPE) do usuário, ou então em unidades de armazenamento distribuídas na rede da operadora sendo denominado então de network PVR (NPVR).

Em qualquer serviço que envolva vídeo, existem dois formatos de definição de imagem:

- Standard Definition Television (SDTV): qualidade comparável à oferecida hoje pela maioria dos serviços de TV paga;

- High Definition Television (HDTV): qualidade de som e imagem bastante superiores e que, por conseqüência, possuem requisitos superiores de banda. A superioridade da qualidade do formato HDTV é mostrada na Tabela 1. 
Tabela 1 - Comparativo entre formatos: Analógico x SDTV x HDTV

\begin{tabular}{|c|c|c|c|}
\hline Característica & Analógico & $\begin{array}{c}\text { Standard } \\
\text { Definition (SDTV) }\end{array}$ & High Definition (HDTV) \\
\hline Linhas ativas & $480 \mathrm{i}$ & 480 i ou $480 p$ & $\begin{array}{c}720 p \text { ou } 1080 \text { i ou } \\
1080 p\end{array}$ \\
\hline Pixels & aprox. 253.000 & aprox. 480.000 & $\begin{array}{c}920.000 @ 720 \mathrm{p} \\
2.000 .000 @ 1080 \mathrm{i} / \mathrm{p}\end{array}$ \\
\hline Formato & $4 \times 3$ & $4 \times 3$ ou $16 \times 9$ & $16 \times 9$ \\
\hline $\begin{array}{l}\text { Progressive } \\
\text { scan }\end{array}$ & Não & Sim & Sim \\
\hline $\begin{array}{l}\text { Interlaced } \\
\text { scan }\end{array}$ & Sim & Sim & Sim \\
\hline Áudio & 2 canais & 2 canais digitais & até 48 canais digitais \\
\hline
\end{tabular}

\subsection{2 Áudio}

Os serviços de áudio (4) incluem:

- Broadcast de música: serviços de transmissão de estações de rádio tradicionais ou de canais de música criados pela operadora, e que podem ser personalizados. Estes serviços já são oferecidos pelas operadoras de TV a cabo e satélite.

- Música sob demanda: serviço análogo ao VOD aplicado no contexto de música, permitindo ao usuário selecionar as músicas que deseja ouvir e até criar coleções personalizadas. 


\subsubsection{Comunicação}

Os serviços de comunicação integrados (4) permitem às operadoras adicionarem funcionalidades avançadas aos serviços tradicionais de telefonia e acesso à Internet, além de oferecerem aos usuários um novo meio de comunicação, a TV. Os serviços e novas funcionalidades de comunicação podem ser agrupados em duas categorias:

- Telefonia: permite aos usuários estenderem as funcionalidades de seus serviços de telefonia utilizando a TV. Exemplo: vídeo telefonia e vídeo conferência.

- Internet: serviços que trazem as facilidades da Internet para a tela da TV. Exemplo: navegação web via TV em portais especialmente desenvolvidos para utilização via TV.

\subsubsection{Entretenimento}

$\mathrm{Na}$ categoria de entretenimento (4) incluem-se os serviços de jogos que variam em complexidade e sofisticação desde os jogos mais simples - single-player - até jogos mais sofisticados - multi-player com recursos tridimensionais, também conhecidos como Massively Multiplayer Online Games (MMOG). Além dos jogos, incluem-se aqui outros serviços de entretenimento como, por exemplo, apostas ou até karaokê.

\subsubsection{Comércio}

Essa categoria inclui o comércio de bens e serviços utilizando a interface da TV (4), também denominado como telecommerce. Essa aplicação é similar ao conceito de e-commerce, mas possui interface adaptada para interatividade via TV. Além do serviço de comércio, se incluem aqui os serviços de propaganda interativa e direcionada. 


\subsubsection{Utilitários}

Além dos serviços listados, existe uma variedade de serviços utilitários (4) que se prestam tanto ao público corporativo quanto residencial. Alguns exemplos nesta categoria são: vigilância, automação residencial, e-learning, aplicações para mercados verticais específicos (ex.: setor hoteleiro).

\subsection{MODELOS DE REFERÊNCIA DE ARQUITETURA TECNOLÓGICA}

Após a compreensão de quais são os serviços envolvidos numa oferta de IPTV para o usuário final e quais os seus requisitos, é importante identificar qual é a arquitetura tecnológica que suporta a oferta.

A seguir são apresentados alguns modelos de referência úteis para compreender os blocos que compõem a arquitetura. O primeiro modelo (13) divide a infra-estrutura tecnológica de acordo com segmentos, que correspondem à topologia da rede e os principais nós. O segundo modelo de referência (13) utiliza uma visão de arquitetura em camadas. A combinação das duas abordagens em um modelo de referência bidimensional (4) permite situar os principais componentes de uma solução IPTV e explorar as suas funcionalidades básicas.

\subsubsection{Modelo de referência em Segmentos}

É possível dividir a arquitetura da infra-estrutura tecnológica de IPTV em segmentos (13), nos quais se pode identificar alguns nós importantes da solução de vídeo Super Head-End (SHE), Video Hub Office (VHO), Video Serving Office (VSO), Delivery Network Gateway (DNG) - e os segmentos de rede que interligam estes nós (Núcleo, Borda/Agregação, Acesso, Residência). O modelo de referência dividido por segmentos está representado na Figura 6. 


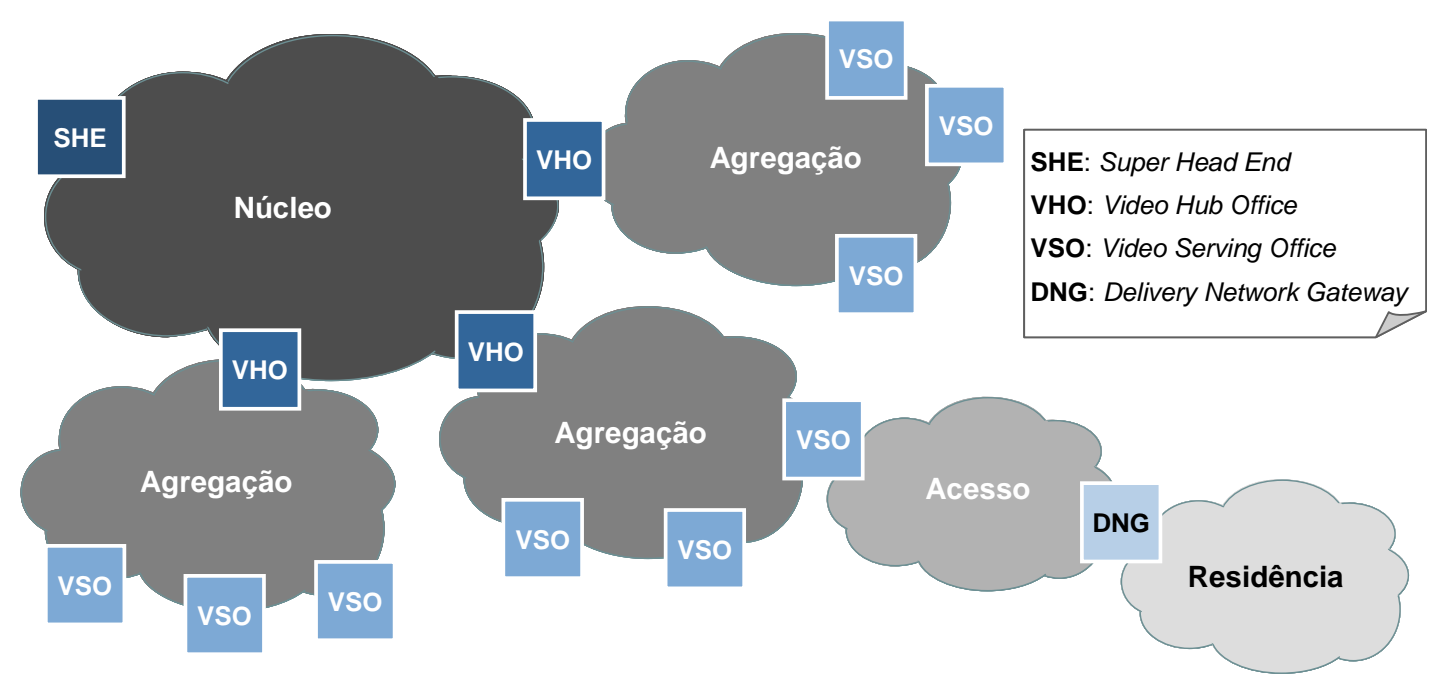

Figura 6 - Arquitetura de referência IPTV: Segmentos (fonte: adaptado de ATIS (13))

Os principais nós de entre os segmentos de rede são:

- Super Head-end (SHE): os SHEs são os pontos centrais de uma solução de IPTV. São as localidades onde é realizada a captura e agregação de conteúdo em nível nacional. Neles ocorre a manipulação do conteúdo de caráter universal e independente de região, incluindo canais de programação (conhecidos como broadcast), inserção de propaganda e conteúdo sob demanda. Os SHEs fornecem conteúdo para todo o sistema de IPTV e constituem o repositório primário de conteúdo, onde se armazenam as matrizes de conteúdo sob demanda.

- Vídeo Hub Office (VHO): os VHOs são pontos de distribuição de vídeo dentro de uma região delimitada. Eles constituem os nós da rede em que é disponibilizado o conteúdo local/regional. O VHO oferece programação local/regional, armazena conteúdo local para acesso sob demanda, e combina com conteúdo vindo do SHE. A inserção de propaganda local também é realizada no $\mathrm{VHO}$.

- Video Serving Office (VSO): o VSO é o equivalente do Central Office (CO) de uma rede de telecomunicações. Ele representa o elo entre a rede de agregação e a rede de acesso. Ele hospeda os sistemas de acesso que permitem conectar os usuários finais à rede. Dependendo da escala da solução, podem existir elementos de armazenamento de vídeo também nessas localidades. 
- DNG (Delivery Network Gateway): é o nó de rede dedicado a um único assinante / domicílio. Em geral, é o elemento que realiza a interface entre a rede da operadora e a rede doméstica do assinante, na qual estarão conectados os televisores por meio dos set-top boxes. Também é conhecido por Customer Premises Equipment (CPE).

Os principais segmentos de rede que interligam os nós principais da solução de vídeo são:

- Núcleo: realizam o transporte do tráfego de vídeo conectando um pequeno número de SHEs aos diversos VHOs.

- Agregação: compreende a borda do núcleo e as redes de agregação que escoam o tráfego do acesso para o núcleo da rede. Conectam os VHOs a uma quantidade ainda maior de VSOs.

- Acesso: é a parte da rede que estabelece a conectividade do VSO com o usuário final.

- Residência: compreende a rede doméstica do usuário, na qual ele conectará os dispositivos convergentes: PC, telefones IP, pontos de acesso sem fio e os terminais de acesso.

\subsubsection{Modelo de referência em Camadas}

Uma maneira complementar de reconhecer os componentes de uma solução é utilizando uma visão em camadas (13). A arquitetura Next Generation Network (NGN) proposta pelo ITU-T é uma referência que pode ser utilizada com este propósito. Ela compreende também os serviços multimídia, por exemplo, serviços conversacionais (baseados em SIP) e serviços de conteúdo, por exemplo, vídeo streaming e broadcasting. 
Legenda:

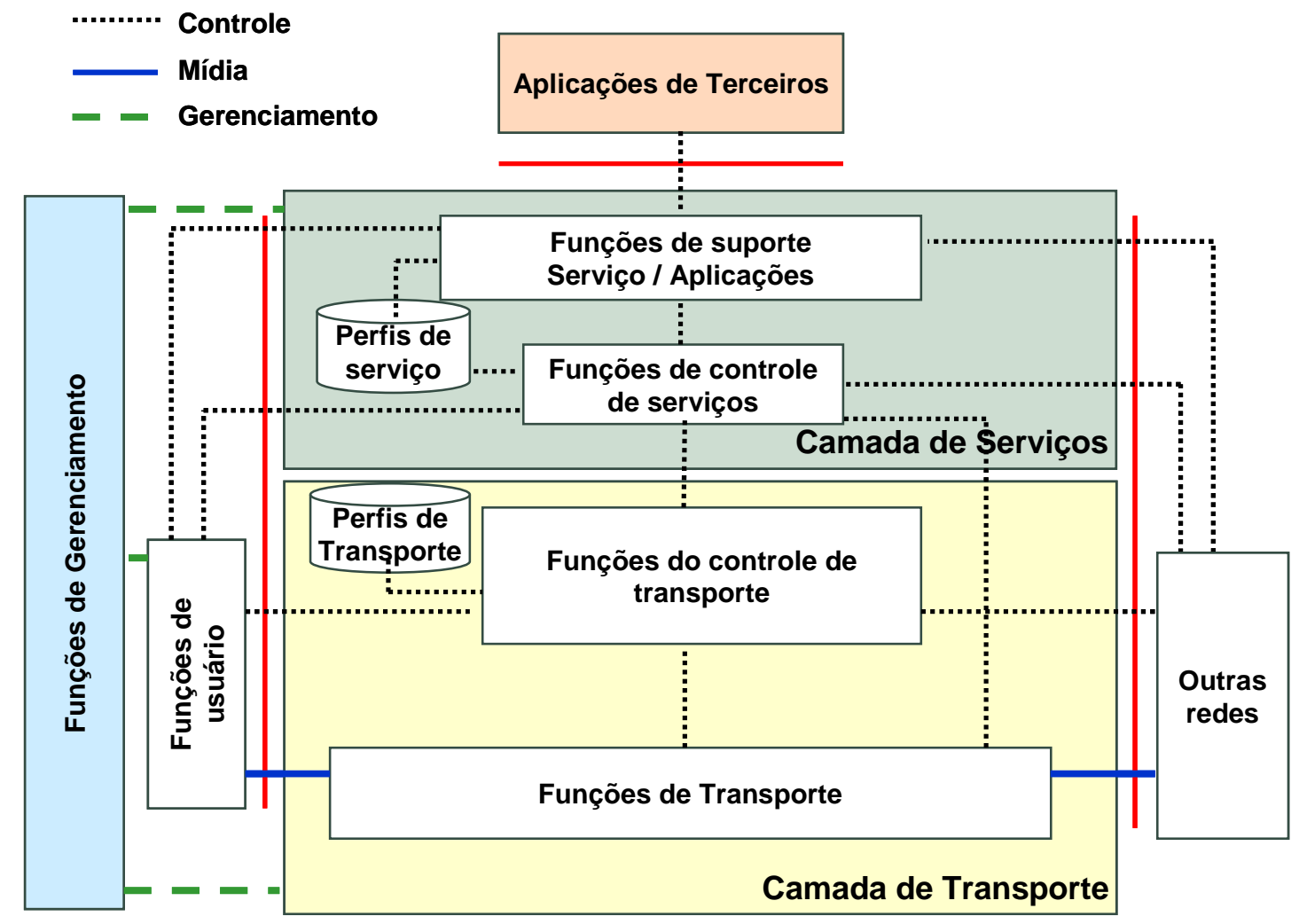

Figura 7 - Arquitetura de referência NGN: Camadas (fonte: adaptado de ITU-T (13))

A Figura 7 mostra a arquitetura funcional NGN dividida em duas camadas: serviço e transporte.

- Serviço: é a camada na qual está depositada a inteligência e controle do serviço, e funções de suporte à aplicação.

- Transporte: provê a conectividade IP entre todos os componentes da NGN, oferecendo suporte ao tráfego de mídia e de controle. As funções de transporte incluem funções de núcleo, borda/agregação e acesso. Esta camada também pode ser denominada por rede. 


\subsubsection{Modelo de referência: Segmento x Camadas}

É possível realizar uma combinação dos modelos de referência apresentados e categorizar os componentes da infra-estrutura tecnológica que suporta um serviço IPTV em duas dimensões: camadas e segmentos (4).

- Camadas: divididas em dois níveis de abstração que são rede (transporte de informações) e serviço. A camada de rede contempla os componentes responsáveis pela comunicação de dados IP, a camada de serviço é responsável pela inteligência do serviço propriamente dito, e a camada de gerenciamento que permeia todas as outras duas sendo responsável pela gestão do serviço.

- Segmentos: divididas de acordo com a distribuição topológica e geográfica dos elementos. Por exemplo, a camada de rede é dividida em: núcleo, borda/agregação e acesso. Analogamente, a camada de serviço fica dividida em: nacional (SHE), regional/distribuição (VHO/VSO) e local/residencial (DNG).

O modelo de referência sugerido combinando as duas dimensões está apresentado na Figura 8. As funções de gerenciamento que são realizadas sobre as duas camadas em todos os seus segmentos estão representadas como uma camada vertical em um bloco separado e que permeia o modelo de referência como um todo. 


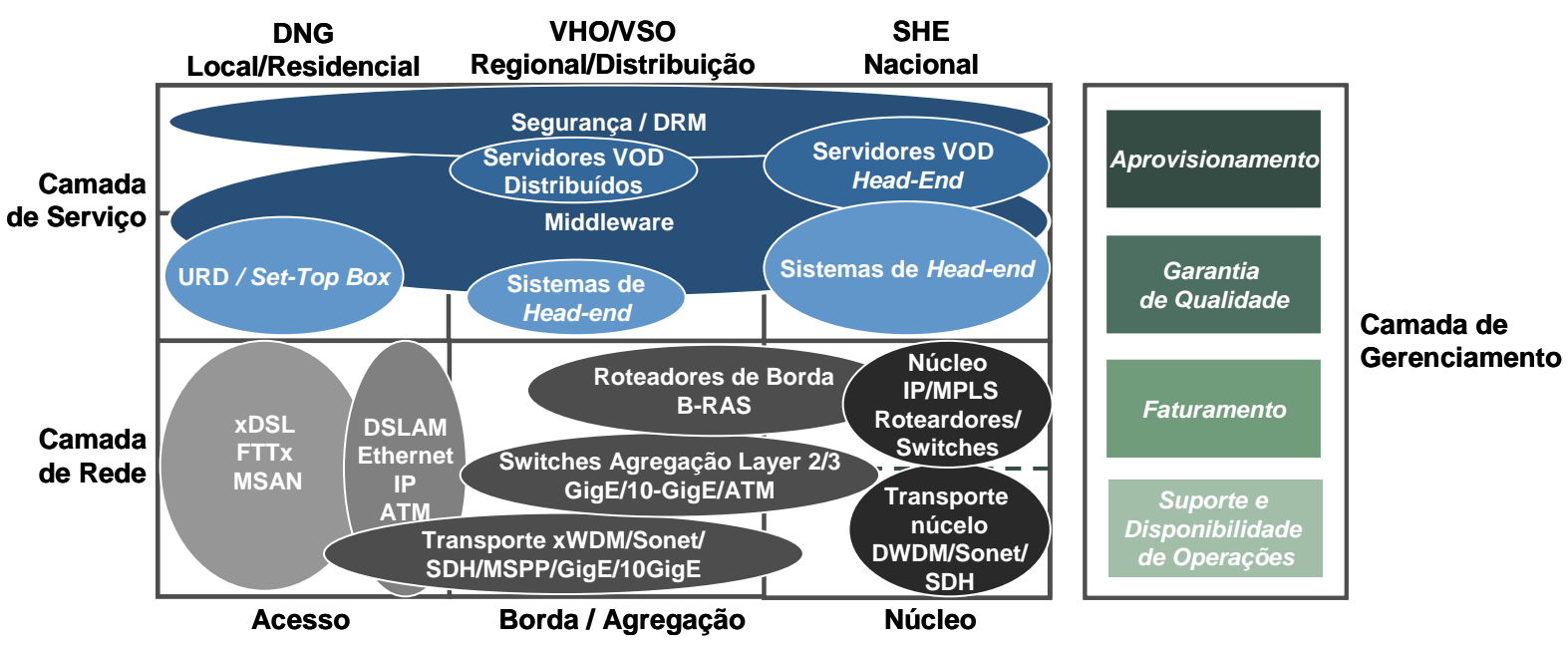

Figura 8 - Modelo de referência: arquitetura tecnológica de IPTV (fonte: adaptado de HeavyReading (4))

De acordo com o modelo de referência mostrado na Figura 8, serão explorados os principais componentes da solução de IPTV em suas diversas camadas: Serviço (vide item 2.7), Rede (vide item 2.8) e Gerenciamento (vide item 2.9).

\subsection{QUALITY OF EXPERIENCE E SERVIÇOS IPTV}

\subsubsection{Conceito de Quality of Experience}

Uma vez definido o modelo de arquitetura tecnológica que suporta serviços IPTV, é importante introduzir o conceito de Qualidade de Experiência mais conhecido por Quality of Experience (QoE) que permeia desde o serviço entregue ao assinante até o delineamento de toda infra-estrutura tecnológica.

Um dos principais desafios das operadoras de telecomunicações relacionado aos serviços IPTV é oferecer uma experiência diferenciada aos seus clientes. O nível de qualidade associado ao serviço precisa, no mínimo, se igualar ao que já é oferecido pelos provedores de TV já estabelecidos como, por exemplo, TV a cabo ou satélite. Oferecer tal nível de serviço torna-se mais complexo quando se transporta vídeo em larga escala utilizando uma infra-estrutura de redes IP onde múltiplos serviços compartilham os mesmos recursos. 
Historicamente, a gestão da Qualidade de Serviço, ou também conhecida por Quality of Service (QoS), associada a serviços IP focaliza principalmente os aspectos relacionados à rede e sistemas (16). A terminologia QoS é entendida como uma medida de desempenho no nível de pacotes a partir da perspectiva da rede. O termo QoS se refere ao conjunto de mecanismos e tecnologias capazes de serem implementados na infra-estrutura de rede de maneira a satisfazerem aos requisitos da aplicação, habilitando, por exemplo, o gerenciamento dos efeitos de congestionamento de tráfego ou oferecendo condições de diferenciação para usuários ou aplicações selecionadas. A partir dessa perspectiva, o desempenho dos serviços é então gerenciado a partir de parâmetros relacionados à rede e os parâmetros mais comuns incluem: atraso, variação do atraso (jitter), perda de pacotes e largura de banda (17).

Entretanto, estes parâmetros não traduzem completamente a experiência do usuário (16). Eles são parâmetros indicativos de que a experiência do usuário esteja degradada, mas não necessariamente existe uma correlação direta. Por exemplo, a taxa elevada de perda de pacotes na rede pode causar diversos efeitos na qualidade de vídeo. O usuário de um serviço IPTV não se importa diretamente com as restrições de desempenho da rede, mas com as características pertencentes a um nível de abstração mais elevado, como é o caso da qualidade do vídeo, o sincronismo ente áudio e vídeo, tempo de atraso na mudança de canais, entre outros.

Os serviços IPTV requerem uma abordagem de gestão de qualidade mais abrangente para garantir a experiência do usuário. A sua percepção está muito além de aspectos de rede e envolve todas as interações entre o usuário e o serviço, traduzindo-se no conceito de QoE. A QoE representa o desempenho geral de um sistema a partir da perspectiva do usuário final e pode ser considerada um indicativo do quão bem o sistema atende às necessidades dos usuários (16). Desta forma, o modelo de QoE se situa em um nível mais alto de abstração e pode ser interpretado como uma extensão do modelo tradicional de QoS, na medida em que caracteriza o desempenho do serviço a partir da perspectiva do usuário enquanto o modelo de QoS está voltado aos aspectos de rede. 


\subsubsection{Modelo integrado de Quality of Experience}

O gerenciamento da qualidade de serviços IPTV deve se valer de uma abordagem mais abrangente fim-a-fim que complemente o modelo tradicional de QoS. O modelo tradicional de QoS voltado para a rede por si só não endereça todas as necessidades dessa categoria de serviços. Sendo assim, os modelos de QoE e QoS podem se combinar em um modelo integrado de camadas em que o domínio de QoE se situa em um nível superior ao de QoS (16). Este modelo pode ser definido em três camadas (17) conforme detalhado a seguir:

- Serviço: representa uma pseudo-camada sobre a camada de aplicação. É a camada exposta ao usuário que representa o serviço propriamente dito e onde os parâmetros de QoE são medidos. Um exemplo de métrica de QoE é o Mean Opinion Score (MOS) que quantifica a percepção do usuário a respeito de diversas formas de degradação.

- Aplicação: onde parâmetros relacionados à aplicação de vídeo (ex.: resolução, taxa de compressão, codecs, número de canais) são gerenciados para atingir os níveis de QoE estabelecidos.

- Transporte: parâmetros relacionados ao transporte e mais especificamente à rede (ex.: atraso, jitter, perda de pacotes) são gerenciados para atender às necessidades de QoE.

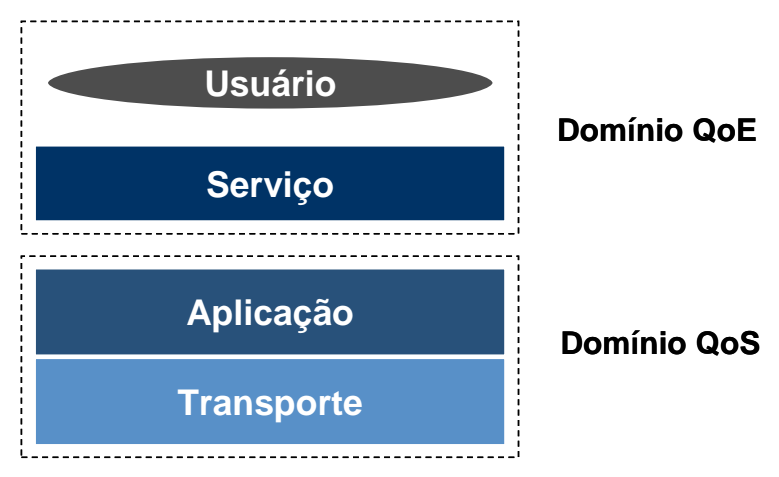

Figura 9 - Modelo de referência: QoE / QoS

É possível estabelecer uma relação direta entre o modelo de QoE / QoS ilustrado na Figura 9 e o modelo de arquitetura tecnológica apresentado no item 2.5.3. Deve-se considerar que a camada de transporte deste modelo refere-se à infra-estrutura de 
rede, e a camada de aplicação à infra-estrutura de serviço definidas no item 2.5.3. Conforme discutido, a camada de serviço aqui não possui vínculo direto com a arquitetura tecnológica e representa o serviço entregue ao usuário final.

As dimensões de QoE relacionadas a IPTV permeiam desde o estabelecimento de uma sessão, a operação do serviço assim que uma sessão é estabelecida até a sua terminação, e incluem (16):

- Fidelidade de informação: qualidade de áudio e vídeo transmitidos;

- Usabilidade: relacionada à manipulação do serviço pelo usuário, desde a interação com o controle remoto do set-top box até a interface gráfica;

- Responsividade: representa o tempo de resposta aos comandos do usuário como, por exemplo, a mudança de canal;

- Segurança: representa a autenticação e autorização dos usuários, além de garantir proteção do conteúdo de vídeo;

- Disponibilidade / Confiabilidade: representa as expectativas dos usuários de contarem com serviço disponível sempre que desejarem.

As principais métricas de desempenho para avaliação de serviços IPTV se distribuem ao longo das diversas camadas apresentadas no modelo e as mais utilizadas recaem em responsividade, qualidade de áudio, vídeo, e a combinação dos dois últimos (18).

A medição da qualidade de vídeo representa um dos maiores desafios das operadoras e possui grande relevância neste contexto. Assim como no caso do áudio, existe uma grande diversidade de degradações que podem afetar a qualidade do vídeo exibido no televisor do usuário final e existem diversos métodos para determinar a qualidade de vídeo (18). Todos os métodos visam à obtenção de métricas de qualidade que reflitam diretamente a percepção do usuário. Existem duas categorias de métodos de medição da qualidade do vídeo (16):

- Métodos subjetivos: utilizam um experimento de visualização de vídeo em que os participantes atribuem uma pontuação à qualidade do vídeo de acordo com escalas pré-definidas. O resultado do experimento é tratado estatisticamente e resulta em uma pontuação de acordo com uma escala de qualidade denominada Mean Opinion Score (MOS), que varia de 1 a 5 onde 5 
é a maior pontuação possível. A pontuação MOS de vídeo é análoga àquela aplicada para a qualidade de voz e não constitui um método prático para medir a qualidade de aplicações de tempo real e larga escala.

- Métodos objetivos: ao invés de experimentos com usuários do serviço, utilizam ferramental para determinar a qualidade de vídeo de maneira objetiva baseado em diversos parâmetros do vídeo. Tais métodos visam aproximar a percepção dos usuários finais e sua principal vantagem é que são repetíveis e podem ser realizados de maneira rápida, favorecendo a gestão de qualidade de serviços IPTV em larga escala. Podem incluir desde métodos que se valem de parâmetros de rede para inferir a qualidade do vídeo até métodos mais sofisticados que replicam o modelo de percepção humana. Estes últimos variam na forma de implementação de acordo com as informações que utilizam do sinal de vídeo na entrada (ex.: sistemas de head-end) e na saída do sistema de vídeo (ex.: domicílio do assinante) e são categorizados em três tipos: full reference (FR) que utilizam o sinal completo da entrada e saída para comparação, reduced reference (RR) que utilizam algumas informações da entrada e saída; e no reference (NR) que utilizam apenas parâmetros da saída. Exemplos de métodos objetivos incluem técnicas como Mean Square Error (MSE) e Peak Signal-to-Noise ratio (PNSR) que indicam a diferença entre os sinais de vídeo de referência completa ou parcial (FR ou RR). Outros exemplos de métodos objetivos de qualidade incluem Moving Picture Quality Metrics (MPQM) e $V$-Factor (uma implementação particular do MPQM) fazem parte de métodos NR. Abordagens mais simples se valem de parâmetros da rede para extrapolar a qualidade de vídeo como é o caso do método de medição denominado Media Delivery Index (MDI). Tais métodos podem não ser os mais precisos, mas podem ser indicativos da qualidade de vídeo a um custo menos elevado.

A escolha da abordagem de medição de qualidade de vídeo varia caso-a-caso. Os métodos objetivos são preferíveis aos subjetivos, e as soluções mais adequadas do ponto de vista de complexidade de implementação são aquelas que se baseiam exclusivamente no sinal de saída (NR). Tais técnicas ainda estão em evolução quando comparadas às técnicas análogas para avaliação de qualidade de voz baseadas somente nas informações de saída. Estratégias possíveis para serviços 
IPTV passam pela utilização de métodos objetivos baseados em modelos de percepção humana complementados com parâmetros de rede.

\subsubsection{Quality of Experience e a Arquitetura Tecnológica}

Considerando a importância do conceito de QoE para o serviço IPTV é natural que existam impactos desde o planejamento e projeto da infra-estrutura tecnológica até a operação do serviço em seu dia-a-dia (16). Do ponto de vista de planejamento, é importante levar em conta uma abordagem top-down que se inicia na identificação dos principais requisitos de QoE e, em seguida, os requisitos de QoS para que então a arquitetura tecnológica possa ser definida.

O delineamento de tal arquitetura tecnológica deve levar em consideração o planejamento de capacidade adequado visando à otimização de recursos como é o caso da utilização de mecanismos multicast no transporte do tráfego de vídeo (vide item 2.8.2) e também arquiteturas de distribuição de conteúdo flexíveis (vide item 2.7.4).

O projeto da infra-estrutura tecnológica também deve incluir mecanismos capazes de suportarem a garantia de QoE durante a fase de operação. Tais mecanismos incluem desde os mecanismos QoS implementados na rede (vide item 2.8.3) como, por exemplo a priorização seletiva de tráfego e o controle de admissão sessões de vídeo, até utilização de ferramental apropriado visando suportar o monitoramento, teste e gerenciamento do serviço de vídeo de maneira fim-a-fim incluindo todos os seus componentes (vide item 2.9).

Os principais blocos que compõem a infra-estrutura tecnológica que suporta serviços IPTV estão detalhados a seguir de acordo com o modelo de referência de arquitetura apresentado na Figura 8. 


\subsection{INFRA-ESTRUTURA DE SERVIÇO}

\subsubsection{Sistemas de Head-end}

O head-end de vídeo (4) é uma das peças centrais da infra-estrutura de um serviço IPTV. Ele possui o papel de capturar conteúdo de diversas fontes (satélite, terrestre, offline sob demanda, etc.), processar e codificar de acordo com padrões de compressão pré-estabelecidos (MPEG-2, MPEG-4, WM9, etc.), encapsular sobre IP e disponibilizar para ser distribuído pela rede. Os sistemas de head-end podem ser divididos em duas partes: recepção e processamento de sinais.

\subsubsection{Recepção}

Os sistemas de recepção podem ser divididos de acordo com o meio que ele é recebido (5) e, em geral, incluem um elemento de captação de sinal e um receptor:

- Recepção via satélite: inclui o conjunto de antenas satélite dedicadas a capturar os sinais vindos via satélite, conversores Low Noise Block (LNB) e splitters para distribuir o sinal recebido até os receptores denominados de Integrated Receivers Decoders (IRDs). Em geral, a recepção via satélite é utilizada para receber canais no SHE que serão transmitidos para todas localidades.

- Recepção via terrestre ("off-air"): inclui o conjunto de antenas VHF/UHF e splitters para sua distribuição até os receptores, que neste caso são demoduladores VHF/UHF. Em geral, a recepção de canais off-air está associada a conteúdo local e regional, e pode ocorrer tanto no SHE e também nos VHO.

- Recepção via conexão dedicada: existe ainda a possibilidade de receber canais de televisão através de uma conexão dedicada, em geral, utilizando fibra-óptica. Neste caso, também se utilizam receptores específicos para este fim. 


\subsubsection{Processamento}

Depois de recebidos, os sinais são processados e codificados para serem então transmitidos (broadcast) ou armazenados (VOD). Da saída dos receptores, os sinais são amplificados e distribuídos para os codificadores, também conhecidos por encoders, que são os principais elementos deste bloco.

Os codificadores são responsáveis por codificar e comprimir o conteúdo recebido, segundo padrões de compressão definidos pela operadora. Em geral, se utiliza o padrão de codificação definido pelo grupo Moving Picture Experts Group (MPEG) da International Standardization Organization (ISO) (12). Os padrões mais utilizados são MPEG-2, MPEG-4 e, mais recentemente, o MPEG-4 Advanced Video Coding (MPEG-4 AVC) ou também conhecido como H.264 (versão padronizada pelo ITU-T) que oferece melhor compressão que os demais. Uma alternativa aos padrões MPEG é o algoritmo de codificação definido pela Microsoft, o Windows Media 9 (WM9) que está em etapa de padronização pela Society of Motion Picture and Television Engineers (SMPTE) sob o nome de VC-1 e que possui resultados de compressão similares ao H.264.

O padrão de codificação MPEG se utiliza de diversos tipos de quadros (frames) para construir o stream de vídeo e realizar a compressão (12). São utilizados três tipos de quadros:

- Tipo I (Intra): é comprimido baseado em informações contidas apenas nesse quadro e não precisa de nenhum outro quadro para se reconstruir;

- Tipo P (Predicted): é comprimido baseado nos dados dele e do último quadro I ou P;

- Tipo B (Bi-Directiona): é comprimido usando os dados do último quadro I ou $P$ e do próximo quadro I ou $P$.

Um conjunto de quadros I, P e B define um Group of Pictures (GOP), que obrigatoriamente conta com um quadro $\mathrm{I}$, e zero ou mais quadros $\mathrm{P}$ e B. A quantidade de quadros que compõe o GOP, o tamanho dos quadros, e o intervalo entre eles determina a taxa de compressão do vídeo. A taxa de compressão varia 
com a natureza do conteúdo e os parâmetros de codificação (12). A comparação de desempenho dos principais padrões de codificação está apresentada na Tabela 2.

Tabela 2 - Comparativo entre Codificadores

\begin{tabular}{ccc}
\hline Qualidade & MPEG-2 & $\begin{array}{c}\text { MEPG-4 } \\
\text { AVC / H.264 }\end{array}$ \\
\hline SDTV & $2,5 \mathrm{Mbps}$ & $1,5-1,8 \mathrm{Mbps}$ \\
HDTV & $12 \mathrm{Mbps}$ & $6-9 \mathrm{Mbps}$ \\
\hline \multicolumn{3}{c}{ (fonte: Tandberg (22)) }
\end{tabular}

Em geral, se utiliza também um switch de vídeo para conectar as saídas dos amplificadores de distribuição aos codificadores, de maneira a facilitar o remanejamento de codificadores e possibilitar a ativação automática de codificadores sobressalentes em caso de falhas.

Se a operadora for autorizada a inserir propaganda nos canais de programação que transmite, são utilizadas plataformas de inserção de propaganda (ad insertion).

Em analogia ao que ocorre com a codificação do conteúdo broadcast, o conteúdo VOD recebido dos provedores e agregadores de conteúdo também precisa ser codificado e preparado adequadamente para ser armazenado nos servidores de vídeo. Para realizar o tratamento e a preparação do conteúdo VOD, são utilizadas plataformas especializadas para esta finalidade.

\subsubsection{Middleware}

O middleware (4) é um elemento de software e é considerado a porção mais crítica de um sistema de IPTV. Ele pode ser encarado como o sistema operacional da solução. É o componente responsável pela inteligência do serviço e permeia a entrega do serviço fim-a-fim, sendo responsável pela interligação das diversas partes do sistema: servidores de vídeo, set-top box, head-end, DRM, elementos de rede. Inicialmente, as soluções oferecidas ao mercado eram fechadas e monolíticas. As mais novas soluções oferecem interfaces abertas, que facilitam a integração com outros blocos de uma solução de IPTV. 
O middleware é o viabilizador da solução de IPTV e é responsável por:

- experiência do serviço do usuário;

- definição dos serviços, pacotes e preços;

- interface com outros blocos da solução;

- gerenciamento de transações, conteúdo de ativos de mídia, dispositivos e assinantes.

O middleware é, portanto, um conjunto de aplicações que suportam as quatro áreas mencionadas. Algumas funções suportadas pelo middleware são:

- Funções para o assinante: Eletronic Program Guide (EPG); apresentação e interatividade dos serviços (VOD, PVR, etc.); apresentação e interatividade de serviços integrados (vídeo telefonia, identificador de chamadas, etc.); informação de programação; parental control; informações da conta do assinante.

- Funções para a operadora: Application Programing Interface (API); kit de desenvolvimento de software (SDK); gestão do serviço; gestão de clientes; gestão de transações; gestão de conteúdo e estratégia de distribuição; controle remoto dos dispositivos de usuário (set-top box); interface com billing; interface com aprovisionamento/ativação; integração com sistemas de segurança; elaboração de relatórios.

Um componente do middleware que merece destaque é o EPG. Ele oferece a interface gráfica de navegação do usuário ao longo dos guias de programação, explorando as opções, funcionalidades e aplicações disponíveis. O EPG é uma das funções mais atrativas de um sistema IPTV e a aplicação do middleware mais acessada pelos assinantes. Ele promove a interatividade e é um dos responsáveis pela experiência do usuário na utilização do serviço.

Conforme observado, o middleware combina diversas funções de gerenciamento e algumas de suas funções podem ser consideradas nos sistemas de gerenciamento que serão explorados no item 2.9 


\subsubsection{Digital Rights Management}

A segurança do conteúdo é um requisito fundamental para viabilizar a oferta de IPTV (4). Atualmente, os grandes estúdios se negam a fornecer conteúdo às operadoras que não possuem ferramentas que garantam a proteção do conteúdo.

Os tradicionais sistemas de acesso condicional ou Conditional Access Systems (CAS) utilizados pelas operadoras de TV paga foram projetados essencialmente para os serviços de broadcast / pay-per-view. Seu principal propósito é garantir que os assinantes tenham acesso apenas ao conteúdo contratado. Tais sistemas legados focalizam principalmente o conteúdo em trânsito, e não o conteúdo armazenado. Eles criptografam o conteúdo no head-end e depois decriptografam na residência do assinante, utilizando autenticação baseada geralmente em smart cards localizados no set-top box.

A segurança no contexto de IPTV vai além desse escopo e compreende também a proteção do conteúdo de vídeo armazenado ao longo da infra-estrutura, seja nos servidores da operadora ou nas dependências do assinante. Surge então a necessidade de soluções mais abrangentes do que as tradicionalmente empregadas. Essa categoria de soluções se denomina de Digital Rights Management (DRM).

O conceito de DRM (13) é mais abrangente do que o CAS. Seu propósito é gerenciar como o conteúdo digital é utilizado baseado em condições específicas definidas pelos direitos de utilização do usuário. O DRM visa garantir (23): controle de acesso (autenticação e autorização), contabilização de utilização (gestão dos direitos de uso), controle de replicação (cópia), autenticidade da fonte, confidencialidade, integridade e disponibilidade do conteúdo protegido.

Os sistemas de DRM oferecem uma infra-estrutura de segurança para prevenir a pirataria do conteúdo de vídeo independentemente se ele está armazenado ou sendo transmitido. O DRM aplica regras de utilização ao conteúdo (16) e, portanto, o protege de ser utilizado de forma ilegal mesmo depois que foi entregue. Tais regras podem incluir a data limite para visualização do conteúdo, o número de vezes que ele pode ser visto ou até o número de vezes que pode ser copiado. 
O funcionamento do DRM (4) é baseado na criptografia do conteúdo no head-end e a sua decriptografia no set-top box utilizando certificados digitais. O conteúdo fica criptografado onde quer que esteja e só é decriptografado na sua exibição. $O$ tradicional método de autenticação utilizando smart cards no set-top box utilizado nas soluções de CAS evoluiu e existe agora a possibilidade de implementar o conceito de virtual smart card através de soluções baseadas em software. Desta forma, a operacionalização de atualizações fica facilitada e a eventual substituição do smart card pode ser feita de maneira remota.

O DRM possui inúmeros pontos de contato ao longo do sistema e, portanto, necessita de integração fim-a-fim com os diversos componentes da solução para garantir a proteção do conteúdo. As soluções disponíveis no mercado para implementação são proprietárias e dificultam a interoperabilidade entre as partes da solução de IPTV.

\subsubsection{Servidores de Vídeo}

Esses servidores (13) são responsáveis por armazenar e disponibilizar conteúdo que é oferecido sob demanda para os assinantes. Armazenam, principalmente, o conteúdo destinado a VOD e também conteúdo broadcast selecionado para habilitar funcionalidades de PVR ao usuário final. Esta modalidade de PVR é conhecida como Network PVR (NPVR) em que o conteúdo não está armazenado nas dependências do usuário, mas nos sistemas da operadora.

Os servidores possuem alta capacidade de armazenamento, alta disponibilidade e suportam elevado número de streams de vídeo simultâneos. Quando se necessita soluções mais complexas e de maior escalabilidade, os servidores possuem inteligência para formar Content Delivery Networks (CDNs)(16) capazes de gerenciar a distribuição de conteúdo entre diversos servidores colocados na rede mais próximos do assinante (por exemplo, nos VHOs e VSOs).

As arquiteturas distribuídas de armazenamento de vídeo mantêm cópias do conteúdo mais acessado mais próximas do usuário final. Tais arquiteturas se justificam pelo fato de que a maior parte dos acessos concentra-se em uma menor 
parcela do conteúdo, enquanto o acesso ao conteúdo de nicho é bastante fragmentado. Tal fenômeno é popularmente conhecido por long tail ou cauda longa em referência ao formato típico da curva de popularidade de acesso ao conteúdo conforme apresentado na Figura 10. Desta forma, uma pequena parcela do conteúdo pode ser replicada em localidades mais próximas ao assinante, otimizando assim a utilização de recursos de rede para a maior parte dos acessos.

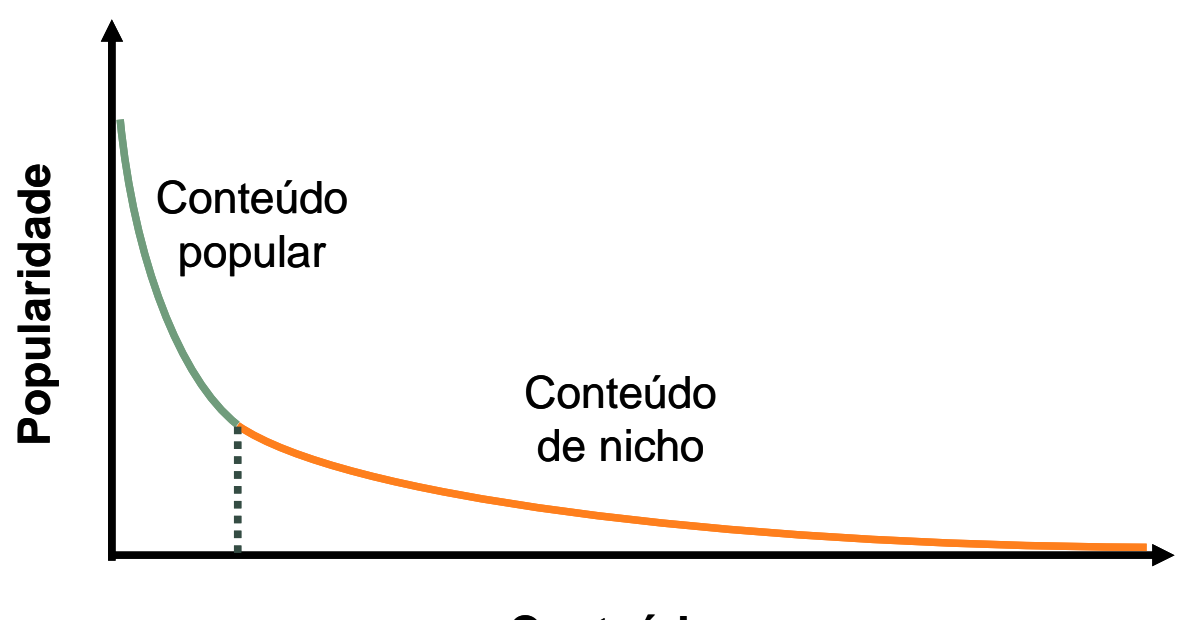

\section{Conteúdo}

Figura 10 - Curva típica de popularidade de conteúdo de vídeo

\subsubsection{Set-top box}

O set-top box (STB) (4) é o elemento da solução que se localiza nas dependências do usuário. O set-top box é o componente da camada de serviço que realiza a interface entre o sistema de IPTV com o usuário e os aparelhos de exibição de conteúdo (televisores, telas de plasma, etc.).

Os set-top boxes hospedam componentes do middleware, DRM, browser de navegação, decodificador e pode ter capacidade de armazenamento de conteúdo local, realizando a função de um PVR. Precisam estar integrados com os outros diversos blocos da solução devido à variedade de clientes de software residentes nele. 


\subsection{INFRA-ESTRUTURA DE REDE}

A infra-estrutura de rede é constituída pelas diversas redes que suportam o serviço IPTV. Em essência, essa camada oferece o serviço IP de maneira fim-a-fim através de uma rede multisserviços. Sua missão é oferecer conectividade de alto desempenho à camada de serviço e os principais requisitos (4)(5)(16) relacionados à rede são:

- Largura de banda adequada para suportar os canais de vídeo (vide item 2.8.1.3 para exemplos de banda requerida). Deve-se notar que apesar da grande necessidade de largura de banda, o tráfego é assimétrico com volume significativamente maior na direção de downstream.

- Inteligência de QoS para garantir os requisitos de QoE desejados (vide item 2.8.3);

- Arquitetura de multicast robusta para suportar a distribuição de vídeo com a otimização de recursos (vide item 2.8.2).

A seguir, a arquitetura da rede será detalhada em seus principais blocos. $\mathrm{Na}$ seqüência, as questões pertinentes a qualidade de serviço e perfil de tráfego serão exploradas em mais detalhes.

\subsubsection{Arquitetura da Rede}

A utilização de novas arquiteturas de rede, e novas funcionalidades de hardware e software vem sendo motivada pela introdução de vídeo nas redes IP. A arquitetura tradicional das redes IP multisserviço pode ser classificada em suas diversas hierarquias conforme mencionado no item 2.5.1: núcleo; borda / agregação; acesso; e residência (13)(25). A Figura 11 exemplifica uma arquitetura de rede típica e os seus principais elementos. 


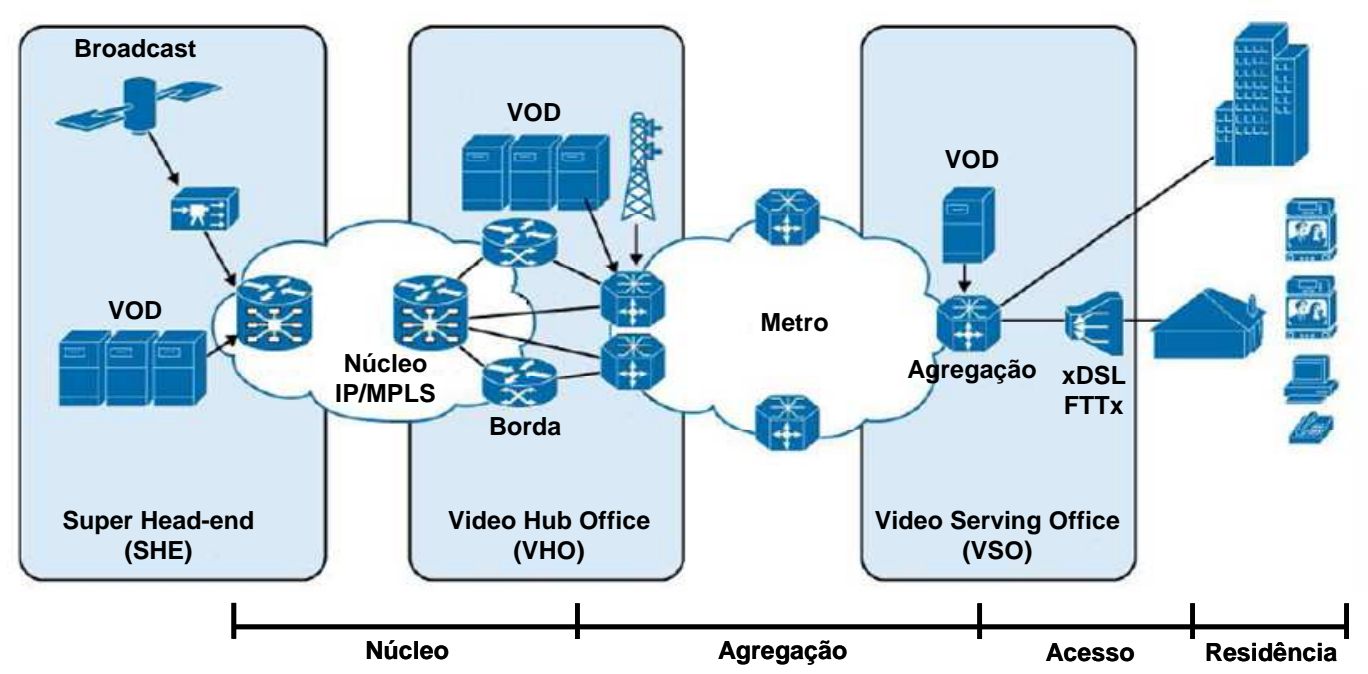

Figura 11 - Exemplo de arquitetura de rede (fonte: Cisco (24))

\subsubsection{Núcleo}

O núcleo da rede IP é responsável por transportar o elevado volume de tráfego das diversas redes de agregação (4), realizando a comunicação entre SHEs e VHOs. Em geral, interconectam diversas regionais e transportam dados entre longas distâncias, ou seja, no âmbito de Wide Area Networks (WAN). Sua função é essencialmente de transporte e roteamento, e combina tradicionalmente tecnologias em duas principais camadas:

- Roteamento/comutação de pacotes: a utilização da dupla IP e Multiprotocol Label Switching (MPLS) é uma realidade nas grandes operadoras ao redor do mundo (25). A utilização de MPLS no núcleo da rede habilita a criação de uma rede estável e escalável. Além de aumentar a velocidade de transmissão com a comutação baseada nos rótulos MPLS, um dos principais ganhos associados à sua utilização é a possibilidade de realizar engenharia de tráfego e assim garantir o desempenho da rede (25).

- Transmissão sobre redes ópticas: as tradicionais tecnologias Synchronous Digital Hierarchy (SDH) / Synchronous Optical Network (SONET) são utilizadas para realizar o transporte de dados de longa distância entre os diversos PoPs de núcleo sobre fibra óptica. Além disso, a utilização Dense 
Wavelength Division Multiplexing (DWDM) na camada óptica é utilizada para maximizar a utilização das fibras ópticas, pois permite a multiplexação de diversos comprimentos de onda em uma única fibra (25).

Duas tendências de evolução são evidenciadas no segmento de núcleo:

- Virtualização: o aumento de tráfego no núcleo das operadoras devido à migração de serviços legados para IP e à introdução de novos serviços de vídeo que demandam grande largura de banda, e a crescente complexidade dos PoPs de núcleo em número de elementos em virtude do crescimento das redes traz novos desafios às operadoras. A necessidade de simplificação da arquitetura de redes leva à utilização do conceito de virtualização nos roteadores de núcleo IP/MPLS (25). Os roteadores empregados para este fim permitem consolidar diversos elementos de rede em um equipamento de grande porte e de alta escalabilidade, que possui elevado nível de modularidade e disponibilidade. Através da virtualização de elementos de rede, é possível criar diversas redes overlay, possibilitando a separação do tráfego e de serviços no plano lógico, mas utilizando uma única rede física.

- IP over Optical: além da tendência de virtualização de elementos de núcleo, outra tendência marcante é a redução de camadas entre o nível IP e o nível óptico, promovendo a integração direta entre IP e DWDM e eliminando assim tecnologias de transporte como SDH/Sonet (25). Essa tendência é impulsionada pela crescente necessidade de banda nas redes IP e pela necessidade de simplificação das redes. Além da integração do plano de dados, a integração do plano de controle também pode ser promovida, por exemplo, com a utilização Generalized Multiprotocol Label Switching (GMPLS), também referido como multi-protocol lambda switching. O GMPLS constitui uma generalização do conceito de MPLS e, neste caso, a inteligência de controle do MPLS é trazida também para o nível óptico realizando o controle de comutação de comprimentos de onda. 


\subsubsection{Agregação}

Neste segmento, estão as redes de agregação no âmbito metropolitano ou Metropolitan Area Network (MAN) que escoam o tráfego entre o acesso e o núcleo da rede. Em geral, tais redes são delimitadas entre os roteadores da borda próximos ao núcleo e os roteadores/switches de agregação próximos do acesso (4) conforme mostra a Figura 11. Além da camada de roteamento e comutação, tais redes compreendem também a camada de transmissão tal como o segmento de núcleo. No caso das redes de agregação de alcance metropolitano, a transmissão pode ocorrer diretamente sobre fibra apagada ou em conjunto com a utilização de tecnologias DWDM ou SDH/Sonet.

Historicamente, as redes de agregação foram construídas para transportar o crescente tráfego de serviços de acesso à Internet banda larga até o núcleo da rede. Essas redes de agregação foram tipicamente implementadas utilizando tecnologia Asynchronous Transfer Mode (ATM) para transporte e elementos de rede Broadband Remote Access Server (B-RAS) para implementar as funções de inteligência do serviço banda larga de maneira centralizada. Neste modelo de arquitetura centralizada, a inteligência reside no B-RAS, onde são gerenciadas e aplicadas as políticas QoS, controle de usuário e perfis de serviço.

Nos últimos anos, as redes de agregação vêm passando pela evolução da tecnologia ATM para Ethernet/IP como reflexo de uma marcante tendência na indústria de telecomunicações rumo à arquitetura de rede all-IP (5). Apesar da evolução da tecnologia nessas redes de agregação, o modelo de inteligência centralizada no B-RAS ainda é uma realidade em boa parte das operadoras.

A oferta de serviços IPTV traz diversos desafios para a arquitetura de inteligência centralizada. Além da necessidade de suportar novas funcionalidades, um dos principais desafios diz respeito à escalabilidade. As redes de agregação banda larga foram originariamente construídas para transportar fluxos de tráfego da ordem de dezenas a centenas de Kbps por usuário e que possuíam perfis de rajada. O advento do vídeo eleva este patamar para níveis de Mbps de fluxos contínuos e prolongados de tráfego, trazendo requisitos diferenciados aos B-RAS que precisa suportar uma quantidade de tráfego bastante superior e novas funcionalidades 
como, por exemplo, mecanismos multicast, aplicação de políticas de QoS ao serviço de vídeo, mecanismos de autenticação diferenciados baseados em DHCP, entre outras (4). Neste contexto, surgem algumas opções de evolução para a arquitetura de borda do serviço (27): continuar com a inteligência centralizada; distribuir a inteligência na rede de agregação; ou adotar um modelo híbrido dependendo de cada serviço.

Além das decisões sobre a centralização ou não da inteligência do serviço, existem diversas maneiras de se implementar a rede de agregação em camada 2 ou camada 3, combinando as tecnologias Ethernet / MPLS / IP. Nas implementações de Camada 3, a inteligência IP é levada até o elemento mais próximo da rede de acesso e, em geral, estão associadas a modelos de inteligência distribuída. Por exemplo, as funcionalidades de IP multicast (vide item 2.8.2.3) são habilitadas até o roteador que interconecta a rede de agregação com a rede de acesso ou, eventualmente, até no primeiro elemento de acesso. Nas implementações de Camada 2, as funcionalidades IP ficam circunscritas ao roteador de borda do núcleo e o modelo de distribuição de inteligência depende das funcionalidades dos elementos da rede de agregação.

Além da escolha dos modelos de distribuição de inteligência e modelo de agregação, a definição do esquema de Virtual Local Área Network (VLAN) é importante nesse segmento de rede. O esquema de VLAN é utilizado para mapear diferentes assinantes e serviços e identificá-los ao longo diferentes segmentos da rede, podendo fazer uso dessa informação para a aplicação de políticas de QoS, por exemplo. O DSL Forum define dois tipos de esquemas de VLANs no relatório técnico TR-101: mapeamento por assinante (1:1) ou por serviço (1:N).

Maiores detalhes a respeito das questões de distribuição de inteligência, modelo de implementação em Camada 2 ou 3, e esquemas de VLAN por assinante ou serviço estão apresentados no Apêndice A. 


\subsubsection{Acesso}

O principal requisito dessas redes é atender às necessidades de largura de banda exigidas pelo serviço de vídeo (4). Na Tabela 3, está apresentada uma comparação da banda necessária de acordo com algumas variações de pacote de serviço considerando as taxas de compressão apresentadas na Tabela 2. A evolução promovida na arquitetura de acesso visa atender tais necessidades elevadas de banda para viabilizar a oferta de IPTV.

Tabela 3 - Comparativo de banda necessária no acesso

\begin{tabular}{lcc}
\hline & \multicolumn{2}{c}{$\begin{array}{c}\text { Largura de Banda } \\
\text { Pecessária (Mbps) }\end{array}$} \\
\cline { 2 - 3 } Pacote de Serviço & MPEG-2 & MPEG-4 AVC \\
\hline 1 SDTV + Internet @ 1Mbps & 3,8 & 3,0 \\
\hline 2 SDTV + Internet @ 1 Mbps & 6,5 & 5,0 \\
\hline 1 HDTV + 1 SDTV + Internet @ 1 Mbps & 17,0 & 11,2 \\
\hline 1 HDTV + 2 SDTV + Internet @ 1 Mbps & 19,7 & 13,2 \\
\hline 2 HDTV + 2 SDTV + Internet @ 1 Mbps & 32,9 & 21,5 \\
\hline \multirow{2}{*}{ *largura banda necessária considerando overhead de protocolos de rede $(16)$}
\end{tabular}

Historicamente, as redes de acesso foram construídas utilizando par metálico. A rede de acesso de telefonia típica tem por objetivo levar os cabos desde o prédio da central também conhecido como Central Office (CO) onde está localizado o Distribuidor Geral (DG) até a residência do assinante. Entre a central e residência do assinante podem existir diversos pontos de flexibilização. Em geral, essa rede se divide em duas partes: primária e secundária. $A$ interligação dos cabos entre a rede primária e secundária é realizada pelos armários de distribuição. Na rede secundária podem existir ainda outros pontos de flexibilização como, por exemplo, as caixas terminais que conectam os usuários finais através do fio externo ou fio drop (29). A Figura 12 mostra a planta externa da rede de acesso de telefonia e seus principais elementos. A Figura 23 mostra uma perspectiva geográfica da rede de acesso, ressaltando as redes primária e secundária e a estrutura em árvore sob a qual essa rede se configura. 


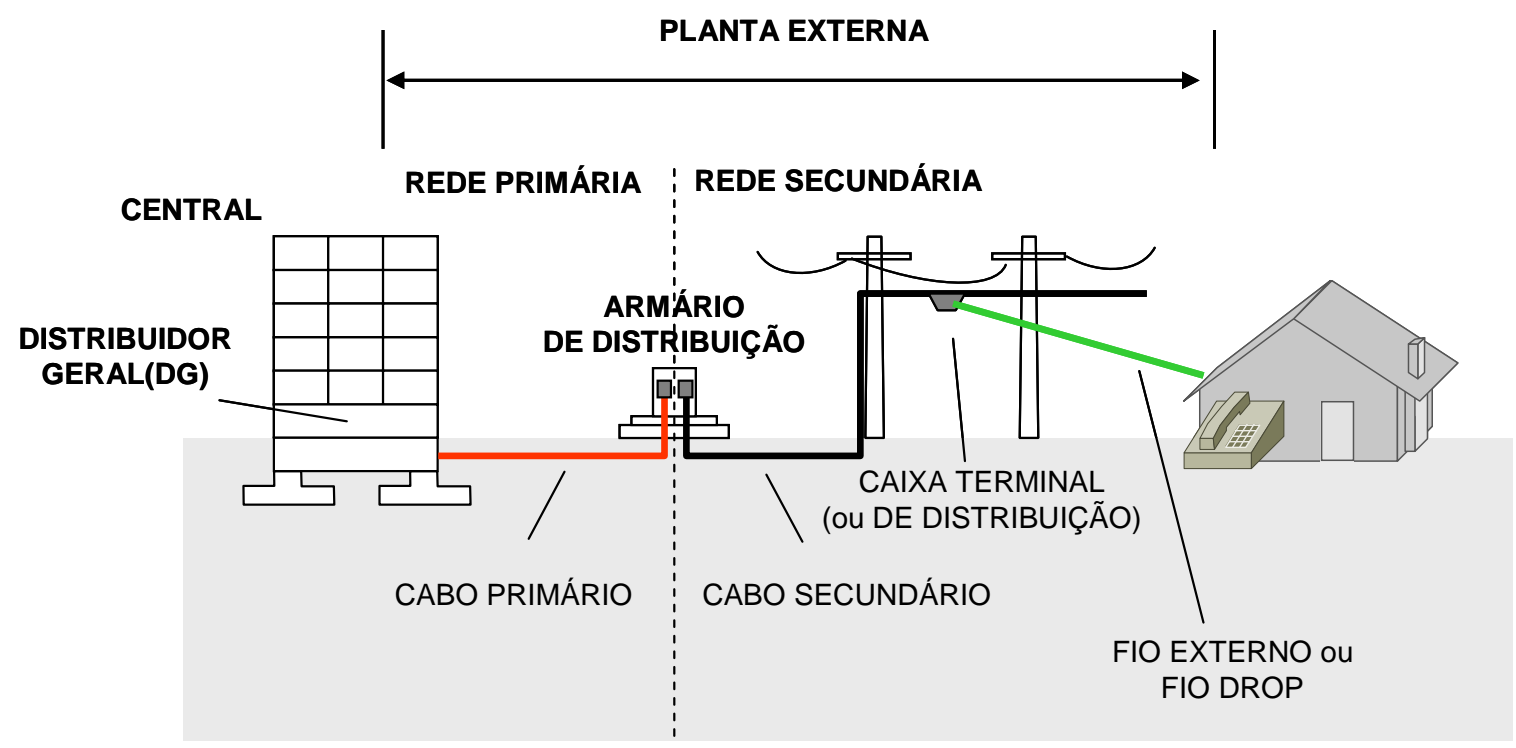

Figura 12 - Topologia típica - rede de acesso

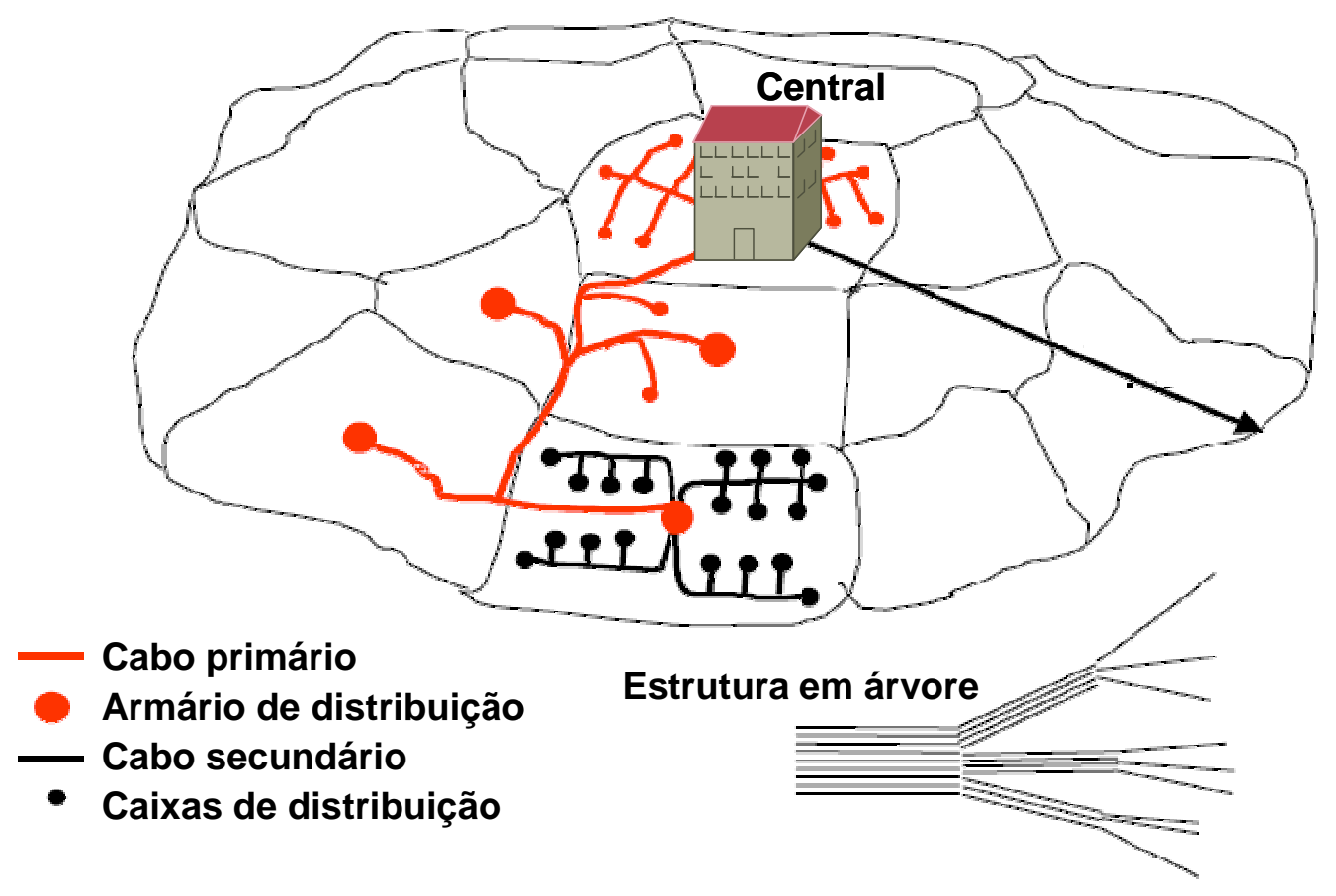

Figura 13 - Distribuição geográfica - rede de acesso (fonte: adaptado de Ecosys (28))

Tais redes construídas utilizando par metálico como meio físico foram adaptadas para prestação de serviços de Internet banda larga com a utilização da tecnologia Digital Subscriber Line (DSL) em suas diversas variações de padrões e o padrão mais difundido atualmente é o Asymetric DSL (ADSL). 
$\mathrm{Na}$ arquitetura xDSL, os DSL Access Multiplexers (DSLAMs) possuem um papel importante pois concentram os acessos de todos os usuários conectados e entregam o tráfego para a rede de agregação. A localização mais comum para os DSLAMs é o prédio da central. Entretanto, eles também podem estar localizados mais próximos dos assinantes como, por exemplo, armários de rua ou então na base de um edifício (29). Tais nós são considerados nós remotos da rede de acesso, também conhecidos como remote nodes (RNs).

Para acompanhar a tendência de migração de tecnologia das redes de agregação os DSLAMs também evoluíram da tecnologia ATM para Ethernet/IP (4). Desta forma, os DSLAMs oferecem interfaces de uplink Ethernet IP chegando a utilizar até interfaces Gigabit Ethernet para suportar o elevado volume de tráfego e também possuem funcionalidades mais sofisticadas que variam desde capacidade de processamento multicast até a capacidade de roteamento IP completa. Alguns DSLAMs mais sofisticados chegam a incorporar funcionalidades de B-RAS distribuídos. Outra evolução percebida nos DSLAMs é a utilização de tecnologias mais avançadas de acesso que oferecem maior largura de banda conforme observado na Figura 14 que mostra a largura de banda oferecida em função da distância do usuário final até o DSLAM para cada tipo de tecnologia.

As principais tecnologias de acesso empregadas para a evolução do acesso xDSL são: Asymetric DSL 2+ (ADSL2+) e Very-high-bit-rate Digital DSL 2 (VDSL2). Comparando as duas tecnologias, nota-se que o VDSL2 possui desempenho superior ao ADSL2+ para curas distâncias e para distâncias maiores eles são equivalentes. Uma alternativa para oferecer maior largura de banda em distâncias maiores é a utilização de dois pares ADSL2+ para um assinante. 
Comparativo de tecnologias xDSL: capacidade vs. distância

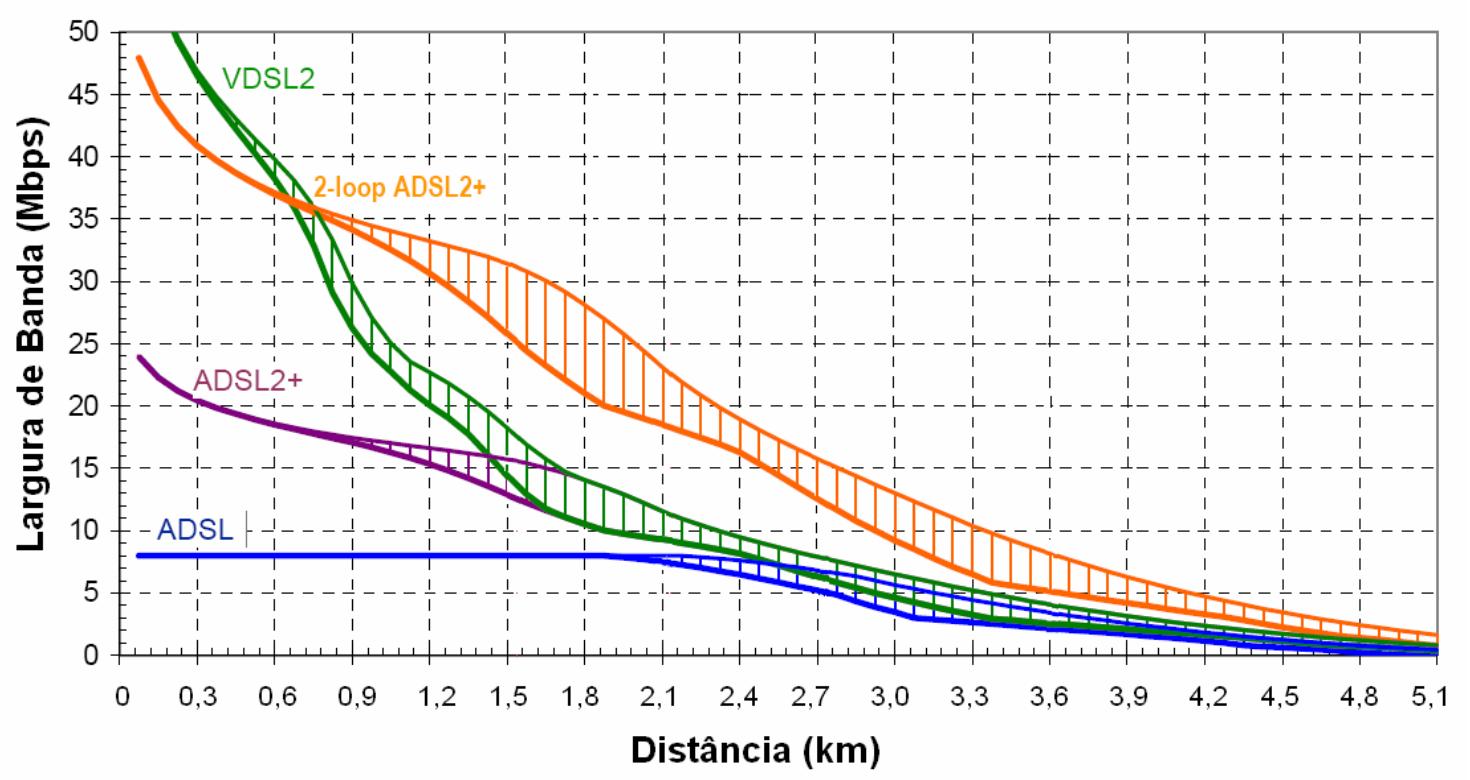

Figura 14 - Comparativo das tecnologias xDSL (fonte: adaptado de HeavyReading (29))

A evolução do acesso para suportar maiores larguras de banda além daquelas apresentadas na Figura 14 depende da introdução de tecnologias ópticas. A composição de meios físicos desde o nó de acesso até o domicílio do assinante determina as principais arquiteturas de redes de acesso (30), conforme indicado na Figura 15. Nestas arquiteturas, o que varia é o quão perto o trecho em fibra óptica chega da residência do assinante. Em geral, o trecho em cobre utiliza os padrões xDSL (ADSL2+ / VDSL2) já descritos.

As variantes que empregam fibra óptica incluem:

- Fiber to the Node / Exchange (FTTN / Exchange): a fibra óptica chega até o nó de acesso, tipicamente localizado na central. Este modelo já é usualmente empregado nas operadoras em regiões com alta concentração de assinantes;

- Fiber to the Cabinet (FTTCab): a fibra-óptica chega até o armário de distribuição;

- Fiber to the Curb (FTTCurb): a fibra-óptica chega até um ponto de distribuição mais próximo dos assinantes, por exemplo, as caixas de distribuição;

- Fiber to the Home / Building (FTTH / FTTB): a rede é implementada em fibra óptica em toda sua extensão. 


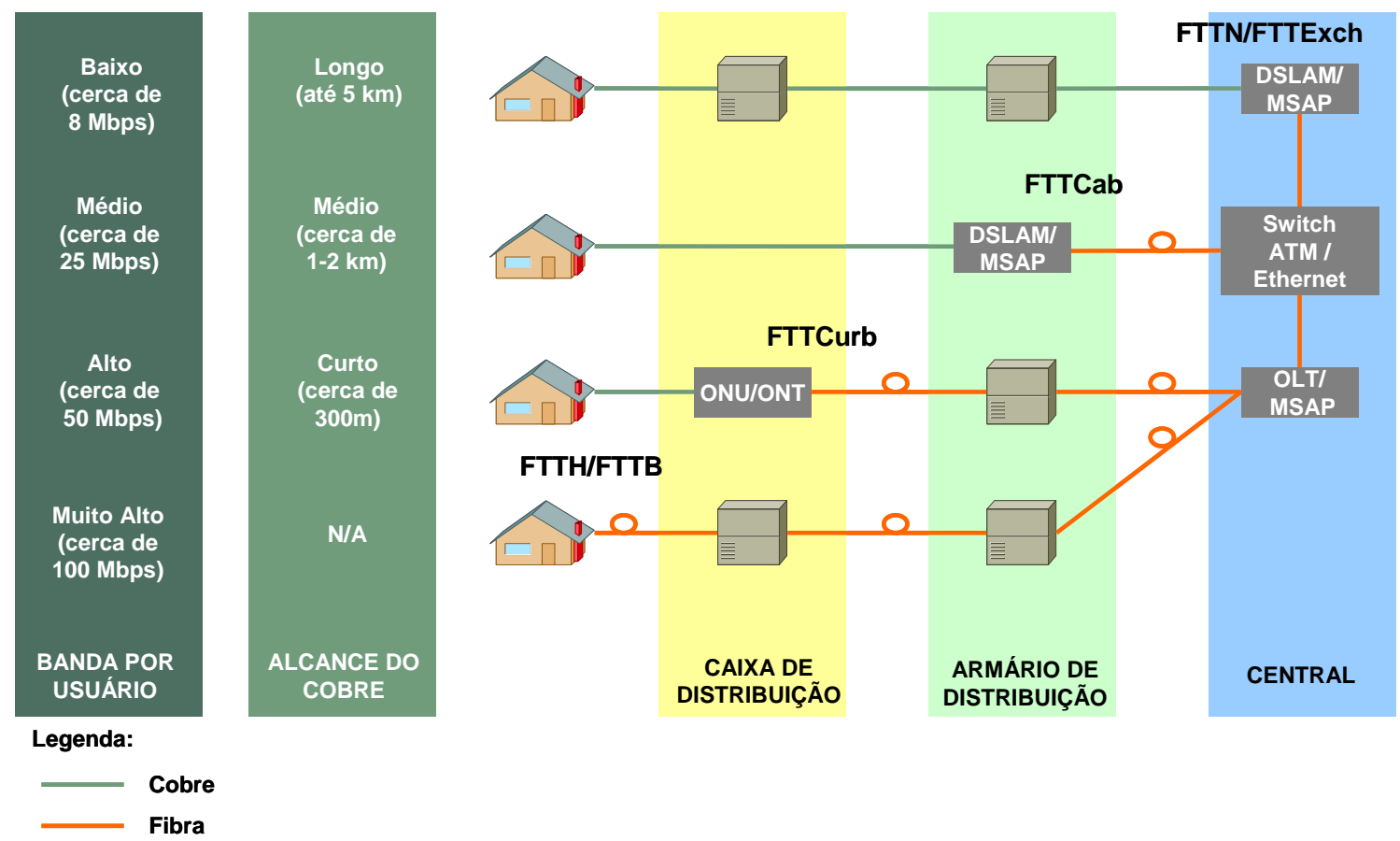

Figura 15 - Topologias de rede de Acesso

(fonte: adaptado de HeavyReading (30))

Nos trechos da rede de acesso que utilizam fibra óptica (5), existem duas modalidades de implementação: tecnologia óptica ativa utilizando tecnologia Ethernet ou passiva também conhecida como Passive Optical Network (PON), que não necessita de equipamentos eletrônicos ativos para transmissão. Existem dois tipos de dispositivos nas redes ópticas PON: um nó central chamado Optical Line Terminal (OLT) que realiza a conexão entre a PON e a rede de agregação; e diversos dispositivos de assinantes denominados Optical Network Termination (ONT) ou Optical Network Unit (ONU). Além desses dispositivos, existe a Optical Distribution Network (ODN) que consiste da rede de fibras ópticas e o conjunto de splitters que a compõe. Em geral, os termos OLT e ONT/ONU também podem ser utilizados como referência aos elementos que estão no nó de acesso e terminais de assinante para as arquiteturas também baseadas em Ethernet. 
As principais topologias de redes puramente ópticas FTTH estão apresentadas na Figura 16 e descritas a seguir (31):

- PON: as redes PON utilizam o conceito de compartilhamento da fibra na rede primária. Para isso, são utilizados splitters passivos que dividem o sinal em direção ao assinante a uma determinada taxa de compartilhamento 1:N;

- Ethernet estrela ativa: implementam o conceito análogo ao da PON, substituindo os splitters por elementos ativos que são switches Ethernet e também compartilhando a fibra da rede primária a uma taxa $1: \mathrm{N}$;

- Ethernet ponto-a-ponto (P2P): implementam o conceito de rede ponto-aponto e não existe compartilhamento de fibra entre assinantes.

PON

\section{Estrela passiva}

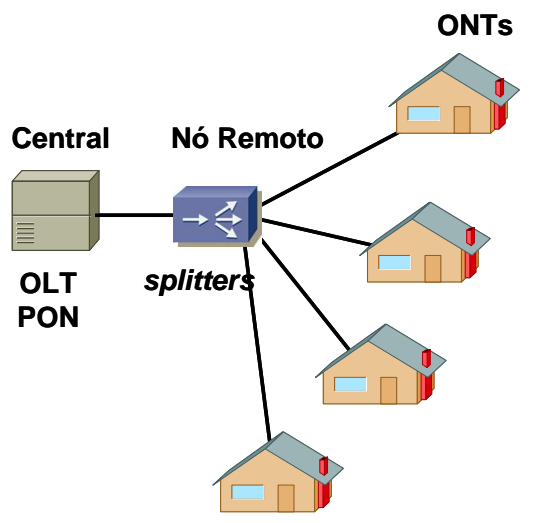

Ethernet

Estrela ativa

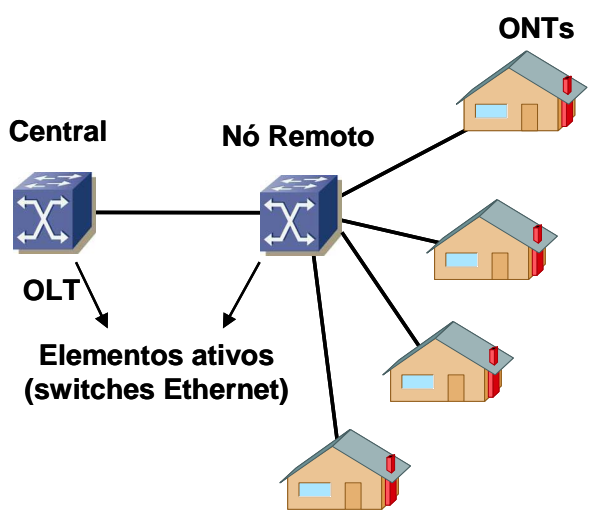

Ethernet

Ponto-a-ponto

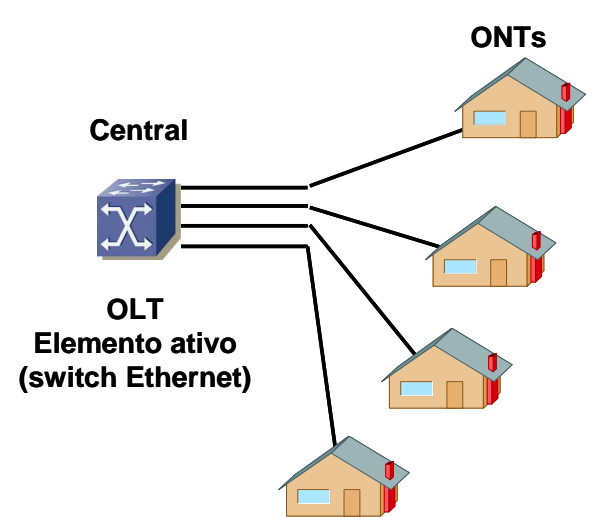

Figura 16 - Topologias de rede de acesso FTTH 
Conforme ilustrado na Tabela 4, existem diversos padrões tecnológicos de PON. O primeiro padrão adotado em larga escala foi o BPON que tinha como base a compatibilidade com a tecnologia ATM e é suportado pelo ITU-T. Seu sucessor é o GPON que possui compatibilidade com as tecnologias ATM e Ethernet. Já o padrão EPON também conhecido como GEPON é inteiramente baseado em Ethernet e suportado pelo IEEE. As próximas evoluções da arquitetura PON se utilizam de tecnologia WDM para aumentar a largura de banda para o usuário final.

Tabela 4 - Padrões PON

\begin{tabular}{lccc}
\hline & BPON & GPON & EPON \\
\hline $\begin{array}{lccc}\text { Largura de Banda } \\
\text { Upstream/Downstream }\end{array}$ & $155 / 622 \mathrm{Mbps}$ & $1,25 / 2,5 \mathrm{Gbps}$ & $1,25 / 1,25 \mathrm{Gbps}$ \\
\hline Largura de Banda $(1: 32)^{*}$ & $16 \mathrm{Mbps}$ & $69 \mathrm{Mbps}$ & $30 \mathrm{Mbps}$ \\
\hline Alcance & $20 \mathrm{~km}$ & $20 \mathrm{~km}$ & $10 \mathrm{~km}$ \\
\hline Protocolo nativo & ATM & GEM & Ethernet \\
\hline Órgão de Padronização & ITU-T & ITU-T & IEEE \\
\hline Data de padronização & 1994 & 2003 & 2004 \\
\hline
\end{tabular}

${ }^{*}$ largura banda considera overhead de protocolos de rede (16)

A largura de banda efetiva disponibilizada ao assinante final varia de acordo com as premissas de cada projeto: taxa de compartilhamento, largura de banda aprovisionada no uplink da OLT e velocidade das portas da OLT (dependendo da arquitetura e padrão selecionado). A Tabela 4 ilustra a largura de banda para o caso da PON considerando taxa de compartilhamento de 1:32.

Além da evolução da tecnologia xDSL e das tecnologias ópticas, vale notar o surgimento de uma nova categoria de dispositivos de acesso multifuncionais, os Multiservice Access Platforms (MSAP). Eles constituem uma plataforma multisserviço que inclui desde o acesso banda larga até funcionalidades de voz. Tais dispositivos possuem desde interfaces xDSL ou PON para assinantes e, desta forma, podem ser utilizados no lugar dos DSLAMs ou até das OLTs, permitindo a oferta de serviços sobre fibra ou cobre a partir de um mesmo equipamento. 


\subsubsection{Perfis de tráfego IPTV}

\subsubsection{Protocolos de tempo real}

Em uma rede IPTV, os pacotes de vídeo são carregados em geral utilizando protocolos de tempo real, de maneira a privilegiar a característica do tráfego multimídia de fluxo contínuo. Após a codificação do vídeo utilizando, por exemplo, o padrão MPEG, os pacotes resultantes da codificação são transportados em geral utilizando User Datagram Protocol (UDP) sobre IP (16). A razão para a utilização do UDP em detrimento do Transmission Control Protocol (TCP) é que ele não prevê retransmissão em caso de perda de pacotes, o que poderia prejudicar o sincronismo que é de fundamental importância no tráfego de vídeo (30).

O encapsulamento dos pacotes UDP é realizado utilizando Real Time Protocol (RTP) (33) que suporta transmissão de conteúdo em tempo real através de mecanismos de controle para sincronizar diversos streams com características temporais. O protocolo RTP pode vir associado de seu protocolo de controle Real Time Control Protocol (RTCP), que oferece funções de feedback de QoS, sincronização, identificação de participantes e informações de controle de sessão.

Adicionalmente, no caso de serviços de VOD, pode-se utilizar o protocolo de controle de sessão Real Time Streaming Protocol (RTSP) (16) em conjunto com RTP para oferecer funcionalidades análogas ao DVD - exemplo: play, pause, rewind - para um serviço baseado em streaming. 


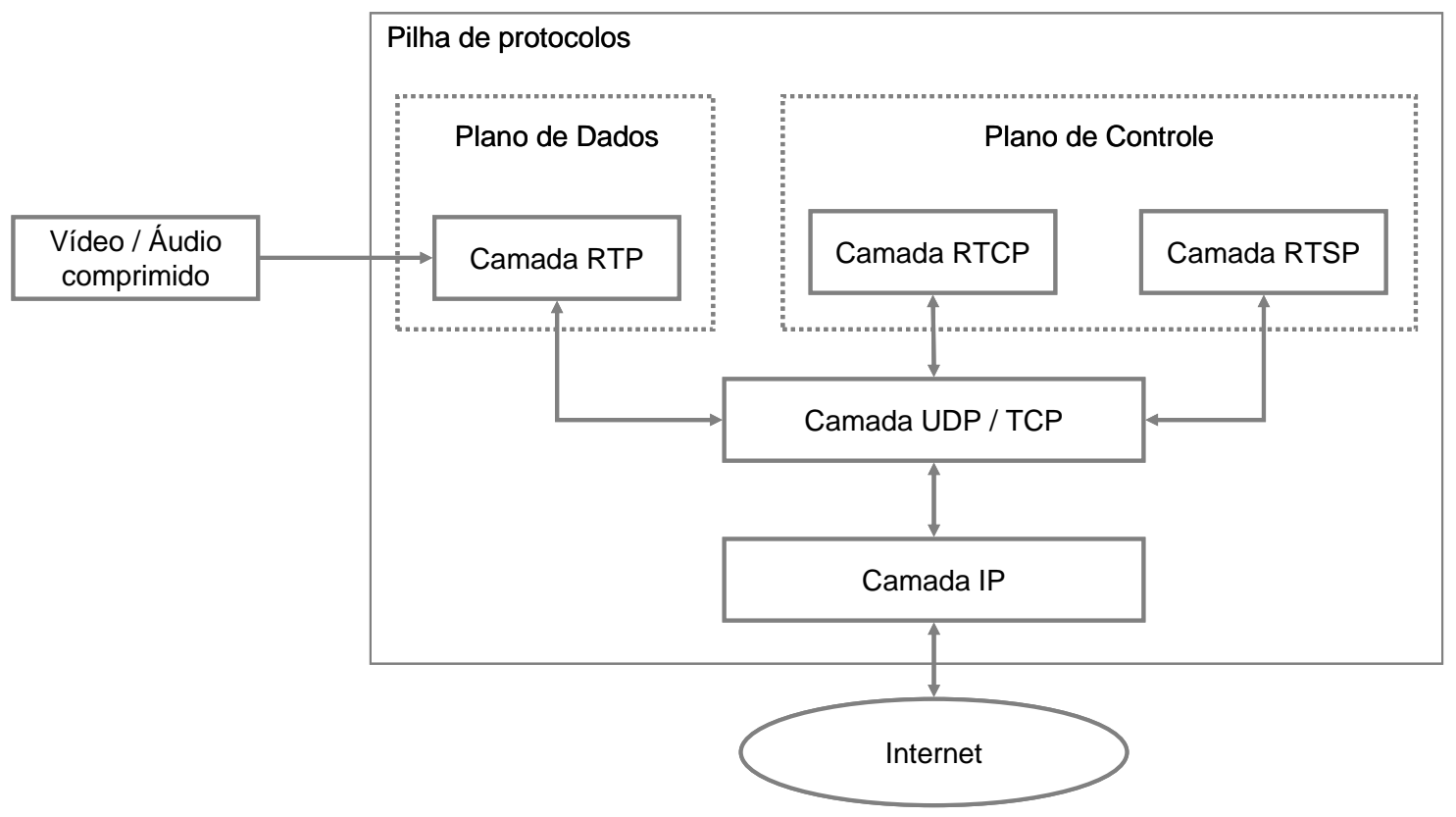

Figura 17 - Pilha de protocolos para transporte multimídia (fonte:adaptado de Rao (33))

O protocolo de transporte do padrão MPEG também é utilizado para encapsulamento (16). O MPEG Transport Stream (MPEG TS) pode ser utilizado diretamente com IP/UDP ou em conjunto com RTP (IP/UDP/RTP) conforme já padronizado pela European Telecommunications Standards Institute (ETSI). Nas implementações realizadas utilizando MPEG como padrão de codificação, a utilização do MPEG-TS em conjunto com o RTP vem sendo empregada.

\subsubsection{Tipos de endereçamento}

Dependendo do tipo de tráfego, existem três tipos de endereçamento capazes de levar pacotes IP ou frames Ethernet de sua origem ao destino: unicast, broadcast e multicast . O endereçamento unicast é utilizado para a comunicação entre dois hosts e apenas uma cópia do conteúdo é enviado da origem ao destino, ou seja, tem-se uma relação de comunicação 1:1. Já o endereçamento broadcast é utilizado quando um host deseja enviar a mesma informação simultaneamente para os outros hosts e, portanto, a comunicação se dá em uma relação de $1: \mathrm{N}$, sendo $\mathrm{N}$ a quantidade total de hosts conectados à rede. O endereçamento multicast é um caso específico do broadcast em que um host deseja enviar a mesma informação simultaneamente 
para um subconjunto dos hosts conectados à rede. Neste caso, a relação de comunicação é de 1:M em que $\mathrm{M}<\mathrm{N}$ e $\mathrm{M}$ representa a quantidade de hosts para os quais se deseja enviar a informação.

Quando o conteúdo transmitido no serviço IPTV é de natureza VOD, utiliza-se o endereçamento unicast para sua transmissão, pois o stream de vídeo está sendo enviado do servidor para apenas um usuário. Em contrapartida, quando os canais de programação são transmitidos, utiliza-se o endereçamento multicast para sua transmissão. Desta forma, um stream é enviado simultaneamente do head-end para um grupo limitado de $\mathrm{M}$ usuários que estejam assistindo o conteúdo naquele momento. $\mathrm{O}$ mecanismo de multicast evita que exista tráfego de vídeo redundante na rede, otimizando assim a utilização de recursos de rede. A Figura 18 ilustra o aumento de eficiência na utilização de recursos de rede ao empregar multicast nessas situações.
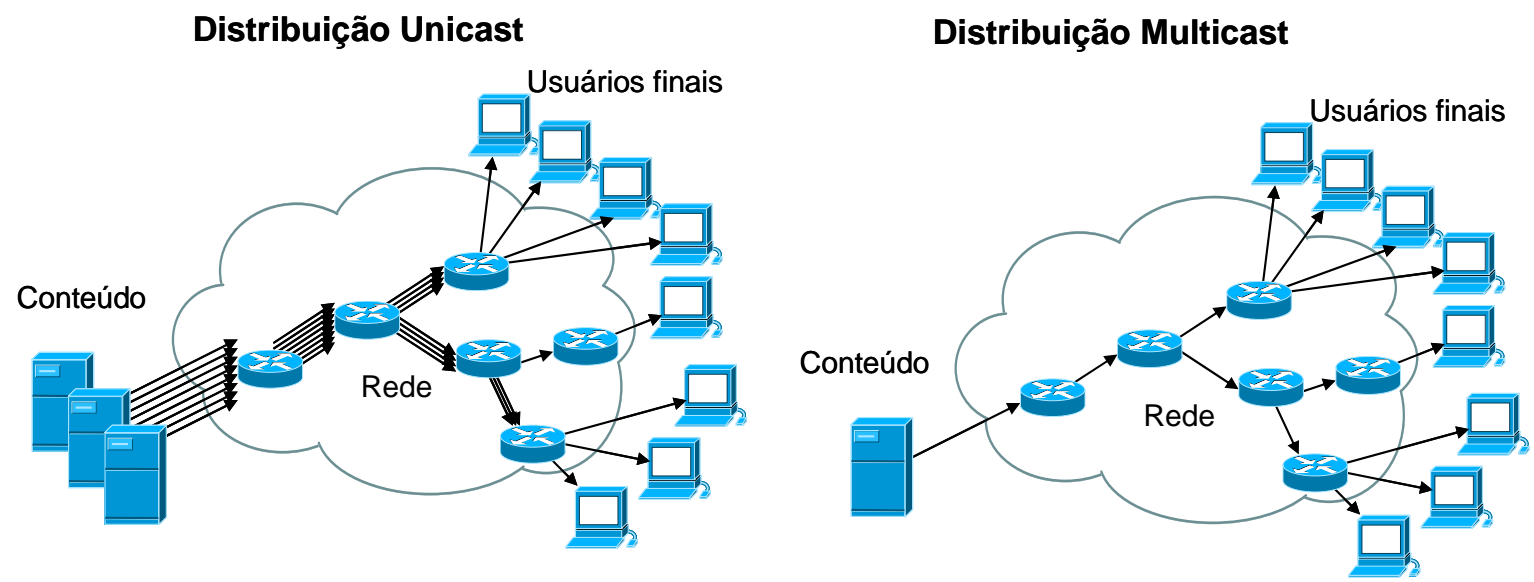

Figura 18 - Ganhos com utilização de distribuição multicast

\subsubsection{Mecanismos multicast}

O multicast é baseado no conceito da criação grupos multicast em que um usuário precisa se afiliar a um grupo para poder receber o conteúdo (25). Quando o usuário não deseja mais receber aquele conteúdo ele deixa um grupo e se afilia a outro para passar a receber outro tipo de conteúdo como, por exemplo, outro canal de programação. O protocolo Internet Group Management Protocol (IGMP) é como protocolo de sinalização do mecanismo multicast entre hosts e a rede, controlando 
desde o anúncio e manutenção dos grupos multicast até o registro (join / leave) ${ }^{2}$ dos receptores aos grupos.

Para limitar a duplicação desnecessária de pacotes na rede em regiões em que assinantes selecionaram um mesmo canal, são empregados os conceitos de árvore de distribuição multicast que especificam um caminho único entre a origem e o grupo de usuários requisitando o conteúdo (30). O objetivo principal das árvores de distribuição é garantir que apenas uma cópia de cada pacote seja encaminhada em cada ramificação da árvore, sendo que as folhas são representadas pelos assinantes e a origem pela fonte de conteúdo. Existem duas abordagens para construir uma árvore de distribuição. Ela pode ser baseada na fonte (source tree ou shortest path tree) em que se constrói uma árvore multicast para cada fonte no grupo multicast. Ou então, a árvore pode ser compartilhada pelo grupo (shared tree), ou seja, existe uma única árvore de roteamento para encaminhar todos os pacotes para os receptores.

Existem diversas categorias de protocolos de roteamento multicast baseados em IP (25):

- Modo denso: que utilizam o conceito de push, enviando pacotes multicast para todos os roteadores ainda que o conteúdo não tenha sido solicitado Distance Vector Multicast Routing Protocol (DVMRP) e Protocol-Independent Multicast Dense Mode (PIM-DM).

- Modo esparso: que utilizam o conceito de pull, considera que o tráfego multicast não é enviado a não ser que seja requerido - Core Based Trees (CBT), Protocol-Independent Multicast Sparse Mode (PIM-SM) e Protocolindependent Multicast Specific Source Mode (PIM-SSM)

- Estado de enlace: que determinam a alcançabilidade de um destino Multicast Open Shortest Path First (MOSPF)

- Inter-domínio: que roteiam pacotes multicast entre domínios distintos Multicast Border Gateway Protocol (MBGP) e Multicast Source-Discovery Protocol (MSDP)

\footnotetext{
${ }^{2}$ Join e Leave são mensagens do protocolo IGMP utilizadas quando um host se afilia e deixa um grupo multicast, respectivamente.
} 
Tais mecanismos considerados até aqui são válidos em uma rede IP, mas também é possível empregar o conceito de multicast em alguma extensão em elementos que não sejam dotados de inteligência IP como, por exemplo, classes de switches Ethernet ou DSLAMs que implementam apenas funcionalidades de camada 2. Neste caso, esses elementos realizam a inspeção do tráfego de sinalização IGMP entre o host e o primeiro elemento que possua funcionalidade multicast. Com base nessas informações, este elemento decide se encaminha ou não o stream de tráfego a que se refere àquela sinalização. Dessa forma, os mecanismos multicast são emulados em alguma extensão também em elementos de camada 2.

Este mecanismo é chamado de IGMP snooping, e o elemento de camada 2 é transparente para os elementos de rede que possuem funcionalidade multicast. Um outro mecanismo empregado, por exemplo, em DSLAMs e que constitui uma variação deste é o IGMP proxy-routing. Neste caso, o DSLAM funciona como proxy atuando como um host para o primeiro elemento multicast da rede e como um elemento IGMP para o receptor. Através desse mecanismo, é possível configurar o DSLAM para receber todos fluxos vindos da rede e replicar os fluxos para o receptor sob demanda, diminuindo assim o tempo para que o usuário receba um novo canal solicitado.

\subsubsection{Distribuição de tráfego IPTV}

Conforme discutido, as considerações relacionadas a tráfego multicast se aplicam à distribuição do conteúdo de canais de programação, também conhecidos por canais broadcast.

Para a distribuição desse tráfego ao longo do núcleo da rede, ou seja, entre SHE e VHOs, algumas alternativas são utilizadas. Duas delas baseiam-se em IP nativo: PIM-SM e o PIM-SSM, e uma terceira baseada em MPLS: Point-multipoint Label Switched Path (P2MP LSP) (34).

- PIM-SSM: necessita que o roteador de borda conheça a fonte do conteúdo que está distribuindo o conteúdo multicast. A especificação do endereço da 
fonte pode ser realizada pelo próprio receptor ou pelo próprio roteador de borda que faz o mapeamento entre o grupo de multicast e a fonte associada.

- PIM-SM: não necessita que o roteador de borda saiba qual é a fonte da distribuição de conteúdo. Um roteador é definido como Rendezvous Point (RP) para o qual os demais roteadores de borda solicitam o endereço da fonte. Esta solução é empregada quando a quantidade de grupos é muito grande ou as fontes são numerosas ou sujeitas a mudança.

- P2MP LSP: é uma solução menos dinâmica do que as que utilizam PIM. A premissa básica que é os roteadores de borda sempre possuem receptores ativos conectados a eles. Quando o tráfego multicast é transmitido pela fonte ele é distribuído para os roteadores de borda através dos circuitos MPLS ponto-multiponto (os LSPs) e é replicado no ponto que for necessário.

Das abordagens para utilização de multicast no núcleo, as mais apropriadas para implementações de IPTV são aquelas baseadas em PIM-SSM e P2MP LSP, sendo que as PIM-SSM contam com maior adoção na indústria (34).

No âmbito das redes de agregação entre os VHOs e VSOs, a distribuição do conteúdo de programação depende do modelo de agregação adotado conforme explicitado no item 2.8.1.2. A utilização de implementações de IP nativo em camada 3 permitem a utilização dos mecanismos de multicast nativos baseado em PIM. Quando combinadas às soluções de núcleo também baseadas em IP nativo, oferecem uma solução de IP multicast homogênea que percorre desde o núcleo até a agregação de maneira fim-a-fim, além de otimizar os recursos da rede de agregação. Abordagens de camada 2 se valem de mecanismos alternativos como é o caso do IGMP snooping, utilização de VLANs ou soluções baseadas em Virtual Private Lablel Switching (VPLS) para otimizar a distribuição de tráfego na agregação (34).

Além dos elementos de agregação, os elementos de acesso também podem contar com inteligência multicast (24). Por exemplo, os DSLAMs, podem incluir desde funcionalidades de IGMP snooping em camada 2 ou até constituírem elementos IP multicast visando otimizar a distribuição de tráfego. Devido às restrições de banda do acesso, uma função importante relacionada à multicast e aplicada aos elementos de acesso (ex.: DSLAMs) é a implementação de fast leave de maneira que a 
transmissão de um canal seja interrompida imediatamente a partir da requisição de mudança de canal pelo usuário. Desta forma, evita-se a possível superposição da transmissão de dois streams de tráfego simultâneos para o set-top box (o canal antigo e o novo) devido ao algoritmo intrínseco ao multicast, o que poderia implicar na degradação de desempenho devido à limitação de banda ou até estouro do buffer do set-top box. Quanto mais próximo dos usuários estiver o primeiro elemento com funcionalidades multicast habilitadas, melhor será a otimização de utilização de recursos da rede.

Deve-se levar em consideração que a utilização de multicast pode também ter impactos na experiência do serviço, pois influencia no tempo de mudança de canal. Ainda que não sejam impactos de grande magnitude quando comparados aos demais fatores que influenciam a mudança de canal (vide item 2.8.3.1), deve-se lembrar que a adoção de multicast e sua forma configuração devem levar em conta o balanço entre otimização de recursos e desempenho. Desde a escolha de quais elementos farão replicação multicast, ou seja, o quão perto os elementos habilitados com IP multicast estão do usuário até a implementação de replicação estática para canais selecionados devem levar em conta estes fatores.

Quanto mais canais disponíveis nos pontos mais próximos do usuário, menor o tempo até o início da transmissão do canal desejado. Em contrapartida, maior será a ocupação de banda nos segmentos de rede em que os canais sejam transmitidos.

\subsubsection{Qualidade de Serviço}

\subsubsection{Desempenho de rede e a percepção do usuário}

As características que, em geral, determinam o comportamento de um serviço são: largura de banda, atraso, variação de atraso e perda de pacotes (21).

Um dos principais parâmetros relacionados à rede que possuem maior impacto em relação à QoE do serviço IPTV é a perda de pacotes, que pode ocorrer em virtude de restrições de largura de banda ou de existência de falhas na rede. Conforme já 
discutido, os streams de vídeo possuem necessidades de largura de banda acima das aplicações correntes nas redes IP e também possuem características de tráfego de fluxo contínuo e tempo real. Desta forma, taxas de perda de pacotes mais elevadas podem impactar fortemente a qualidade do vídeo (17).

A perda de pacotes pode ter maiores efeitos sobre a qualidade do vídeo quando da utilização de taxas de compressão mais elevadas no conteúdo codificado. Além disso, dependendo do tipo de quadro sendo transmitido, os erros devido à perda de informação podem ser mais pronunciados e se propagar por diversos quadros. Para reduzir a quantidade de banda para a transmissão de vídeo, métodos de compressão como o MPEG se utilizam de diversos tipos de quadro conhecidos como I, P e B para codificar o sinal. Os quadros do tipo I não dependem de nenhum quadro para serem construídos e utilizam apenas sua informação para apresentar o sinal ao assinante. Os outros tipos de quadros $\mathrm{P}$ e B dependem da informação de outros quadros para serem construídos. Um grupo de imagens também conhecido como Group of Pictures (GOP) é uma coleção desses quadros MPEG (12). Dessa maneira o intervalo entre 2 quadros I é proporcional ao tamanho do GOP e da quantidade de frames por unidade de tempo. Quando a perda de pacotes afeta um quadro I, as distorções na imagem podem se propagar até a chegada de outro quadro I.

Em geral, problemas atraso fim-a-fim e jitter não são tão críticos quanto os problemas com perda de informação no caso do IPTV, pois os set-top boxes contam com buffers que amenizam esses problemas, conciliando o desempenho de rede com a plataforma de vídeo. O nível de jitter da rede deve estar dentro dos limites dos buffers dos set-top boxes utilizados, pois o transbordo do buffer implica em perda de informação. Um aspecto importante relacionado ao atraso diz respeito à perspectiva do usuário quando compara o atraso do sinal do IPTV com o sinal dos canais transmitidos via serviços tradicionais de TV aberta. O atraso não pode ser de tal magnitude que gere desconforto ao assinante.

A Tabela 5 mostra exemplos de parâmetros de qualidade aceitáveis para 0 transporte de dados fim-a-fim, utilizando taxas de codificação distintas e também dependendo da qualidade do conteúdo: SDTV ou HDTV. 


\begin{tabular}{|c|c|c|c|c|c|}
\hline $\begin{array}{l}0 \\
0 \\
\frac{\pi}{0} \\
\frac{0}{\pi} \\
\frac{\pi}{2} \\
0\end{array}$ & 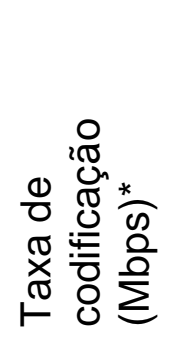 & 怘 & 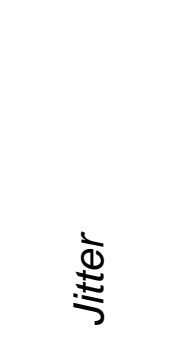 & 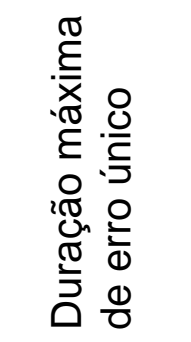 & 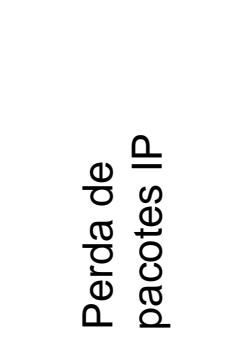 \\
\hline SDTV & 1,75 & $<200 \mathrm{~ms}$ & $<50 \mathrm{~ms}$ & $<=16 \mathrm{~ms}$ & $<=6,68 \mathrm{E}-06$ \\
\hline SDTV & 2,0 & $<200 \mathrm{~ms}$ & $<50 \mathrm{~ms}$ & $<=16 \mathrm{~ms}$ & $<=7,31 \mathrm{E}-06$ \\
\hline HDTV & 8 & $<200 \mathrm{~ms}$ & $<50 \mathrm{~ms}$ & $<=16 \mathrm{~ms}$ & $<=1,28 E-06$ \\
\hline HDTV & 10 & $<200 \mathrm{~ms}$ & $<50 \mathrm{~ms}$ & $<=16 \mathrm{~ms}$ & $<=1,24 \mathrm{E}-06$ \\
\hline
\end{tabular}

Além dos aspectos relacionados ao plano de dados, é importante considerar os atrasos do plano de controle, em especial, no caso de mudança de canal. Conforme visto no item 2.6, além da qualidade do vídeo a responsividade do serviço é um dos fatores mais importantes associados à QoE percebida pelo usuário final. O tempo da mudança de canal é uma das características de responsividade que possui relação direta com o desempenho da rede devido à utilização de mecanismos de multicast para otimizar a utilização de recursos.

Parte do atraso relacionado à mudança de canal se deve às etapas do processo relacionadas à sinalização IGMP, desde o momento em que o set-top box do usuário envia uma mensagem de leave de um grupo multicast e, em seguida, uma mensagem de join a um novo grupo, até o processamento dessas mensagens pela rede e o início da transmissão do novo canal para o usuário. Além do atraso relacionado à sinalização multicast na rede, existem outros fatores que influenciam o atraso total:

- Atraso de processamento de comando no set-op box desde o acionamento do botão do controle remoto até o envio das mensagens de leave e join;

- Atraso para a chegada do primeiro quadro MPEG do tipo I do novo canal;

- Atraso de processamento dos pacotes recebidos, incluindo também processos de autorização e decriptografia associados ao DRM; 
- Atraso para encher o buffer do set-top box para suportar variações de atraso;

- Atraso de decodificação do conteúdo;

Segundo o DSL Forum, para garantir interatividade e QoE satisfatória, o atraso relacionado a mudança de canal deve ser menor do que 2 segundos. Simulações realizadas dão conta que os fatores relacionados à rede não são predominantes na mudança de canal. Um dos fatores que determina primariamente este atraso é o tempo para a chegada de um quadro MPEG do tipo I do novo canal até o set-top box, pois este é o único tipo de quadro que não necessita de nenhum quadro de referência anterior para ser reconstruído corretamente. Se a mudança de canal ocorrer imediatamente após um quadro I, o sistema precisa esperar até o próximo quadro I para iniciar a exibição do conteúdo. Este atraso pode ser da ordem de 500 a $1000 \mathrm{~ms}$ e varia com a taxa de codificação e quantidade de quadros do GOP. A Figura 19 mostra um exemplo de atraso relacionado à mudança de canal a partir de uma simulação realizada pelo DSL Forum (17).

\section{Atraso de mudança de canal}

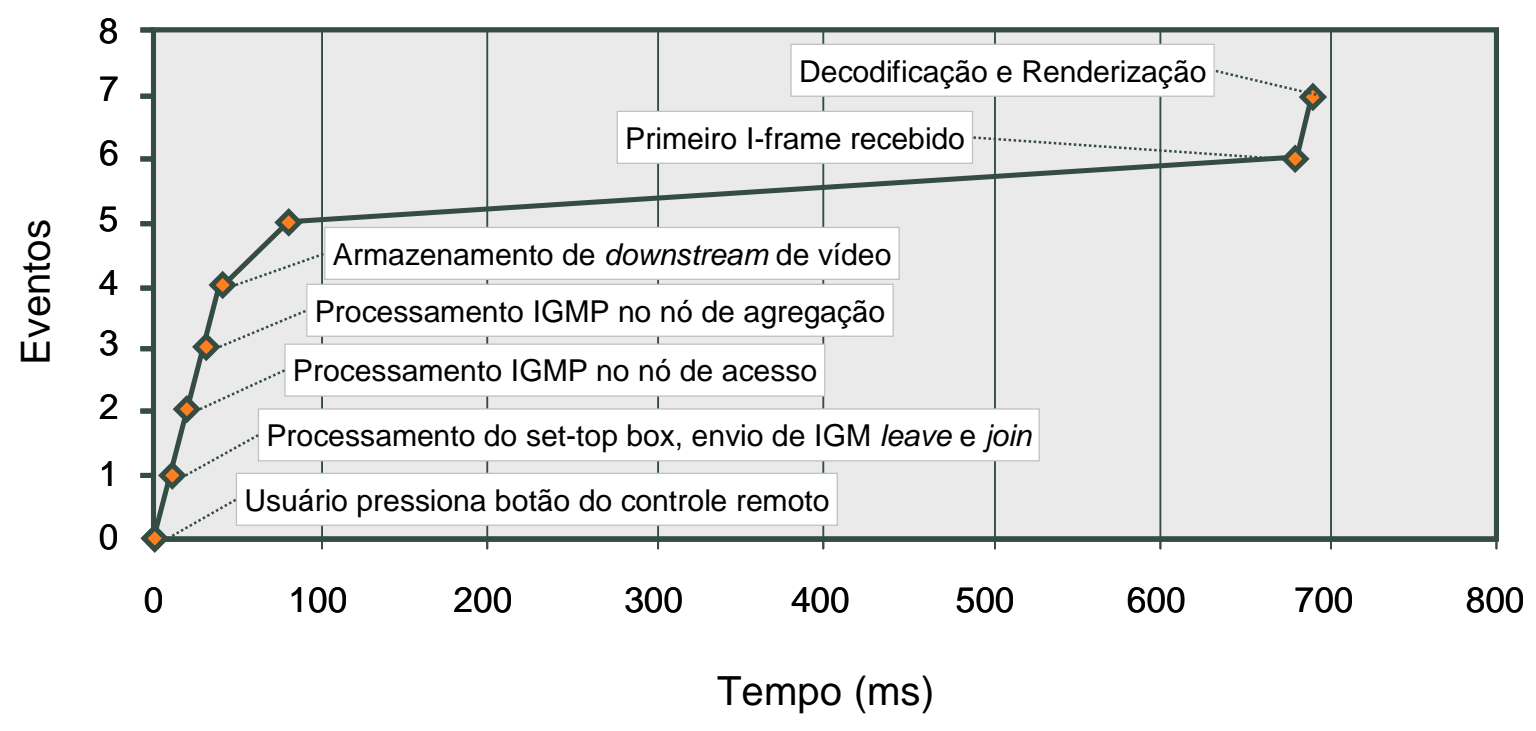

Figura 19 - Exemplo de atraso de mudança de canal (fonte: DSL Forum (17)) 


\subsubsection{Mecanismos de QoS aplicados à IPTV}

As redes IP são redes de pacotes e tradicionalmente não oferecem garantia de qualidade de serviço. Tornar uma infra-estrutura IP capaz de suportar serviços multimídia, requer a adoção de mecanismos para implementar QoS (30). Dois conceitos se destacam visando à garantia de QoS no nível de rede: diferenciação de serviços e controle de admissão, e serão detalhados na seqüência. Além desses mecanismos, devem ser utilizadas arquiteturas de rede robustas e redundantes de maneira que privilegiem elevados níveis de disponibilidade e o menor tempo de restauração em caso de falhas.

\subsection{Diferenciação por serviço}

O conceito de transmissão de dados best-effort não é suficiente para os serviços IPTV. A diferenciação dos serviços IPTV se faz necessária devido a coexistência de serviços competindo pelos mesmos recursos de rede: acesso à Internet, VolP, serviços corporativos, etc. É nesse contexto que se enquadra o conceito de Classe de Serviço (CoS) que consiste no agrupamento dos serviços de acordo com características comuns, permitindo o tratamento diferenciado em relação às outras classes. Cada CoS possui um conjunto de parâmetros que a caracteriza. A garantia de QoS é obtida através do tratamento diferenciado das diversas CoS ao longo da rede.

A aplicação de QoS é bastante dependente do modelo de distribuição de inteligência dos serviços utilizado, ou seja, se a inteligência de serviços está centralizada ou distribuída ao longo da rede de agregação, a aplicação de QoS também deverá realizada da mesma forma. O nível de granularidade das políticas de QoS também depende do modelo de VLAN implementado: por serviço ou por assinante. Além disso, os mecanismos de QoS disponíveis variam de acordo com implementações de tecnologias de camada 2 ou 3.

Em domínios de camada 3, o modelo de diferenciação e priorização de tráfego baseado em DiffServ é um dos mais empregados (21) e pode ser utilizado para 
suportar serviços IPTV. A diferenciação é conseguida através da classificação e marcação de cada pacote IP manipulando o campo Differentiated Services CodePoint (DSCP). O campo DSCP refletirá a classe de serviço a qual o pacote pertence e quando o pacote circula pela rede, o valor do DSCP é utilizado para a aplicação de um comportamento Per-hop Behavior (PHB) em cada elemento ativo na rede.

$\mathrm{Na}$ arquitetura DiffServ, o processamento mais complexo relacionado à classificação e marcação do tráfego fica localizado na borda da rede. Além dessas funções, os elementos de borda desempenham funções de aplicação de políticas (policing), moldagem (shaping), controle e gerenciamento de congestionamento através de filas, além de fragmentação e compressão. No interior da rede, os elementos ativos respondem à marcação realizada na borda para priorizar o tráfego segundo os recursos alocados para cada classe.

Para garantir QoS de maneira fim-a-fim, é necessário que o conceito de priorização seja válido em todos os domínios da rede. Até o momento, as considerações apresentadas dizem respeito apenas ao domínio IP de camada 3. Desta forma, a marcação deve ser replicada em qualquer domínio como, por exemplo, MPLS, ATM ou Ethernet. Para tanto, é necessário realizar o mapeamento entre as classes de serviços nas bordas da rede, ou seja, quando o pacote passa de um domínio a outro.

Por exemplo, se o núcleo da rede utilizar uma implementação de camada 3 e a rede de agregação for implementada da mesma forma, o modelo de Diffserv se aplica de maneira fim-a-fim. Caso a rede de agregação seja implementada em camada 2, os elementos de rede podem realizar a diferenciação de serviços e assinantes através de diversos parâmetros que o identificam dependendo da sua modalidade de implementação como, por exemplo, o identificador de VLAN, endereço MAC, bits 802.1p ou rótulo MPLS. O mapeamento de classes de serviço também se faz necessário para possibilitar a aplicação de QoS no acesso. 


\subsection{Controle de Admissão}

Além dos mecanismos de diferenciação de serviços discutidos, existem implementações que se utilizam da técnica de controle de admissão para garantia de QoS (16). Com o objetivo de prevenir congestionamentos na rede e afetar a QoE dos assinantes como um todo, são utilizados mecanismos que permitem o início do envio de um stream de vídeo para o assinante apenas quando houver capacidade disponível para tal.

Os recursos necessários para a transmissão são reservados para um assinante antes de seu início e liberados após a finalização de sua sessão. Um sistema capaz de monitorar a disponibilidade de recursos da rede gerencia o processo de maneira fim-a-fim e faz uso de protocolos como o Resource Reservation Protocol (RSVP) para a alocação e liberação dos recursos de rede.

O mecanismo de controle de admissão oferece maior robustez contra situações de utilização de pico. Este mecanismo é particularmente utilizado para o tráfego do serviço VOD. Em condições específicas, a simultaneidade na situação de pico pode demandar maior largura de banda do que o esperado devido à natureza unicast do tráfego VOD. Quando o limite de utilização de recursos for atingido, os usuários que requisitarem um novo conteúdo não serão atendidos, pelo menos instantaneamente, evitando assim a degradação do desempenho da rede como um todo. De maneira análoga, este recurso também pode ser aplicado ao tráfego multicast.

\subsection{INFRA-ESTRUTURA DE GERENCIAMENTO}

O TeleManagement Forum (TMF) define o Enhanced Telecommunications Operations Model (eTOM) (34), que é um modelo operacional de uma operadora de telecomunicações. O eTOM define processos que são divididos em quatro três categorias: Estratégia, Infra-estrutura e Produto; Operações; e Gestão empresarial. As diversas ferramentas que compõem a infra-estrutura de gerenciamento suportam principalmente o grupo de processos de Operações. 
No eTOM os principais processos de Operações são definidos em quatro níveis: Cliente, Serviço, Recursos (aplicações e rede) e Fornecedores/Parceiros. Ao longo dos quatro níveis, são definidos quatro tipos de processos: Aprovisionamento (Fullfilment), Garantia de Qualidade (Assurance), Faturamento (Billing) e Suporte e Disponibilidade de Operações (Operations Support and Readiness) conforme apresentado na Figura 20.

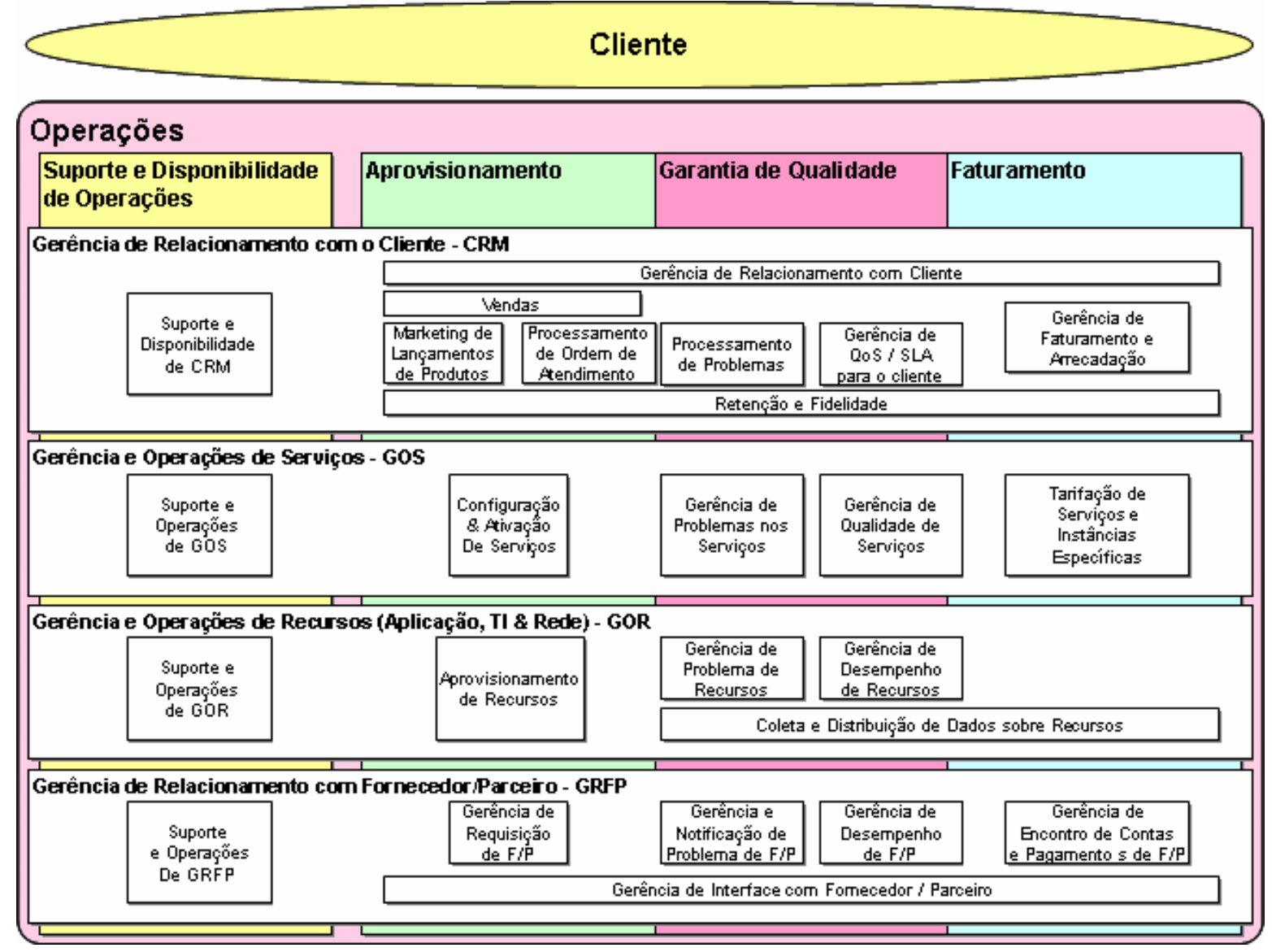

Figura 20 - Modelo eTOM: Operações (fonte: adaptado TeleManagement Forum (34))

Para suportar os processos de Operações definidos no eTOM, existem diversas ferramentas. Elas são conhecidas como sistemas de suporte a operação e aos negócios também conhecidos por Operations Support System (OSS) e Business Support System (BSS) (34). A primeira categoria está mais relacionada ao gerenciamento da rede e plataformas, e a segunda mais relacionada ao gerenciamento do cliente. Na Figura 21 está representado um exemplo de arquitetura OSS/BSS (36) que suporta os diversos processos definidos no eTOM. 


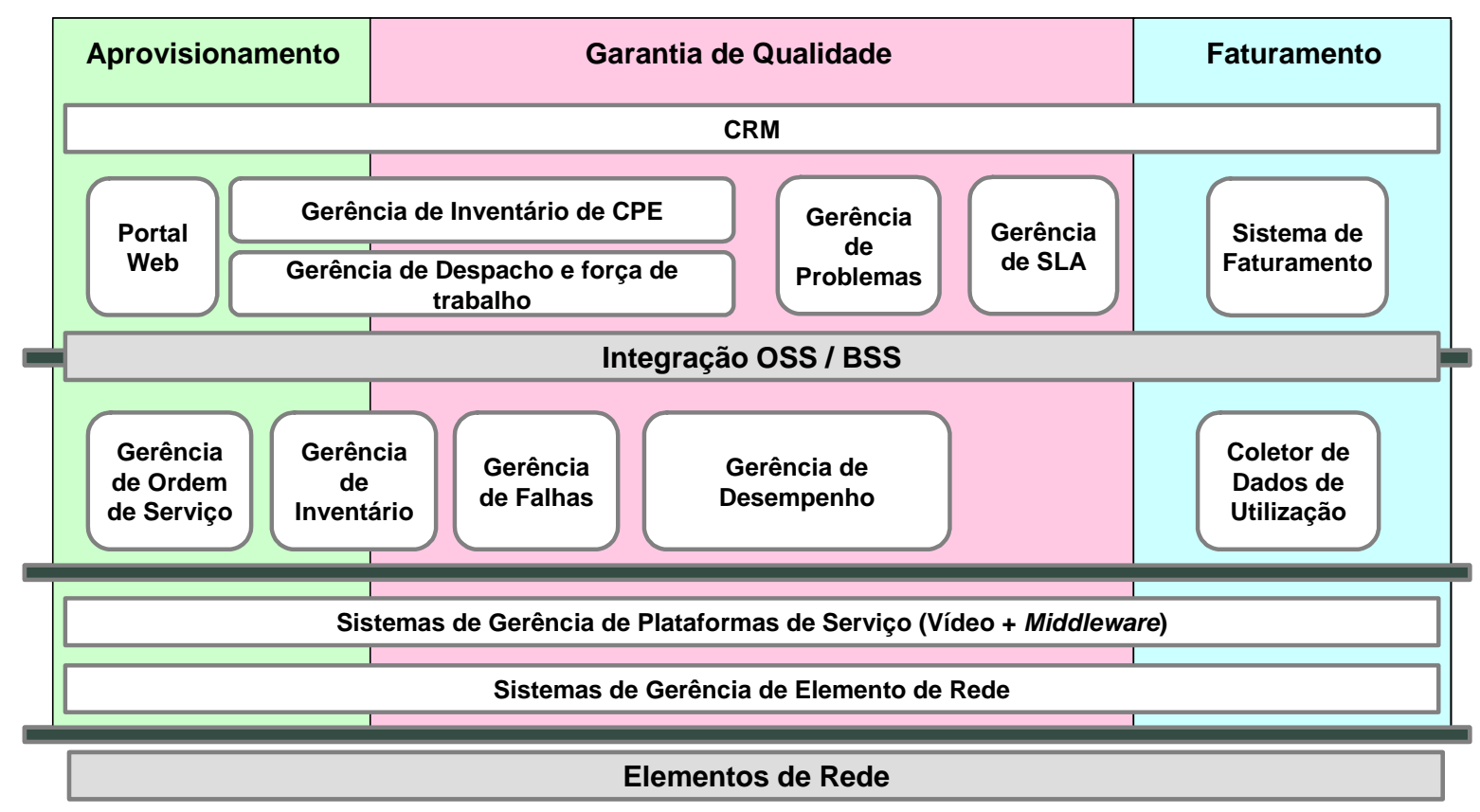

Figura 21 - Exemplo de arquitetura típica de OSS/BSS (fonte: TeleManagement Forum (36))

Tais ferramentas de OSS/BSS são fundamentais para suportar serviços IPTV durante sua operação e garantir níveis de QoE adequados. Como um novo serviço, o serviço IPTV necessita que novas funções sejam realizadas pelas ferramentas de OSS/BSS, pois possuem novos requisitos de processo e introduzem novos elementos tecnológicos que deverão ser gerenciados.

As novas necessidades de OSS/BSS podem ser atendidas através de ferramentas de prateleira disponíveis no mercado ou soluções customizadas desenvolvidas para suprir as necessidades específicas da operadora. Além disso, existem abordagens incrementais e disruptivas quanto à estratégia de OSS/BSS para suportar os serviços IPTV. As primeiras focalizam a modificação dos processos e ferramentas existentes para integrar o novo serviço na estrutura existente. Já as abordagens disruptivas focalizam na criação de uma nova estrutura de OSS/BSS para suportar o novo serviço e os sistemas legados devem ser capazes de se integrar na nova arquitetura (36).

As principais funções associadas às ferramentas de OSS/BSS que se destacam para suportar o serviço IPTV de acordo com as grandes áreas de processos do eTOM estão descritas a seguir (36)(37):

- Aprovisionamento: ferramentas relacionadas à ativação e entrega do serviço desde sua solicitação pelo cliente. Suas funções principais incluem 
principalmente a gestão de configuração e aprovisionamento de todas as plataformas e sistemas desde a camada de rede, passando pelo serviço até o assinante. Além disso, incluem funções de gestão do serviço / produto possibilitando a criação de novos pacotes e perfis de serviço; e de gestão de conteúdo (ex.: título VOD e canais broadcast) durante todo seu ciclo de vida, incluindo a sua distribuição.

- Garantia de Qualidade: ferramentas relacionadas à garantia de QoE/QoS e suas funções incluem principalmente a gestão de falhas, desempenho e nível de serviço. Devido às necessidades diferenciadas que o serviço IPTV traz em termos de QoE conforme discutido no item 2.6.3 é necessário que exista uma arquitetura de ferramentas que focalize o gerenciamento de qualidade de maneira fim-a-fim conforme ilustrado na Figura 22, em que todas as plataformas tecnológicas envolvidas no serviço são gerenciadas de forma integrada, desde os elementos de rede até as plataformas de vídeo (37). De modo geral, para realizar o gerenciamento da qualidade do serviço de vídeo, são utilizados agentes de medição distribuídos no head-end, na rede e até no set-top box do assinante que permitem a obtenção de diversos parâmetros e métricas relevantes ao gerenciamento de qualidade nos diversos níveis apresentados no item 2.6.2. Tais parâmetros são enviados a um sistema integrado que realiza a sua correlação e oferece uma visão consolidada da qualidade do serviço IPTV de maneira fim-a-fim ao operador do sistema. 


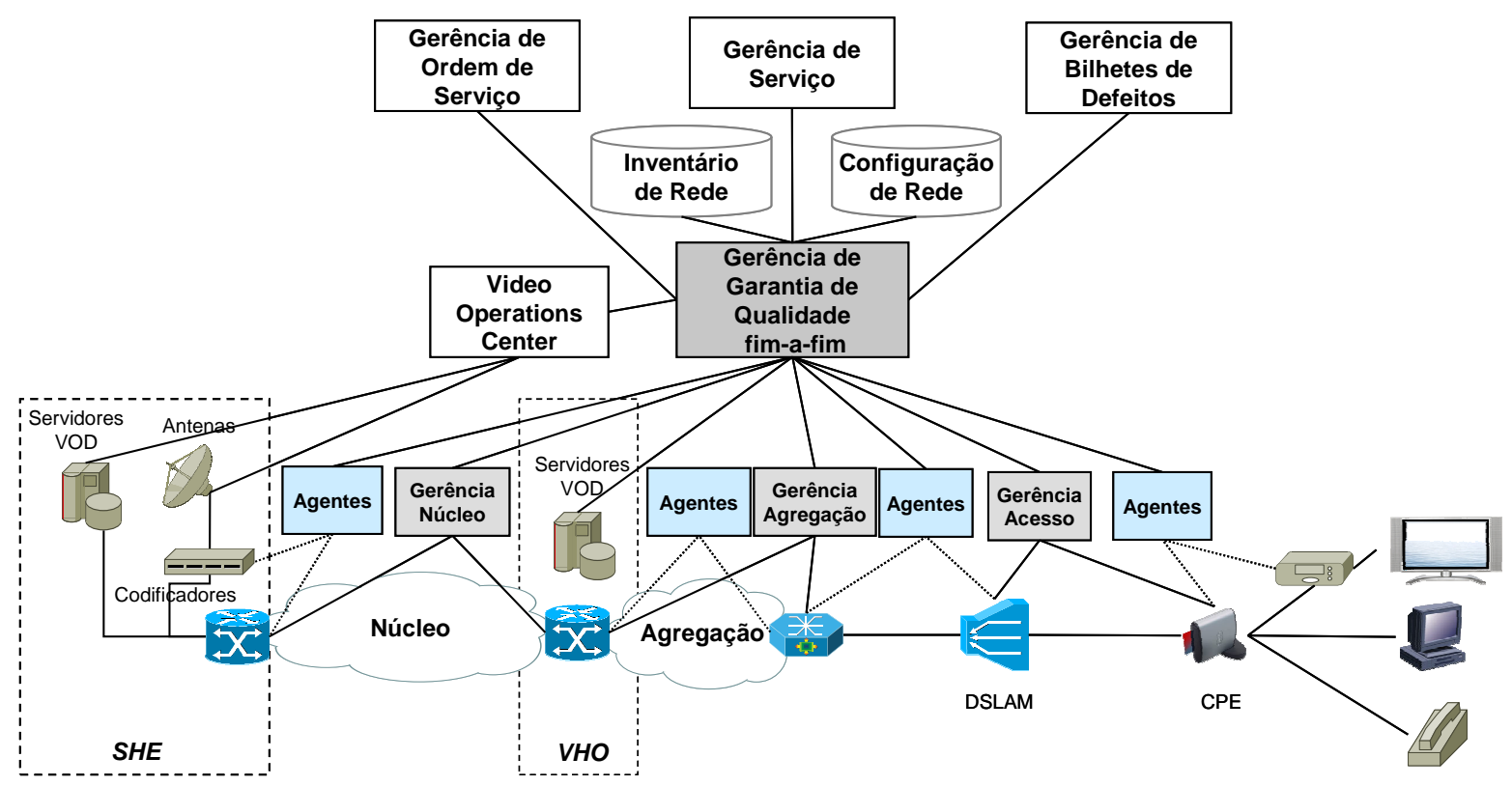

Figura 22 - Sistema integrado de gerenciamento - IPTV (fonte: adaptado de Telcordia (37))

- Faturamento: ferramentas relacionadas à cobrança e faturamento do serviço. Suas funções incluem desde coleta de dados de utilização dos assinantes até a emissão de faturas e o encontro de contas com os provedores de conteúdo.

- Suporte e Disponibilidade de Operações: ferramentas que servem de base para a execução efetiva dos demais processos descritos. Os sistemas típicos dessa categoria incluem os sistemas de inventário das plataformas tecnológicas. Além disso, os sistemas que incluem as bases cadastrais, sejam elas de assinantes, de perfis de serviços ou do conteúdo disponibilizado estão nesta categoria.

Além das ferramentas de gerenciamento mais diretamente associadas aos serviços IPTV já mencionadas, existem diversas outras ferramentas que compõem a arquitetura de OSS/BSS de uma operadora e que servem de base ao seu funcionamento. Algumas delas cobrem os processos de uma operadora de maneira fim-a-fim como é o caso dos sistemas de Customer Relationship Management (CRM), gerenciamento de ordens de serviço (order management) e força de trabalho (workforce management). A integração entre as diversas ferramentas de gerenciamento é fundamental para a plena operação do serviço.

Conforme apresentado no item 2.7.2, o middleware possui um papel central na arquitetura tecnológica de suporte a serviços IPTV, pois concentra grande parte da 
inteligência do serviço e serve de elo entre as diversas plataformas do ecossistema de IPTV. Desta forma, muitas funções de gerenciamento acabam sendo implementadas pelo próprio middleware (36) como, por exemplo, a definição dos serviços, a gestão dos clientes, o armazenamento dos dados de utilização, a gestão do conteúdo, a obtenção de algumas estatísticas de desempenho, entre outras.

Além do middleware, um dos elementos que merece destaque na arquitetura de OSS/BSS relacionada a IPTV é o gerenciamento de qualidade de vídeo voltado à garantia de QoE, que implica na necessidade de uma arquitetura de gerenciamento fim-a-fim: do head-end ao set-top box, incluindo os diversos elementos de rede e conta com ferramentas sofisticadas de medição de qualidade de vídeo (37).

Em geral, uma estrutura de operações a parte é criada para suportar as operações do serviço IPTV devido às peculiaridades intrínsecas ao novo serviço. Tal estrutura é denominada Video Operations Center (VOC) em analogia ao Network Operations Center (NOC) que já existe nas operadoras para suportar os serviços tradicionais de voz e conectividade. O papel do VOC é supervisionar as operações do serviço IPTV, implementando os diversos processos do modelo do eTOM específicos para o serviço de vídeo, visando à garantia de QoE.

\subsection{ESFORÇOS DE PADRONIZAÇÃO}

Até o momento, poucos são os padrões consolidados no campo de soluções de IPTV. Algumas entidades já publicaram alguns padrões e as iniciativas em andamento nesse sentido são numerosas (39). O que se percebe é que as soluções da camada de transporte e de codificação de vídeo seguem os padrões que herdaram já consolidados na indústria.

- Transporte: os padrões de transporte seguem aqueles já estabelecidos e consolidados pelo IETF que também são capazes de fornecer funções de controle de multimídia (IP, UDP, RTP, RTCP, RTSP, IGMP). Além disso, existe uma parte do MPEG, o Transport Stream dedicado ao encapsulamento de tráfego de vídeo para transporte. Com relação ao transporte na rede de acesso, o DSLForum também possui recomendações. 
- Codificação: os padrões MPEG-2 e MPRG-4 são atualmente empregados para codificação de vídeo nas soluções IPTV.

Uma outra área em que existem diversas iniciativas de padronização é a de redes residenciais (home network) (40). Existem iniciativas em andamento lideradas por Digital Living Network Alliance (DLNA), Home Gateway Institute (HGI), Universal Plug and Play Forum (UPnP) e DSLForum.

Nas outras áreas, os fabricantes e integradores têm utilizado mecanismos proprietários enquanto não se estabelece um padrão. Existe um movimento na indústria rumo à disponibilização de soluções com interfaces abertas para customização. Um exemplo é o middleware que, devido ao seu papel central na solução e a constante necessidade de integração com novos elementos, vem sendo disponibilizado em implementações proprietárias que oferecem interfaces e toolkits abertos para facilitar a integração com outros componentes.

Existem outros fóruns de discussão e padronização que possuem escopo mais abrangente visando à integração de diversas partes da solução ao invés de enfocar um único aspecto. Os principais são:

- Digital Vídeo Broadcast (DVB) + European Telecommunications Standards Institute (ETSI): as duas entidades estão empreendendo esforços na padronização em diversas frentes, visando aproveitar ao máximo o que já foi desenvolvido para TV digital. As áreas de padronização incluem: transporte, descoberta e seleção de serviços, metadados, middleware, gerenciamento remoto de set-top box e segurança. Já existem recomendações publicadas no que diz respeito à iniciativa ao encapsulamento de tráfego de vídeo. Em especial, a ETSI possui uma preocupação da integração do IPTV no contexto da rede de uma operadora, focalizando em especial aspectos como arquitetura Next Generation Networks (NGN) e IP Multimedia Subsystem (IMS).

- Alliance for Telecommunications Industry Solutions (ATIS): através do IPTV Interoperability Forum (IIF), a ATIS vem empreendendo esforços na interoperabilidade da solução de IPTV fim-a-fim, incluindo: QoS/QoE, arquitetura tecnológica como um todo, segurança e interoperabilidade. 
- Internet Streaming Media Alliance (ISMA): abrange diversas áreas das quais se destacam: armazenamento, transporte, controle, metadados e a segurança da mídia. Já possui recomendações publicadas.

- ITU-T: criou um Focus Group sobre o tema de IPTV. A idéia é trabalhar em cooperação com as outras diversas iniciativas em andamento visando o estabelecimento de padrões com escopo abrangente.

\subsection{RESUMO}

Este capítulo apresentou ao leitor os principais conceitos relacionados aos serviços IPTV e a arquitetura tecnológica que os suporta. Foram discutidos os principais motivadores para a oferta dos serviços IPTV, seu modelo de negócios e cadeia de valor, e os principais elementos de uma oferta de serviços típica: vídeo, áudio, comunicação, entretenimento, comércio e utilitários.

Foi apresentado também o conceito de Quality of Experience que focaliza a percepção do serviço do ponto de vista do usuário final e o orienta o delineamento da arquitetura tecnológica de suporte ao serviço. Além da conceituação de Quality of Experience, foi estabelecido um paralelo com o conceito de Quality of Service e proposto um modelo integrado de garantia de qualidade voltado para serviços IPTV.

A partir da caracterização dos serviços, foram apresentados modelos de referência de arquitetura tecnológica para suportar a discussão dos seus principais componentes. A arquitetura conceitual foi dividida em três grandes blocos de infraestrutura: serviço, rede e gerenciamento. Para cada um dos blocos, foram apresentados os principais elementos, e discutidas suas funções e características relevantes a partir da perspectiva de uma operadora de telecomunicações. Por fim, foi apresentada uma perspectiva a respeito dos esforços de padronização envolvendo os principais blocos de uma solução que suporta serviços IPTV. 


\section{CONCEITOS DE ANÁLISE TÉCNICO-ECONÔMICA}

Este capítulo apresenta os principais conceitos de análise técnico-econômica que foram tomados como base para o desenvolvimento deste trabalho. Além das metodologias que foram tomadas como referências para este trabalho, nesse capítulo serão descritas as técnicas de decisão de investimento que podem ser aplicadas para analisar projetos a partir da perspectiva econômica.

\subsection{METODOLOGIAS DE ANÁLISE TÉCNICO-ECONÔMICA DE REFERÊNCIA}

Diversos projetos de pesquisa foram desenvolvidos na Europa desde o início dos anos $90 \mathrm{com}$ o propósito de realizar análise técnico-econômica de serviços e redes no ambiente de telecomunicações. Tais projetos foram realizados de forma multidisciplinar com a participação de universidades, operadoras e fabricantes de equipamentos do setor de telecomunicações. A maior parte dos projetos está relacionada a programas de pesquisa de União Européia. Os projetos mais relevantes na área (11) estão referenciados na Tabela 6.

Ao longo dos projetos, foi desenvolvido um conjunto de métodos e ferramentas para suportar a análise de novos serviços e redes de comunicação, levando em consideração aspectos econômicos e tecnológicos em diversos cenários de análise delineados. As características principais de cada um dos projetos está detalhada a seguir (11):

- Iool for Introduction scenario and Iechnical evaluation for Access Network (TITAN): fez parte do programa Research in Advance Communications in Europe (RACE II) ligado à União Européia, que tinha por objetivo a pesquisa sobre a introdução de serviços banda larga. O principal objetivo do projeto TITAN foi desenvolver uma metodologia e uma ferramenta para avaliação técnico-econômica da introdução de novos serviços banda estreita e banda larga nos mercados residencial e de pequenas empresas. $\mathrm{O}$ 
foco de seu estudo compreende as redes de acesso, examinando as diversas alternativas tecnológicas de evolução.

- OPTImised architectures for MUltiMedia networks and services (OPTIMUM): fez parte do programa Advanced Communications Technologies and Services (ACTS) ligado à União Européia. O objetivo principal do projeto foi estabelecer diretrizes para redes de comunicação multimídia e realizar a análise técnico-econômica dos diversos serviços oferecidos por tais redes, visando estimular a sua utilização. Especial atenção foi conferida ao estudo de serviços multimídia. No projeto OPTIMUM, a metodologia TITAN foi adaptada para sua aplicação a esses serviços.

- Iechno-Économic Results from ACTS (TERA): também fez parte do programa ACTS. O objetivo do projeto foi suportar a consolidação e a racionalização das diretrizes de implementação para serviços e redes de comunicação avançados. O projeto aplicou e aprimorou a metodologia e as ferramentas desenvolvidas nos projetos anteriores - TITAN e OPTIMUM tornando a metodologia padronizada para ser aplicada em outros contextos e iniciativas. Especial atenção foi dedicada à avaliação de redes de acesso banda larga e satélite, em comparação com as demais alternativas de acesso.

- Technㅡ-EcoNomICs of IP optimised networks and services (TONIC): fez parte do programa Information Society Technologies (IST) ligado à União Européia. Baseado no projeto TERA e seus predecessores, o projeto TONIC desenvolveu uma metodologia e ferramentas para análise técnico-econômica de redes e serviços de comunicação de maneira fim-a-fim. Ele estendeu o escopo das arquiteturas tecnológicas do acesso para a rede toda, tanto em redes fixas como em redes móveis.

- Techno-ECOnomics of integrated communication SYStems and services (ECOSYS): faz parte do programa de pesquisa CELTIC ligado à entidade EUREKA. Seu objetivo é a definição de métodos detalhados para realização de avaliações técnico-econômicas para diferentes tecnologias e escopo de modelagem. Um de seus principais objetivos é aprimorar ainda mais as técnicas desenvolvidas pelos projetos predecessores. Além do desenvolvimento da metodologia, o projeto visa realizar a análise técnico- 
econômica das diversas alternativas de acesso fixo banda larga, tecnologias emergentes de acesso móvel, e caminhos de evolução para redes fixas e móveis totalmente convergentes.

Tabela 6 - Projetos envolvendo análise técnico-econômica em telecomunicações

\begin{tabular}{llll}
\hline \multicolumn{1}{c}{ Projeto } & \multicolumn{1}{c}{$\begin{array}{c}\text { Programa de } \\
\text { pesquisa }\end{array}$} & Órgão de fomento & Período \\
\hline TITAN & RACE II & União Européia & $1992-1996$ \\
\hline OPTIMUM & ACTS & União Européia & $1994-1998$ \\
\hline TERA & ACTS & União Européia & $1994-1998$ \\
\hline TONIC & IST & União Européia & $1998-2002$ \\
\hline ECOSYS & CELTIC & EUREKA & $2004-2007$ \\
\hline
\end{tabular}

A metodologia de análise técnico-econômica empregada foi sofisticada ao longo dos projetos mencionados (11). Todos os trabalhos constantes dessa linha de pesquisa se utilizam de uma metodologia básica que pode ser caracterizada em grandes blocos, e que tiveram seu algoritmo de implementação e nível de automatização incrementados ao longo do tempo, através da utilização de ferramentas computacionais. A metodologia e a abordagem empregada nos referidos projetos pode ser vista como uma forma de estabelecer uma ponte entre a demanda por serviços de telecomunicações com a oferta desses serviços pelas operadoras, escolhendo as soluções tecnológicas mais adequadas, de acordo com condições econômicas viáveis. 


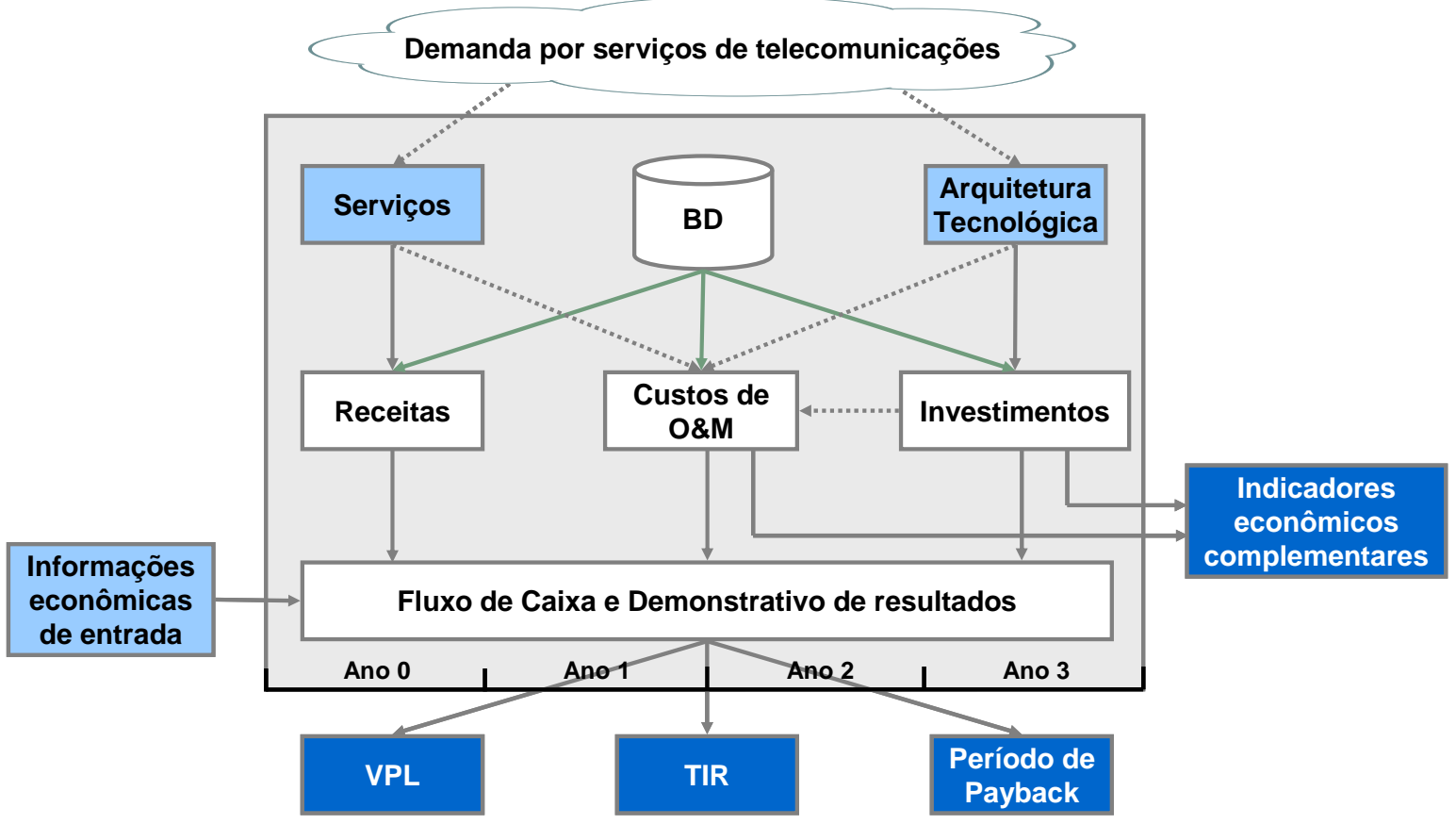

Figura 23 - Metodologia de análise técnico-econômica de referência (fonte: Projeto ECOSYS (11))

O esquema da Figura 23 ilustra os principais blocos da metodologia empregada nos projetos e os principais passos estão descritos a seguir. A partir do entendimento da demanda por serviços de telecomunicações e sua perspectiva de evolução, é realizada a especificação do cenário de serviços que serão ofertados aos usuários finais. Nela são delimitadas quais as componentes dos serviços, suas características e funcionalidades, a expectativa de adoção, perfil de utilização e os modelos e níveis de precificação associados. Em geral, todos esses parâmetros advêm de estudos de mercado detalhados que capturam as características da demanda e da oferta dos concorrentes locais. A partir da perspectiva de adoção e modelo de precificação, é calculada a receita gerada pelo cenário de serviços.

De posse da caracterização dos serviços, é realizada a definição do cenário de arquiteturas tecnológicas relevantes para suportar tais serviços selecionados. A arquitetura tecnológica depende de cada serviço e, em geral, não existe uma metodologia padrão para tratá-la. Sendo assim, o conhecimento para sua determinação é bastante específico está em grande parte fora da metodologia delineada. A definição do cenário de arquitetura implica na determinação e dimensionamento de todas as plataformas tecnológicas que deverão ser adquiridas ou adaptadas. A partir da definição da arquitetura e seus componentes, são 
determinados os investimentos diretamente associados ao serviço, também conhecidos como Capital Expenditures (CAPEX).

Em seguida, é feita a identificação dos custos e despesas operacionais associados ao serviço, também conhecidos como Operating Expenditures (OPEX). Em uma operadora de telecomunicações, incluem itens de naturezas diversas como, por exemplo: suporte e manutenção de equipamentos, salários de equipes de operação, marketing e vendas, cobrança, aluguel de recursos de rede de terceiros, interconexão, conteúdo de terceiros, entre outros.

A partir da obtenção da receita dos serviços, investimentos, custos e despesas operacionais, e premissas gerais de cunho econômico (ex.: inflação, taxa de desconto, alíquota de impostos), é realizada a modelagem econômica e simulação dos cenários definidos anteriormente. Nesta etapa, é realizado o cálculo do fluxo de caixa associado ao projeto que serve de base para a determinação de indicadores econômicos consagrados para a tomada de decisão de investimento que serão detalhados no item 3.2.

Ao final da modelagem e simulações é realizada a interpretação dos resultados para extrair conclusões. A meta principal é determinar a arquitetura mais adequada com base em parâmetros econômicos e tecnológicos obtidos ao longo do processo de análise. Para melhor compreensão dos resultados e de suas variações, artifícios como análises de cenários e de sensibilidade dos resultados face às variações de parâmetros de entrada relevantes se fazem necessárias.

Em cada um dos projetos citados, a metodologia descrita foi exercitada e adaptada para serviços e tecnologias distintos, respeitando suas peculiaridades. Por exemplo, no projeto TONIC, foram realizados estudos de caso para: serviços IP sobre redes móveis, Mobile Virtual Network Operator (MVNO), serviços IP sobre redes fixas de banda larga e avaliação de viabilidade de serviços banda larga em áreas não competitivas.

A metodologia desenvolvida também foi aplicada fora do domínio dos projetos mencionados e o resultado de sua aplicação e adaptação consta em diversas publicações. Alguns exemplos incluem: estratégia de evolução de redes de acesso banda larga (41); acesso banda larga sem fio utilizando tecnologia WiMax (42); e tecnologias de acesso móvel além da terceira geração (43). 
Esta metodologia serviu como referência para este trabalho que se propõe ao desenvolvimento e a aplicação de uma metodologia de análise técnico-econômica voltada para serviços IPTV.

Além da metodologia de referência descrita, os trabalhos de Carvalho (45) e Separovic (44) serviram como referência para o desenvolvimento da metodologia de análise técnico-econômica proposta neste trabalho. O primeiro trabalho versa sobre metodologia de projetos de redes locais e o segundo sobre a metodologia de análise de viabilidade financeira da implantação de VOIP em uma corporação. Ambos serviram de referência no que diz respeito à elaboração de uma metodologia estruturada de análise e projeto.

\subsection{CONCEITOS DE ANÁLISE DE INVESTIMENTO}

Em geral, as empresas possuem mais projetos tecnicamente viáveis do que recursos disponíveis para financiá-los, e precisam selecionar aqueles que sejam economicamente viáveis e apresentem maior atratividade. Tais projetos envolvem investimentos, ou seja, a empresa precisa comprometer recursos financeiros hoje com a expectativa de retorno futuro, seja na forma de entradas adicionais de dinheiro ou na forma da redução do fluxo de desembolsos (46).

Neste contexto, o processo de tomada de decisão de investimento se coloca como fundamental para garantir que os projetos serão selecionados adequadamente. Os diversos métodos de análise de investimento visam à geração de indicadores objetivos que facilitem a tomada de decisão e garantam a escolha dos melhores projetos.

As decisões de investimento podem ser classificadas como decisões de triagem ou decisões de preferência (46). As decisões de triagem são aquelas que se propõem a verificar se um projeto atende a algum critério de aceitação específico como, por exemplo, satisfazer a uma taxa mínima de atratividade. As decisões de triagem não visam comparar dois projetos entre si, mas apenas verificar se um projeto deve ser aceito ou não. Já as decisões de preferência dizem respeito à seleção entre diversos projetos, ou seja, é necessário comparar os projetos entre si. 
Para amparar tais decisões, diversos métodos foram desenvolvidos, dos quais se destacam os seguintes: Valor Presente Líquido (VPL), Taxa Interna de Retorno (TIR) e período de recuperação de investimento, mais comumente conhecido como período de payback. Dos três métodos, a técnica do VPL é reconhecida por ser a mais robusta para realizar a avaliação de investimentos e levar às melhores decisões (47)(48).

Tais métodos de análise de investimento são sempre aplicados com base no fluxo de caixa associado ao projeto. Este fluxo de caixa retrata todas as entradas e saídas de caixa relacionadas ao projeto e um esquema de fluxo de caixa típico de um projeto está representado na Figura 24, onde $\mathrm{FC}_{\mathrm{i}}$ são as diversas componentes do fluxo de caixa no final de cada período i, durante $n$ períodos de tempo. Elas representam a diferença entre as entradas e as saídas de caixa do período. Apesar desse fluxo de caixa mostrar apenas uma componente negativa no instante 0 e as demais positivas, não significa que todos os fluxos de caixa associados sigam esse padrão. O sinal das diversas componentes do fluxo de caixa pode variar ao longo do tempo conforme suas características.

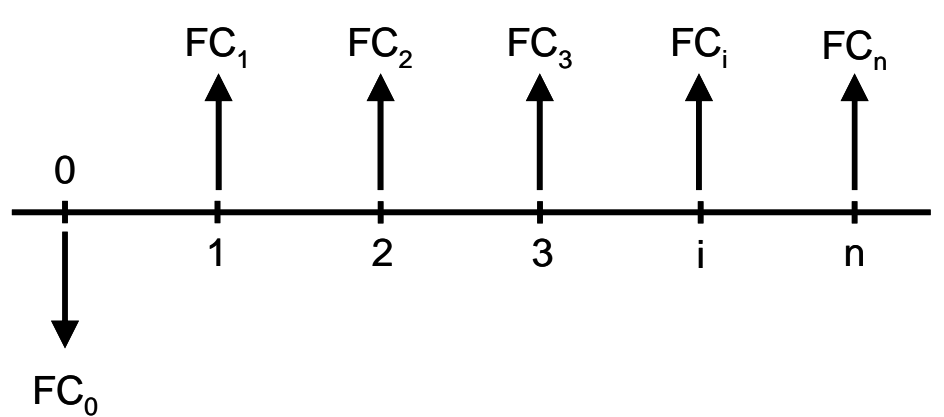

Figura 24 - Fluxo de caixa típico

Nas seções subseqüentes estão apresentadas considerações relevantes a respeito do fluxo de caixa associado a um projeto e os métodos de avaliação de investimento referidos. 


\subsubsection{Fluxo de Caixa}

As análises de decisão de investimento devem ser realizadas com base no fluxo de caixa do projeto e não no seu lucro contábil (47). Apesar de servir a muitos propósitos, o lucro contábil não deve ser tomado como base para análise de investimento. O lucro contábil não retrata as reais entradas e desembolsos associados a um projeto, pois está sujeito a artifícios contábeis. As principais razões que determinam as diferenças entre o fluxo de caixa e o lucro contábil estão descritas a seguir:

- Reconhecimento de receita: o regime contábil reconhece receitas no ato da venda, mas nem sempre o recebimento ocorre no mesmo exercício pois o pagamento pode não ocorrer à vista.

- Reconhecimento de despesas: as despesas apuradas no demonstrativo de resultados que levam ao cálculo do lucro contábil são relacionadas às vendas reconhecidas no período, mas da mesma forma seu pagamento pode ocorrer mais tarde.

- Depreciação: as despesas de depreciação não são de fato incorridas, pois não representam saídas de caixa. Elas possuem efeito apenas para dedução de imposto de renda.

A seguir, estão enumeradas algumas diretrizes relacionadas ao que deve ser considerado nos fluxos de caixa a serem considerados no projeto (47) (48):

- Fluxo incremental: é importante que uma análise de investimento considere apenas o fluxo de caixa incremental, ou seja, apenas as entradas e saídas de caixa relacionadas ao projeto.

- Custos irrecuperáveis: são aqueles custos que já ocorreram e não devem ser considerados já que não é possível alterá-los em função da aceitação ou não do projeto.

- Custos de oportunidade: se o projeto utilizará ativos que poderiam ser utilizados em alguma outra atividade geradora de receita, as suas receitas potenciais de uso alternativo serão perdidas e devem ser encaradas como custos; 
- Efeitos colaterais: se o projeto afeta os resultados de outras unidades operacionais, por exemplo, diminuindo a receita de um outro produto, essa alteração deve ser levada em consideração no fluxo de caixa.

- Capital de giro: as necessidades adicionais de capital de giro líquido devem ser levadas em conta no cálculo do fluxo de caixa. A fórmula do capital de giro líquido está apresentada na equação (1). É importante ressaltar que apenas a variação de capital de giro é que deve ser considerada no fluxo de caixa. Aumentos de capital de giro são encarados como uma componente negativa ao fluxo.

Capital de Giro Líquido ${ }^{3}=$ Ativo Circulante - Passivo Circulante

- Extinção do projeto: devem ser consideradas as entradas e desembolsos de caixa decorrentes do término do projeto, por exemplo, a liberação de capital de giro, a venda de um ativo pelo seu valor de mercado ao final de sua utilização. Caso o projeto seja de longo prazo, pode-se estimar o valor terminal pelo princípio da perpetuidade a partir do fluxo de caixa do seu último período.

- Custos indiretos: devem ser considerados apenas os incrementos de custos indiretos que acontecem em virtude do projeto. Existem projetos que podem contribuir para o aumento de custos indiretos, mas também existem projetos que não os afetam.

- Inflação: deve ser dado tratamento consistente à inflação. Se os fluxos de caixa consideram a inflação, a taxa de desconto também deve ser considerada. Sendo assim, para fluxos de caixa nominais (consideram a inflação) deve ser considerada a taxa de desconto nominal. Para fluxos de caixa reais (não consideram o efeito da inflação), devem ser utilizada taxa de desconto real. A fórmula de equivalência entre as duas taxas está apresentada na equação (2).

$$
\text { Taxa de desconto real }=\frac{1+\text { Taxa de desconto nominal }}{1+\text { Taxa de inflação }}-1
$$

- Imposto de Renda: devem ser considerados os fluxos de caixa depois do pagamento de imposto de renda. Sendo assim, apesar do lucro contábil não

\footnotetext{
${ }^{3}$ Para as fins de fluxo de caixa, o cálculo do capital de giro deve desconsiderar itens de Caixa do Ativo Circulante e itens de Dívida de Curto Prazo do Passivo Circulante (49).
} 
ser utilizado como base da análise de investimento, é necessário apurá-lo para poder determinar o imposto de renda devido.

- Depreciação: as despesas com depreciação utilizadas no cálculo do lucro também não devem ser consideradas no fluxo de caixa. $O$ cálculo da depreciação pode ser realizado de acordo com o sistema americano Modified Accelerated Cost Recovery (MACRS) ou pelo método linear (46).

- Juros: as decisões de investimento e de financiamento devem ser tratadas de forma separada. Sendo assim, a premissa para cálculo de fluxos de caixa do projeto é que não existe escassez de recursos e que o projeto será totalmente financiado com recursos próprios. Desta forma, não se considera a utilização de financiamento com recursos de terceiros. Não devem ser consideradas, portanto, despesas de juros devido ao financiamento do projeto. Quaisquer ajustes relacionados ao financiamento com recursos de terceiros devem ser levados em conta na taxa de desconto e não no fluxo de caixa.

Com base nessas considerações, deve-se realizar a estimativa do fluxo de caixa do projeto. Quando não se dispõe da demonstração contábil oficial de fluxo de caixa, o cálculo do fluxo de caixa pode ser bem aproximado sob a perspectiva financeira a partir do lucro contábil levando em conta uma série de ajustes (49). As fórmulas para cálculo do fluxo de caixa estão detalhadas nas equações (3), (4) e (5). 


$$
\begin{gathered}
\mathrm{FC}=\mathrm{EBIT}-\mathrm{T}+\mathrm{DA}-\Delta \mathrm{WC}-\mathrm{I} \\
\mathrm{EBIT}=\mathrm{R}-\mathrm{CD}-\mathrm{DA} \\
\mathrm{T}=\mathrm{EBIT} \times(1-\mathrm{t})
\end{gathered}
$$

Onde:

- $\quad F C=$ fluxo de caixa total do projeto ${ }^{4}$

- $\mathrm{EBIT}=$ Resultado antes de juros e imposto de renda, também conhecido como Earnings Before Interets and Taxes (EBIT)

- $\mathrm{t}$ = alíquota de imposto sobre o lucro

- $\quad \mathrm{T}=$ imposto de renda

- $R=$ Receita (já deve desconsiderar deduções de impostos sobre vendas, também conhecida como receita líquida)

- $\quad C D=$ Custos e Despesas Operacionais (inclui todos os custos e despesas incorridas pelo projeto)

- $\mathrm{DA}=$ Despesas relacionadas à depreciação e amortização

- $\quad \Delta \mathrm{WC}=$ variação (aumento) de capital de giro líquido conforme mencionado no item

- $\quad \mathrm{I}$ = investimentos associados ao projeto

\subsubsection{Taxa Mínima de Atratividade}

A Taxa Mínima de Atratividade (TMA) de um projeto, também conhecida por hurdle rate, corresponde à taxa mínima de retorno que a empresa espera do projeto (49). Ela é utilizada para decidir se o investimento em um determinado projeto é aceitável ou não. A TMA reflete diretamente o risco associado ao projeto: quanto maior o seu risco, maior deverá ser sua TMA. Além disso, a TMA deve levar em consideração a

\footnotetext{
${ }^{4}$ A partir da equação (3), encontra-se o fluxo de caixa para a empresa, que difere da visão do fluxo de caixa para o acionista (49).
} 
composição de financiamento do projeto: recursos próprios versus recursos de terceiros.

O custo de capital ${ }^{5}$ é geralmente a escolha mais apropriada para a TMA (48). Ele representa a taxa média de retorno que a empresa precisa pagar aos seus acionistas e aos seus credores pelo uso de seus recursos e, portanto, resulta da ponderação do custo de capital de terceiros e de capital próprio. Ele é referido como Custo Médio Ponderado de Capital ou, mais frequentemente, por Weighted Average Cost of Capital (WACC).

O custo de capital próprio deve refletir o retorno de um ativo financeiro de mesmo risco, pois o projeto só será atrativo se apresentar um retorno superior ao que se pode encontrar aplicando o dinheiro no mercado. O custo de capital de terceiros reflete a taxa de juros que a empresa paga quando capta dinheiro em fontes externas de financiamento. Como o pagamento de juros pode ser abatido de imposto de renda, deve-se considerar esse efeito em seu cálculo.

O detalhamento da metodologia de cálculo do WACC não é o foco deste trabalho, mas é explorada em detalhes na literatura de finanças corporativas (46)(47)(48). A fórmula de cálculo primária do WACC (48) e que reflete os conceitos de ponderação discutidos até aqui está apresentada na equação (6).

$$
W A C C=\frac{E}{D+E} \times r_{e}+\frac{D}{D+E} \times r_{d} \times\left(1-T_{C}\right)
$$

Onde:

- $\quad$ WACC = custo médio ponderado de capital

- $r_{e}=$ custo de capital próprio

- $r_{d}=$ custo de capital de terceiros

- $\mathrm{E}$ = patrimônio líquido (Equity) a valor de mercado

- $\mathrm{D}$ = dívida a valor de mercado

- Tc = alíquota marginal de imposto de renda

\footnotetext{
${ }^{5}$ A utilização do custo de capital calculado pela equação (6) como TMA deve ser aplicada quando se considera o fluxo de caixa para a empresa conforme a equação (3). Quando se considera o fluxo de caixa para o acionista, deve se utilizar o custo de capital próprio como TMA (49).
} 
Deve-se ressaltar que o custo de capital da empresa deve ser usado como taxa mínima de atratividade apenas nos projetos que possuam características de risco similares às da empresa. A estimação de um custo de capital específico para o projeto deve ser realizada se isso não ocorrer (49).

Sendo assim, se o risco do projeto for de natureza diferente do risco ao qual a empresa está exposta, ajustes devem ser realizados no custo de capital próprio. Se a percepção de risco do projeto for maior do que a da empresa, isto deve resultar em um custo de capital do projeto mais elevado. Além disso, se a composição de capital do projeto for diferente da estrutura de capital empresa devido às suas necessidades de financiamento, isso também deve ser levado em consideração na determinação do custo de capital.

\subsubsection{Métodos de Análise de Investimento}

De posse do fluxo de caixa e da taxa mínima de atratividade do projeto, é possível aplicar diversos métodos para avaliar a sua atratividade. A seguir, estão apresentados os métodos do VPL, TIR e período de payback.

\subsubsection{Valor Presente Líquido}

A técnica do Valor Presente Líquido (VPL) é considerada a mais robusta para a análise de investimentos e retrata o valor gerado para a empresa em decorrência da realização de um investimento (47). O VPL é resultado da diferença entre valor presente de todas as entradas de caixa de um projeto de investimento e o valor presente de todos os seus desembolsos (48).

O VPL pode ser calculado pela soma algébrica de todos os fluxos de caixa associados ao projeto (entradas e desembolsos) descontados a valor presente. A sua fórmula de cálculo está representada na equação (7). 


$$
V P L=\sum_{i=0}^{n} \frac{F C_{i}}{(1+r)^{i}}
$$

Onde:

- $\quad \mathrm{VPL}=$ Valor Presente Líquido

- $\quad \mathrm{FC}_{\mathrm{i}}=$ Fluxo de Caixa associado ao projeto no instante $\mathrm{i}$

- $r=$ taxa de desconto

- $\mathrm{i}$ = instante de tempo em que ocorre o FC, considerando $\mathrm{i}=0$ como o instante inicial, e que cada FC está associado ao final do período i

- $\mathrm{n}=$ vida útil do investimento

A taxa de desconto (r) utilizada é a taxa mínima de atratividade (TMA) do projeto conforme já discutido no item 3.2.2

Dentre os principais atributos que tornam o VPL um método bastante robusto para análise de investimentos, pode-se destacar (47)(48):

- Leva em consideração o valor do dinheiro no tempo ao descontar os fluxos de caixa, ou seja, uma unidade monetária hoje vale mais do que essa mesma unidade monetária amanhã.

- Depende exclusivamente dos fluxos de caixa e da taxa de retorno exigida, não sofrendo a influência de fatores artificiais como é o caso da utilização dos lucros contábeis.

- Leva em consideração todos os fluxos de caixa de um projeto, o que não ocorre em outros métodos que podem desprezar fluxos de caixa a partir de um determinado instante de tempo.

Para realizar a triagem de projetos utilizando a regra de decisão do VPL, se o VPL é positivo, o projeto deve ser aceito, pois gera valor para a empresa. Para a classificação de projetos visando à seleção entre projetos mutuamente excludentes, o projeto que apresentar VPL mais alto deve ser escolhido, pois gera maior valor para a empresa quando não houver nenhuma condição de restrição de investimentos.

Quando existem condições de restrição de investimentos e é necessário comparar projetos entre si, a decisão pelo VPL pode não ser a melhor, pois podem existir 
casos em que o VPL de um projeto seja maior, mas o investimento necessário também. Nestes casos, um método de ajuste pode ser aplicado no VPL (48), através da seleção pelo Índice de Rentabilidade (IR) mostrado cuja fórmula está apresentada na equação (8).

$$
\mathrm{IR}=\frac{\mathrm{VPL}}{\mathrm{VP}(\text { Investimentos })}
$$

Onde:

- $\quad \mathrm{IR}$ = Índice de Rentabilidade

- $\mathrm{VPL}=$ Valor Presente Líquido do projeto

- VP (Investimentos $)=$ valor presente dos investimentos associados ao projeto. Caso exista apenas o investimento inicial, este valor é igual a $\mathrm{FC}_{0}$.

O IR reflete uma medida de VPL por unidade de dinheiro investida. Desta forma, quando existem restrições de recursos financeiros, os projetos que possuem maior IR são preferíveis aos demais.

\subsubsection{Taxa Interna de Retorno}

A Taxa Interna de Retorno (TIR) é a medida do retorno de um projeto durante a sua vida útil. Ela representa a taxa de retorno que iguala o valor presente dos fluxos de entradas e de saídas de caixa de um projeto. Ou seja, é a taxa de desconto que anula o VPL de um projeto (48).

A idéia básica por trás da TIR é utilizar um parâmetro único que sintetize a atratividade um projeto. Esse parâmetro independe do custo de capital da empresa. É um indicador interno e intrínseco ao projeto, não dependendo de qualquer outra informação além dos fluxos de caixa do projeto.

Seu cálculo se dá através da condição $r=$ TIR que satisfaz à equação (9). Entretanto, para resolver essa equação, é necessário empregar o método de interpolação de valores de $r$ na equação (7) até se encontrar a TIR. Dessa forma, atribuem-se valores de $r$ até obter a TIR que satisfaça a equação (9). 


$$
\operatorname{VPL}=\sum_{i=0}^{n} \frac{F}{(1+r)^{i}}=0
$$

Onde:

- $\quad \mathrm{FC}_{\mathrm{i}}=$ Fluxo de Caixa associado ao projeto no instante $\mathrm{i}$

- $r=$ taxa de desconto

- $\mathrm{i}$ = instante de tempo em que ocorre o FC, considerando $\mathrm{i}=0$ como o instante inicial, e que cada FC está associado ao final do período i

- $\mathrm{n}=$ vida útil do investimento

A regra básica de aplicação da TIR diz que se deve aceitar um projeto se a TIR for superior à TMA discutida no item 3.2.2, ou seja, se sua atratividade for maior do que aquela esperada para o investimento.

Em teoria, os resultados de triagem de projetos utilizando a TIR deveriam ser iguais, mas existem algumas condições que fazem a decisão da TIR divergente da decisão pelo VPL (47)(48):

- Financiamento versus Investimento: se avaliarmos um financiamento ao invés de um investimento, ou seja, se tivermos um fluxo de caixa típico de investimento invertido em que existe uma entrada de caixa no instante inicial e desembolsos subseqüentes, o resultado da TIR é contrário ao do VPL;

- Múltiplas taxas de retorno: se o fluxo de caixa mudar de sinal ao longo do tempo, pode existir mais de uma taxa de desconto que satisfaça à equação (9) e, portanto, pode existir mais de uma TIR associada ao projeto. Neste caso, não há TIR válida e deve-se utilizar o critério do VPL.

Quando se está comparando dois projetos entre si, segundo a regra de decisão da TIR, deve-se selecionar o projeto que apresentar maior TIR. Entretanto, essa abordagem pode ter algumas divergências em alguns casos quando comparadas com o método do VPL por força de diferenças de escala dos projetos ou distribuição de fluxos de caixa no tempo. Se o método da TIR for utilizado, projetos de curta duração com investimento inicial relativamente baixo serão privilegiados, ainda que não venham a adicionar tanto valor para a empresa. 
Desta forma, deve-se selecionar o projeto que apresente o maior VPL quando se estiver escolhendo entre dois projetos mutuamente excludentes e não exista nenhuma restrição de investimento por parte da empresa. Quando existem restrições de investimento, selecionar o projeto de maior VPL pode limitar investimentos em projetos vindouros. Neste caso, o método da TIR pode levar à melhor escolha, pois ela privilegia projetos menores e que recuperam o investimento de forma mais rápida. Mesmo nestes casos, o VPL pode ser utilizado desde que ajustado pelo índice de rentabilidade (48) conforme visto no item 3.2.3.1

\subsubsection{Período de payback}

O período de payback ou período de recuperação de investimento é definido como o período de tempo em que os fluxos de caixa cumulativos se igualam à zero. Ou seja, é o período de tempo que o projeto leva para compensar o investimento realizado com os fluxos de caixa por ele gerados (48).

Pela regra do payback, quanto mais rápido o projeto recupera o investimento, mais atraente ele será. Para realizar a triagem de projetos, segundo a regra geral do payback um investimento é aceito se seu período de payback calculado for menor do que algum número pré-determinado de períodos. Quando se está realizando a comparação entre dois projetos mutuamente excludentes, o projeto que apresentar menor período de payback deve ser escolhido.

O método do payback é de fácil aplicação, pois não requer a estimativa de taxa mínima de atratividade nem requer cálculos elaborados para descontar os fluxos de caixa a valor presente. Entretanto, este método apresenta algumas deficiências (47):

- Distribuição no tempo: não leva em conta o valor do dinheiro no tempo, pois não utiliza fluxo de caixa descontado;

- Fluxos de caixa posteriores: ele ignora os fluxos de caixa após o momento em que o investimento é recuperado;

- Referência: não existe uma referência clara para o parâmetro de aceitação de projetos e a escolha do período máximo de recuperação aceitável é arbitrária. 
Uma evolução da técnica do payback é a utilização do payback descontado (47), que elimina a deficiência relacionada ao valor do dinheiro no tempo. Com a utilização do payback descontado, é possível determinar de forma mais precisa quando o projeto recupera seu investimento.

Sendo assim, a utilização do payback como critério de decisão pode não levar às melhores decisões de investimento. O método do payback pode ser utilizado como apoio aos métodos do VPL e da TIR.

\subsection{RESUMO}

Este capítulo apresentou ao leitor os principais conceitos relacionados à análise técnico-econômica e técnicas de decisão de investimentos utilizadas para suportar a análise de projetos sob a perspectiva econômica.

Inicialmente, foram analisados projetos de pesquisa desenvolvidos na Europa desde o início da década de 90 cujo objetivo era realizar a análise técnico-econômica de serviços e redes de telecomunicações. A metodologia de análise empregada por tais projetos foi então analisada e discutida.

Além disso, foram apresentados os principais conceitos de análise de investimento, passando pela definição e princípios envolvidos na elaboração de um fluxo de caixa associado a um projeto até a avaliação de sua atratividade econômica.

Foram discutidos três principais métodos empregados na análise e decisão de investimentos: Valor Presente Líquido (VPL), Taxa Interna de Retorno (TIR) e período de payback. Além das características principais e metodologia de cálculo envolvida em cada método, foram apresentadas ao leitor as vantagens e desvantagens associadas a cada um deles. 


\section{METODOLOGIA DE ANÁLISE PROPOSTA}

\subsection{INTRODUÇÃO}

A metodologia proposta neste trabalho suporta o processo de análise técnicoeconômica da introdução de serviços IPTV por operadoras de telecomunicações de maneira fim-a-fim. Além de considerar os aspectos tecnológicos associados ao novo serviço e seu impacto na infra-estrutura tecnológica de uma operadora, a metodologia se vale de recursos de modelagem econômica para avaliar em quais condições a viabilidade econômica do serviço se verifica.

Desta forma, a metodologia foi delineada com base no entendimento dos principais elementos que compõem os serviços IPTV e arquitetura tecnológica que os suporta apresentados no Capítulo 2, e nos conceitos de análise técnico-econômica apresentados no Capítulo 3.

Os serviços de vídeo (broadcast e $V O D$ ) explorados no item 2.4.1 são o principal objeto da metodologia, pois constituem os pilares de uma oferta de IPTV. Os demais serviços apresentados no item 2.4.1 tais como, vídeo telefonia, jogos interativos, são abordados de maneira indireta sob a perspectiva de evolução da oferta de serviços IPTV. A sua análise detalhada necessita a adequação da metodologia para suas características específicas tal como foi realizado para os serviços de vídeo.

A metodologia proposta neste trabalho é constituída de etapas bem definidas que estão apresentadas na Figura 25 e descritas brevemente a seguir. $O$ detalhamento das etapas da metodologia está apresentado ao longo do item 4.2.

- Definição de objetivos e escopo de análise: inclui a captura dos principais objetivos que se pretende atingir com a análise e a definição de qual será o escopo da análise realizada;

- Modelagem de serviços e arquitetura tecnológica: abrange desde a definição dos principais serviços que serão oferecidos e suas características até a identificação dos seus principais requisitos, e que afetam diretamente a infra-estrutura tecnológica. Com base nos principais requisitos, são 
identificadas as principais alternativas de arquitetura tecnológica e o seu dimensionamento é realizado. A composição das características dos serviços com as características da arquitetura tecnológica define cenários possíveis de serviços e tecnologia. É importante ressaltar, que a definição dos serviços tem por objetivo apenas capturar as principais características dos serviços e suas variáveis. A determinação de quais serviços serão oferecidos bem como suas características de precificação, perspectivas de adoção e de perfil de utilização estão fora do escopo da metodologia apresentada e são consideradas informações de entrada necessárias à sua execução.

- Modelagem econômica: a partir da definição dos cenários de serviços e tecnologias e suas características, é realizada a modelagem econômica do projeto com o objetivo de gerar indicadores econômicos capazes de refletir a atratividade do projeto nos diversos cenários.

- Análise de sensibilidade e cenários: uma vez realizada a modelagem de serviços e arquitetura tecnológica, e a modelagem econômica, análises desta etapa são realizadas visando identificar o impacto das principais variáveis nos resultados.

- Análise dos resultados: a partir dos resultados obtidos ao longo das etapas anteriores, é possível realizar sua análise, emitir recomendações que suportarão o processo de tomada de decisão a respeito da viabilidade técnicoeconômica do projeto e em quais condições ela se verifica.

Uma vez realizada uma seqüência das etapas descritas desde a definição de objetivos e escopo da análise até a análise de resultados, é possível que sejam realizados outros ciclos. Dependendo dos resultados obtidos, pode-se reiniciar o processo redefinindo o objeto de análise, ou então, retornar à etapa de modelagem de serviços e arquitetura tecnológica, conforme ilustrado na Figura 25. 


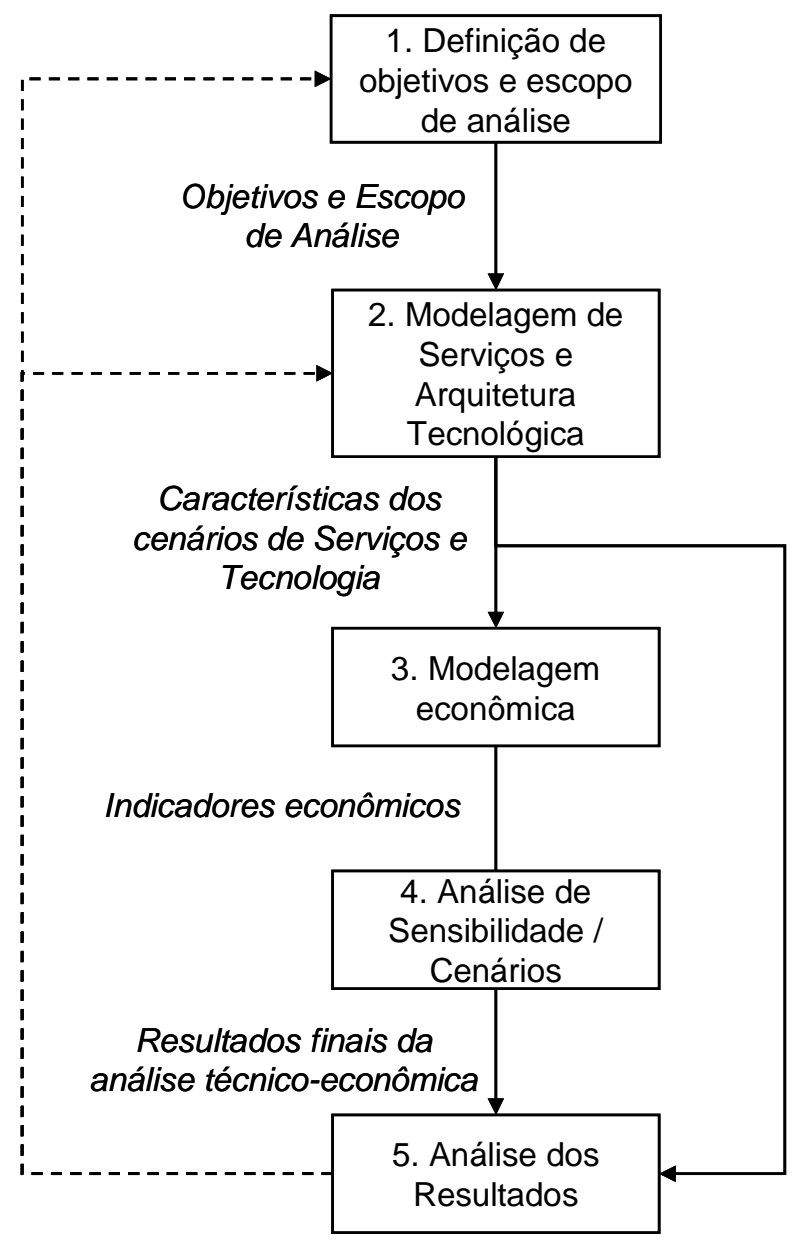

Figura 25 - Metodologia de análise técnico-econômica proposta

\subsection{ETAPAS DA METODOLOGIA}

\subsubsection{Definição de Objetivos e Escopo da Análise}

Antes do início da análise técnico-econômica propriamente dita, é fundamental definir qual o contexto em que a análise se insere, os seus objetivos, o seu escopo e as premissas gerais para a avaliação como um todo. Esta etapa conta com dados de entrada externos que incluem a análise do ambiente mercadológico e regulatório em que a operadora está inserida, suas necessidades de negócio e também tendências tecnológicas. 


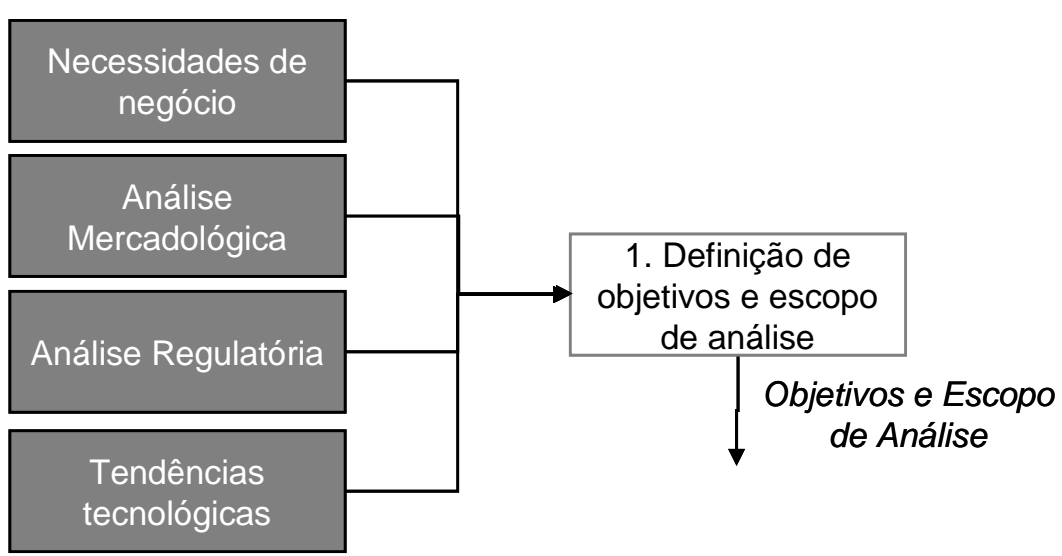

Figura 26 - Definição de objetivos e escopo de análise

Esta etapa inclui a definição de:

- Contexto: descrição do contexto de mercado e tecnologia em que a análise técnico-econômica em questão se insere. Algumas perguntas importantes para situar a análise são: Quem é a operadora em questão? Qual o mercado em que compete? Quais são seus motivadores para a oferta de IPTV? Quais as principais restrições que se colocam?

- Objetivos: delineamento do objetivo principal da análise e quais as principais perguntas que se deseja responder com a análise. A principal pergunta a ser respondida é: "Os cenários delineados pelos serviços a serem oferecidos e arquitetura tecnológica correspondente são economicamente atrativos em quais circunstâncias?".

- Escopo: delineamento do que será realizado na análise técnico-econômica e quais serão os principais métodos e ferramentas empregados para conduzi-la. Deve ser determinado qual o período sob o qual se realizará a modelagem.

- Premissas Gerais: definição de premissas básicas que norteiam o estudo como um todo. As principais premissas gerais incluem:

- horizonte de tempo de análise e as principais etapas que compõem o projeto: início da implantação da infra-estrutura, da oferta do serviço;

- ambiente / geografia em que a operadora atua . 


\subsubsection{Modelagem de Serviços e Arquitetura Tecnológica}

O detalhamento desta etapa está apresentado na Figura 27 e as principais subetapas que a compõem estão descritas a seguir:

- Definição dos serviços: caracterização dos serviços IPTV a serem oferecidos e que constituem o objeto da análise;

- Análise de Requisitos: nesta etapa as características dos serviços são transpostas para os principais requisitos que influenciam a arquitetura tecnológica;

- Análise da arquitetura tecnológica atual: levantamento e análise da infraestrutura tecnológica existente na operadora além das suas perspectivas de evolução futura;

- Definição e dimensionamento da arquitetura tecnológica: com base nas informações da infra-estrutura tecnológica vigente, nos requisitos impostos pelos novos serviços e informações externas complementares, são identificadas as principais alternativas tecnológicas e é realizado seu dimensionamento;

- Definição dos cenários de serviços e tecnologia: as características dos serviços e das alternativas tecnológicas são combinadas em cenários de serviços e tecnologia pertinentes. 


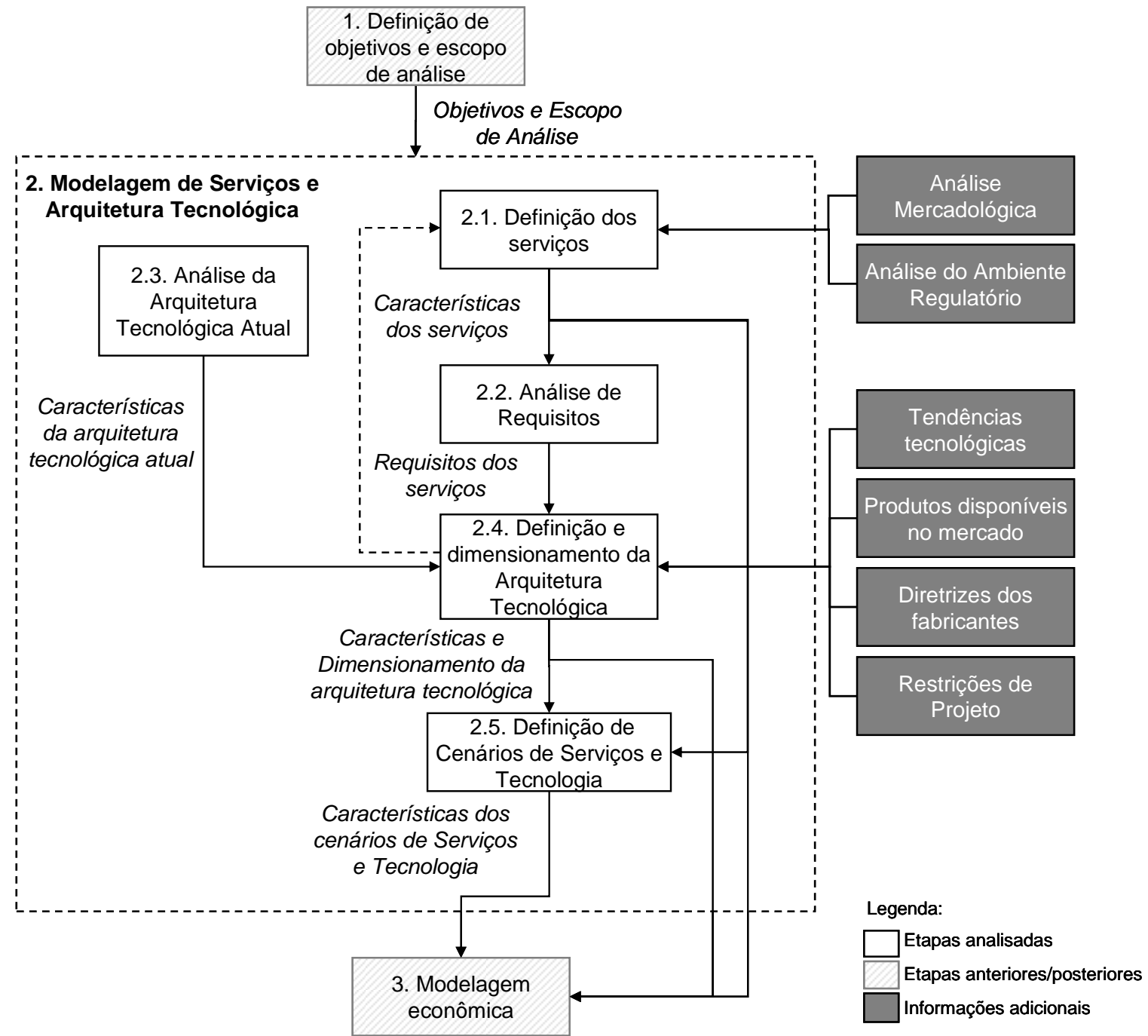

Figura 27 - Etapa de Modelagem de Serviços e Arquitetura Tecnológica

\subsubsection{Definição dos Serviços}

A descrição das principais características do serviço oferecido ao cliente final são fundamentais para a realização análise técnico-econômica, pois influenciam diretamente a infra-estrutura tecnológica necessária, investimentos, custos e despesas operacionais e o modelo de geração de receitas. 


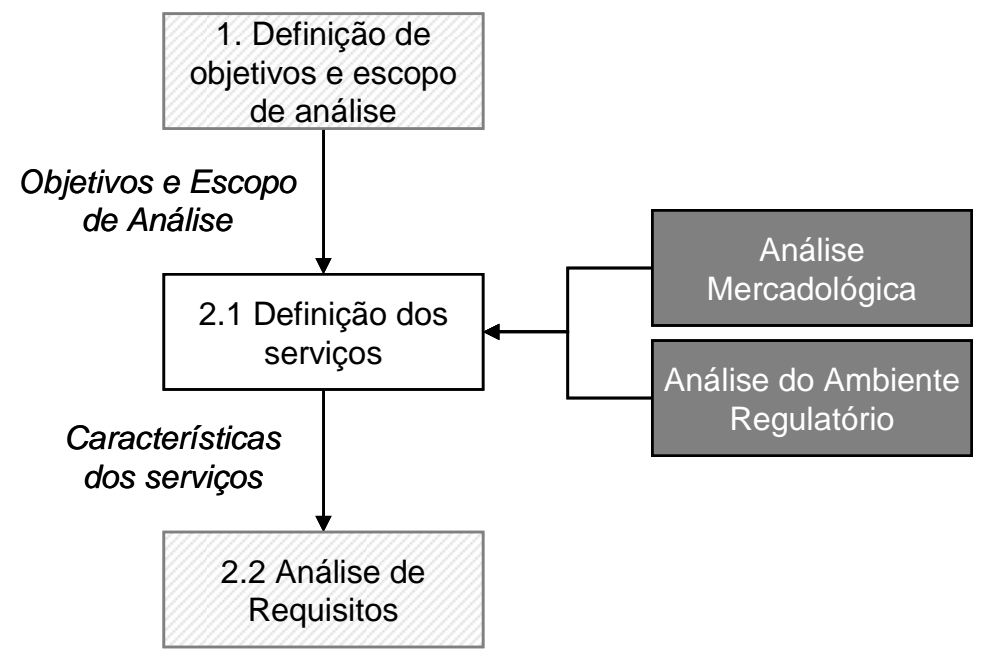

Figura 28 - Etapa de Definição dos Serviços

Em geral, esta etapa é precedida por análises do ambiente mercadológico e regulatório que não fazem parte do escopo da metodologia de análise técnicoeconômica aqui descrita. Os parâmetros derivados dessas análises são tomados como dados de entrada e utilizados para suportar a definição dos serviços que serão objeto de estudo. Desta forma, as atividades relacionadas à confecção dessas análises são pré-requisitos para a metodologia. Alguns exemplos de tais atividades incluem: o estudo do ambiente mercadológico local de TV por assinatura e telecomunicações; a realização de benchmarks da oferta de serviços IPTV em âmbito local e internacional; o estudo detalhado do comportamento da demanda; a seleção dos serviços e pacotes a serem oferecidos ao usuário final; a determinação da grade de canais, variedade e quantidade de títulos sob demanda oferecidos; a previsão de adoção do serviço e perfis de utilização; a determinação do modelo e níveis de precificação adotados; a identificação das restrições regulatórias existentes, entre outras.

Portanto, esta etapa compreende apenas a caracterização dos serviços que serão objeto de estudo e a identificação das principais variáveis associadas aos serviços que impactam a arquitetura tecnológica. Todo o detalhamento de análises de suporte que levaram às escolhas que serão descritas e documentadas nesta etapa não está contemplado no escopo desta metodologia.

As principais informações do serviço que precisam ser descritas nesta fase são:

- Componentes e funcionalidades dos serviços: identificação das componentes do serviço a partir do modelo de referência apresentado na 
Figura 5, e detalhamento de suas principais funcionalidades e características. Tradicionalmente, os serviços IPTV têm em seu pilar a oferta de vídeo (broadcast e VOD) e estes são o foco da metodologia proposta. Exemplos de informações a serem detalhadas são:

- Broadcast: quantidade e variedade de canais (por tipo SDTV / HDTV), pacotes oferecidos;

- VOD: quantidade de títulos oferecidos e duração média (por tipo SDTV / HDTV), e modalidade de oferta (FVOD, SVOD, VOD, NVOD).

- Modelo de precificação: definição da forma de precificação do serviço e estimativa dos níveis de precificação do serviço, de acordo com os níveis praticados pela concorrência e que podem ser absorvidos pela demanda. Devem ser definidos, por exemplo: taxas de instalação / adesão; taxa de assinatura; preços dos serviços adicionais (VOD, conteúdo exclusivo, qualidade do conteúdo em SDTV/HDTV, etc.).

- Modelo de negócios: para cada um dos componentes de serviços a serem oferecidos, é preciso delinear o modelo de negócios. Ou seja, é necessário identificar o nível de controle que a operadora exercerá em cada elo da cadeia de valor da oferta de cada serviço. Por exemplo, no caso da oferta de vídeo, é necessário definir qual será o papel de operadora em relação ao conteúdo oferecido ao cliente final. O papel da operadora se limitará à distribuição do conteúdo? Ou realizará também a agregação e eventualmente a produção de conteúdo premium? O modelo de negócios influencia diretamente no valor capturado pela oferta em questão e é necessário determinar quanto da receita a operadora repassa aos provedores e agregadores de conteúdo. Dependendo do modelo de negócios adotado, a operadora necessita repassar maior ou menor parcela da receita arrecadada com as diversas componentes do serviço.

- Projeção de assinantes dos serviços: estimativa da evolução da base de assinantes ao longo do tempo de acordo com pesquisas de mercado. A evolução dos assinantes deve ser estratificada de acordo com as componentes do serviço e sua distribuição geográfica. Características da base de assinantes que impactam diretamente a infra-estrutura tecnológica também 
devem ser determinadas como, por exemplo, a densidade demográfica dos assinantes onde o serviço será oferecido.

- Perfil de utilização dos serviços: além da quantidade de assinantes que são clientes do serviço, deve-se delinear o perfil de utilização de cada serviço pelos assinantes. O perfil de utilização determina características como o perfil de tráfego na rede e o dimensionamento das diversas plataformas. Exemplos de características de utilização incluem: quantidade de pontos por residência (SDTV / HDTV); penetração de SDTV / HDTV; penetração de broadcast / VOD; taxa de simultaneidade de utilização de broadcast / VOD; entre outras.

Durante o processo de definição de serviços, além de caracterizar os serviços e seus atributos, é importante identificar suas principais variáveis com o objetivo de subsidiar a composição dos cenários de serviços e tecnologia, e a análise de cenários e sensibilidade. Por exemplo, a determinação da projeção de assinantes bem como o perfil de utilização de serviços possui valores mais prováveis, mas podem variar entre uma faixa de valores.

\subsubsection{Análise de Requisitos}

A partir da definição dos serviços, é possível realizar a análise dos seus requisitos sobre a infra-estrutura tecnológica. A análise de requisitos pressupõe 0 entendimento dos blocos básicos que compõem a arquitetura tecnológica de suporte, conforme explicitado na Figura 8. O mapeamento de requisitos inclui duas categorias de requisitos:

- Funcionais: são relacionados à função principal dos sistemas, ou seja, descrevem o que o serviço deve fazer, e não como ele deve operar.

- Não funcionais: são relacionados a características de suporte do sistema, ou seja, características que habilitam ou restringem seu funcionamento. Podem ser de diversas naturezas. Alguns exemplos são: desempenho, confiabilidade, disponibilidade, usabilidade, interoperabilidade. 


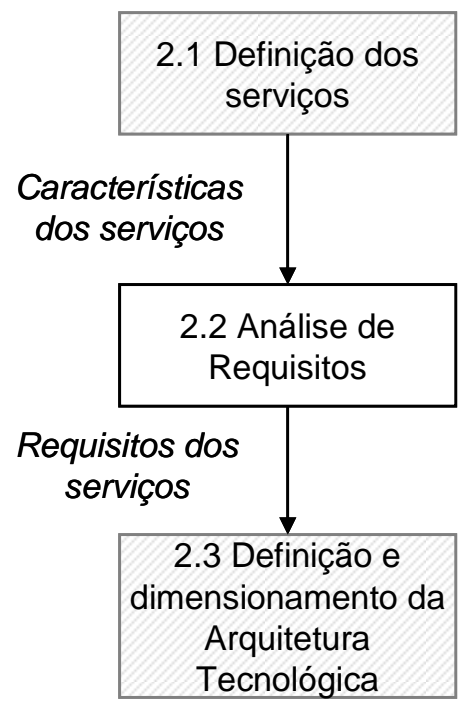

Figura 29 - Etapa de Análise de Requisitos

A característica multimídia e de tempo real dos serviços IPTV traz requisitos diferenciados à arquitetura tecnológica. Os diversos requisitos funcionais e não funcionais pertinentes são agrupados de acordo com sua aplicabilidade nas seguintes categorias: funcionalidade; capacidade e escalabilidade; desempenho; disponibilidade; confiabilidade; segurança; gerenciabilidade; usabilidade; e adaptabilidade. Cada um dos grupos de requisitos está descrito a seguir:

- Funcionalidade: os requisitos de funcionalidades dizem respeito às principais características do serviço descrito na etapa anterior. Aqui são descritas as características básicas das categorias de serviços que compõem a oferta como, por exemplo, serviços de broadcast, VOD, jogos, vídeo telefonia.

- Capacidade e Escalabilidade: definem a capacidade que a infra-estrutura tecnológica deverá suportar para garantir o correto funcionamento do serviço. Tais requisitos são fortemente relacionados com a quantidade de assinantes do serviço e do perfil de utilização das diversas categorias do serviço. Os serviços IPTV são direcionados ao público de massa e, desta forma, podem atingir milhões de assinantes dependendo das condições mercadológicas. A capacidade e escalabilidade futura (16) das plataformas tecnológicas são fundamentais para o sucesso da oferta.

- Desempenho: uma das principais características de serviços IPTV é o seu desempenho de maneira a atingir os níveis de QoE adequados. Aqui se enquadram os requisitos relacionados ao desempenho do serviço de maneira 
fim-a-fim e que afetam diretamente a percepção de qualidade pelo usuário final. Incluem-se aqui: qualidade do vídeo, tempo de resposta, atraso, variação de atraso, perda de informações, entre outros.

- Disponibilidade / Confiabilidade: considerando que o serviço possui a missão de substituir e superar os serviços tradicionais de TV a cabo e satélite, o nível de disponibilidade de serviço é um fator-chave na percepção do usuário. Desta maneira, o projeto da arquitetura tecnológica deve ser orientado visando maximizar a disponibilidade do serviço (16). A disponibilidade é definida como a parte do tempo em que um sistema permanece funcionando, quando comparado com o seu tempo de vida, e a confiabilidade é definida como a probabilidade de tempo de um sistema não falhar em um dado intervalo de tempo.

- Segurança: a proteção do conteúdo (4) é um requisito importante na implementação de um serviço IPTV. A natureza distribuída da arquitetura de IPTV implica que o conteúdo pode estar armazenado em mais locais do que as redes tradicionais de TV a cabo, criando maiores riscos à sua segurança. Deve-se lembrar que o conteúdo também trafega pela rede IP que, em geral, é compartilhada por outros serviços e sujeita a brechas de segurança. Ou seja, além da camada de serviço, devem existir medidas de segurança na camada de rede. Soma-se a isso o fato de que todo e qualquer conteúdo digital pode ser facilmente copiado indevidamente e distribuído através de sistemas de compartilhamento peer-to-peer. Todos esses fatores somados reforçam a importância da segurança no serviço IPTV, que precisa proteger os direitos de propriedade do conteúdo. Além da proteção do conteúdo, a correta identificação, autenticação e autorização de usuários são fundamentais para o correto funcionamento do sistema.

- Gerenciabilidade: o gerenciamento do serviço de forma fim-a-fim (36) também é importante para suportar a oferta de IPTV. A capacidade de gerenciar o ciclo de vida do cliente - desde o aprovisionamento até 0 desempenho de seu serviço no dia-a-dia - abrangendo as diversas camadas de abstração - do nível de serviço até a camada de rede - de forma integrada é essencial para o sucesso do serviço. 
- Usabilidade: a facilidade de uso do sistema é um requisito importante para serviços IPTV. A interface com o usuário final para acessar os diversos recursos do serviço possui um papel importante na interatividade intrínseca do serviço. Desta forma, a facilidade para buscar conteúdo, comprar títulos sob demanda, avançar ou retroceder em um determinado programa em exibição e outras funções relacionadas à interface com o usuário final incluem-se nessa categoria de requisito.

- Adaptabilidade: os requisitos de adaptabilidade são relacionados à flexibilidade da infra-estrutura tecnológica se adaptar a mudanças. Ao se definir a arquitetura tecnológica deve-se evitar a inserção de elementos que dificultem a implementação de novos serviços e tecnologias. Por exemplo, a arquitetura tecnológica deve suportar, na medida do possível, a introdução de novas categorias de serviços IPTV de maneira fácil e modular.

Os principais requisitos funcionais e não funcionais de cada grupo de requisitos descrito estão exemplificados na Tabela 7. Os requisitos identificados e definidos nesta etapa deverão nortear a etapa de dimensionamento da arquitetura tecnológica.

Tais requisitos do serviço permeiam desde a infra-estrutura de serviço de vídeo, rede e gerenciamento, e determinam as possíveis alternativas de arquitetura e as suas características. 
Tabela 7 - Principais requisitos de Serviço - Exemplos

\begin{tabular}{|c|c|c|}
\hline \multirow{2}{*}{$\begin{array}{l}\text { Grupos de } \\
\text { Requisitos }\end{array}$} & \multicolumn{2}{|c|}{ Principais Requisitos } \\
\hline & Funcionais & Não funcionais \\
\hline Funcionalidades & $\begin{array}{l}\text { Componentes de serviço } \\
\text { IPTV (vídeo, áudio, } \\
\text { comunicação, } \\
\text { entretenimento, comércio e } \\
\text { utilitários) }\end{array}$ & \\
\hline $\begin{array}{l}\text { Capacidade / } \\
\text { Escalabilidade }\end{array}$ & & $\begin{array}{l}\text { Quantidade de assinantes } \\
\text {. Quantidade de canais } \\
\text { (SDTV / HDTV) } \\
\text {. Quantidade de títulos } \\
\text { (SDTV / HDTV) } \\
\text {. Qualidade do conteúdo } \\
\text {. Perfil de utilização de } \\
\text { serviços }\end{array}$ \\
\hline Desempenho & $\begin{array}{l}\text { Mecanismos de garantia } \\
\text { de QoE / QoS }\end{array}$ & $\begin{array}{l}\text { Qualidade de vídeo / áudio } \\
\text {.Tempo de resposta (tempo } \\
\text { de inicialização, mudança } \\
\text { de canal, interações com } \\
\text { interface) }\end{array}$ \\
\hline $\begin{array}{l}\text { Disponibilidade / } \\
\text { Confiabilidade }\end{array}$ & $\begin{array}{l}\text { Mecanismos de } \\
\text { restauração automática } \\
\text { Recursos de contingência } \\
\text {. Mecanismos de } \\
\text { verificação e correção de } \\
\text { erros }\end{array}$ & $\begin{array}{l}. \% \text { de disponibilidade do } \\
\text { serviço ao longo de um } \\
\text { período }\end{array}$ \\
\hline Segurança & $\begin{array}{l}\text { Mecanismos de proteção } \\
\text { de conteúdo } \\
\text {. Mecanismos de } \\
\text { Autenticação / Autorização } \\
\text { / Contabilização }\end{array}$ & \\
\hline Gerenciabilidade & $\begin{array}{l}\text { Mecanismos e } \\
\text { ferramentas de } \\
\text { gerenciamento fim-a-fim }\end{array}$ & \\
\hline Usabilidade & $\begin{array}{l}\text { Tipos de Interface de } \\
\text { usuário } \\
\text {. Electronic Program } \\
\text { Guide (EPG) } \\
\text {. Modos de visualização }\end{array}$ & \\
\hline Adaptabilidade & $\begin{array}{l}\text {. Inserção de novos } \\
\text { serviços }\end{array}$ & \\
\hline
\end{tabular}




\subsubsection{Análise da Arquitetura Tecnológica Atual}

A análise da arquitetura tecnológica atual compreende o levantamento de informações da infra-estrutura implementada na operadora e das tendências de evolução dessa infra-estrutura que já estão planejadas ou identificadas.

A arquitetura tecnológica referida aqui diz respeito à infra-estrutura que suporta os serviços de comunicação baseados em tecnologia IP. A metodologia apresentada neste trabalho pressupõe que a operadora não possua ainda nenhum serviço IPTV em operação e, portanto, o levantamento de informações a respeito da infraestrutura tecnológica se restringe à camada de rede e gerenciamento associado ao modelo de referência apresentado na Figura 8. Outra hipótese para a análise da arquitetura atual é a de que as operadoras-alvo dessa metodologia já possuam alguma infra-estrutura para oferta de serviços IP. Caso a operadora esteja iniciando operações do zero e sem contar com nenhuma infra-estrutura anterior, esta etapa não existe e a definição da arquitetura tecnológica não levará em conta a existência de nenhuma infra-estrutura prévia.

Esta etapa de análise possui um papel bastante importante visto que 0 dimensionamento da arquitetura tecnológica que irá suportar os novos serviços depende do que está implementado hoje, do seu nível de utilização e possibilidades de expansão. Quanto maior a possibilidade de utilizar a infra-estrutura existente, melhores serão os resultados de viabilidade econômica da nova oferta.

A análise da arquitetura atual pode ser dividida em três sub-etapas conforme apresentado na Figura 30. 


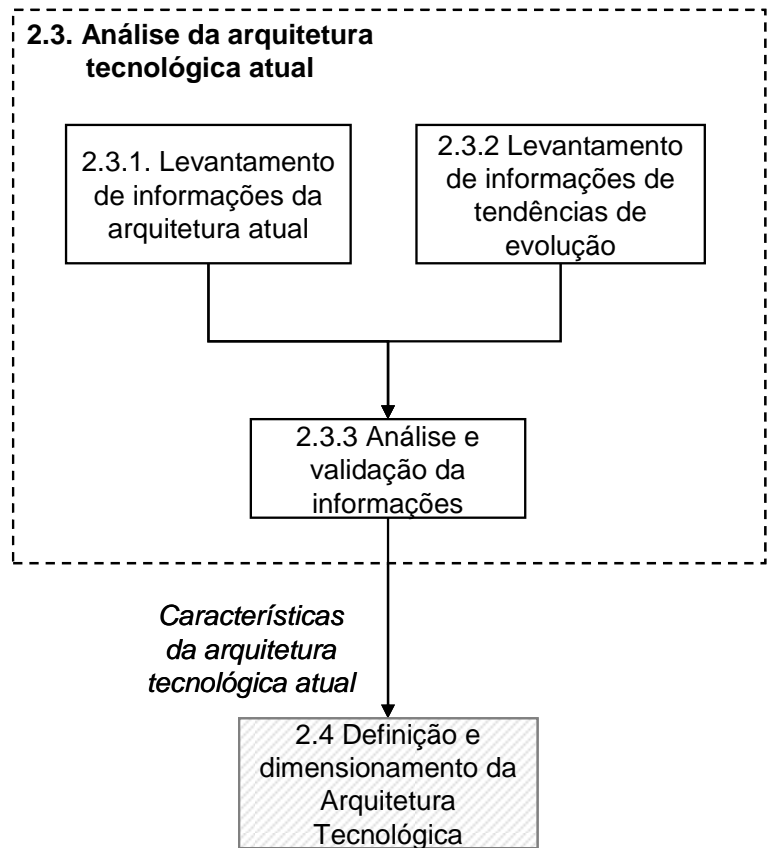

Figura 30 - Etapa de Análise da Arquitetura Tecnológica Atual

\subsection{Levantamento das informações da Arquitetura Atual}

Esta etapa compreende o levantamento de informações da infra-estrutura de rede e gerenciamento que suportará o serviço IPTV, com as devidas adaptações e expansões que se fizerem necessárias.

- Rede:

- Serviços suportados: identificação dos principais serviços IP suportados pela rede existente; quantidade de assinantes; perfil de utilização dos serviços;

- Características de rede: topologia macro das redes utilizadas para oferecer serviços IP; topologia da rede dividida nos segmentos núcleo, borda / agregação e acesso; características de cada segmento (tecnologias empregadas, equipamentos de rede, enlaces, infra-estrutura de transmissão (própria / terceiros), nível de utilização de recursos, expansibilidade e localização física); tecnologias e protocolos utilizados; mecanismos de segurança empregados (autenticação e controle de acesso, transporte seguro de informações); métricas de desempenho da 
rede (atraso, jitter, perda de pacotes, disponibilidade, etc.) e mecanismos empregados visando garantir QoS.

- Gerenciamento: identificação das ferramentas de gerenciamento utilizadas para suportar a operação de serviços IP de maneira fim-a-fim. Mapeamento das ferramentas de OSS/BSS utilizadas de acordo com o modelo de referência do eTOM apresentado na Figura 20 e discutido no item 2.9.

\subsection{Levantamento de informações de tendências de evolução}

Esta etapa tem por objetivo mapear as evoluções previstas para a arquitetura de rede e gerenciamento com o crescimento e sofisticação dos serviços existentes. Dessa maneira, o dimensionamento da arquitetura tecnológica pode se valer dos caminhos de evolução já vislumbrados para delinear a infra-estrutura que suportará o serviço de vídeo e também sugerir caminhos alternativos com base nos requisitos identificados.

Tais tendências de evolução podem acontecer na rede como, por exemplo: a ampliação de capacidade para suportar serviço de acesso à Internet de maior capacidade; ou a escolha já realizada da implantação de tecnologias de acesso baseadas em fibra. As tendências podem se situar também no plano de gerenciamento, por exemplo: mudança do sistema de billing visando incorporar a cobrança por conteúdo sob demanda.

Todas essas considerações devem ser levadas em conta no momento do dimensionamento da arquitetura tecnológica visando obter uma análise técnicoeconômica mais próxima da realidade da operadora.

\subsection{Análise e validação das informações}

A análise das informações obtidas a respeito da arquitetura atual e das tendências de evolução permite a elaboração de uma descrição do ambiente da operadora e suas perspectivas futuras. Esse processo de análise permite à equipe que 
identifique pontos que podem ser mais bem explorados ou otimizados na infraestrutura atual e também a identificação de potenciais problemas e limitações ao crescimento futuro.

A eventual falta de informações ou a existência informações conflitantes pode ocorrer durante o processo de análise de tudo o que foi coletado. Nestes casos, é necessária a validação das informações junto às equipes apropriadas da operadora em questão.

Ao fim desta etapa, existe um entendimento do ambiente atual da operadora, sobre o qual será oferecido o novo serviço IPTV após as devidas adequações e expansões da infra-estrutura.

\subsubsection{Definição e dimensionamento da Arquitetura Tecnológica}

A partir da identificação dos requisitos do serviço e das informações levantadas a respeito da arquitetura tecnológica existente na operadora, é possível delinear a arquitetura tecnológica a ser implementada para suportar o novo serviço e as adaptações necessárias na arquitetura atual. Este processo também deve levar em consideração informações externas à metodologia: tendências de evolução tecnológica, produtos disponíveis no mercado, recomendações dos fabricantes dos diversos componentes (sugestões de arquiteturas tecnológicas e regras de dimensionamento), e restrições de projeto (tecnologia, custo e prazo).

Esta etapa define os possíveis cenários de arquitetura tecnológica que suportam os serviços delineados. O resultado dessa fase consiste na descrição das características das alternativas tecnológicas plausíveis para suportar os serviços e no seu dimensionamento de alto nível, de maneira que se possa realizar a estimativa de investimentos e custos operacionais derivados das plataformas tecnológicas.

Nesta etapa da metodologia, estão descritos os principais fatores a considerar na definição da arquitetura tecnológica e seu dimensionamento, visando sempre atender os requisitos de serviços, maximizar a utilização da infra-estrutura já existente e balancear a equação de otimização de utilização de recursos versus desempenho. 
É importante ressaltar que o dimensionamento da arquitetura tecnológica não corresponde ao projeto detalhado da solução a ser implementada. A análise técnicoeconômica do novo serviço é realizada com base na definição da arquitetura tecnológica e seu dimensionamento em alto nível. Uma vez decidindo-se pela implantação do serviço e selecionada a arquitetura tecnológica mais adequada, deverão ser elaborados o projeto físico e lógico detalhados da solução, e o dimensionamento deverá ser refinado levando em conta as peculiaridades do ambiente e com vistas à implementação. $O$ propósito da definição da arquitetura e seu dimensionamento em alto nível é subsidiar a fase de planejamento e a decisão de seguir adiante com a implementação do serviço IPTV, ou da escolha da melhor alternativa tecnológica.

A arquitetura tecnológica delineada nesta etapa pode ser dividida nos seguintes blocos conforme apresentado no modelo de referência da Figura 8:

- Serviço: plataformas que são diretamente relacionadas ao serviço IPTV como, por exemplo, a infra-estrutura do head-end, servidores de vídeo, entre outros;

- Rede: rede IP multisserviço em seus diversos segmentos;

- Gerenciamento: sistemas que habilitam o gerenciamento do cliente, serviço e infra-estrutura de maneira fim-a-fim.

A análise de alternativas e dimensionamento de arquitetura foi dividida segundo os três blocos mencionados (serviço, rede e gerenciamento). Todos os três blocos possuem interação entre si, mas a metodologia apresentada visa à definição da arquitetura de maneira top-down, ou seja, partindo da infra-estrutura de serviços, para, em seguida, analisar a rede com base no perfil de tráfego gerado. Apesar dessa abordagem, a arquitetura de serviço é influenciada pela arquitetura de rede e deve ser planejada com base nisso. Um exemplo que mostra a relação entre plataformas de serviço e redes, é a distribuição do conteúdo VOD que será examinada no item 4.2.2.4.1.1.4, em que arquiteturas com diferentes níveis de centralização impactam o tráfego na rede de forma diferenciada e a decisão da arquitetura empregada deve levar em conta os dois planos: serviço e rede. Por fim, as plataformas de gerenciamento são analisadas com base nas arquiteturas de serviço e rede. 
Ao final, deve existir uma etapa de análise e validação das arquiteturas propostas segundo os requisitos especificados. Tal validação pode contar com recursos computacionais para simular o funcionamento da solução e apurar métricas de capacidade e desempenho. A Figura 31 mostra as principais atividades relacionadas a esta etapa.

Dependendo dos resultados relacionados à arquitetura e seu dimensionamento, é possível retroceder à etapa de definição de serviços a fim de realizar ajustes e realimentar o processo.

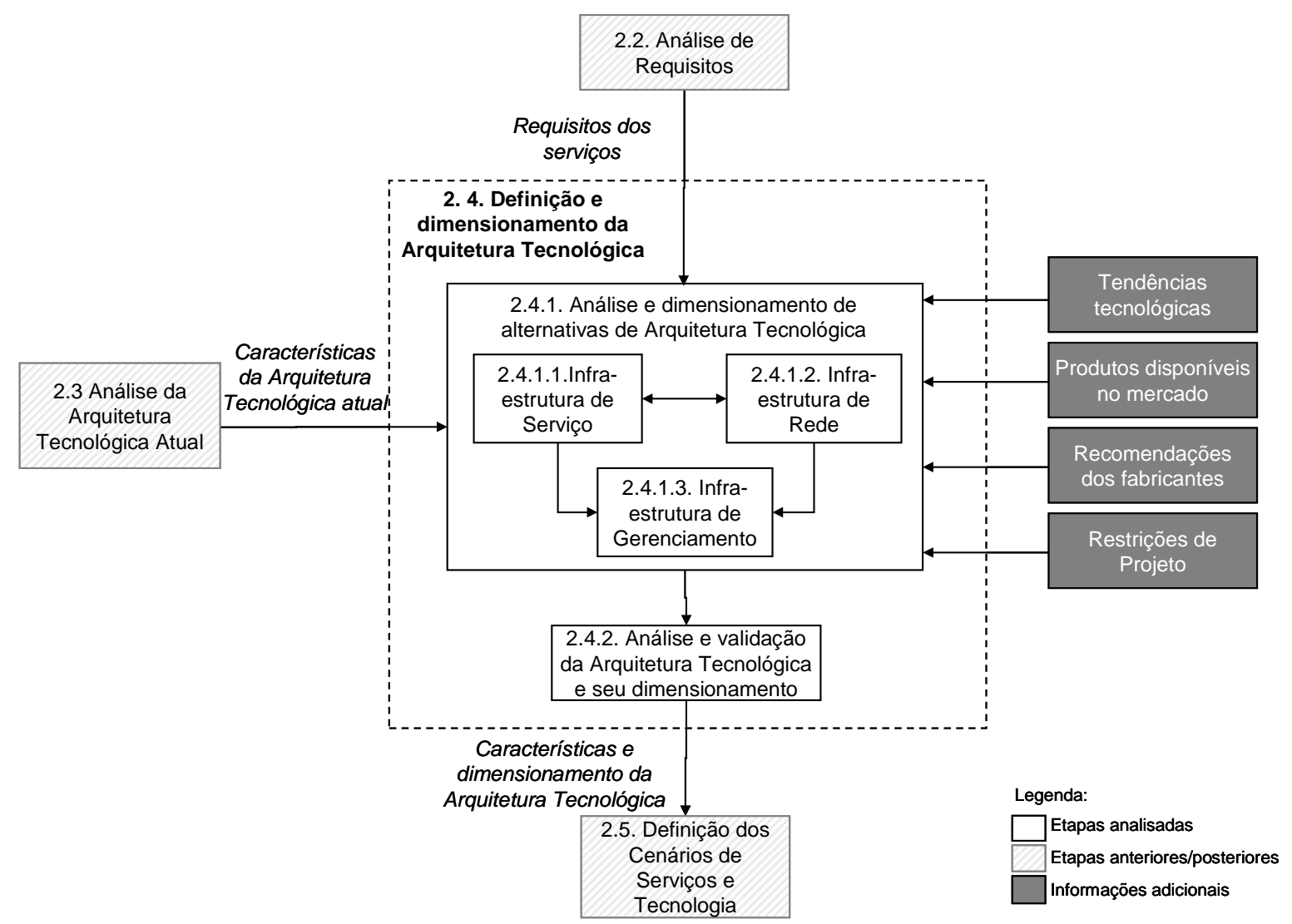

Figura 31 - Etapa de Definição da Arquitetura Tecnológica 


\subsection{Análise e dimensionamento de alternativas de arquitetura tecnológica}

\subsection{Infra-estrutura de Serviço}

A infra-estrutura de serviço diz respeito essencialmente aos componentes da solução de vídeo e para este item ela considerada os mesmos blocos definidos na arquitetura de referência da Figura 8: sistemas de head-end, middleware, DRM, servidores de vídeo e set-top box. A análise e dimensionamento da infra-estrutura de serviço é um pré-requisito para a infra-estrutura rede, pois algumas definições na plataforma de vídeo são decisivas para o delineamento da arquitetura de redes. Entretanto, conforme já discutido, a definição da arquitetura de serviço e rede se realimentam.

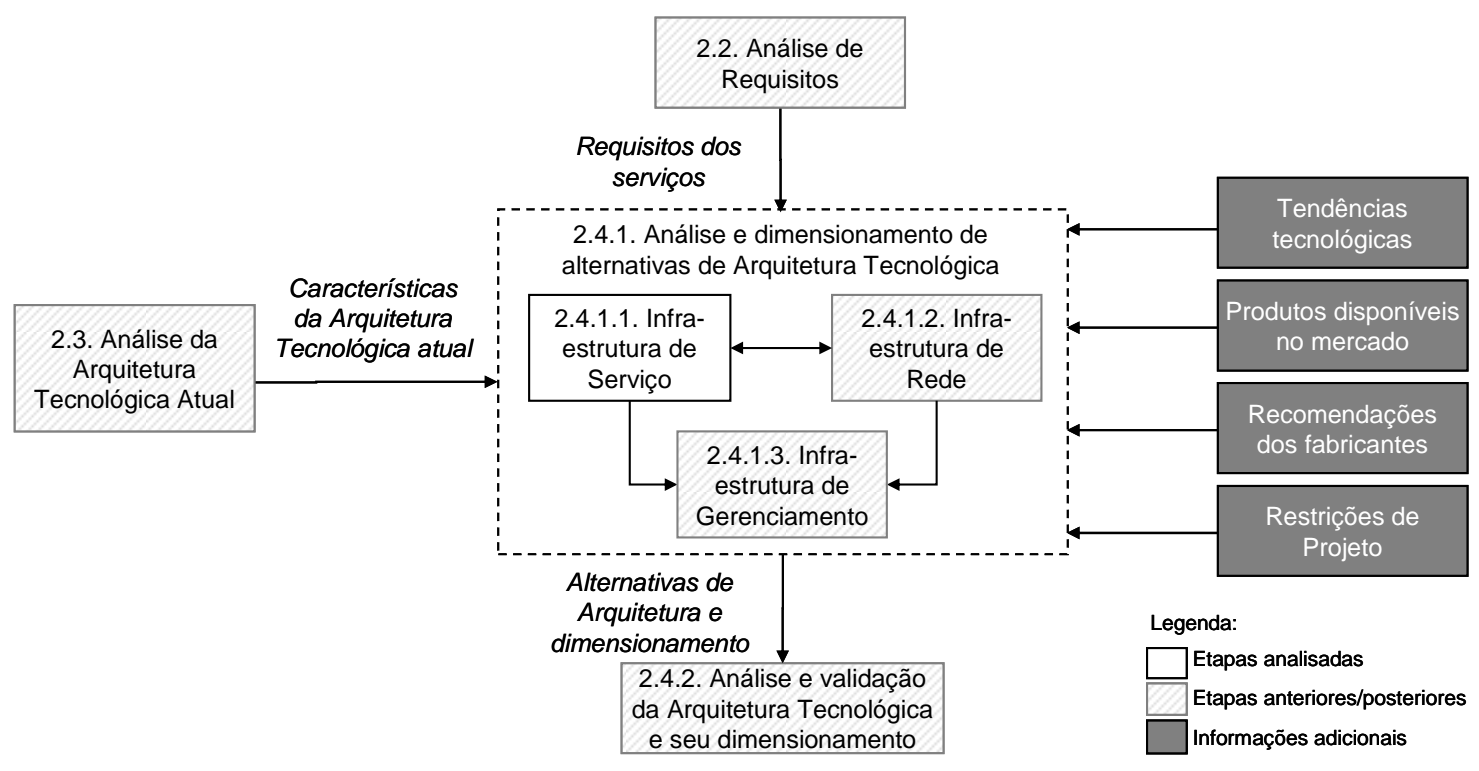

Figura 32 - Etapa de Análise e Dimensionamento - Serviço

Nas seções subseqüentes, encontram-se diretrizes de alto nível que norteiam o delineamento da infra-estrutura de serviço. Uma das primeiras atividades desta etapa é a definição da arquitetura macro da infra-estrutura de serviço a partir da definição das localidades em que será ofertado o serviço IPTV:

- Localização e quantidade head-ends principais, também conhecidos por Super Head-ends (SHEs), responsáveis pela injeção do conteúdo de caráter 
nacional. Em geral, existe um SHE por solução, podendo haver sua replicação na mesma ou em outra localidade por questões de redundância.

- Localização e quantidade de head-ends secundários, também conhecidos por Vídeo Hub Offices (VHOs), onde acontece a injeção de conteúdo de caráter regional ou local.

- Localização e quantidade de Vídeo Serving Offices (VSOs), onde pode residir o armazenamento de conteúdo mais próximo do assinante.

\subsection{Sistemas de Head-End}

Os sistemas de head-end possuem a função de injetar conteúdo no sistema de IPTV. Para cada head-end em que exista a inserção de conteúdo (SHEs e VHOs, em geral) devem ser levadas em conta as considerações a seguir. Os sistemas de head-end podem ser divididos em sistemas de recepção e processamento dos sinais.

\subsection{1.1 Recepção}

Os sistemas de recepção são responsáveis por disponibilizar o conteúdo que será exibido ao usuário final no formato de broadcast, e portanto, são diretamente relacionados à grade de canais definida. As formas mais populares de receber o sinal de televisão que será distribuído são: via satélite, transmissão terrestre ("offair") ou conexão dedicada.

- Satélite: no caso de recepção de canais via satélite, é necessário determinar a quantidade de antenas, conversores Low Noise Block (LNB) e splitters para distribuir o sinal recebido até os receptores, mais conhecidos como Integrated Receivers Decoders (IRDs). Para o dimensionamento da quantidade antenas, é necessário estabelecer a grade de canais de programação e identificar em qual satélite cada canal se encontra. Em geral, se utiliza um IRD para cada 
canal recebido, e o tipo do IRD (analógico / digital) depende da forma como o canal é transmitido.

- Transmissão terrestre ("off-air"): no caso da recepção de canais locais via terrestre, cada canal é recebido em uma faixa de freqüência definida. Desta maneira, são necessárias antenas VHF/UHF que cubram as freqüências recebidas e um conjunto de splitters para sua distribuição até os receptores, que são demoduladores VHF/UHF neste caso. Em geral, se utiliza um demodulador para cada canal recebido.

- Fibra óptica: existe ainda a possibilidade de receber canais de televisão através de uma conexão dedicada, em geral, utilizando de fibra-óptica. Neste caso, além da conexão de fibra, é necessário um receptor (conversor eletroóptico) para cada canal.

No dimensionamento dos elementos mencionados, deve-se considerar a utilização de elementos redundantes sempre que possível, dada a importância da transmissão dos canais broadcast para o serviço IPTV.

Até aqui, foi considerada apenas a recepção dos sinas que farão parte da grade de programação de broadcast do serviço. Entretanto, a operadora também recebe conteúdo de VOD de diversos parceiros (agregadores e produtores de conteúdo). A recepção dessa categoria de conteúdo ocorre, em geral, via transferência de arquivos utilizando conexões de dados seguras ou ainda entrega da mídia em meio físico.

\subsection{1.2 Processamento}

Depois de recebidos através das diversas formas, ocorre o processamento do conteúdo no head-end. Esta etapa de processamento corresponde essencialmente à distribuição dos sinais que saem dos receptores e a codificação dos mesmos para serem transmitidos na rede de acordo com padrões definidos, conforme ilustrado na seção 2.7.1.

A escolha do padrão de codificação (MPEG-2, MPEG-4 ou WM9) é de grande importância, pois impacta diretamente diversos elementos da solução de IPTV. O 
principal impacto está na largura de banda que deverá ser suportada pela infraestrutura de rede. Quanto maior a eficiência do padrão escolhido, menor a largura de banda necessária e, portanto, menores recursos de rede serão necessários. Além da infra-estrutura de rede, a escolha da codificação impacta outro elemento da solução, o set-top box. O padrão de codificação escolhido determinará os set-top boxes compatíveis, ou seja, aqueles que são capazes de decodificar o padrão determinado.

O dimensionamento da quantidade de codificadores (encoders) necessários depende da quantidade de canais a serem codificados, padrão de codificação e se eles serão transmitidos em qualidade SDTV ou HDTV. Em geral, se utiliza um codificador para cada canal, mas é necessário prever a quantidade de codificadores sobressalentes para o caso de falhas.

Para distribuir os sinais dos receptores até os codificadores, é necessário considerar a utilização de amplificadores de distribuição. Além disso, para simplificar o processo de conexão entre as diversas fontes de conteúdo (saídas dos amplificadores) e os codificadores (ativos e sobressalentes), em geral, se utiliza um switch de vídeo (ou matriz de vídeo). O switch de vídeo permite a alocação dinâmica de codificadores em caso de falha de algum, evitando assim conexões manuais e maior complexidade operacional.

Se necessário, deve-se considerar a utilização de uma plataforma de inserção de comerciais (ad insertion), dependendo dos acordos das operadoras com os produtores de conteúdo.

Com relação ao conteúdo de VOD, é necessário considerar uma plataforma de inserção de conteúdo que permite tratar desde o conteúdo VOD recebido em seu formato original dos produtores e transformá-lo de acordo com os padrões de codificação para que seja armazenado nos servidores de vídeo.

\subsection{Middleware}

A natureza proprietária das plataformas de middleware IPTV faz com que cada implementação seja bastante dependente do fornecedor da solução. Desta maneira, 
o dimensionamento da infra-estrutura necessária e da plataforma de middleware propriamente dita dependem de cada implementação. Os parâmetros principais que determinam o dimensionamento da plataforma são:

- Quantidade de assinantes e quantidade de pontos por assinante (modelos de licenciamento de software, em geral, dependem da quantidade total de terminais ativos que pode ser maior do que o número de assinantes dependendo da quantidade de pontos por assinante, etc.);

- Taxa de simultaneidade de acesso ao serviço;

- Serviços oferecidos (broadcast, VOD, NPVR, time-shifted TV, etc.);

- Quantidade de canais e títulos VOD;

- Funcionalidades para o assinante (ex.: características do EPG, nível de interatividade, recursos gráficos, etc.) e para a operadora (ex.: composição de grade de programação, gestão do serviço);

- Possibilidade de integração com outras aplicações (ex.: jogos).

Considerando o papel central do middleware na solução de IPTV, é importante ressaltar que essa plataforma deve ser compatível e integrável com os diversos componentes da solução. Desta maneira, existem implicações principalmente para a seleção e dimensionamento do set-top boxes e sistemas de DRM devido à sua estreita relação com o middleware.

\subsection{Digital Rights Management}

Da mesma forma que o middleware, as soluções de DRM apresentam caráter proprietário e cada implementação é bastante dependente do fornecedor de solução. Desta forma, o seu dimensionamento depende de cada implementação. Os parâmetros principais para dimensionar a solução de DRM incluem:

- Quantidade de assinantes e quantidade de pontos por assinante (modelos de licenciamento de software, em geral, dependem da quantidade total de terminais ativos); 
- Taxa de simultaneidade de acesso ao serviço;

- Serviços oferecidos (broadcast, VOD, NPVR, time-shifted TV, etc);

- Quantidade de canais e títulos VOD;

- Método de autenticação: smart cards (baseado em hardware) ou virtual smart cards (baseado em software)

Um aspecto relevante a ser considerado na arquitetura de DRM é a forma de autenticação que será utilizada nos dispositivos clientes: smart cards (soluções baseadas em hardware) ou virtual smart cards (soluções baseadas em software). Além de uma decisão tecnológica, essa decisão possui um impacto operacional significativo. Usualmente, as soluções baseadas em smart cards possuem uma complexidade operacional maior devido à necessidade de substituição do cartão no local em caso de problemas.

A definição do DRM impacta diretamente outros elementos da solução. Os principais impactados e que precisam ser compatíveis com a solução escolhida são o set-top box e o middleware.

\subsection{4 Servidores de Vídeo}

Os servidores de vídeo abrigarão toda forma de conteúdo de vídeo sob demanda que o usuário possa acessar. Além da função de armazenamento, eles cumprem a função de streaming do conteúdo armazenado. As modalidades desse conteúdo variam com as modalidades de vídeo sob demanda oferecidas ao usuário conforme delineado no item 2.4.1. As modalidades mais comuns em que a operadora armazena o conteúdo são: $V O D$, time shifted TV e virtual channels .

O dimensionamento dos servidores de vídeo é diretamente proporcional a dois parâmetros:

- Espaço de armazenamento requerido: este parâmetro é obtido pela estimativa de tempo de vídeo que será armazenado nos servidores (incluindo todas as modalidades de vídeo sob demanda) multiplicado pela sua respectiva taxa de codificação. 
- Vazão ou Streams transmitidos simultaneamente: este parâmetro é obtido pela estimativa da taxa de simultaneidade para cada modalidade de vídeo sob demanda. A quantidade de streams simultâneos multiplicada pela taxa de codificação do vídeo resulta na vazão que os servidores de vídeo deverão suportar. Deve-se considerar também o overhead de protocolos de rede no cálculo da vazão.

A arquitetura dos servidores de vídeo pode ser centralizada ou distribuída. $\mathrm{Na}$ arquitetura centralizada, o conteúdo fica armazenado em uma localidade única, por exemplo, o SHE e todas requisições são atendidas por essa localidade. $\mathrm{Na}$ arquitetura distribuída, réplicas do conteúdo mais acessado são copiadas para localidades mais próximas do usuário final, por exemplo, nos VHO ou até no VSO quando aplicável. A arquitetura distribuída visa à economia de recurso de rede e maior desempenho disponibilizando o conteúdo mais próximo ao usuário.

Em implementações de maior escala, as arquiteturas distribuídas vêm sendo empregadas. Entretanto, a decisão de distribuir ou não o conteúdo depende da economia de recursos de rede em oposição ao investimento em servidores de vídeo distribuídos. Além disso, fatores relacionados ao desempenho também podem influir na decisão de uma arquitetura distribuída em detrimento de uma arquitetura centralizada.

Para o dimensionamento da arquitetura, em cada um dos nós (SHE, VHO e VSO) onde houver vídeo armazenado, deve-se calcular os parâmetros de espaço de armazenamento e vazão necessária. Além disso, no cálculo deve-se considerar a qualidade do conteúdo (SDTV / HDTV) que será armazenado.

\subsection{5 Set-top box}

A sofisticação dos set-top boxes pode variar de acordo com a especificação do serviço e outros blocos da solução. Os set-top boxes selecionados para a solução devem ser compatíveis com o middleware utilizado, com o esquema de DRM e também devem ser capazes de interpretar o padrão de codificação escolhido para o serviço. 
Além disso, os set-top boxes podem conter também espaço de armazenamento local para suportar funções de PVR em que o usuário grava conteúdo selecionado no próprio dispositivo. Deve-se considerar também a qualidade do sinal que ele irá decodificar: SDTV ou HDTV.

O dimensionamento dos set-top boxes depende diretamente da quantidade de assinantes do serviço, quantidade de pontos por assinante e da natureza de cada ponto habilitado (SDTV / HDTV). Deve-se notar, que o possível reaproveitamento de set-top boxes de assinantes que deixam de assinar o serviço para novos assinantes pode contribuir para otimizar a quantidade de novas unidades a cada ano.

\subsection{Infra-estrutura de rede}

O dimensionamento da infra-estrutura de rede para suportar serviços IPTV deve levar em consideração os requisitos de serviço e a arquitetura tecnológica atual de rede visando à maximização da utilização dos recursos já existentes. Além disso, deve considerar tendências de evolução tecnológica, os produtos disponíveis no mercado, recomendações dos fabricantes (dimensionamento e arquitetura) e restrições de projeto relacionadas a tecnologia, custo e prazo de implementação.

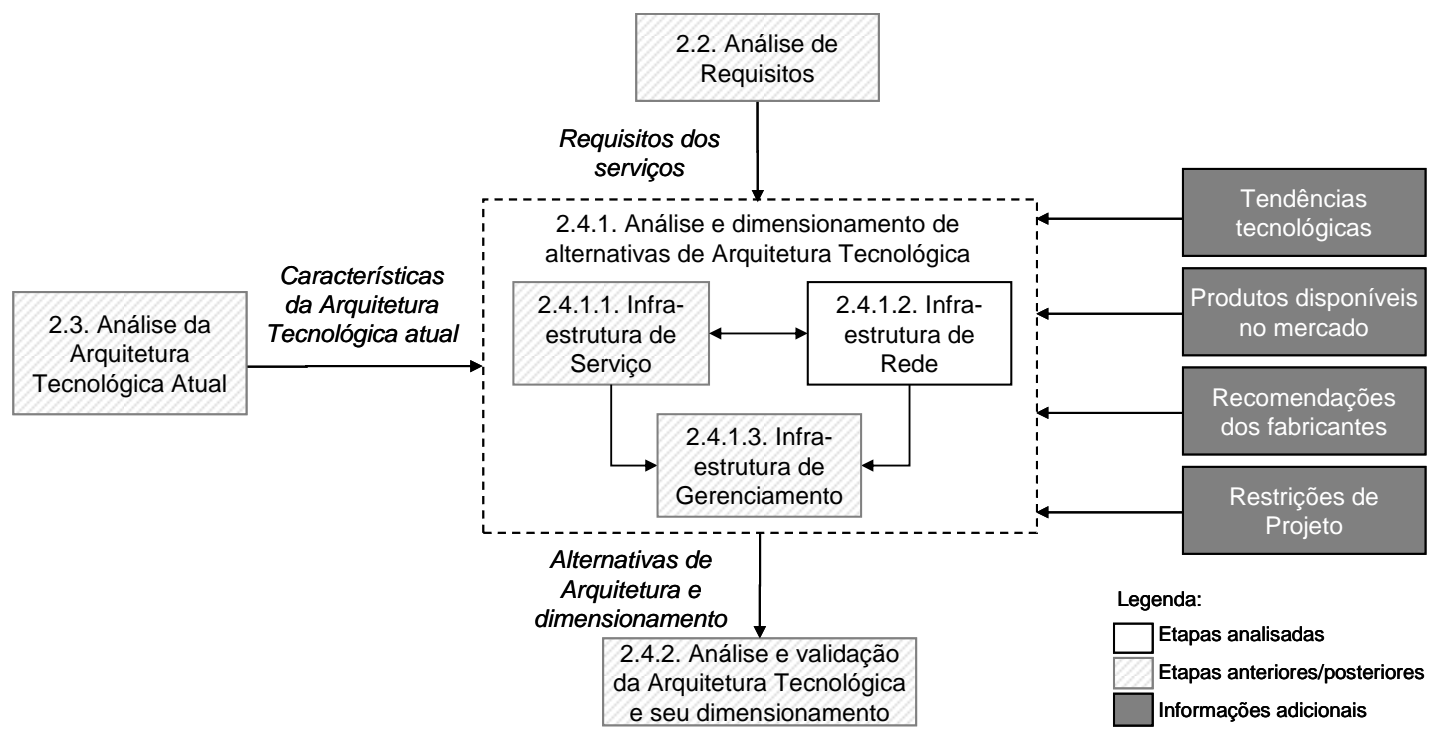

Figura 33 - Etapa de Análise e Dimensionamento - Rede

A análise e a determinação das arquiteturas de rede e seu dimensionamento deve se iniciar pelo entendimento da característica do tráfego gerado pelo serviço em 
cada segmento de rede, para então analisar as características da arquitetura e realizar o dimensionamento de seus elementos.

- Caracterização do tráfego gerado pelo serviço: identificação do perfil de tráfego gerado pelo serviço de vídeo: fluxos de tráfego (origem/destino), ocupação de banda, comportamento no tempo e características de desempenho (delay, jitter, perda de pacotes);

- Delineamento e dimensionamento da arquitetura: caracterização da rede em nível de arquitetura incluindo: topologia e hierarquia; quantidade de elementos e distribuição geográfica; capacidade dos enlaces; tecnologias e protocolos empregados; mecanismos de roteamento e endereçamento; mecanismos de segurança; mecanismos de garantia de desempenho; e mecanismos de gerenciamento.

As características do perfil de tráfego IPTV foram discutidas no item 2.8.2 e 2.8.3. Uma das principais características fundamentais e que determinam a arquitetura e dimensionamento da rede é a largura de banda. Os serviços IPTV são intrinsecamente intensivos de utilização de largura de banda e podem estar sujeitos a flutuações de demanda. Os principais parâmetros que contribuem para a falta de previsibilidade e a intensa utilização de recursos de rede incluem (18):

- Conteúdo sob demanda: a quantidade de sessões de conteúdo sob demanda (as diversas variantes de VOD, NPVR, etc.) simultâneas possui efeito direto na quantidade de tráfego unicast na rede, e pode adicionar grande variabilidade no perfil de tráfego.

- Canais broadcast: a quantidade de canais assistidos simultaneamente afeta o mecanismo de replicação multicast, e também o perfil de tráfego ao longo da rede;

- Conteúdo em qualidade HDTV: o crescimento da utilização de conteúdo em qualidade HDTV também influencia o volume de tráfego na rede, seja ele unicast ou multicast;

- Quantidade de pontos por assinante: a quantidade de set-top boxes para cada assinante possui um efeito multiplicador no tráfego da rede. Cada ponto 
de TV adicional na residência de um assinante representa mais um usuário do serviço e que utiliza recursos da rede.

Considerando que o tráfego de vídeo possui característica de fluxo contínuo e tempo real, a largura de banda necessária para cada stream deve ser garantida durante sua transmissão para o usuário final visando garantir o desempenho da rede e do serviço conforme ilustrado no item 2.8.3.1.

Desta forma, a caracterização da ocupação de banda na rede deve levar em conta premissas de taxa de concorrência ou simultaneidade de utilização do serviço em situações de pico. Para lidar com flutuações de utilização do serviço acima do esperado, são utilizados mecanismos de QoS voltados ao controle de admissão e de diferenciação de serviço discutidos no item 2.8.3.2. Além da taxa de simultaneidade, a qualidade do conteúdo transmitido (HDTV / SDTV) e a quantidade de pontos por assinante devem ser levadas em consideração.

A arquitetura de distribuição de conteúdo possui relevância no perfil de tráfego. A disposição da arquitetura de vídeo e seu nível de distribuição possuem um papel importante do ponto de vista do tráfego associado ao serviço VOD. As localidades em que ocorre inserção de conteúdo broadcast na rede e os pontos de replicação do mecanismo multicast são importantes para determinar o tráfego relacionado ao serviço broadcast.

O perfil de tráfego deve ser determinado em cada um dos nós e segmentos de rede, e a sua caracterização pode se dar conforme descrito a seguir. Tais considerações são simplificadas na última milha do acesso conforme será discutido no item 4.2.2.4.1.2.1.

- Tráfego de conteúdo sob demanda: devido à característica unicast do tráfego, a determinação da largura de banda necessária é realizada a partir da taxa de simultaneidade de assinantes assistindo conteúdo sob demanda em situações de pico. A equação (10) exemplifica o método de cálculo. Para cada segmento ou nó de rede, o cálculo a seguir deve ser realizado para o tráfego do conteúdo SDTV e HDTV individualmente e depois somado. Além disso, deve-se considerar as diversas variantes de conteúdo sob demanda (VOD, NPVR, etc.). 


$$
B_{V O D}=N \times q \times p_{V O D} \times c_{V O D} \times r
$$

Onde:

- $B_{V O D}=$ largura de banda para o serviço VOD no nó ou segmento da rede

- $\mathrm{N}$ = quantidade de assinantes conectados ao nó / segmento da rede

- $q=$ quantidade de pontos por assinante

- $p_{V O D}=$ percentual da base de assinantes que utiliza VOD

- $C_{V O D}=$ percentual dos assinantes que utiliza o serviço VOD de forma simultânea (situação de pico)

- $r$ = largura de banda esperada para um stream de vídeo a uma dada compressão (depende do padrão de codificação empregado e da qualidade do conteúdo: SDTV / HDTV) e deve levar em conta overhead de protocolos de rede

- Tráfego do conteúdo broadcast: a determinação da largura de banda ocupada pelos canais broadcast em cada segmento ou nó da rede depende de quantos canais são assistidos simultaneamente, ponto de inserção de conteúdo e do mecanismo multicast. Para determinar quantos canais de uma grade de programação são assistidos simultaneamente em uma população de assinantes, pode-se utilizar análise estatística considerando a probabilidade de cada canal ser assistido em um dado momento conforme apresentado nas equação (11). Esta probabilidade é dada por uma distribuição de probabilidades que reflete a popularidade dos canais (24) e é bem caracterizada pela função Zipf (51). Quando não se conhece a grade de canais previamente e a popularidade de cada canal é desconhecida, deve-se arbitrar uma função de distribuição de probabilidade. Uma simplificação consiste em adotar uma distribuição de probabilidades uniforme, conforme mostra a equação (12). Quando se adota uma distribuição de canais uniforme, a quantidade de canais assistidos simultaneamente fica bem próxima da quantidade total de canais na condição em que o número de assinantes conectados ao nó da rede ou segmento é elevado conforme apresentado na (13). Assumindo que o mecanismo de replicação multicast está ativo no segmento ou nó em avaliação, a largura de banda necessária é determinada 
pela equação (14). Para cada segmento ou nó de rede, o procedimento de cálculo deve ser realizado para o tráfego do conteúdo SDTV e HDTV individualmente e depois somado.

$$
\begin{gathered}
C_{A}=\sum_{k=1}^{C}\left[1-\left(1-p_{k}\right)^{N}\right] \\
C_{A}=C \times\left[1-\left(1-\frac{1}{C}\right)^{N}\right] \text { se } p_{k} \text { é uniforme } \\
C_{A} \cong C \text { se } p_{k} \text { é uniforme e } N>C \\
B_{\text {broadcast }}=C_{A} \times r
\end{gathered}
$$

Onde:

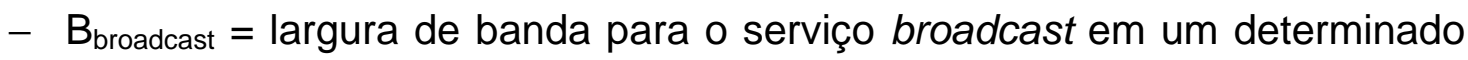
nó ou segmento da rede

- $\mathrm{C}_{\mathrm{A}}=$ quantidade de canais simultâneos assistidos, ou seja, canais em uso em um dado momento

- $C$ = quantidade total de canais

- $\mathrm{N}$ = quantidade de assinantes conectados ao nó / segmento da rede

- $\mathrm{p}_{\mathrm{k}}=$ probabilidade de um usuário selecionar o canal $\mathrm{k}$

- $r$ = largura de banda esperada para um stream de vídeo a uma dada compressão (depende do padrão de codificação empregado e da qualidade do conteúdo: SDTV / HDTV) e deve levar em conta overhead de protocolos de rede

Uma vez realizada a caracterização do perfil de tráfego na rede em seus principais segmentos (núcleo, agregação e acesso conforme explorado no item 2.8.1), deve-se proceder às análises relativas à arquitetura e dimensionamento da rede. Neste processo, é necessário tomar em conta algumas considerações relacionadas ao serviço IPTV que permeiam a rede de maneira fim-a-fim:

- Características de tráfego IPTV: tempo real e fluxo contínuo 
- Largura de Banda elevada e assimetria de tráfego (transmissão voltada para downstream)

- Requisitos de desempenho elevados

- Arquitetura voltada para alta disponibilidade: rotas alternativas e redundância de elementos críticos para garantir a disponibilidade do serviço em caso de falhas de rede

- Otimização da utilização recursos de rede através utilização de mecanismos multicast quando aplicável

- Flexibilidade para injetar conteúdo em diversos pontos da rede visando à otimização da utilização de recursos

- Inteligência de monitoramento da disponibilidade de recursos de maneira fima-fim

- Mecanismos para garantir QoS no nível de rede

- Controle de serviço fim-a-fim e aplicação de políticas em nível de assinante / serviço

- Controle de Admissão: para tráfego unicast e multicast

A seguir encontram-se algumas diretrizes de alto nível que norteiam o delineamento da arquitetura de rede e o seu dimensionamento para cada um dos segmentos. A análise deve começar pelo acesso, percorrer as redes de agregação e depois o segmento de núcleo. Além dos segmentos de rede, deve ser contemplada a criação de uma rede local em cada nó de serviço (SHE, VHO e VSO) que servirá de suporte para interconectar os elementos das plataformas de serviço à rede.

\subsection{1 Acesso}

A definição da arquitetura tecnológica do acesso depende principalmente dos requisitos de banda impostos pelos serviços oferecidos ao usuário final. Desta forma, é necessário identificar a quantidade total de banda necessária para cada assinante na condição em que ele estiver utilizando todos os serviços, por exemplo, 
IPTV, Internet Banda Larga e VoIP. Para o cálculo de banda requerida pelo serviço IPTV, considera-se a quantidade de pontos por assinante, a qualidade de conteúdo (SDTV / HDTV) que é recebido em cada ponto, o padrão de codificação utilizado e o overhead de protocolos de rede. Deve-se considerar ainda que a demanda de tráfego pelo usuário final evolui ao longo do tempo, e a solução tecnológica deve suportar tal evolução.

A partir disso, deve-se avaliar quais as possíveis arquiteturas e tecnologias adotadas na rede de acesso que atendem às necessidades de banda do usuário final. As principais alternativas estão apresentadas no item 2.8.1.3 e são baseadas em fibra óptica e/ou cobre como meio de acesso físico. Não foram incluídas nesta análise as tecnologias de acesso sem fio, considerando que ainda não existem soluções maduras nessa categoria que suportem a largura de banda necessária para os serviços IPTV em larga escala.

Cada alternativa tecnológica apresenta um conjunto de características que podem se mostrar mais adequadas em determinadas situações, apresentando perfis de custos distintos, e dependem fortemente da arquitetura de acesso já existente.

Depois de identificadas as alternativas tecnológicas possíveis, deve-se delinear a arquitetura da rede em maior nível de detalhes e realizar seu dimensionamento. Os principais parâmetros utilizados para dimensionar a rede de acesso são:

- Largura de banda necessária por assinante;

- Quantidade de assinantes;

- Dispersão geográfica dos assinantes;

- Topologia da rede de acesso (quantidade e distribuição de nós de acesso, centrais e armários de distribuição; topologia das redes primária e secundária e distâncias envolvidas; distribuição típica de assinantes);

- Funcionalidades requeridas nos equipamentos de acesso para suportar o serviço definido (por exemplo, funcionalidades relacionadas o mecanismo multicast).

A seguir estão apresentadas diretrizes de dimensionamento em alto nível para cada uma das principais alternativas tecnológicas apresentadas no item 2.8.1.3: 
- FTTN: as soluções inteiramente baseadas em xDSL permitem o aproveitamento da rede de cobre já existente na operadora para oferecer serviços de voz e acesso Internet banda larga. Deve-se selecionar a tecnologia xDSL (ADSL 2+ ou VDSL2) que será utilizada no acesso levando em conta a largura de banda necessária e a distância média entre os nós de acesso e os domicílios dos usuários. É importante notar que as implementações da tecnologia ADSL para oferta de banda larga atualmente possuem restrições quanto à largura de banda necessária ao transporte de vídeo. Portanto, deve-se considerar a evolução das portas dos DSLAMs para tecnologias mais avançadas (ADSL2+ / VDSL2) quando possível, ou então, a sua substituição. A determinação da quantidade e características de DSLAMs e de CPEs é necessária para o dimensionamento da rede. Além disso, devese determinar a quantidade em distância de cabos par metálico e dutos a serem instalados ou substituídos, quando necessário.

- FTTH: pressupõe a criação de uma nova rede de acesso levando a fibra desde os nós de acesso até o domicílio do usuário. Deve-se selecionar a tecnologia a ser empregada e realizar o seu respectivo dimensionamento. A seguir estão apresentadas duas alternativas de implementação:

- PON: seleção do padrão de PON a ser utilizado (APON / BPON / GPON / EPON) de acordo com a largura de banda necessária e a compatibilidade tecnológica com o ambiente existente na operadora. Deve-se determinar: a taxa de compartilhamento da rede óptica, a quantidade e características dos equipamentos da rede de acesso (splitters, OLTs e ONTs), bem como a quantidade em distância de cabos de fibra óptica e dutos a ser instalada.

- Ethernet: seleção da topologia de implementação (estrela ativa ou pontoa-ponto). Deve-se determinar, a taxa de compartilhamento (no caso da estrela ativa), a quantidade e as características dos equipamentos na rede de acesso (switches Ethernet e CPEs) e a quantidade em distância de cabos de fibra óptica e dutos a serem instalados. A terminologia OLT e ONT também pode ser utilizada para esta classe de arquiteturas, indicando elementos da central e do assinante, respectivamente. 
- FTTCab / FTTCurb: constituem implementações híbridas de redes de cobre e fibra. Tais modalidades de implementação representam uma solução de compromisso até se chegar à opticalização completa do acesso, permitindo o aproveitamento parcial da base instalada de pares metálicos. A diferença fundamental entre os dois modelos reside no quão perto do usuário final se chega utilizando fibra óptica. No modelo FTTCab, os nós em que se chega com fibra óptica agregam uma quantidade maior de assinantes do que no modelo FTTCurb, e a distância do usuário até o primeiro elemento óptico é maior. Para o seu dimensionamento, deve-se determinar até onde a fibra óptica se estenderá, ou seja, distância do segmento de cobre e quantos assinantes concentrará o nó de fibra óptica mais próximo do usuário. A partir de então, o dimensionamento pode ser realizado a partir da composição das considerações das modalidades de FTTH e FTTN.

Além do detalhamento de cada alternativa tecnológica do nó de acesso até o assinante, deve-se determinar como se dá a interligação dos nós de acesso com os PoPs de agregação, lembrando que um PoP de agregação concentra diversos nós de acesso. Nas regiões de maior densidade, os PoPs de agregação e os nós de acesso podem coexistir na mesma localidade física, o prédio da central.

\subsection{2 Agregação}

As decisões a respeito da arquitetura das redes de agregação e da borda do serviço são fundamentais para o dimensionamento da infra-estrutura para suportar um serviço IPTV. Conforme discutido no item 2.8.1.2, a oferta de vídeo traz diversos desafios relacionados à escalabilidade e distribuição da inteligência que devem ser tomados em conta na escolha da arquitetura.

Neste contexto, surgem algumas opções de evolução para a arquitetura de borda do serviço com relação à distribuição da inteligência ao longo da rede. Além das decisões sobre a centralização ou não da inteligência do serviço, existem diversas maneiras de se implementar a rede de agregação em Camada 2 ou 3, e diferentes formas de utilização de esquemas de VLAN mapeadas por assinante ou serviço. 
Com base nas escolhas relacionadas ao modelo de implementação da rede de agregação, deve-se delinear a arquitetura da rede em maiores detalhes $e$ dimensioná-la. A largura de banda é o principal parâmetro para o dimensionamento das redes de agregação e pode ser determinada de acordo com os métodos apresentados no item 4.2.2.4. Deve-se notar que a habilitação ou não dos mecanismos multicast no núcleo dependem do modelo de implementação adotado e influenciam diretamente a otimização de recursos. Além disso, deve-se levar em conta as questões relacionadas a desempenho (funcionalidades de QoS requeridas) e disponibilidade (tempo de restauração do serviço).

Para realizar o dimensionamento da agregação, deve-se determinar a sua topologia incluindo a quantidade de PoPs, sua localização, forma de interligação entre os PoPs, e interligação com o núcleo e acesso. Com base nisso, deve-se dimensionar os elementos de rede e enlaces que os interligam levando em conta a rede já implantada. O dimensionamento deve levar em conta duas camadas conforme mencionado no item 2.8.1.2:

- Roteamento/Comutação: dimensionamento dos roteadores e switches de borda/distribuição e agregação;

- Transmissão: dimensionamento dos enlaces que interconectam os PoPs de agregação e equipamentos de transmissão quando aplicável, por exemplo, elementos de rede óptica DWDM ou SDH/Sonet.

\subsection{3 Núcleo}

O núcleo da rede, em geral, é implementado utilizando tecnologias IP e MPLS. Com relação às decisões de arquitetura, deve-se levar em consideração as tendências de evolução no sentido de virtualização de elementos de rede e da aproximação do nível óptico da camada IP conforme apresentado em 2.8.1.1.

Com base nas arquiteturas tecnológicas selecionadas, deve-se realizar o seu dimensionamento. O principal parâmetro a ser considerado no dimensionamento do núcleo é a largura de banda que deve ser suportada e pode ser determinada de acordo com os métodos apresentados no item 4.2.2.4. Desta maneira, a etapa de 
caracterização do tráfego é fundamental para o delineamento da capacidade necessária em todos os PoP de núcleo e nos enlaces que os interligam.

A utilização de mecanismos multicast no núcleo é de fundamental importância para a otimização de utilização de recursos de rede, pois todo o conteúdo de caráter nacional que chega ao SHE deve atravessar o núcleo da rede para alcançar os VHOs.

Para realizar o dimensionamento do núcleo, deve-se determinar a sua topologia em linhas gerais, incluindo o número de PoPs e como se dá a sua interligação, levando em consideração a topologia já implantada. Com base nisso, é possível determinar o dimensionamento dos elementos e enlaces que o compõem. $O$ dimensionamento deve levar em conta duas camadas conforme mencionado no item 2.8.1.1:

- Roteamento: dimensionamento dos roteadores de núcleo (IP/MPLS);

- Transmissão: dimensionamento dos equipamentos de transmissão e enlaces que interconectam os PoPs de núcleo, utilizando as tecnologias tradicionais de transmissão.

\subsection{4 Infra-estrutura de rede nos nós de serviço}

Além da determinação da arquitetura da rede em seus principais segmentos (núcleo, agregação e acesso), é importante ressaltar a necessidade da criação de uma infraestrutura de rede local em cada uma dos nós de serviço (SHE, VHO e VSO) em que haverá injeção de conteúdo na rede.

Desta forma, faz-se necessário o dimensionamento dessa infra-estrutura que interconecta os diversos elementos da plataforma de serviço (servidores de vídeo, codificadores, middleware, DRM, etc.) à rede.

A infra-estrutura de rede local conta, em geral, com switches e elementos voltados à segurança no nível de rede como, por exemplo, proteção de perímetro - conhecidos como firewalls - e combate à intrusão - conhecidos como Intursion Detection System (IDS) e Intrusion Prevention System (IPS). 


\subsection{Infra-estrutura de Gerenciamento}

Depois de realizadas as análises da infra-estrutura de rede e de serviço, deve-se dimensionar a infra-estrutura de gerenciamento que suportará o serviço IPTV no seu dia-a-dia de operação. Conforme ilustrado na seção 2.9, deve-se considerar as principais funções dos sistemas OSS/BSS (Aprovisionamento, Garantia de qualidade, Faturamento e Suporte e Disponibilidade de Operações) para a identificação da necessidade de novas ferramentas, ou atualizações e expansões necessárias nas ferramentas existentes.

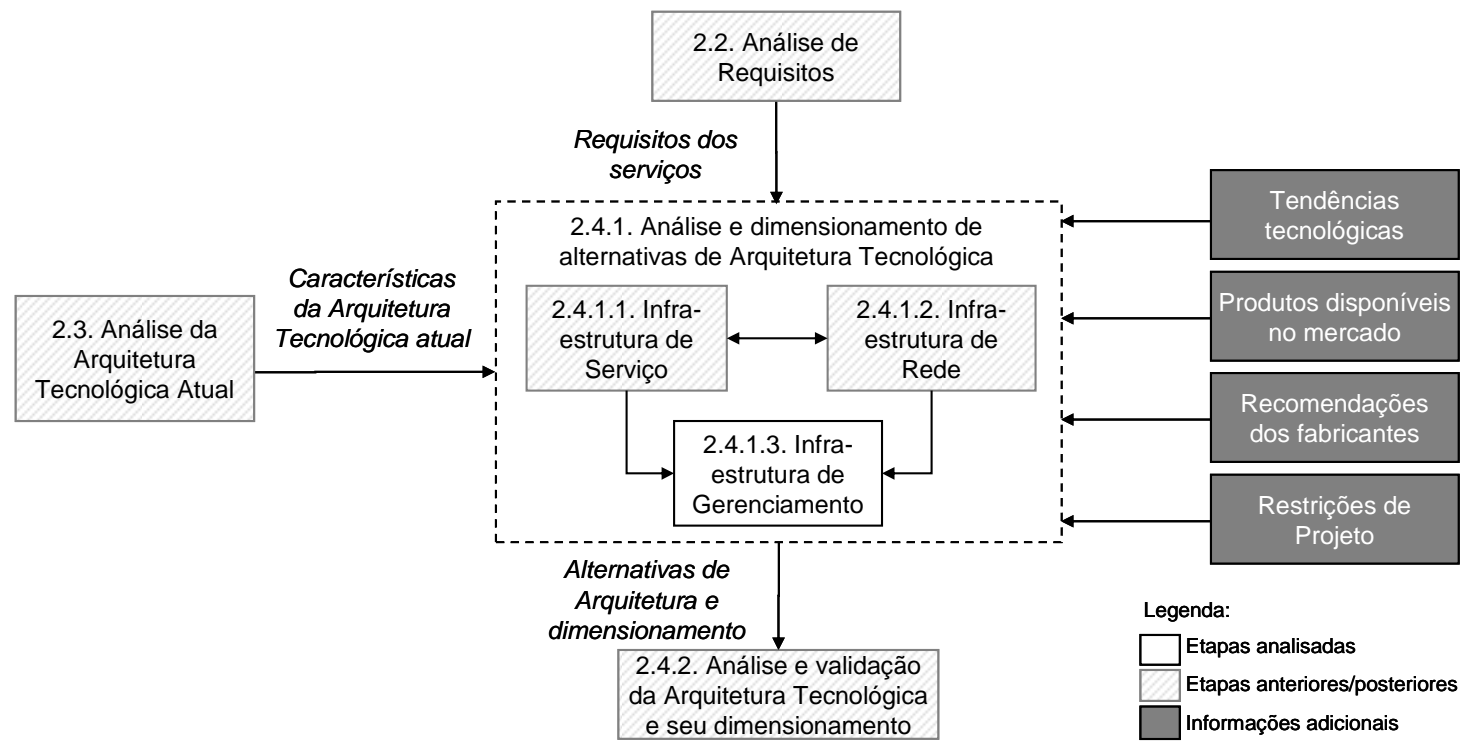

Figura 34 - Etapa de Análise e Dimensionamento - Gerenciamento

Com base na análise da arquitetura atual e nos requisitos do novo serviço, deve-se elaborar um mapa da nova arquitetura de OSS/BSS para suportar o serviço IPTV. Conforme explicitado no item 2.9, a nova arquitetura deverá incluir elementos novos como o monitoramento e gerenciamento de qualidade vídeo e, potencialmente, a criação de um Video Operations Center (VOC) para suportar a operação do serviço. A delimitação do papel do middleware e suas funções voltadas à OSS/BSS é importante na elaboração da arquitetura.

A partir da definição da arquitetura, é possível dimensionar as ferramentas de OSS/BSS incluindo componentes de hardware (infra-estrutura de servidores e armazenamento) e software (conjunto de sistemas de OSS/BSS propriamente ditos). A natureza proprietária das plataformas de OSS/BSS faz com que cada 
implementação seja muito dependente do fornecedor da solução. Desta maneira, o dimensionamento da infra-estrutura necessária e dos sistemas propriamente ditos dependem de cada implementação.

Os principais parâmetros para o dimensionamento dos sistemas de OSS/BSS são:

- Funcionalidades desejadas nas plataformas de gerenciamento;

- Quantidade de assinantes do serviço e quantidade de pontos por assinante;

- Quantidade de administradores de rede que utilizarão os sistemas.

\subsection{Análise e validação da arquitetura e dimensionamento}

O final do processo de definição e dimensionamento da arquitetura tecnológica deve passar por uma etapa de análise e validação. Nesta etapa, é realizada a verificação da consistência entre as características e os requisitos de serviço, e a arquitetura tecnológica delineada.

Além do processo de análise tradicional, esta etapa pode contar com recursos de simulação computacional que auxiliam na validação da arquitetura proposta e seu dimensionamento, e verificam se o planejamento de capacidade realizado atende os requisitos de desempenho impostos pelo serviço. 


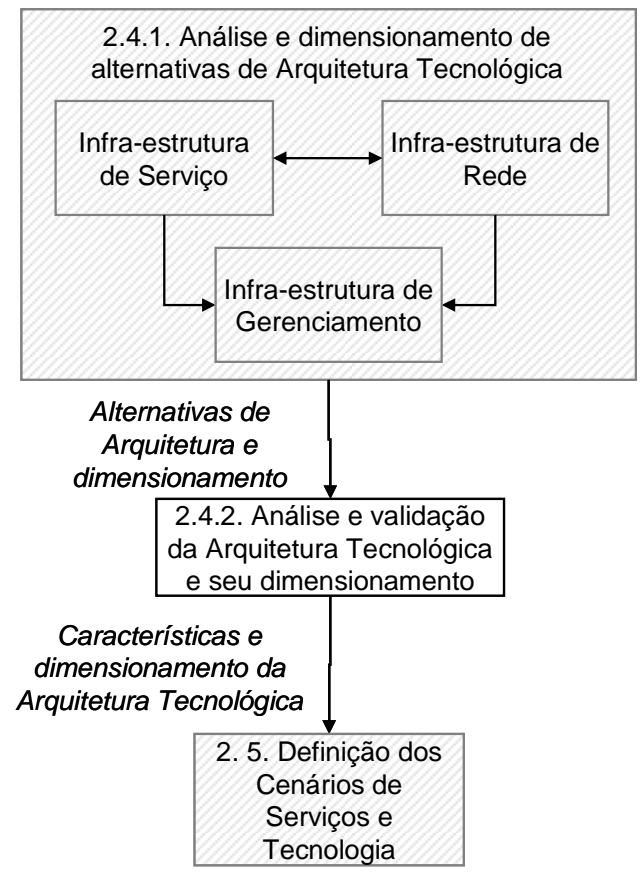

Figura 35 - Etapa de Validação da Arquitetura Tecnológica e Dimensionamento

\subsubsection{Definição dos Cenários de Serviços e Tecnologia}

O processo de modelagem de serviços e tecnologia termina com a combinação das características do serviço e da arquitetura tecnológica. Ou seja, nesta etapa, o serviço definido e suas potenciais variações são combinadas com as arquiteturas tecnológicas selecionadas que o suportam. Por exemplo, a oferta ou não de HDTV implica em decisões relacionadas às tecnologias de acesso que devem ser combinadas para formar cenários distintos. Um outro exemplo diz respeito à decisão de ofertar ou não conteúdo broadcast que implica na inclusão ou exclusão da infraestrutura de head-end como parte da arquitetura tecnológica.

Ao final desta etapa, é obtido um mapa com os principais cenários que servirão de base para a modelagem econômica, incluindo aspectos de serviços e da arquitetura tecnológica e suas principais características. 


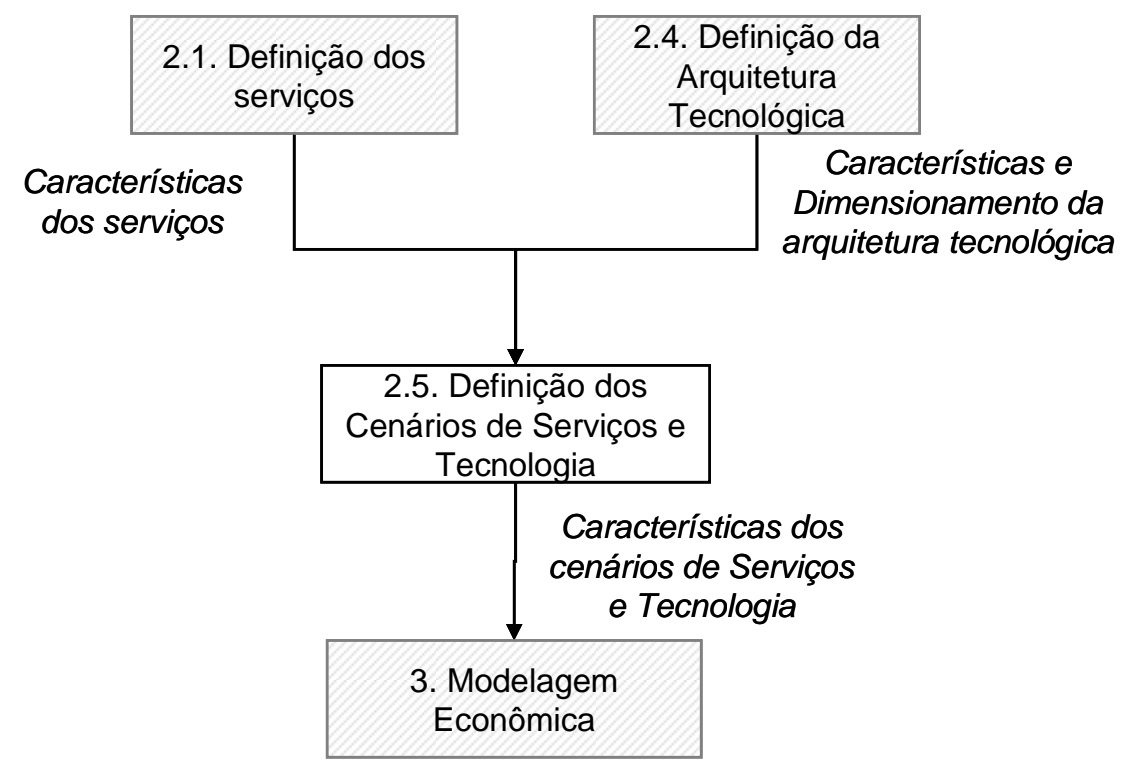

Figura 36 - Etapa de Definição dos Cenários de Serviços e Tecnologia

\subsubsection{Modelagem Econômica}

A modelagem econômica concatena as etapas anteriores visando verificar a viabilidade econômica do serviço proposto e quais as condições em que isso ocorre. É necessário definir qual o horizonte de tempo em que se deseja realizar a avaliação econômica. A modelagem conta com dados de entrada de natureza econômica (ex.: inflação, taxa de câmbio, taxa mínima de atratividade, alíquotas de imposto) e dados da definição dos cenários serviços e arquitetura tecnológica.

A modelagem econômica pode ser dividida nas seguintes etapas conforme ilustrado na Figura 37:

- Receitas: identificação e projeção de receitas associadas aos serviços definidos no item 4.2.2.1;

- Custos e Despesas Operacionais: identificação e projeção dos custos e despesas associados aos serviços definidos no item 4.2.2.1 e à arquitetura tecnológica definida no item 4.2.2.4;

- Investimentos: identificação e projeção dos investimentos, relacionados principalmente à arquitetura tecnológica definida no item 4.2.2.4; 
- Fluxo de caixa: elaboração do fluxo de caixa associado ao projeto com base nos resultados dos itens anteriores e de acordo com as diretrizes do item 3.2.1;

- Indicadores Econômicos: a partir do fluxo de caixa, são obtidos indicadores que permitem avaliar a atratividade do projeto conforme apresentado no item 3.2.3. Nesta metodologia, foram consideradas as métricas de: Valor Presente Líquido (VPL), Taxa Interna de Retorno (TIR) e Período de payback descontado. Adicionalmente, podem ser utilizados indicadores complementares associados visando à comparação dos diversos cenários. Alguns indicadores incluem: receita média por usuário também conhecida como Average Revenue per User (ARPU); e investimento médio por usuário.

Ao final desta etapa, espera-se a obtenção do modelo econômico do serviço e que sintetize todo processo de análise em informações econômicas. 


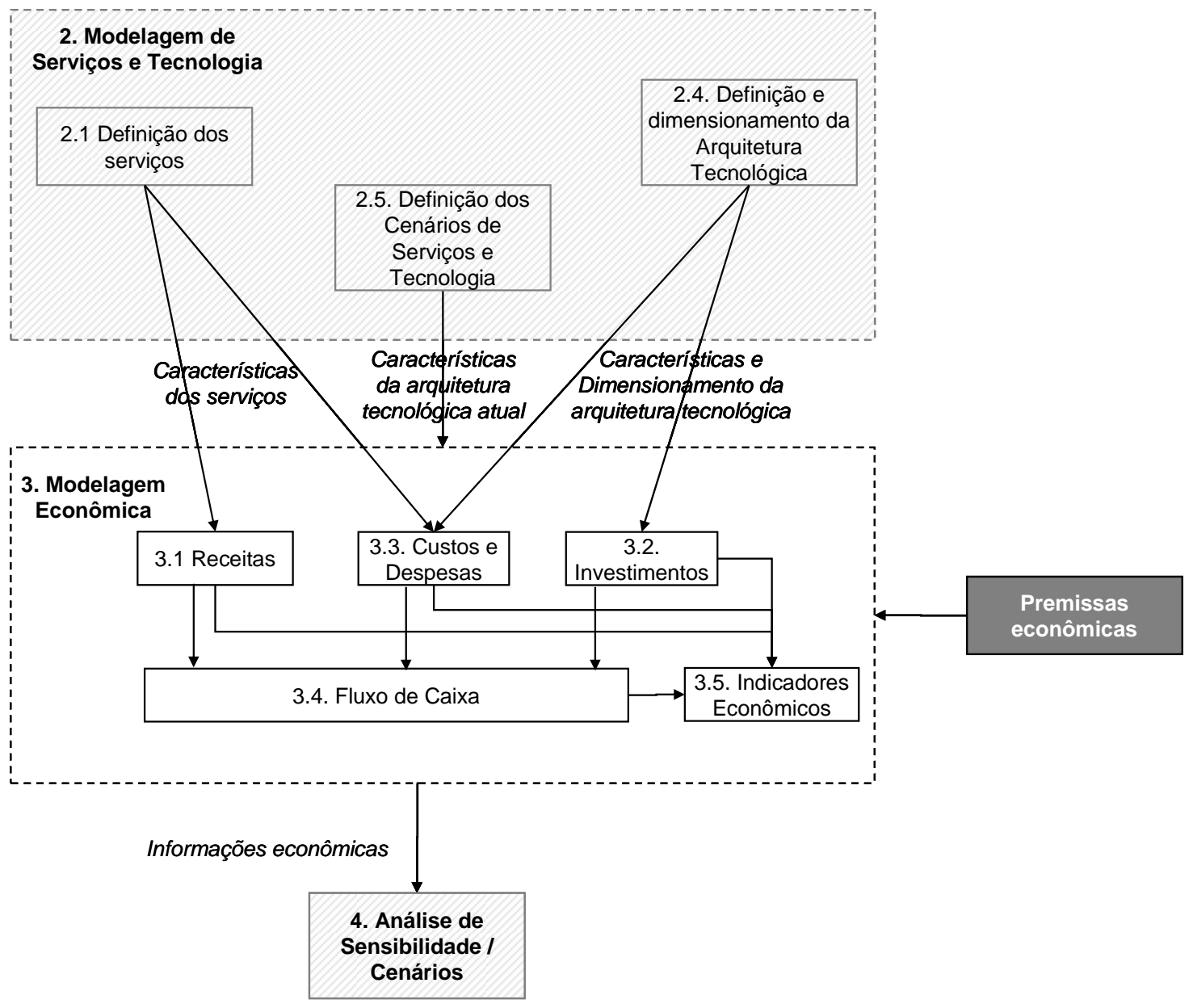

Figura 37 - Etapa de Modelagem Econômica

\subsubsection{Análise de Sensibilidade e Cenários}

A análise técnico-econômica inclui também a etapa de análise de sensibilidade e cenários. A partir dos principais resultados obtidos, é possível realizar as simulações selecionadas a fim de verificar o quão sensíveis os parâmetros de saída são em relação à variação dos principais dados de entrada, e assim realizar uma análise dos riscos e incertezas envolvidos.

Tais análises incluem tipicamente os cenários de serviços e tecnologia definidos e também podem incluir análises adicionais visando identificar aspectos específicos não capturados nos cenários.

Os parâmetros de saída avaliados incluem desde indicadores relacionados à modelagem econômica (ex.: indicadores de atratividade) e também à modelagem 
tecnologia e serviços (tráfego na rede, quantidade de espaço de armazenamento requerido). Os parâmetros de entrada incluem variáveis qualitativas e quantitativas identificadas na etapa de definição dos cenários de serviços e tecnologia.

Ao final desta esta, são obtidos resultados completos da análise técnico-econômica que serão objeto de análise na etapa de Análise de Resultados.

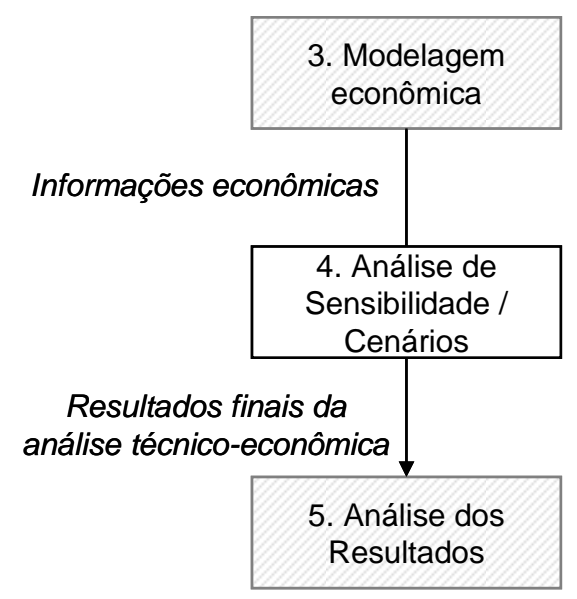

Figura 38 - Etapas de Análise de Sensibilidade / Cenários e Resultados

\subsubsection{Análise de Resultados}

Uma vez realizado todo o processo, desde a modelagem de serviços e tecnologia até a modelagem econômica, é possível realizar a análise dos resultados, extrair conclusões e emitir as recomendações.

É possível verificar se o serviço é viável e em quais cenários, ou seja, é possível determinar as condições de viabilidade tanto do ponto de vista do serviço quanto da arquitetura tecnológica.

A Figura 39 apresenta um mapa completo da metodologia mostrando todas as suas etapas de maneira detalhada. 


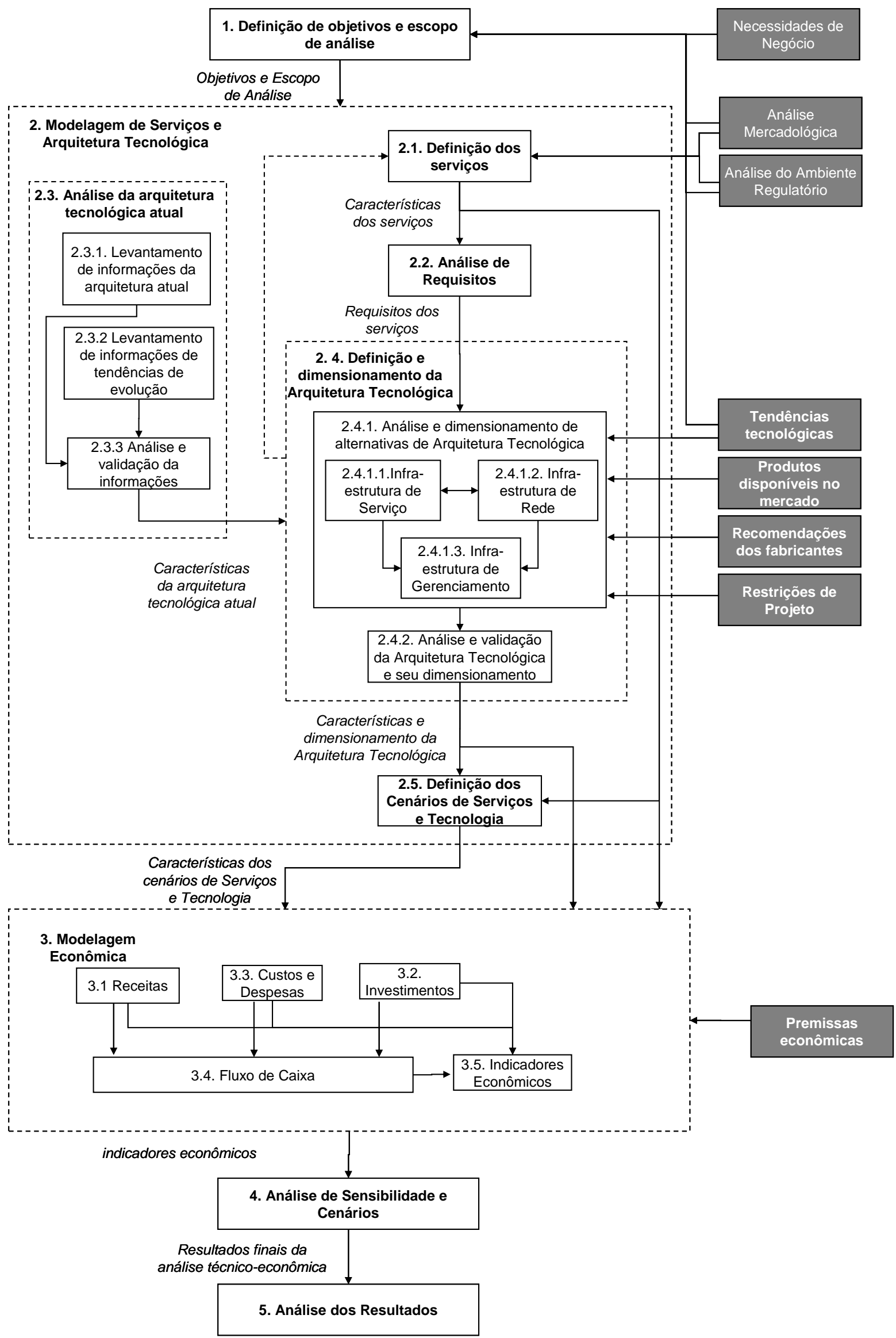

Figura 39 - Metodologia de análise técnico-econômica detalhada 


\section{APLICAÇÃO DA METODOLOGIA PROPOSTA}

A metodologia proposta foi aplicada a um caso de referência representativo da realidade de uma operadora de telecomunicações típica. O caso de referência foi definido a partir de conhecimento teórico e prático a respeito do mercado de telecomunicações.

Através da sua aplicação, deseja-se verificar que a metodologia proposta permite:

- Realizar a avaliação técnico-econômica da introdução de serviços IPTV em uma operadora de telecomunicações de maneira sistemática;

- Determinar as arquiteturas tecnológicas que suportarão o serviço e o seu impacto econômico baseado na análise técnico-econômica de sua viabilidade.

O detalhamento da aplicação da metodologia ao caso de referência e a avaliação da metodologia estão apresentados a seguir.

\subsection{ETAPAS DA METODOLOGIA E RESULTADOS}

A análise do caso foi realizada segundo a metodologia definida no Capítulo 4. Maiores detalhes estão referenciados nas etapas da metodologia e complementados com informações adicionais no Apêndice B.

\subsubsection{Definição de Objetivos e Escopo da Análise}

O caso de referência escolhido para aplicar a metodologia diz respeito a uma operadora de telefonia fixa fictícia denominada $A C M E$ que já presta serviços de telefonia e de acesso à Internet em um país com características similares ao Brasil. Atualmente, conta com aproximadamente 2 milhões de assinantes de telefonia, 1 milhão de Internet banda estreita e 350 mil de Internet banda larga. As operações da ACME estão divididas em cinco grandes regiões de características urbana. 
Devido às ameaças das operadoras de TV a cabo, a operadora está avaliando a oferta integrada de telefonia, Internet Banda Larga e TV Paga. A ACME já possui uma infra-estrutura de rede IP e poderia complementar sua oferta atual com serviços IPTV utilizando sua rede. A equipe da ACME já conduziu análises mercadológicas e do ambiente regulatório que fornecem subsídios para a análise da introdução do novo serviço.

Neste contexto, necessita realizar uma análise técnico-econômica da oferta de serviços IPTV com o objetivo de verificar a viabilidade econômica de acordo com características do serviço e sua arquitetura tecnológica.

O escopo das análises compreende as atividades definidas na metodologia descrita no item 4.2. Como suporte do processo de análise foi utilizada uma ferramenta baseada em planilhas eletrônicas para suportar o dimensionamento e modelagem econômica deste caso. O período de análise considerado diz respeito a um horizonte de tempo de 10 anos. Informações mais detalhadas acerca dos objetivos e escopo da análise estão apresentadas no item B.1.

\subsubsection{Modelagem de Serviços e Tecnologia}

\subsubsection{Definição dos Serviços}

Para a execução desta etapa da metodologia em um caso real seria necessária a realização de uma análise regulatória e mercadológica que serviriam como dados de entrada da metodologia conforme ressaltado no item 4.2.2.1. Para o caso ACME, assume-se que tais análises foram realizadas e os parâmetros necessários à execução da metodologia foram estimados com base em referências de mercado. No que diz respeito aos parâmetros mercadológicos tais como as principais características do serviço, perfis de utilização, modelo de precificação e níveis de preço, foram utilizadas referências de operadoras que já implantaram serviços similares no exterior e também referências do mercado local de TV paga para sua determinação. Para o ambiente regulatório, o marco regulatório brasileiro foi utilizado como referência. 
A operadora ACME deverá oferecer serviços IPTV voltados para serviços de vídeo em um primeiro momento. A operadora não realizará funções de produção ou agregação de conteúdo e deverá se posicionar como distribuidora de conteúdo. O serviço IPTV deverá incluir dois elementos principais:

- Broadcast: 200 canais (SDTV: 130 / HDTV:70)

- Vídeo armazenado:

- VOD: 2.000 títulos (SDTV: 1400 / HDTV: 600)

- PVR integrado ao set-top box do usuário

Pesquisas de mercado indicaram que a ACME tem potencial capturar em torno de 500.000 assinantes IPTV no longo prazo, o que representa aproximadamente $30 \%$ dos assinantes banda larga previstos para o mesmo horizonte de tempo. Entretanto, esta projeção pode variar bastante: desde estimativas conservadoras de 100.000 usuários até mais agressivas de 1.000.000.

Existem condições regulatórias locais que podem restringir a oferta de broadcast. A oferta de VOD ainda é bastante embrionária no seu mercado e a perspectiva de adoção pode variar bastante. Além disso, existem movimentações no mercado local acelerando a oferta de conteúdo em HDTV pelos provedores de TV paga e TV aberta, o que pode impulsionar sua adoção. Apesar disso, existe bastante incerteza acerca de sua perspectiva de adoção.

Os detalhes das características do serviço, modelo de precificação, modelo de negócios, projeção de assinantes, perfil de utilização e características dos cenários de serviços podem ser encontrados no item B.2.1. As principais alternativas de cenários de serviços identificadas incluem:

- Adoção do serviço: pode variar de conservadora até agressiva.

- Broadcast / VOD: o mais provável é que aconteça a oferta de broadcast + VOD, e deve-se considerar grande incerteza quanto à adoção de VOD. Existe também possibilidade de existir a oferta de cada serviço isoladamente.

- SDTV / HDTV: o mais provável é que aconteça a oferta de SDTV + HDTV, mas a adoção de HDTV ainda é sujeita a grande incerteza. A ACME considera ainda a possibilidade de ofertar apenas SDTV. 
- Modalidade de oferta do set-top box: as modalidades vislumbradas incluem os casos em que o usuário compra o set-top box ou a operadora fornece o aparelho em regime de comodato. É mais provável que a segunda modalidade ocorra devido às condições de oferta de TV paga do mercado local em que o set-top box já é oferecido sem custo adicional ao assinante.

\subsubsection{Análise de Requisitos}

Com base nas principais características do serviço, os principais requisitos foram identificados e mapeados nas seguintes categorias: funcionalidades; capacidade e escalabilidade; desempenho; disponibilidade / confiabilidade; segurança; gerenciabilidade; usabilidade; e adaptabilidade. O mapeamento detalhado dos requisitos ao longo dessas categorias está apresentado no item B.2.2.

\subsubsection{Análise da Arquitetura Tecnológica Atual}

A ACME já possui uma infra-estrutura de rede consolidada para suportar os serviços de comunicação IP. Os serviços suportados pela infra-estrutura IP são os seguintes:

- Internet discada

- Internet banda larga (250 kbps, 500 kpbs, 1 Mbps, 2 Mbps, 4Mbps e 8 Mbps)

- Serviços Corporativos

- Acesso IP dedicado

- Conectividade LAN-to-LAN sobre Ethernet

- Redes virtuais privativas sobre IP/MPLS, conhecidas como Virtual Private Networks (VPNs)

O detalhamento da quantidade de portas e do tráfego gerado por cada serviço está apresentado no item B.2.3.1.1.1. 
A arquitetura de rede da ACME para suportar tais serviços está ilustrada na Figura 40. A arquitetura ilustrada é conceitual e os elementos ressaltados são voltados para a prestação de serviços de Internet banda larga e serviços IP, e são os elementos mais relevantes na avaliação da introdução serviço IPTV.

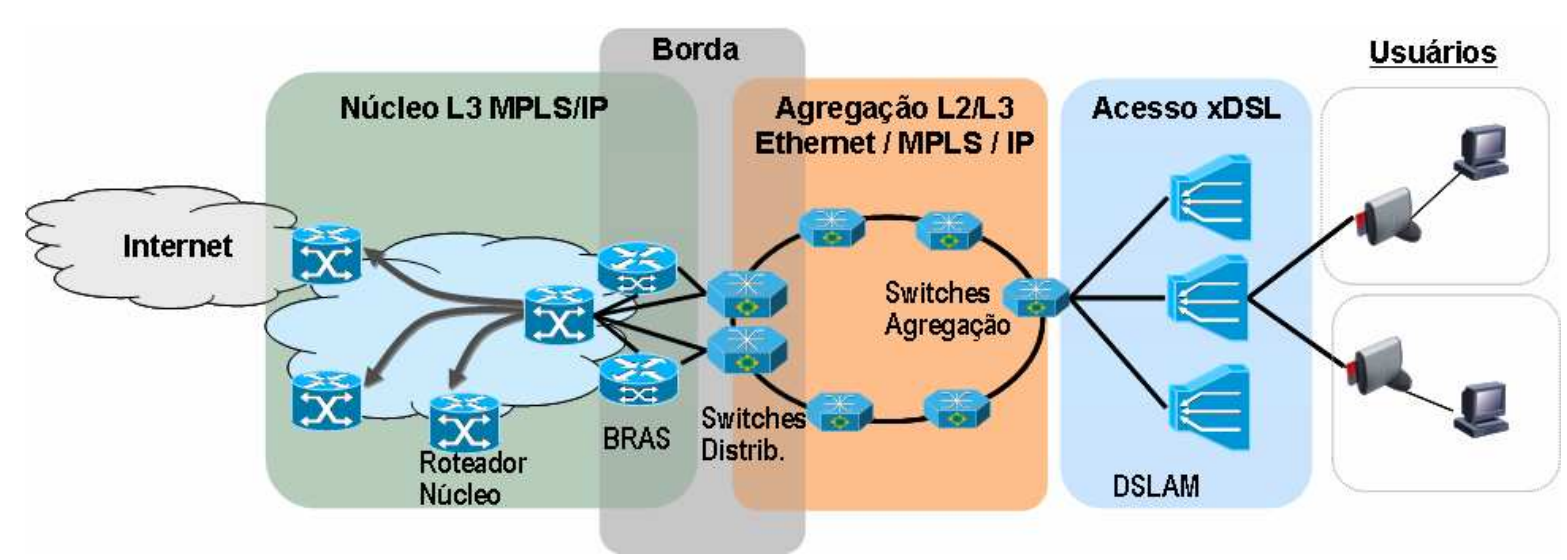

Figura 40 - Arquitetura da Rede IP: ACME

A rede conta com os blocos tradicionais de uma rede IP: núcleo, agregação e acesso. Uma breve descrição de cada segmento está apresentada a seguir. Maiores detalhes a respeito de cada segmento da rede podem ser encontrados no item B.2.3.1.1.

- Núcleo: implementado em camada 3 utilizando tecnologia IP/MPLS. Conta com cinco PoPs, um em cada região onde a ACME atua, sendo que existe saída para Internet apenas nos dois POPs que concentram maior parte dos assinantes. Os PoPs são interconectados entre si através de uma rede de transmissão óptica que utiliza tecnologia DWDM (vide item B.2.3.1.1.2).

- Agregação: rede ambivalente Camada 2 / Camada 3 utilizando tecnologia Ethernet/IP. É capaz de implementar serviços nas duas camadas dependendo das características do serviço. É implementada em topologia de anéis concêntricos que são terminados nos PoPs de núcleo. A conexão entre os PoPs de agregação e realizada utilizando fibra apagada. A inteligência dos serviços está concentrada na borda da rede e o B-RAS centraliza a inteligência do serviço de Internet Banda Larga (vide item B.2.3.1.1.3).

- Acesso: rede de acesso baseada em cobre e utiliza a tecnologia ADSL. Os DSLAMs utilizados na rede são da modalidade predial e estão localizados nos 
prédios de central (arquitetura FTTN tradicional). Nas áreas de maior concentração de assinantes, os switches de agregação e DSLAMs coexistem no mesmo prédio (vide item B.2.3.1.1.4).

Além do levantamento de informações a respeito da rede, foram identificados os principais sistemas de OSS/BSS utilizados pela ACME segundo as grandes áreas do modelo de referência do eTOM (Aprovisionamento, Garantia de Qualidade, Faturamento, e Suporte e Disponibilidade de Operações) e seu detalhamento está apresentado no item B.2.3.1.2.

Ao final, foram mapeadas as principais tendências de evolução no âmbito de rede e sistemas de OSS/BSS conforme detalhado no item B.2.3.2.

\subsubsection{Definição e Dimensionamento de Arquitetura Tecnológica}

Considerando a arquitetura atual da rede e sistemas da operadora ACME e as localidades em que o serviço IPTV será prestado, a infra-estrutura tecnológica necessária, as principais alternativas e o seu dimensionamento estão apresentados a seguir. Ao final desta etapa, dispõe-se de informações necessárias à composição dos cenários de serviços e de tecnologia para realizar a modelagem econômica.

\subsection{Análise e dimensionamento de alternativas de arquitetura tecnológica}

Esta etapa foi realizada conforme indicado o item 4.2.2.4.1 da metodologia proposta. Ela se inicia a partir da infra-estrutura de serviço, passa pela a rede para então chegar às plataformas de gerenciamento. Os principais resultados estão apresentados a seguir e maiores detalhes a respeito de cada premissa e análise realizada podem ser encontrados no item B.2.4.1. 


\subsection{Infra-estrutura de Serviço}

A arquitetura que suportará o serviço IPTV da ACME contará com a estrutura básica de 1 SHE que estará localizado na região 1, que concentra a maior parte dos assinantes. Existirão também 4 VHOs nas regiões 2, 3, 4 e 5 que recebem conteúdo do SHE, e onde é inserido conteúdo e propaganda local das respectivas regiões. Os SHEs e VHOs estão fisicamente localizados nas mesmas localidades dos PoPs de núcleo da rede IP/MPLS. A quantidade de VSOs é equivalente à quantidade de PoPs da rede de agregação. A Figura 41 mostra a arquitetura da solução em linhas gerais.

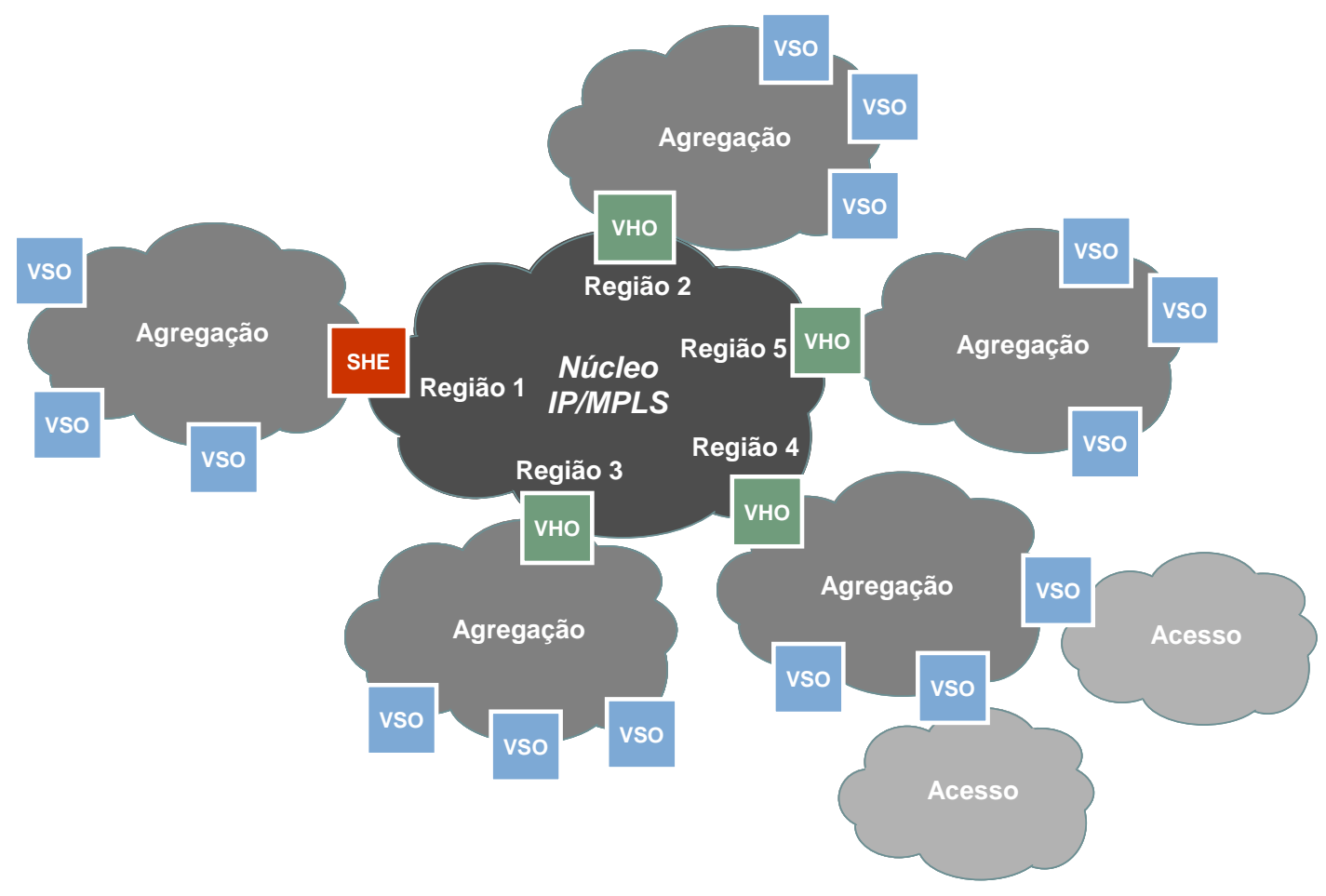

Figura 41 - Arquitetura da solução de IPTV - ACME

A seguir estão apresentadas as principais considerações relacionadas à infraestrutura de serviço no caso ACME considerando seus principais elementos:

- Sistemas de Head-end: com base na quantidade de canais definida e padrão de qualidade (HDTV / SDTV) associado aos canais foram dimensionados os sistemas de recepção e de processamento que estarão localizados no SHE e VHOs. A arquitetura do head-end é impactada pelos cenários de oferta SDTV / 
HDTV. Os detalhes da arquitetura e dimensionamento dos sistemas de headend estão descritos no item B.2.4.1.1.1.

- Recepção: o conteúdo broadcast será recebido via satélite, terrestre (VHF/UHF) e fibra óptica. Apenas no SHE haverá a recepção de conteúdo via satélite que corresponde ao conteúdo de caráter nacional e será retransmitido aos VHOs através da rede IP. Canais locais são recebidos tanto no SHE e VHO através de VHF/UHF e fibra óptica.

- Processamento: o padrão de codificação adotado foi o MPEG-4 AVC, que norteará o dimensionamento da largura de banda necessária para a transmissão dos streams de vídeo. As partes integrantes do bloco de processamento foram determinadas com base na quantidade e tipos de canais. Considerou-se também a utilização de um switch de vídeo e plataforma para inserção de conteúdo VOD.

- Middleware: a plataforma de middleware foi dimensionada com base em seus requisitos de funcionalidades e a quantidade de assinantes. Os detalhes dos parâmetros utilizados para dimensionamento estão apresentados no item B.2.4.1.1.2.

- DRM: a plataforma de DRM considerada na arquitetura da ACME é baseada em virtual smart cards. Seu dimensionamento foi realizado com base em seus requisitos de funcionalidades e quantidade de assinantes. Os detalhes dos parâmetros utilizados para dimensionamento estão apresentados no item B.2.4.1.1.3.

- Servidores de vídeo: para o caso da ACME, foram consideradas três arquiteturas possíveis de distribuição de conteúdo de vídeo conforme descrito a seguir. $\mathrm{O}$ dimensionamento de cada arquitetura e exemplos do seu impacto no tráfego da rede estão detalhados no item B.2.4.1.1.4. Além das alternativas de arquitetura, o nível de adoção do serviço IPTV e o grau de adoção de serviços VOD impactam diretamente o dimensionamento dos servidores de vídeo.

- Centralizada no SHE: todo o conteúdo fica armazenado apenas no SHE, todas as requisições são atendidas por ele e todos streams de VOD passam pelo núcleo e agregação; 
- Distribuída até o VHO: o SHE armazena 100\% do conteúdo e o conteúdo mais popular fica replicado nos VHOs onde grande parte das requisições são atendidas, diminuindo o tráfego no núcleo;

- Distribuída até o VSO: o SHE ainda continua como ponto de injeção de conteúdo e armazena $100 \%$ do conteúdo, mas não atende mais requisições de usuários, pois funciona apenas como ponto único de injeção e $100 \%$ do conteúdo é replicado para cada VHO. O conteúdo mais popular fica replicado nos VSOs que atende a maior parte das requisições. Dessa forma, o tráfego no núcleo é praticamente nulo e o tráfego na agregação também fica bastante diminuído.

- Set-top box: a qualidade do sinal a ser recebido pelo assinante (SDTV / HDTV), o padrão de codificação e a adição de funcionalidades de PVR são os principais fatores que influenciam o dimensionamento dos set-top boxes. Além disso, existe o fator de reaproveitamento dos set-top boxes dos assinantes que desistem do serviço no cenário em que o aparelho é cedido em regime de comodato. Maiores detalhes a respeito do dimensionamento dos set-top boxes, exemplos da composição de tipos de aparelhos e do efeito da recuperação de set-top boxes já utilizados fazem parte do item B.2.4.1.1.5

\subsection{Infra-estrutura de Rede}

A análise da arquitetura e dimensionamento da rede depende diretamente da caracterização do tráfego e é realizada a partir do acesso em direção ao núcleo.

Os dois principais serviços IPTV considerados na caracterização do tráfego IPTV no caso da ACME são: VOD e canais broadcast. O dimensionamento do tráfego dos serviços VOD e broadcast foi realizado para cada segmento da rede com base nas diretrizes indicadas no item 4.2.2.4.1.2 da metodologia proposta e levou em consideração a qualidade do conteúdo transmitido (SDTV / HDTV).

A Figura 42 e a Figura 43 ilustram o tráfego total na rede relacionado aos serviços VOD e broadcast no cenário base. Observa-se que o tráfego VOD na rede é bastante superior ao tráfego dos canais broadcast, devido à otimização conferida 
pelo o mecanismo de replicação multicast associado ao tráfego dos canais de programação. Além disso, apesar da pequena proporção de conteúdo transmitido em HDTV (vide item B.2.1.1) e de assinantes que contratam essa modalidade de serviço (vide item B.2.1.5), seu perfil de tráfego é bastante relevante quando comparado ao tráfego total. 
Tráfego do serviço VOD: SDTV e HDTV

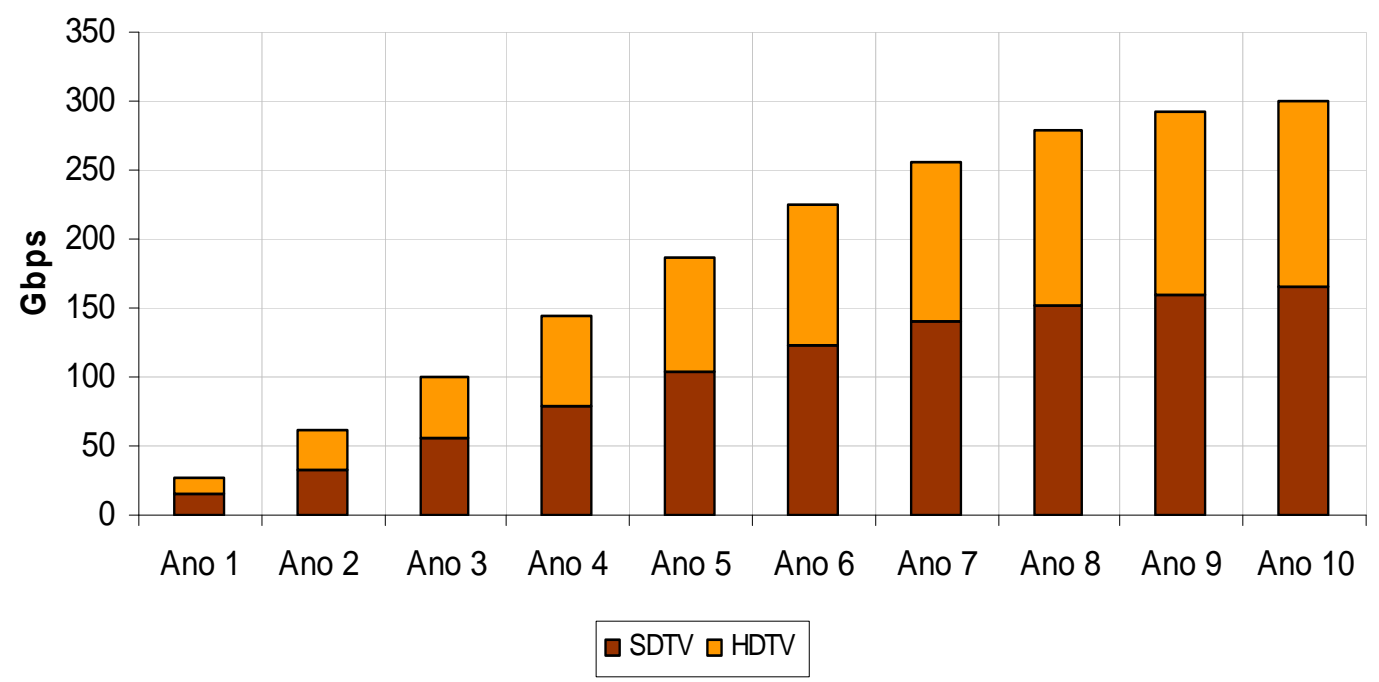

Figura 42 - Tráfego IPTV: Serviço VOD

\section{Tráfego do serviço broadcast: SDTV e HDTV}

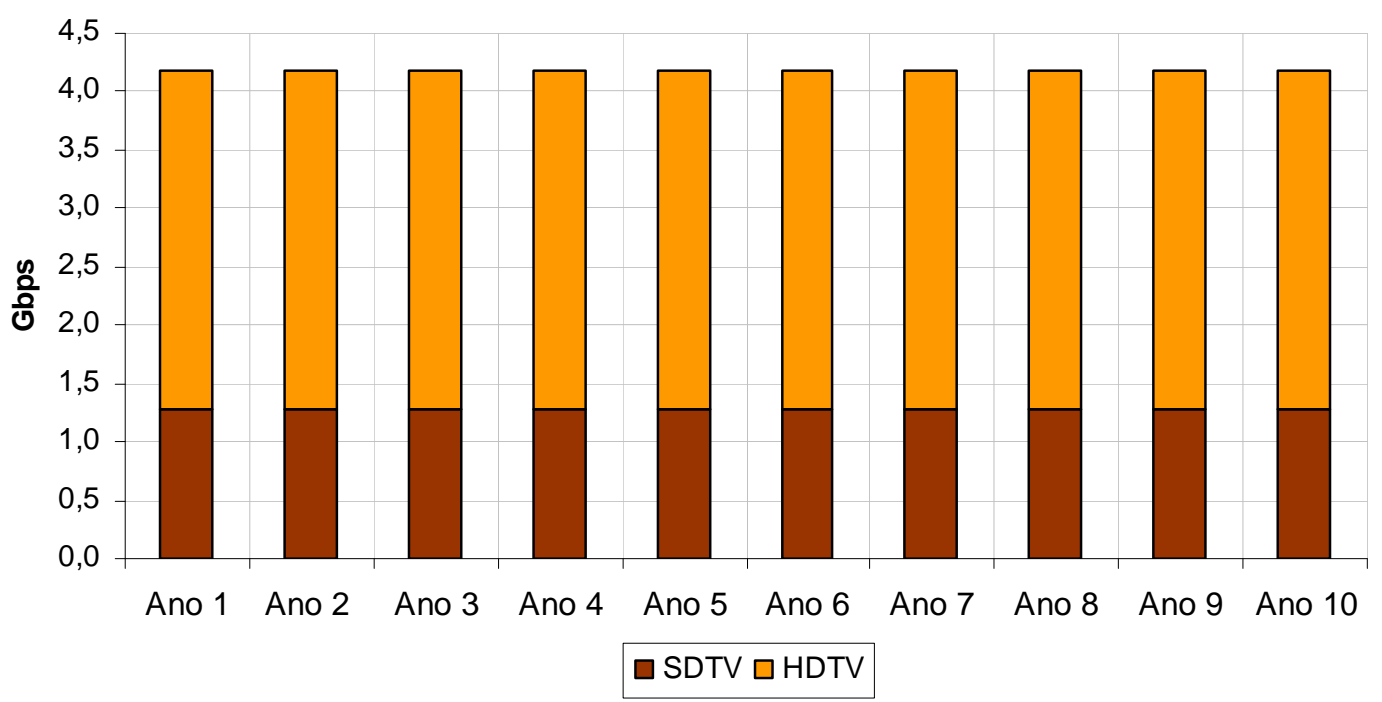

Figura 43 - Tráfego IPTV: Serviço broadcast 
A soma do tráfego VOD e broadcast resulta no tráfego total associado ao serviço IPTV, que pode ser comparado com os demais serviços presentes na rede, conforme apresentado na Figura 44. Nota-se que o tráfego referente ao serviço IPTV no cenário base é equivalente ao tráfego de todos os outros serviços IP da ACME, evidenciando o impacto que o lançamento de um novo serviço de vídeo tem na infraestrutura de uma operadora.

\section{Tráfego Total}

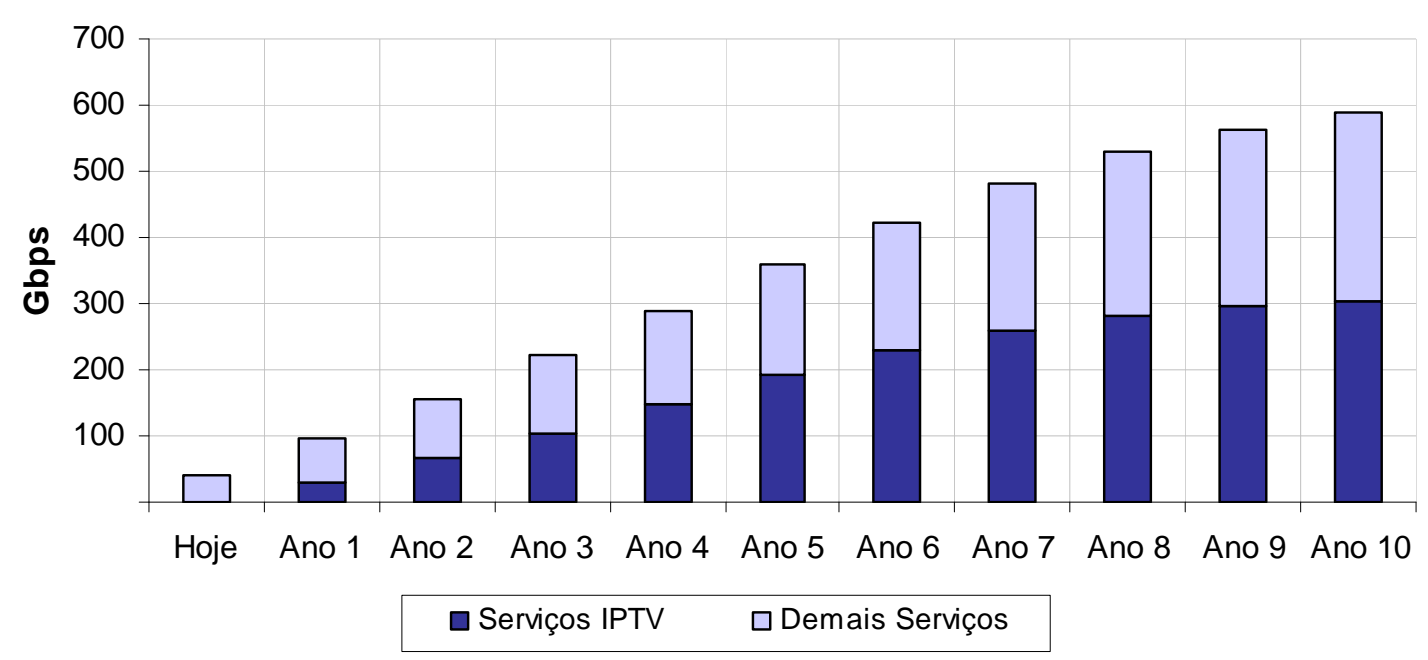

Figura 44 - Tráfego total na rede

Uma vez realizada a caracterização do tráfego, foram delineadas as alternativas tecnológicas em cada segmento de rede e realizado seu dimensionamento. Os principais parâmetros utilizados para o dimensionamento da rede foram: largura de banda necessária e quantidade de portas. A premissa que suporta 0 dimensionamento é que, havendo banda disponível, existem mecanismos que asseguram a qualidade de serviço e de experiência ao usuário, conforme discutido no item 2.8.3.2.

A seguir encontram-se as principais considerações relacionadas a cada segmento de rede na ordem em que foram analisados: acesso, agregação e núcleo. Maiores detalhes a respeito do tráfego, arquitetura e dimensionamento de cada uma delas podem ser encontrados no item B.2.4.1.2.

- Acesso: a partir das análises de perfis da utilização de serviços pelo assinante e a adequação das diversas tecnologias de acesso são 
consideradas alternativas para cada tipo de perfil de assinante. As análises de perfil utilização de serviços e dimensionamento de cada alternativa estão detalhadas no item B.2.4.1.2.1.

- Assinantes SDTV: manutenção da arquitetura FTTN, utilizando ADSL2+;

- Assinantes HDTV: introdução da arquitetura FTTCab, utilizando VDSL2. Entretanto, visando maior escalabilidade futura na oferta de maiores velocidades de acesso e mais pontos de televisão em HDTV, arquiteturas de FTTH também foram consideradas como cenários alternativos.

- Agregação: o modelo de agregação considerado para a ACME leva em conta uma rede Ethernet/IP capaz de implementar serviços em camada 2 ou 3. Sendo assim, o serviço de vídeo será implementado em camada 3 se valendo dos mecanismos de IP multicast, e da inteligência de serviços distribuída na rede. O serviço de Internet banda larga continua implementado em camada 2 e centralizado no B-RAS. Possíveis evoluções também podem incluir a distribuição da inteligência do serviço banda larga. Os detalhes a respeito do dimensionamento de tráfego que orienta o dimensionamento dos enlaces e elementos de rede estão apresentados no item B.2.4.1.2.2.

- Núcleo: para distribuir o conteúdo do SHE para os VHOs do sistema sobre o núcleo IP/MPLS da ACME, considera-se a utilização do mecanismo multicast visando otimizar os recursos da rede. Combinando o emprego de multicast aos esquemas de distribuição de conteúdo, nota-se que o impacto do serviço IPTV sobre o núcleo é sensivelmente menor quando comparado à rede de agregação no cenário base. $\mathrm{O}$ item B.2.4.1.2.3 detalha o volume de tráfego que serve como base para dimensionamento dos enlaces e elementos de rede.

Além do delineamento e dimensionamento da rede em seus diversos segmentos, foi considerada a criação de uma infra-estrutura de rede local em cada nó de serviço onde existe a injeção de conteúdo na rede (SHE e VHO). 


\subsection{Infra-estrutura de Gerenciamento}

Com relação à arquitetura de gerenciamento associada ao serviço, considerou-se que as novas funções requeridas são oferecidas pelo sistema de gerenciamento associado ao middleware, e pela adoção de um sistema de monitoramento de vídeo fim-a-fim que permeia desde a camada de rede até o serviço (vídeo).

Além disso, considerou-se a criação de um Video Operations Center (VOC) para suportar a operação contínua do serviço em analogia à estrutura de Network Operations Center (NOC) existente para os serviços de comunicação tradicionais. O VOC é responsável pela garantia de QoE do serviço e se vale das diversas ferramentas de gerenciamento para isso.

\subsection{Análise e validação da arquitetura e dimensionamento}

Para a condução das análises do caso ACME, supõe-se que o dimensionamento realizado atende aos requisitos identificados conforme mapeamento realizado no item 5.1.2.2. Supõe-se que os mecanismos de QoS (diferenciação de serviços e controle de admissão) empregados na rede e os demais mecanismos de monitoramento suportados pelas ferramentas de gerenciamento voltadas à garantia de qualidade de vídeo, permitem que os requisitos de QoE do serviço sejam devidamente atingidos. Tal validação poderia ser incrementada com a utilização de ferramentas de simulação para suportar a análise de desempenho versus planejamento de capacidade.

\subsubsection{Definição dos Cenários de Serviços e Tecnologia}

O objetivo da etapa é a definição detalhada de quais cenários que servirão de entrada para a modelagem econômica e, em seguida, servirão de base para a análise de sensibilidade e cenários. Tais cenários visam capturar o efeito das 
principais variáveis que influenciam a os serviços, a arquitetura tecnológica e o desempenho econômico relacionados à oferta de IPTV da ACME.

A partir da definição de serviços e da arquitetura tecnológica nos itens 5.1.2.1 e 5.1.2.4, respectivamente, foi possível capturar quais as principais variáveis para o caso da ACME. As variáveis podem ser de natureza qualitativa ou quantitativa. No caso das variáveis quantitativas, foram consideradas três condições de cenário possíveis: conservador, moderado e agressivo. Os principais cenários que se delineiam a partir da análise do caso estão apresentados a seguir e consolidados na Tabela 8. A partir de um cenário base que caracteriza uma situação típica, deriva-se os diversos cenários que caracterizam os efeitos de uma variável. Cada cenário é determinado por valores distintos de uma variável, mantendo as demais variáveis inalteradas visando obter-se uma mesma base para comparação. As categorias de cenários considerados são:

- Cenário base: em que são satisfeitas as características da situação típica do serviço;

- Perfil de adoção do serviço IPTV: desde conservador até agressivo;

- Oferta de broadcast e/ou VOD: a composição da oferta pode variar devido às potenciais restrições regulatórias e os cenários devem contemplar as incertezas a respeito do perfil de adoção e utilização do serviço VOD;

- Oferta de conteúdo em qualidade SDTV e HDTV: a composição da oferta pode variar devido a pressões mercadológicas e os cenários devem contemplar incertezas a respeito da perspectiva de adoção de HDTV;

- Modalidade de oferta set-top box: oferta de set-top box para os assinantes na modalidade de comodato ou compra;

- Distribuição de conteúdo: a arquitetura de distribuição de conteúdo VOD pode variar em nível de centralização e afeta diretamente o tráfego na rede;

- Tecnologia de rede de acesso: a largura de banda no acesso é uma das principais restrições ao serviço IPTV e, em especial, para os usuários de HDTV. Diversas arquiteturas baseadas em FTTH podem endereçar esta questão. 
Tabela 8 - Cenários de Serviços e Tecnologia - IPTV ACME

\begin{tabular}{|c|c|c|c|c|c|c|c|c|c|}
\hline & & 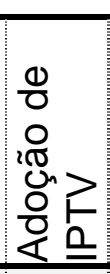 & 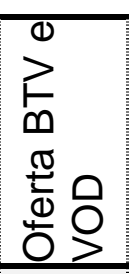 & 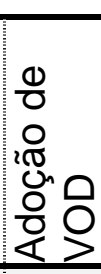 & 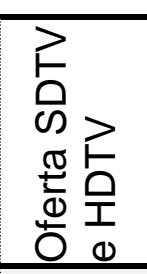 & 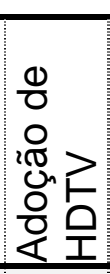 & $\begin{array}{l}x \\
8 \\
0 \\
0 \\
\frac{1}{0} \\
\frac{1}{0} \\
0\end{array}$ & 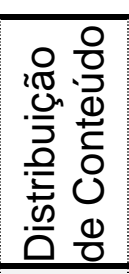 & 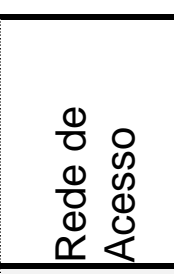 \\
\hline 1 & Cenário Base & & & & & & & & \\
\hline 1.1 & Situação típica & M & $\begin{array}{l}\text { BTV } \\
\text { VOD }\end{array}$ & M & $\begin{array}{l}\text { SDTV } \\
\text { HDTV }\end{array}$ & M & Operadora & $\mathrm{VHO}$ & $\begin{array}{r}\text { FTTN } \\
\text { FTTCab } \\
\end{array}$ \\
\hline 2 & Adoção de IPTV & & & & & & & & \\
\hline 2.1 & $\begin{array}{l}\text { Adoção } \\
\text { agressiva }\end{array}$ & A & $\begin{array}{l}\text { BTV } \\
\text { VOD }\end{array}$ & M & $\begin{array}{l}\text { SDTV } \\
\text { HDTV }\end{array}$ & M & Operadora & $\mathrm{VHO}$ & $\begin{array}{l}\text { FTTN } \\
\text { FTTCab }\end{array}$ \\
\hline 2.2 & $\begin{array}{l}\text { Adoção } \\
\text { conservadora }\end{array}$ & $\mathrm{C}$ & $\begin{array}{l}\text { BTV } \\
\text { VOD }\end{array}$ & M & $\begin{array}{l}\text { SDTV } \\
\text { HDTV }\end{array}$ & M & Operadora & $\mathrm{VHO}$ & $\begin{array}{l}\text { FTTN } \\
\text { FTTCab }\end{array}$ \\
\hline 3 & HDTV & & & & & & & & \\
\hline 3.1 & $\begin{array}{l}\text { Adoção HDTV } \\
\text { Conservadora }\end{array}$ & M & $\begin{array}{l}\text { BTV } \\
\text { VOD }\end{array}$ & M & $\begin{array}{l}\text { SDTV } \\
\text { HDTV }\end{array}$ & C & Operadora & $\mathrm{VHO}$ & $\begin{array}{l}\text { FTTN } \\
\text { FTTCab }\end{array}$ \\
\hline 3.2 & $\begin{array}{l}\text { Adoção HDTV } \\
\text { Agressiva }\end{array}$ & M & $\begin{array}{l}\text { BTV } \\
\text { VOD }\end{array}$ & M & $\begin{array}{l}\text { SDTV } \\
\text { HDTV }\end{array}$ & A & Operadora & VHO & $\begin{array}{l}\text { FTTN } \\
\text { FTTCab }\end{array}$ \\
\hline 3.3 & $\begin{array}{l}\text { Apenas SDTV } \\
\text { (sem HDTV) }\end{array}$ & M & $\begin{array}{l}\text { BTV } \\
\text { VOD }\end{array}$ & $\mathrm{M}$ & SDTV & M & Operadora & $\mathrm{VHO}$ & FTTN \\
\hline 4 & VOD & & & & & & & & \\
\hline 4.1 & $\begin{array}{l}\text { Adoção VOD } \\
\text { Conservadora }\end{array}$ & M & $\begin{array}{l}\text { BTV } \\
\text { VOD }\end{array}$ & C & $\begin{array}{l}\text { SDTV } \\
\text { HDTV }\end{array}$ & M & Operadora & $\mathrm{VHO}$ & $\begin{array}{c}\text { FTTN } \\
\text { FTTCab }\end{array}$ \\
\hline 4.2 & $\begin{array}{l}\text { Adoção VOD } \\
\text { Agressiva }\end{array}$ & M & $\begin{array}{l}\text { BTV } \\
\text { VOD }\end{array}$ & A & $\begin{array}{l}\text { SDTV } \\
\text { HDTV }\end{array}$ & M & Operadora & $\mathrm{VHO}$ & $\begin{array}{l}\text { FTTN } \\
\text { FTTCab }\end{array}$ \\
\hline 4.3 & Sem VOD & M & BTV & M & $\begin{array}{l}\text { SDTV } \\
\text { HDTV }\end{array}$ & M & Operadora & $\mathrm{VHO}$ & $\begin{array}{l}\text { FTTN } \\
\text { FTTCab }\end{array}$ \\
\hline 4.4 & Apenas VOD & M & VOD & M & $\begin{array}{l}\text { SDTV } \\
\text { HDTV }\end{array}$ & M & Operadora & $\mathrm{VHO}$ & $\begin{array}{l}\text { FTTN } \\
\text { FTTCab }\end{array}$ \\
\hline 5 & Set-top box & & & & & & & & \\
\hline 5.1 & $\begin{array}{l}\text { Propriedade do } \\
\text { assinante }\end{array}$ & M & $\begin{array}{l}\text { BTV } \\
\text { VOD }\end{array}$ & M & $\begin{array}{l}\text { SDTV } \\
\text { HDTV }\end{array}$ & M & Assinante & $\mathrm{VHO}$ & $\begin{array}{c}\text { FTTN } \\
\text { FTTCab }\end{array}$ \\
\hline 6 & $\begin{array}{l}\text { Distribuição } \\
\text { conteúdo }\end{array}$ & & & & & & & & \\
\hline 6.1 & $\begin{array}{l}\text { Concentrado no } \\
\text { SHE }\end{array}$ & M & $\begin{array}{l}\text { BTV } \\
\text { VOD }\end{array}$ & M & $\begin{array}{l}\text { SDTV } \\
\text { HDTV }\end{array}$ & M & Operadora & SHE & $\begin{array}{l}\text { FTTN } \\
\text { FTTCab }\end{array}$ \\
\hline 6.2 & $\begin{array}{l}\text { Distribuído até } \\
\text { VSO }\end{array}$ & M & $\begin{array}{l}\text { BTV } \\
\text { VOD }\end{array}$ & M & $\begin{array}{l}\text { SDTV } \\
\text { HDTV }\end{array}$ & M & Operadora & VSO & $\begin{array}{l}\text { FTTN } \\
\text { FTTCab }\end{array}$ \\
\hline 7 & $\begin{array}{l}\text { Tecnologia de } \\
\text { Acesso }\end{array}$ & & & & & & & & \\
\hline 7.1 & $\begin{array}{l}\text { FTTH - Ethernet } \\
\text { Ponto-a-ponto }\end{array}$ & M & $\begin{array}{l}\text { BTV } \\
\text { VOD }\end{array}$ & M & $\begin{array}{l}\text { SDTV } \\
\text { HDTV }\end{array}$ & M & Operadora & VHO & $\begin{array}{l}\text { FTTN } \\
\text { FTTH }\end{array}$ \\
\hline 7.2 & $\begin{array}{l}\text { FTTH - Estrela } \\
\text { Ativa }\end{array}$ & M & $\begin{array}{l}\text { BTV } \\
\text { VOD }\end{array}$ & M & $\begin{array}{l}\text { SDTV } \\
\text { HDTV }\end{array}$ & M & Operadora & $\mathrm{VHO}$ & $\begin{array}{l}\text { FTTN } \\
\text { FTTH }\end{array}$ \\
\hline 7.3 & FTTH - EPON & M & $\begin{array}{l}\text { BTV } \\
\text { VOD }\end{array}$ & M & $\begin{array}{l}\text { SDTV } \\
\text { HDTV }\end{array}$ & M & Operadora & $\mathrm{VHO}$ & $\begin{array}{l}\text { FTTN } \\
\text { FTTH }\end{array}$ \\
\hline 7.4 & FTTH - GPON & $\mathrm{M}$ & $\begin{array}{l}\text { BTV } \\
\text { VOD }\end{array}$ & M & $\begin{array}{l}\text { SDTV } \\
\text { HDTV }\end{array}$ & M & Operadora & $\mathrm{VHO}$ & $\begin{array}{l}\text { FTTN } \\
\text { FTTH }\end{array}$ \\
\hline
\end{tabular}




\subsubsection{Modelagem Econômica}

A modelagem econômica do caso da ACME passa pela elaboração dos modelos de: receita, custos e despesas, e investimentos que se conjugam na elaboração do fluxo de caixa associado ao serviço IPTV e na obtenção dos indicadores tais como: VPL, TIR e período de payback conforme detalhado no item 4.2.3 .

O processo de modelagem econômica parte dos cenários identificados na etapa de modelagem de serviços e tecnologia descrita ao longo do item 5.1.2. Para cada um dos cenários delineados, é realizada a modelagem visando identificar sua viabilidade e atratividade em comparação com os demais.

Como premissa para esta etapa, considera-se que a moeda corrente no país em que a operadora atua é o Real ( $R \$)$, e possui uma taxa de inflação média de $5 \%$, taxa real de juros de $10 \%$ ao ano e taxa de câmbio de $R \$ 2,00$ com relação ao dólar. Além disso, a taxa mínima de atratividade requerida pela ACME é de $15 \%$ conforme critérios detalhados no item B.3.4.

Os principais resultados para o cenário base estão apresentados a seguir. 0 detalhamento de cálculo e as premissas utilizadas para sua obtenção podem ser encontrados no item B.3.

- Receitas: foram calculadas de acordo com a definição do serviço. Conforme apresentado na Figura 45, no cenário base, a maior parte das receitas é advinda da assinatura do serviço. Os serviços VOD representam o segundo maior elemento da receita, mas ainda assim são pouco representativos quando comparados com o total (vide item B.3.1). 


\section{Receitas}

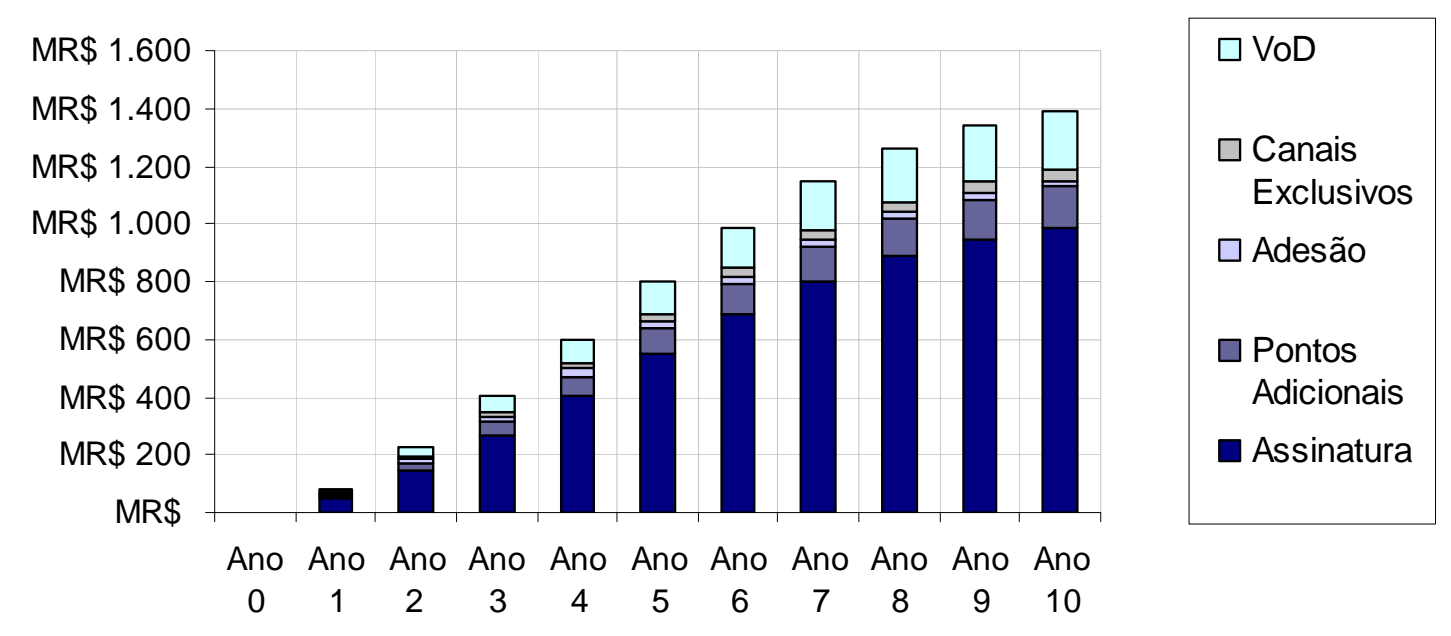

Figura 45 - Receitas - IPTV

- Custos e despesas operacionais: incluem os custos de serviços prestados, custos de equipamentos, despesas de comercialização, gerais e administrativas. Conforme o gráfico da Figura 46, os custos com provedores de conteúdo são os mais significativos na estrutura de custos do serviço IPTV da ACME (vide item B.3.2).

\section{Custos e Despesas Operacionais}

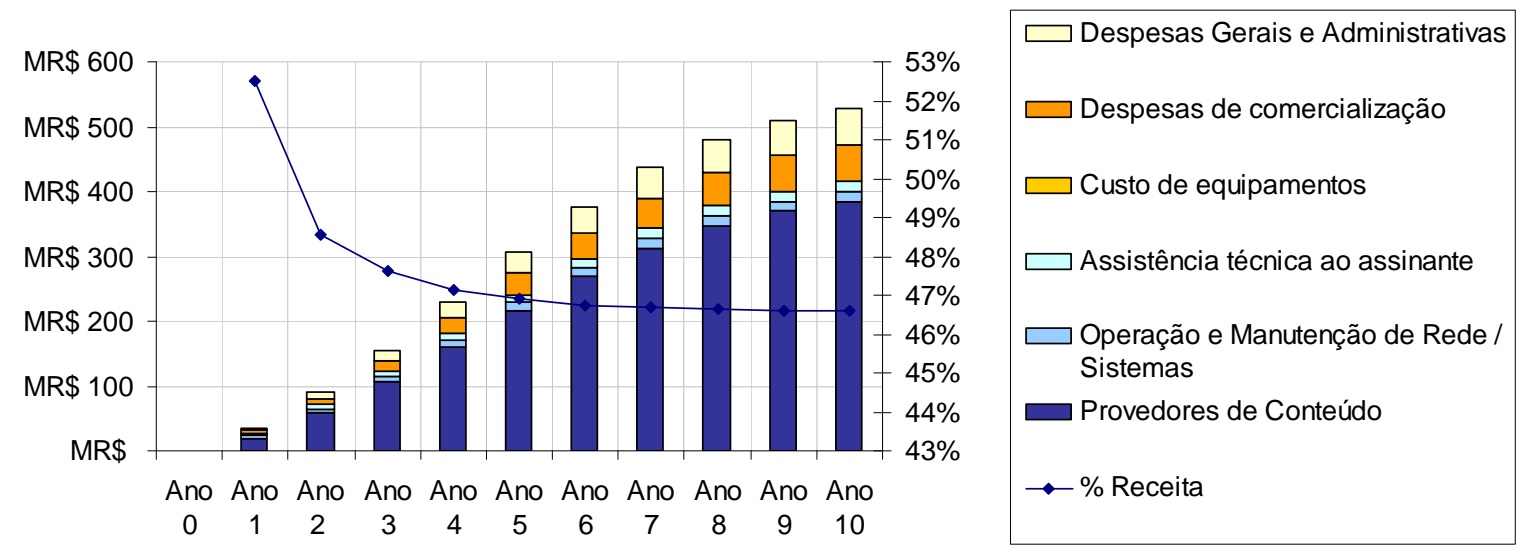

Figura 46 - Custos e despesas operacionais - IPTV

- Investimentos: os principais investimentos associados ao serviço foram obtidos com base em cotações com fornecedores e referências de mercado e estão apresentados na Figura 47. Além das cotações e referências de 
mercado para se calcular os investimentos associados à solução, foram adotadas curvas de queda de custo de tecnologia para cada elemento da solução também com base em referenciais de mercado e expectativa de evolução de cada tecnologia. Assume-se que os investimentos são realizados sempre para atender a demanda do ano vindouro. A Figura 48 apresenta 0 investimento médio por assinante com base nos investimentos cumulativos divididos pela quantidade de assinantes. A partir dos dois gráficos, nota-se que os set-top boxes representam os elementos mais relevantes do ponto de vista de investimento necessário, e que os sistemas de head-end (recepção e processamento de sinais) se diluem com a adoção do serviço (vide item B.3.3).

\section{Investimentos Totais}

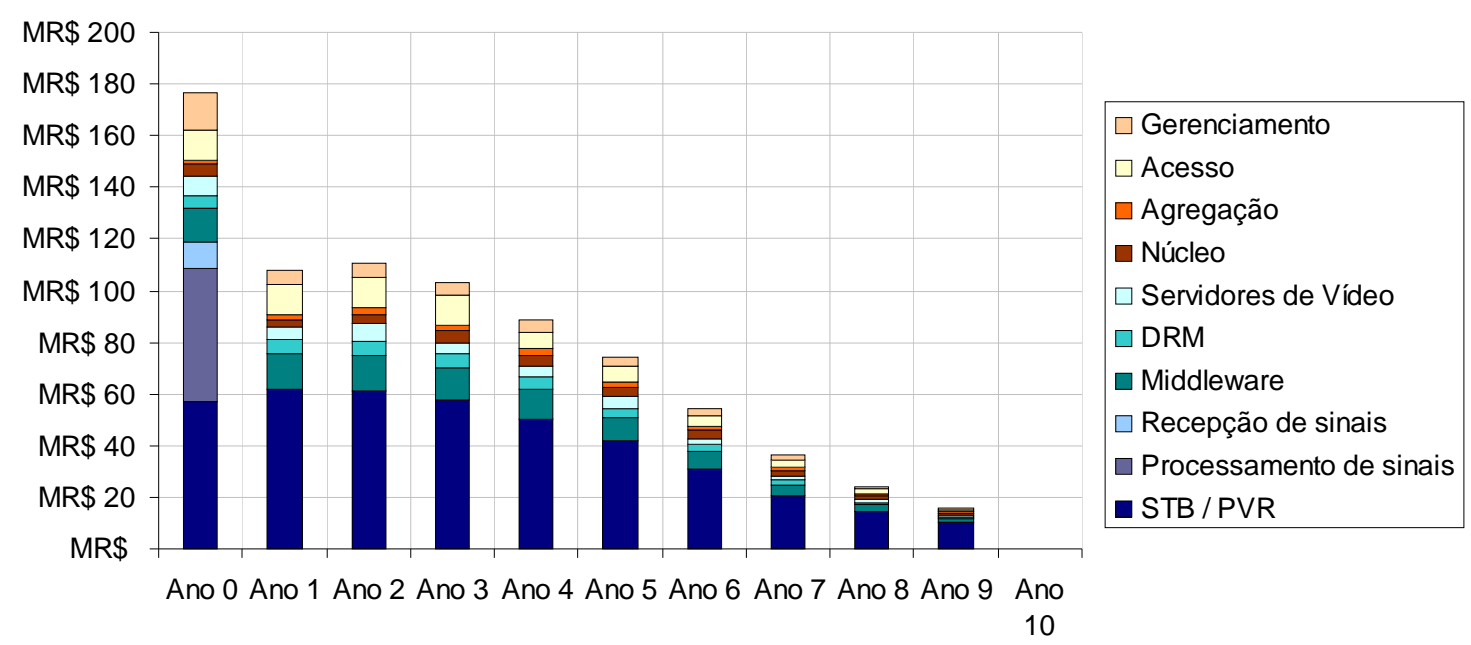

Figura 47 - Investimentos - IPTV 


\section{Investimento médio por assinante}

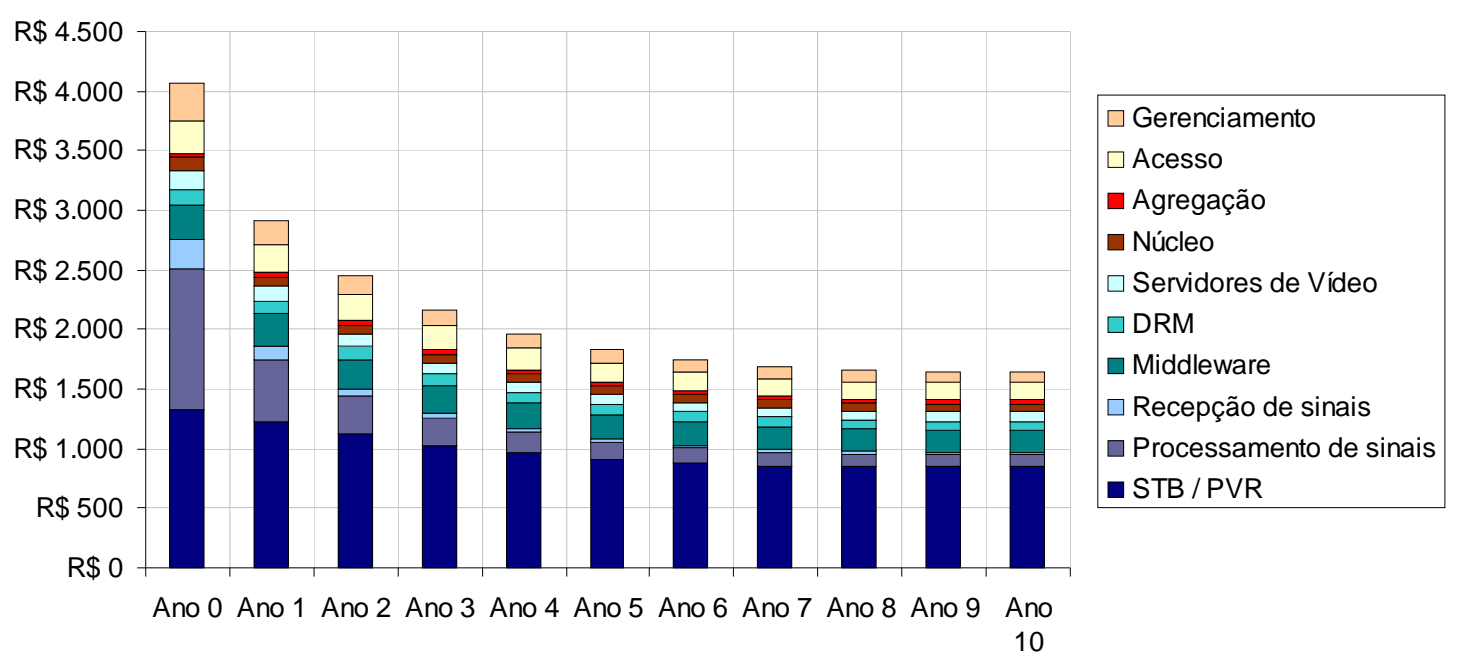

Figura 48 - Investimento médio por assinante - IPTV

- Fluxo de Caixa (FC): foi obtido com base nas dimensões de receita, custos e despesas operacionais, e investimentos conforme explicitado em 3.2.1. Além disso, o fluxo de caixa foi descontado a valor presente utilizando a taxa de desconto de $15 \%$ que conforme detalhado em B.3.4. A Figura 49 apresenta a as componentes do fluxo de caixa associadas às operações e aos investimentos, o valor líquido e acumulado ao longo do tempo. Além disso, apresenta o valor do fluxo de caixa descontado acumulado ao longo do tempo que representa a evolução do VPL do projeto no tempo. 


\section{Fluxo de Caixa}

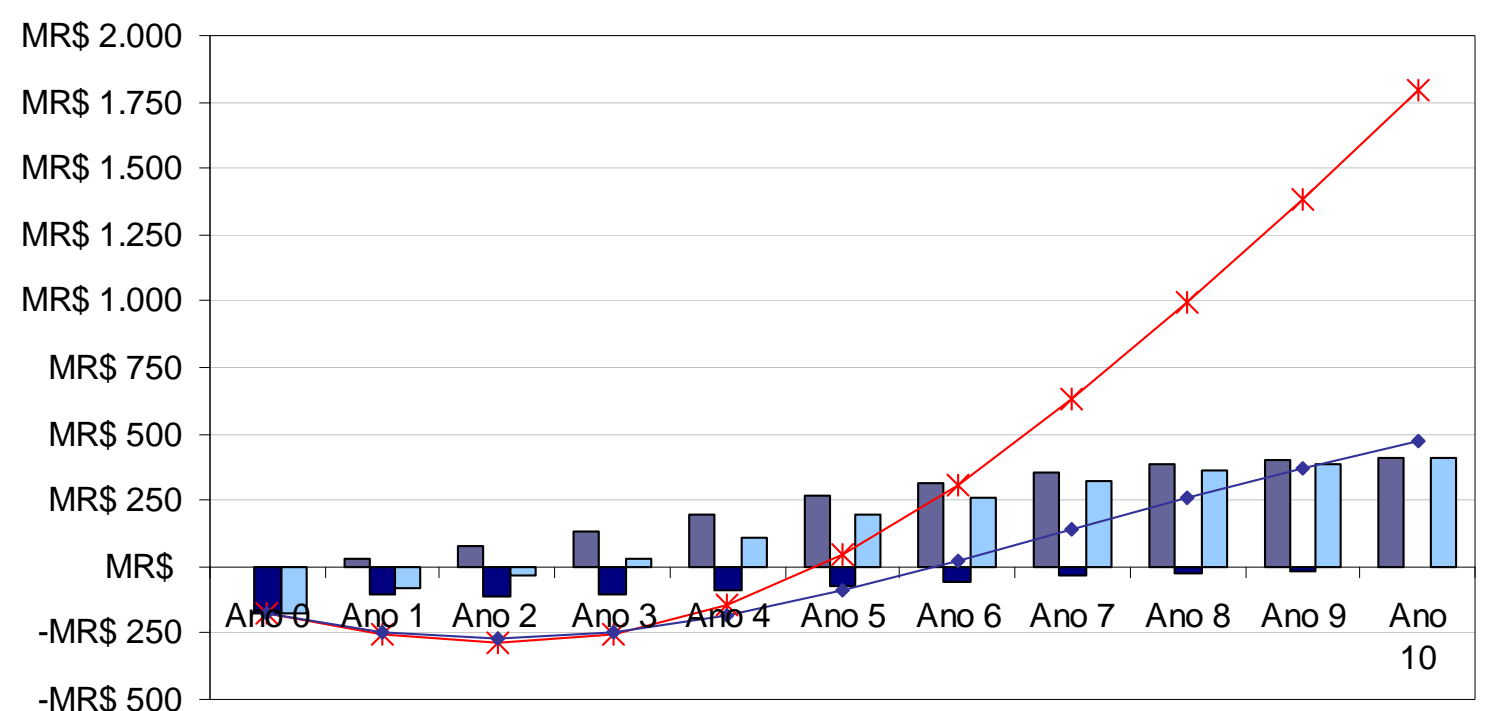

$\square$ FC Operações $\square$ FC Investimentos $\square$ Fluxo de Caixa
$\rightarrow$ FC Acumulado
F VP FC Acumulado

Figura 49 - Fluxo de Caixa - IPTV

- Indicadores: uma vez determinado o fluxo de caixa, foram calculados os indicadores econômicos: VPL, TIR e período de payback descontado associados ao projeto conforme detalhado em 3.2.3. A principal métrica utilizada para avaliação da atratividade de um cenário e comparação com os demais é o VPL. As métricas de TIR e período de payback são complementares ao VPL. A partir dos indicadores obtidos para o cenário base apresentados na Tabela 9 verifica-se que o projeto é viável no horizonte de 10 anos, pois VPL $>0$ e TIR é maior que a taxa de desconto. Além disso, o projeto tem seus investimentos recuperados e passa a gerar valor em 5,8 anos.

Tabela 9 - Indicadores econômicos - cenário base

\begin{tabular}{lc}
\hline Indicador & Valor \\
\hline VPL & MR \$475 \\
\hline TIR & $35 \%$ \\
\hline Payback & \\
Descontado & 5,8 \\
\hline
\end{tabular}




\subsubsection{Análise de Sensibilidade e Cenários}

A análise de sensibilidade e cenários consiste na análise da variação dos parâmetros de saída da análise técnico-econômica de acordo com a variação de parâmetros de entrada selecionados. Seu principal objetivo é capturar as principais fontes de incertezas presentes no processo de modelagem como um todo e, assim, permitir uma análise de risco do projeto. Desta maneira, é possível verificar quais as principais variáveis que mais afetam o resultado de modelagem.

Para o caso da ACME, foram levados em conta os cenários identificados no item 4.2.2.5. Adicionalmente aos cenários delineados, foram incluídos os seguintes cenários:

- Variação do preço: o aumento ou diminuição do preço do serviço influenciam diretamente na sua viabilidade econômica, pois estão diretamente relacionados à receita e, por isso, deseja-se verificar o seu impacto.

- Variação dos custos com conteúdo: dada a representatividade dos custos associados a provedores de conteúdo, deseja-se verificar o seu impacto na viabilidade econômica do serviço.

- Variação do investimento: seja por força da variação de condições contratuais ou da queda de custo intrínseca à tecnologia por conta de escala de adoção em caráter global, o nível de investimento sofre variações e, por isso, deseja-se avaliar sua influência.

- Variação da taxa de desconto: caso o retorno exigido do projeto seja maior ou menor, o perfil de fluxo de caixa descontado de acordo com sua distribuição e ao conceito do valor do dinheiro no tempo. Sendo assim, o entendimento das condições de viabilidade econômica também deve passar pelos efeitos da taxa de desconto. 
A análise de cada cenário e os principais resultados está detalhada no item B.4. As principais constatações para os diversos cenários estão sumarizadas no item 5.1.5 como parte da análise dos resultados.

\subsubsection{Análise de Resultados}

A partir dos resultados da aplicação da metodologia, as principais constatações extraídas para o caso ACME encontram-se sumarizadas a seguir.

- A viabilidade do serviço IPTV deve ser pensada num horizonte de médio e longo prazo (5 a 10 anos) devido à necessidade de investimentos vultosos e características do modelo de negócios que determinam a relação receitas versus custos, despesas, e investimentos.

- Tal perspectiva de recuperação de investimentos pode ser melhorada com a consideração de novos serviços e modelos de negócios alternativos. A análise do caso ACME incluiu apenas os serviços básicos de conteúdo de vídeo e que são remunerados essencialmente pelo assinante final. Além de novos serviços que possam auxiliar a rentabillização dos investimentos por parte do assinante tais como jogos online e integração de funções de comunicação na plataforma IPTV, modelos de negócio alternativos em que outras entidades contribuam com a geração de receitas devem ser exercitados. É o caso de modalidades de propaganda direcionada e comércio de bens e serviços utilizando a plataforma de IPTV e alavancando a sua flexibilidade intrínseca para tais finalidades conforme explorado no item 2.4 .

- Conforme mencionado, no caso da ACME apenas as receitas associadas ao conteúdo de vídeo foram consideradas. Neste caso, a maior parte da receita advém dos serviços tradicionais de broadcast e os serviços de VOD contribuem com uma parcela de aproximadamente $20 \%$ do total para as condições de utilização e precificação consideradas no item B.2.1.

- Deve-se considerar que a viabilidade econômica do serviço é bastante sensível ao seu nível de preço (vide item B.4.8) e, portanto, a sua determinação adequada é fundamental para a oferta bem sucedida. Além 
disso, deve-se ressaltar que as estratégias de diferenciação orientadas a preço podem tornar o serviço vulnerável em caso de oscilações de preço, por exemplo, motivadas pela concorrência. Assim sendo, a estratégia pela diferenciação de conteúdo e serviços mais sofisticados é um possível caminho para diminuir a susceptibilidade do serviço ao preço.

- Os custos relacionados aos provedores de conteúdo são bastante significativos quando comparados às demais categorias de custos e despesas e chegam a representar $50 \%$ a $60 \%$ dos custos e despesas totais no longo prazo. Em razão disso, a viabilidade econômica do serviço possui grande sensibilidade à variação dos custos com conteúdo (vide item B.4.9). Desta maneira, os acordos com provedores e agregadores de conteúdo impactam o serviço não só na experiência do usuário, mas também da perspectiva econômica.

- A infra-estrutura de serviço é responsável por aproximadamente $80 \%$ dos investimentos acumulados. Dessa infra-estrutura, um dos itens de maior relevância é o set-top box, responsável por $50 \%$ dos investimentos totais. A infra-estrutura de rede contribui com aproximadamente $10 \%$ dos investimentos e as plataformas de gerenciamento com aproximadamente $5 \%$.

- Ainda que não seja intensa da mesma forma que o nível de preço afeta a viabilidade econômica do serviço, a variação do custo dos componentes da arquitetura tecnológica que suportam o serviço influencia na sua viabilidade. Desta forma, o nível de escala de adoção de IPTV no mundo e melhores condições contratuais podem melhorar sua atratividade econômica em alguma extensão (vide B.4.10).

- Outro aspecto importante é o efeito da taxa de desconto na viabilidade econômica do serviço. Variações da ordem de $5 \%$ na taxa alteraram significativamente o resultado do VPL, mas não modificaram o período de recuperação do investimento devido às características do fluxo de caixa que possui grandes desembolsos em seu início e só começa a ter massa crítica de receitas após alguns anos. Desta forma, ainda que se exigisse um retorno menor do projeto utilizando uma taxa de retorno mais branda, a recuperação o investimento ocorreria num horizonte de 5 a 6 anos. 
- A quantidade de pontos por assinante possui um papel importante no dimensionamento da infra-estrutura tecnológica e, por conseqüência, nos investimentos. Existe uma relação direta entre a quantidade de pontos e diversos elementos tecnológicos que possuem peso relevante nos investimentos como, por exemplo, set-top boxes, licenças de middleware e DRM, e o próprio dimensionamento da rede para suportar o tráfego que é proporcional à quantidade de pontos.

- Modelos alternativos em que o set-top box não é totalmente subsidiado pela operadora e fornecido em regime de comodato colaboram substancialmente para melhorar as condições de viabilidade econômica do serviço, considerando sua relevância nos investimentos totais (vide item B.4.5).

- A adoção do serviço em maior escala favorece a sua viabilidade econômica devido aos ganhos de escala e diluição de investimentos. Isto ocorre, principalmente, porque os investimentos em recepção e processamento de sinais se diluem ao longo do tempo, pois são compartilhados por todos os assinantes (vide item B.4.2).

- Do ponto de vista da rede, a utilização de mecanismos multicast aplicada ao tráfego de canais broadcast é fundamental para a otimização da utilização dos recursos de rede e, por conseqüência, dos investimentos associados. Grande parte aumento do tráfego na rede é devido ao serviço de VOD devido à sua característica unicast.

- Algumas medidas de distribuição de conteúdo VOD são adotadas para otimizar os investimentos em rede, especialmente no segmento de núcleo. As arquiteturas de distribuição de conteúdo que se valem da disponibilização de conteúdo mais próximo ao assinante apresentaram menor nível de investimento. Entretanto, percebe-se que a maior parte dos ganhos associados à redução de investimento é capturada pelo armazenamento de réplicas do conteúdo mais acessado nos VHOs. A distribuição do conteúdo até o VSOs apresentou pequenos ganhos em relação a esta última arquitetura a partir da perspectiva de investimento e, eventualmente, pode implicar em maior complexidade operacional (vide item B.4.6). 
- Além das considerações do tipo de serviço (VOD / broadcast), a transmissão do conteúdo em alta definição possui forte impacto no tráfego da rede. Cada stream de tráfego HDTV atualmente ocupa aproximadamente 4 vezes mais recursos de rede do que um stream de tráfego SDTV. A maior utilização de recursos por HDTV tem um efeito multiplicador quando se analisa o tráfego VOD devido a sua característica unicast.

- O aumento de investimento associado à maior adoção de HDTV na rede é significativo principalmente porque afeta o custo do set-top box que é um elemento importante da composição de investimentos no sistema. No caso da ACME, o aumento da receita associada ao serviço pela adoção de HDTV é suficiente para equilibrar tal acréscimo de investimento, gerando maior valor no longo prazo nas condições de maior adoção e minimizando os efeitos negativos do maior investimento no fluxo de caixa. Entretanto, tal equilíbrio pode não se verificar dependendo das condições de precificação adotadas (vide item B.4.3)

- A maior adoção de VOD apresentou menores impactos no nível de investimento pois afeta principalmente as plataformas de servidores de vídeo e rede, que são menos representativas em relação ao total dos investimentos. $O$ aumento de receitas neste cenário também proporcionou a compensação dos investimentos, gerando maior valor e diminuindo alterações no fluxo de caixa. Da mesma forma que no caso de maior adoção de HDTV, tal condição pode não se verificar e depende diretamente do modelo de precificação adotado para o serviço e seu perfil de utilização pelos usuários. O cenário de oferta exclusiva de VOD não se mostrou interessante do ponto de vista econômico e as mesmas ressalvas relacionadas ao modelo de precificação valem para esta condição (vide item B.4.4).

- As adequações da rede de acesso para atender às necessidades de maior largura de banda são as responsáveis pela maior parte dos investimentos em rede no cenário base que considera a utilização de arquitetura FTTN para usuários em qualidade SDTV e a arquitetura FTTCab para usuários HDTV. As análises considerando a utilização de alternativas de acesso FTTH para os usuários HDTV mostraram que os impactos no investimento são bastante significativos e influenciam bastante na viabilidade econômica do serviço IPTV 
em quaisquer arquiteturas adotadas. As arquiteturas baseadas em fibra-óptica compartilhada representam ganhos de redução de investimento (PON e Ethernet estrela ativa).

- A arquitetura baseada em GPON apresentou menores investimentos quando comparada à EPON devido à sua maior capacidade de largura de banda. Entretanto, a tecnologia EPON deverá sofrer evolução de 1 Gbps para 10 Gbps, o que pode reduzir o nível de investimento por assinante associado a ela. As arquiteturas baseadas em Ethernet apresentam maior investimento do que as baseadas em PON. Apesar das tecnologias PON apresentarem menor nível de investimento, a decisão entre Ethernet ponto-a-ponto versus PON deve ser analisada também sob a perspectiva qualitativa, pois, apesar de exigir investimentos em torno de $30 \%$ superiores, a arquitetura baseada pontoa-ponto oferece vantagens de escalabilidade no longo prazo (vide item B.4.7).

- A evolução do acesso deve ser pensada considerando o cenário de evolução de serviços de forma integrada e a sua evolução em etapas constitui um caminho interessante da perspectiva econômica, iniciando com modelos FTTCab para depois evoluindo para FTTH.

Deve-se ressaltar que todos os resultados e constatações apresentados no item 5.1 são válidos exclusivamente para o caso específico da $\mathrm{ACME}$ e não devem ser generalizadas para outras situações. Os resultados aqui apresentados ilustram as condições de uma operadora típica, mas ajustes se fazem necessários para a situação específica de cada operadora e mercado onde atua.

Desta forma, a mesma análise técnico-econômica conduzida para uma outra operadora em outro contexto pode levar a constatações divergentes das levantadas neste caso. O caso da ACME serviu para ilustrar a aplicação da metodologia definida no item 4, e permite que seja verificada sua aplicabilidade de forma prática e mais detalhada. 


\subsection{AVALIAÇÃO DA METODOLOGIA}

A metodologia desenvolvida e aplicada neste trabalho pode ser avaliada de acordo com critérios definidos por Walford (52). Ele define que uma metodologia pode ser pensada como um procedimento para transformar uma entidade em outra. Neste caso, uma série de necessidades de negócio relacionadas a serviços IPTV é transformada em cenários de serviço e arquitetura tecnológica acompanhados de indicadores econômicos capazes de refletir sua atratividade. Segundo Walford (52), o nível de abstração de cada metodologia pode variar com seu propósito mas, de modo geral, uma metodologia deve satisfazer os seguintes requisitos:

- Especificação formal: a metodologia deve consistir de um conjunto de operações e atividades definidas de maneira rigorosa e não ambígua;

- Atividades definíveis: da mesma forma que as atividades são necessárias, deve ser possível definir cada uma das atividades que constituem as etapas da metodologia;

- Transformação completa: as etapas precisam ser essencialmente completas. A aplicação da metodologia por si só deve garantir a obtenção dos resultados esperados, sem a necessidade de atividades adicionais que não estavam previamente definidas;

- Ações implementáveis: as atividades da metodologia devem ser factíveis e capazes de serem executadas dentro de restrições de prazo e recursos existentes.

Caso um desses requisitos não esteja presente, a metodologia não será efetiva em seu propósito. A metodologia definida neste trabalho foi especificada segundo um conjunto de etapas. Cada etapa, por sua vez, foi descrita através um conjunto de atividades não-ambíguas, que se valem de diversos parâmetros de entrada, que sofrem transformações e resultam em dados de saída. Desta maneira, o primeiro e o segundo critérios são satisfeitos.

A Figura 25 mostra as diversas etapas que compõem a metodologia. A execução de todas as etapas conforme indicado ao longo do Capítulo 4, são suficientes para 
realização da análise técnico-econômica da introdução de serviços IPTV, atendendo ao terceiro requisito.

O quarto requisito é atendido na medida em que as atividades mencionadas na metodologia são implementáveis $e$ isto foi verificado através da aplicação da metodologia no estudo de caso ACME descrito ao longo do item 5.1. 


\section{CONSIDERAÇÕES FINAIS}

\subsection{AVALIAÇÃO DOS RESULTADOS}

Ao longo do desenvolvimento deste trabalho, foram obtidos resultados importantes que incluem: compilação dos principais conceitos relacionados a serviços IPTV e a arquitetura tecnológica correspondente; compilação dos principais conceitos de análise técnico-econômica; o desenvolvimento da metodologia de análise técnicoeconômica específica para serviços IPTV; e sua aplicação em um caso de referência.

Durante a extensa revisão da literatura, foi possível construir um nível de entendimento bastante completo a respeito das características dos serviços IPTV e como eles se relacionam com a infra-estrutura tecnológica em seus diversos blocos: serviço, rede e gerenciamento. No que diz respeito à infra-estrutura de serviços foi possível identificar os principais elementos que constituem uma plataforma IPTV, incluindo sistemas de head-end, middleware, DRM, servidores de vídeo e set-top boxes. A partir da perspectiva de rede, foram identificados os principais desafios para tornar uma rede IP capaz de oferecer serviços IPTV em seus diversos segmentos: núcleo, agregação e acesso. Do ponto de vista dos sistemas de gerenciamento, foram identificados os principais elementos de sua arquitetura que habilitam a oferta de serviços IPTV e suportam sua operação, com destaque para os sistemas de monitoramento de qualidade de vídeo. Além dos conceitos relacionados a IPTV, foram identificadas metodologias de análise técnico-econômica de referência e também os principais métodos para realização da análise de investimentos em projetos.

Com base nisso, foi proposta uma metodologia detalhada de análise técnicoeconômica específica para os serviços IPTV que consta de cinco grandes etapas: definição de escopo e objetivos da análise; modelagem de serviços e tecnologia; modelagem econômica; análise de sensibilidade e cenários; e análise de resultados. A metodologia estruturada considera os aspectos tecnológicos associados ao novo serviço e seu impacto na infra-estrutura de uma operadora, e também utiliza a 
modelagem econômica para determinar as suas condições de viabilidade. Desta forma, os resultados da aplicação da metodologia servem de subsídios à análise da introdução de serviços IPTV em uma operadora vinculando as dimensões de serviços, tecnologia e aspectos econômicos.

A metodologia estruturada serve de guia completo das atividades que precisam ser realizadas para conduzir o processo de análise técnico-econômica de maneira fim-afim e alcançar os seus objetivos. Além de facilitar a condução da análise técnicoeconômica, a metodologia proposta diminui o nível de subjetividade do processo quando realizado de forma desestruturada.

A sua aplicação foi demonstrada de forma detalhada para a operadora fictícia ACME que representa um caso de referência de uma operadora fixa. A partir do estudo de caso, foi possível verificar os principais impactos do novo serviço na infra-estrutura de rede da operadora, os novos elementos necessários à sua implementação e os respectivos aspectos econômicos. Foram analisados também diversos cenários que capturam o efeito de variáveis do domínio de serviços e tecnologia: perfil de adoção do serviço; oferta de conteúdo HDTV versus SDTV; oferta de broadcast versus VOD; arquitetura de distribuição de conteúdo; modalidade de oferta do set-top box; e tecnologias de rede de acesso. Além dessas variáveis os resultados de viabilidade econômica foram analisados com base na variação da taxa de desconto, preço dos serviços, custos associados aos componentes tecnológicos e custos associados a provedores de conteúdo. Ao final, foram extraídas diversas implicações que suportariam o processo de tomada de decisão a respeito da escolha de arquitetura tecnológica e funcionalidades de serviço a serem oferecidas.

\subsection{CONTRIBUIÇÕES DO TRABALHO}

A primeira contribuição relacionada a este trabalho é de caráter informativo e se refere essencialmente aos capítulos 2 e 3 . O capítulo 2 fornece uma compilação a respeito dos principais aspectos que permeiam o tema IPTV desde os principais serviços oferecidos até os principais blocos de sua arquitetura tecnológica. $O$ capítulo 3 fornece uma compilação a respeito dos métodos envolvidos de análise 
técnico-econômica, especialmente do ponto de vista de análise de investimento e que podem ser utilizados para avaliar demais serviços e tecnologias.

A segunda contribuição relevante desde trabalho é a proposição de uma metodologia estruturada para análise técnico-econômica da introdução de serviços IPTV descrita ao longo do capítulo 4, realizando a ligação entre a definição de serviços, a sua transposição em infra-estrutura tecnológica e, por fim, a sua análise de viabilidade econômica.

A terceira contribuição importante é a aplicação da metodologia proposta ao caso de referência de uma operadora típica. Através do estudo de caso foi possível ilustrar e demonstrar em detalhes as etapas da metodologia e o seu valor como instrumento de suporte à tomada de decisão.

\subsection{TRABALHOS FUTUROS}

A continuidade deste trabalho pode se dar em diversas frentes. A primeira delas compreende a extensão do escopo da metodologia aqui proposta e aplicada para o serviço IPTV para os demais serviços convergentes de uma operadora de telecomunicações, por exemplo, Internet banda larga e VolP, oferecendo assim uma ferramenta de análise técnico-econômica de serviços integrados.

A sofisticação dessa metodologia também pode acontecer do ponto de vista da validação das arquiteturas tecnológicas propostas e seu dimensionamento para suportar o serviço IPTV. Além da análise de consistência de informações, tal validação poderia incluir a utilização de ferramentas de simulação de redes e sistemas, verificando assim o desempenho do serviço de acordo com as diversas arquiteturas e seus parâmetros de seu dimensionamento.

Além das potenciais sofisticações à metodologia, sua aplicação poderia ser automatizada através da criação de uma ferramenta que suportasse todo o processo de análise técnico-econômica e que fosse genérica o suficiente para absorver as características específicas de cada operadora e seu contexto. 


\section{LISTA DE REFERÊNCIAS}

(1) BERMAN, S. J.; DUFFY N.; SHIPNUCK L. The end of television as we know it. New York: IBM Institute for Business Value, 2006. 27p.

(2) GRIFFITHS, S. Broadcast TV and broadband video: collision and disruption. London: Breakthroo. 2005. 45 p.

(3) KOZAMERNIK F.; VERMAELE L. Will broadband TV shape the future of broadcasting?. EBU Technical Review, Geneva, n. 303, p. 121, abr. 2005.

(4) THOMPSON, R. IPTV and the future of Telecom Video Network Architectures. New York: Light Reading, Jun. 2005. 84 p. (Heavy Reading, v. 3, n. 9)

(5) HEATH, J. IPTV impact on public networks. Maryland: Dittberner Associates, 2006. $196 \mathrm{p}$.

(6) WALKO, J. I Love my IPTV. Communications Engineer: Stevenage, v.3, n.6, p. 16-19. , Dec. 2005/Jan. 2006.

(7) BACHELET. C. Telco TV strategies: key success factors. London: Ovum, 2006. $16 p$.

(8) FALEIROS, M. Telemar, Telefônica e BrT vão lançar novo serviço de IPTV. O Estado de São Paulo, São Paulo, jul. 2006. Disponível em: $<$ http://www.estadao.com.br/tecnologia/telecom/noticias/2006/jul/17/73.htm>. Acesso em: 17 jul. 2006.

(9) COOPER, R. Product leadership: creating and launching superior new products. New York: Perseus Books Group, 2000. 314 p.

(10) BELLIKA, T.; DAVIDSEN. B. A managing innovation - an overview of the last decades' experience with tools and methods. Telektronikk, Fornebu, v.2, p. 92$101,2004$.

(11) LÄHTEENOJA, M. et al. Report on tool and methodology. Helsinki: ECOSYS, 2006. 81 p. (ECOSYS, Relatório 16) 
(12) SIMPSON, W. Video over IP: a practical guide for to technology and applications. Massachusetts: Focal Press Media Technology Professional, 2006. $493 \mathrm{p}$.

(13) ALLIANCE FOR TELECOMMUNICATIONS INDUSTRY SOLUTIONS. IPTV Interoperability Forum. IPTV Architecture Requirements. Standard ATIS0800002. Washington: ATIS, May 2006. 118 p.

(14) GORTON, M.; SEPHTON, J.; MITCHELL D. Value chain study: content industries \& services. London: Ovum , Aug. 2005. 27 p.

(15) DELANEY, J.; DAVIES, C.; WILSON B. IPTV: strategies for service providers. London: Ovum, Aug. 2004. 14 p.

(16) ZAPATER M. N.; BRESSAN, G. A proposed approach for Quality of Experience Assurance of IPTV. In: FIRST INTERNATIONAL CONFERENCE ON THE DIGITAL SOCIETY, 1., 2007, Guadeloupe. Proceedings... Guadeloupe: IEEE, 2007. p. 25-30.

(17) DSL FORUM. Triple-play Services Quality of Experience (QoE) Requirements. California: DSLFORUM, Dez. 2006. 129 p. (Technical Report TR-126)

(18) TELEMANAGEMENT FORUM. Application Note to SLA Management Handbook: Video over IP / Wireline \& Wireless Application Note, Versão 0.7. New Jersey: TMFORUM, Out. 2006. $51 \mathrm{p}$.

(19) HEAVY READING. Assuring Quality of Experience for IPTV. White Paper. New York: Light Reading, Jul. 2006. 18 p.

(20) UNITED STATES TELECOM ASSOCIATION. IP video implementation and planning guide. Washington: USTA, 2005. $235 \mathrm{p}$.

(21) RÄISÄNEN, V. Implementing service quality in IP networks. Chichester: John Wiley \& Sons, 2003. $356 \mathrm{p}$.

(22) GOLDMAN, M. et. al. Advanced Compression Technologies for High Definition. London: IET. Trabalho apresentado ao IET - Visions of Broadcasting in the 21st Century, Dez. 2005. 18 p. Não publicado. 
(23) ALLIANCE FOR TELECOMMUNICATIONS INDUSTRY SOLUTIONS. IPTV Interoperability Forum. DRM Requirements. Standard ATIS0800002. Washington: ATIS, Apr. 2006. 22 p.

(24) CISCO. Cisco Wireline Video/IPTV Solution: Design and Implementation Guide, Versão 1.1. San Jose: CISCO, 2006. 376 p.

(25) MORROW, M.; VIJAYANANDA, K. Developing IP Based services. San Francisco: Morgan Kaufmann, 2003. 311 p.

(26) BIEBERICH. Secure Router Virtualization: critical solutions for optimizing IP/MPLS Network Convergence. Boston: Yankee Group, Set. 2005. 8 p.

(27) THOMPSON, R. IP Video and the New Broadband Edge. New York: Light Reading, Dec. 2005. 63 p. (Heavy Reading, v. 3, n. 20)

(28) ELNEGAARD, N. K. et al. Multi-service broadband access network migration in urban and rural areas. Helsinki: ECOSYS, 2006. $58 \mathrm{p}$. (ECOSYS, Relatório 15)

(29) CLAVEnNA, S. Telco Triple Play: the DSL imperative. New York: Light Reading, July 2004. 47 p. (Heavy Reading, v.2, n.17)

(30) BENISTON, G. MSAPs: A Heavy Reading Competitive Analysis. New York: Light Reading, Out. 2005. 87 p. (Heavy Reading, v. 3, n. 18)

(31) BANERJEE A.; SIRBU M. Towards Technologically and Competitively Neutral Fiber to the Home (FTTH) Infrastructure. Pittsburgh: CMU, 2006. $31 \mathrm{p}$.

(32) KUROSE, J. F.; ROSS, K. W. Redes de computadores e a Internet: uma abordagem topdown. Revisão técnica de Wagner Luiz Zucchi. $3^{a}$ ed. São Paulo: Pearson Addison Wesley, 2006. 634 p.

(33) RAO, K. R.; BOJKOVIC, Z. S.; MILANOVIC, D. A. Introduction to multimedia communications: applications, middleware, networking. New Jersey: John Wiley \& Sons, 2006. 773 p.

(34) SEERY. M. IPTV multicast: many different ways to skin the cat. London: Ovum, Abr. 2006. 19p. 
(35) TELEMANAGEMENT FORUM. Enhanced Telecom Operations Map (eTOM): the Business Process Framework, Versão 6.0. New Jersey: TMFORUM, Nov. 2005. $81 \mathrm{p}$.

(36) RILEY, M. Provisioning and assurance for converged IPTV video. Nice: TMForum. Trabalho apresentado ao TeleManagement Forum, Nov. 2005. 38 p. Não publicado.

(37) KERPEZ, K. et al. IPTV Service Assurance. IEEE Communications Magazine, v. 44, n. 9, p. 166-172, Sept. 2006.

(38) FLEURY, J. R. IPTV: the need for standards. In: INTERNATIONAL BROADCAST CONVENTION, 12., 2005, Amsterdam. Anais... Amsterdam: IBC, 2005.

(39) LEVIN, O. IPTV Standards Perspective. San Diego: ITUT, mai. 2006. 39 p. Trabalho apresentado ao Joint ITUT Workshop and IMTC Forum 2006 "H.323, SIP: is H.325 next?" Não publicado.

(40) THOMPSON, R. Multimedia Whole-Home Networking: solving the IPTV distribution dilemma. New York: Light Reading, May 2006. 70 p. (Heavy Reading, v. 4, no. 6).

(41) MONATH, T. et al. Economics of fixed broadband access network strategies. IEEE Communications Magazine, v. 71, n. 9, p. 132-139, Sept. 2003.

(42) SMURA, TIMO. Technoeconomic analysis of IEEE 802.16abased fixed wireless access netowrks. 2004. 124 p. Dissertação (Mestrado em Engenharia) Department of Electrical and Communications Engineering, Helsinki University of Technology. Helsinki, 2004.

(43) VENTURIN R. et al. A method for the business analysis of B3G system. In: INTERNATIONAL CONFERENCE ON TELECOMMUNICATIONS - CONTEL, 7., 2003, Zagreb. Proceedings. Zagreb: IEEE, 2003. p. 97-104.

(44) SEPAROVIC, E. Metodologia de Estudo de Viabilidade Financeira de Migração para telefonia IP no ambiente corporativo. 2002. 209 p. Dissertação (Mestrado em Engenharia) - Escola Politécnica, Universidade de São Paulo. São Paulo, 2002.

(45) CARVALHO, T. C. M. B. Metodologia e ferramentas de projeto de redes locais. 1995. 298 p. Tese (Doutorado em Engenharia) - Escola Politécnica, Universidade de São Paulo. São Paulo, 2005. 
(46) GARRISON, R. H.; NOREEN, E. W. Contabilidade Gerencial. 9a ed. São Paulo: LTC Editora, 2001. 643 p.

(47) ROSS S. A. et. al. Administração financeira. $1^{a}$ ed. São Paulo: Atlas, 1995. $700 \mathrm{p}$.

(48) BREALEY, R. B.; MYERS, S. C. Principles of corporate finance. $7^{\text {a }}$ ed. New York: McGrawHill, 2003. 1075 p.

(49) DAMODARAN A. Applied Corporate Finance: A User's Manual. $2^{\mathrm{a}}$ ed. New York: Wiley, 2005. $672 \mathrm{p}$.

(50) MCCABE, J. D. Network analysis, architecture, and design. $2^{\text {a }}$ ed. San Francisco: Morgan Kauffman, 2003. 450 p.

(51) VEEN, D. T. et al. An analysis of the technical and economic essentials for providing video over fiber-to-the-premises networks. Bell Labs Technical Journal, v. 10, n. 1, p. 181-200, 2005.

(52) WALFORD, R. Information networks: a design and implementation methodology. Massachussets: Addison Wesley, 1990. 358 p.

(53) TELECO: INFORMAÇOES EM TELECOMUNICAÇÕES. São Paulo. WACC: Weighted Average Cost of Capital. Disponível em: < http://www.teleco.com.br/tutoriais/tutorialwacc/default.asp>. Acesso em: 10 jan.. 2007.

(54) VAN DEN BULT, C. Want to know how diffusion speed varies across countries and products? Try using a Bass model. PDMA Visions, v. 26, n. 4, p. 12-15, Out. 2002.

(55) LYNGSAT. Disponível em: <http://www.lyngsat.com/>. Acesso em: 10 fev. 2007. 


\section{APÊNDICE A - ARQUITETURA DE REDES DE AGREGAÇÃO}

A seguir serão discutidas algumas questões relevantes no tocante à redes de agregação passando pelo modelo de distribuição de inteligência, da adoção de soluções da camada 2/3 e esquemas de VLAN. Diversas combinações implementação das alternativas relacionadas à agregação são encontradas no mercado. A seleção da arquitetura mais adequada varia caso-a-caso e a escolha depende da oferta de serviços existente, de objetivos futuros de evolução e da base de equipamentos instalada na operadora.

\section{A.1 INTELIGÊNCIA CENTRALIZADA E DISTRIBUÍDA}

A seguir estão detalhadas algumas opções de evolução para a arquitetura de borda do serviço: continuar com a inteligência centralizada; distribuir a inteligência na rede de agregação; ou adotar um modelo híbrido dependendo de cada serviço (27).

- Inteligência centralizada: neste caso a arquitetura em vigor permanece inalterada e o B-RAS continua um elemento central tanto para a implementação da inteligência do serviço de acesso à Internet quanto do serviço de vídeo. Essa arquitetura implica na necessidade de uma rede de agregação relativamente simples implementada em Camada 2 com um papel eminentemente de transporte e sem grande dose de inteligência. Uma das principais limitações dessa abordagem é a escalabilidade necessária para que - B-RAS suporte o volume de tráfego e as funcionalidades avançadas requeridas pelo serviço de vídeo. Para atender a esses requisitos vem surgindo no mercado uma nova geração de elementos B-RAS, denominada pelo DSL Forum de Broadband Service Switch Router (BSSR).

- Inteligência distribuída: nesta arquitetura a inteligência dos diversos serviços (acesso à Internet, Vídeo e Voz) é distribuída ao longo da rede de agregação. O conceito de um B-RAS que atua como nó concentrador inexiste nesta arquitetura e o roteador de borda não mais concentra toda a inteligência do serviço. A rede de agregação passa a ter, portanto, um papel além do 
transporte tradicional e os elementos da rede passam a incluir funcionalidades de inteligência do serviço. Apesar da aplicação de políticas de QoS acontecer de maneira distribuída nos diversos elementos da rede de agregação, elas são gerenciadas de forma centralizada e fim-a-fim. Este modelo de arquitetura traz vantagens relacionadas à escalabilidade e flexibilidade. A distribuição da inteligência implica que os elementos da rede de agregação devem possuir um maior nível de sofisticação. Idealmente, todos os elementos da rede de agregação poderiam ser roteadores IP que implementam uma rede de Camada 3, trazendo toda a inteligência IP até os elementos mais próximos do acesso. Entretanto, a rede de agregação também pode ser implementada com elementos de Camada 2 que possuam alguma inteligência de serviços. Esses switches são menos sofisticados do que um roteador, mas possuem algumas funcionalidades avançadas que permitem, por exemplo, a aplicação de políticas de QoS em alguma extensão.

- Modelo Híbrido: pode existir ainda um modelo intermediário de implementação que combina modelos distintos (centralizado ou distribuído) para cada serviço. Por exemplo, o serviço de acesso à Internet pode continuar com sua arquitetura tradicionalmente centralizada, em que as sessões são terminadas no B-RAS. Já o serviço de vídeo pode ser implementado sobre um modelo de arquitetura distribuída em que o tráfego de vídeo não passa necessariamente pelo B-RAS, e as políticas de QoS e controle de usuário são aplicadas de maneira distribuída ao longo de uma rede de agregação com funcionalidades mais inteligentes. Esta modalidade híbrida pode ser empregada, por exemplo, em um período de transição durante a introdução do serviço de vídeo, mantendo a arquitetura já existente para o tráfego banda larga até que o modelo completamente distribuído seja empregado de maneira uniforme na rede para todos os serviços. 


\section{A.2 MODELOS DE CAMADA 2 E CAMADA 3}

Existem diversas maneiras de se implementar a rede de agregação em camada 2 ou camada 3, combinando modelos de agregação Ethernet / MPLS / IP. Nas implementações de Camada 3, a inteligência IP é levada até o elemento mais próximo da rede de acesso e, em geral, estão associadas a modelos de inteligência distribuída. Nas implementações de Camada 2, as funcionalidades IP ficam circunscritas ao roteador de borda do núcleo e o modelo de distribuição de inteligência depende das funcionalidades dos elementos da rede de agregação.

Algumas modalidades de implementação de camada 2 e 3 estão ilustradas a seguir (27)(34)(24):

- Camada 2 - Ethernet Nativo: maneira mais simples de implementar o transporte do tráfego de vídeo sobre Ethernet utilizando o conceito de VLAN. É uma solução de Camada 2 em que transporte de tráfego da rede de acesso até o núcleo da rede é realizado sobre VLANs distintas por serviço ou por usuário dependendo do modelo de implementação (vide item 2.8.3 para detalhes sobre mapeamento de VLANs). Apesar de ser uma das soluções com custo bastante atraente devido à simplicidade inerente às implementações Ethernet em Camada 2, apresenta algumas restrições:

- escalabilidade limitada pelo número máximo de VLANs suportadas nos equipamentos;

- suporte limitado às funções de QoS inerentes ao Ethernet;

- utilização ineficiente dos recursos: originalmente em redes Ethernet, o tráfego dos canais broadcast inundaria a rede pois seriam retransmitidos a cada nó para todos os elementos, mas alguma otimização da banda é obtida através da separação do tráfego em VLANs e técnicas de inspeção dos pacotes IGMP;

- tempo para restauração pode ser alto dependendo da complexidade da rede, pois depende dos mecanismos associados ao Spanning Tree Protocol (STP) e sua evolução Rapid Spanning Tree Protocol (RSTP); 
- Camada 2 - MPLS: pode ser considerada uma sofisticação da implementação de bridged Ethernet visando endereçar suas principais limitações com a utilização de MPLS, incluindo tecnologias como: Ethernet over MPLS (EoMPLS) ou Virtual Private LAN Services (VPLS). As soluções baseadas em VPLS são bastante empregadas e utilizam o conceito de VPN multipontomultiponto (full mesh) em Camada 2. Tais soluções são baseadas em MPLS e emulam uma Ethernet LAN sobre uma rede MPLS de abrangência MAN/WAN. $O$ conceito de VPLS pode transcender o limite de uma rede de agregação e transportar o tráfego de diversas redes de agregação através do núcleo como se todas elas constituíssem uma única LAN de grandes dimensões. No caso das soluções empregadas para IPTV, em geral, a VPLS se restringe ao âmbito de uma rede de agregação. A solução de VPLS endereça algumas das limitações impostas pelo Ethernet Nativo:

- apesar das limitações da topologia full mesh do VPLS, a escalabilidade é aumentada através da criação de redes VPLS com níveis hierárquicos Hierarchical VPLS (H-VPLS);

- com a utilização de H-VPLS, implementa a otimização no transporte do tráfego e apenas uma cópia dos canais broadcast é retransmitida para os diversos nós da rede como se fizessem parte de um anel. Assim, apenas um feixe com todos os canais ocupa recursos da rede;

- a utilização do mecanismo de Fast Reroute (FRR) do MPLS diminui o tempo de restauração em caso de falhas;

- através da utilização de mecanismos de engenharia de tráfego, pode incrementar a implementação de QoS na rede.

- Camada 3 - IP: é a arquitetura que implementa o transporte de vídeo fim-afim em Camada 3. Nesta categoria de arquitetura, o roteamento IP é implementado na rede de agregação baseada em Ethernet, que passa a ser composta por roteadores e não mais switches. A inteligência do serviço IP é trazida o mais próximo possível do acesso. Desta maneira, a operadora possui uma rede IP fim-a-fim, desde o seu núcleo até a agregação, garantindo a homogeneidade do serviço. Este tipo de arquitetura apresenta maior nível de sofisticação em comparação com as outras abordagens baseadas em 
Camada 2. Deve-se notar que apesar de serem elementos de camada 3 , existem implementações capazes de habilitar os serviços de camada 2 nestes equipamentos formando uma rede ambivalente que consegue oferecer serviços de camadas 2 e 3 a partir de uma plataforma única. Existem diversos benefícios em se trazer a borda IP para mais próximo do usuário:

- utilização dos mecanismos de QoS da camada IP (potencialmente em conjunto com MPLS) de maneira fim-a-fim e consistente desde o núcleo até a agregação;

- elevada escalabilidade intrínseca ao IP;

- suporta O IP multicast de maneira nativa, permitindo o melhor aproveitamento de recursos de rede e fazendo com que cada assinante e o respectivo nó da rede receba apenas o canal que está assistindo;

- oferece flexibilidade de inserção de conteúdo na rede de agregação.

\section{A.3 VLAN POR USUÁRIO E POR SERVIÇO}

Além da escolha dos modelos de distribuição de inteligência e modelo de agregação, a definição do esquema de VLANs é importante na agregação. O esquema de VLAN é utilizado para mapear diferentes assinantes e serviços com as devidas tags e identificá-los em diferentes segmentos da rede, podendo fazer uso dessa informação para a aplicação de políticas, por exemplo. O DSL Forum define dois tipos de esquemas de VLANs de acordo com o relatório técnico TR-101 (27): mapeamento por assinante $(1: 1)$ ou por serviço $(1: N)$.

As abordagens que focalizam o mapeamento por assinante possuem desafios de escalabilidade (quantidade de VLANs), mas permitem um nível de controle de maior granularidade como, por exemplo, a aplicação de políticas de QoS por usuário. Já os esquemas de mapeamento por serviço preservam o controle em nível agregado de tráfego por serviço e não por assinante.

Tais modelos podem ser combinados em diversos segmentos da rede dependendo do propósito. Por exemplo, nos switches de agregação (elemento mais próximo do 
acesso), pode-se utilizar mapeamento por usuário e então utilizar o mapeamento por serviços no switch de distribuição (mais próximo do núcleo) visando a aplicação de políticas diferenciadas em níveis de granularidade diferenciados: por usuário ou por serviços. 


\section{APÊNDICE B - INFORMAÇÕES COMPLEMENTARES À APLICAÇÃO DA METODOLOGIA}

\section{B.1 DEFINIÇÃO DE OBJETIVOS E ESCOPO DA ANÁLISE}

\section{B.1.1 Contexto}

A operadora $\mathrm{ACME}$ é uma operadora de telefonia fixa que oferece serviços de comunicação de voz e dados ao público residencial e corporativo em um país com características similares ao Brasil e atendendo uma região que totaliza 10 milhões de habitantes distribuídos em 2,5 milhões de domicílios. Para o público residencial, além da telefonia tradicional, oferece serviços de acesso à Internet banda estreita e banda larga. Atualmente, a base de assinantes residenciais se divide da seguinte maneira:

- Telefonia: 2 milhões (saturada)

- Internet banda estreita: 1 milhão (crescimento vegetativo)

- Internet banda larga: 350 mil (fase de expansão)

A operadora ACME sempre foi a líder em serviços de telefonia em sua região, mas vem sendo fortemente ameaçada pelas operadoras de TV a cabo que já contam com um volume de assinantes de Internet banda larga equivalente à base de assinantes da ACME. As operadoras de TV estão adicionando telefonia em sua oferta e já começam a incomodar a ACME com ofertas agressivas de pacotes integrados incluindo Telefonia + Internet + TV paga. Diante das ameaças dos concorrentes, a ACME está avaliando a introdução de serviços de TV em seu portfolio utilizando IPTV para fazer frente à oferta integrada das operadoras de TV a cabo. Para isso, está realizando uma análise técnico-econômica da introdução dos novos serviços em sua oferta. 


\section{B.1.2 Objetivos}

A operadora ACME já possui uma infra-estrutura de rede IP robusta para oferecer serviços. A avaliação técnico-econômica da oferta de serviços IPTV aproveitando a infra-estrutura IP existente tem por objetivo verificar a viabilidade econômica de acordo com diferentes características do serviço e sua arquitetura tecnológica.

\section{B.1.3 Escopo}

A avaliação técnico-econômica terá como resultado uma análise que responde como se dá a viabilidade econômica do serviço IPTV nas circunstâncias referenciadas no item anterior. Esta abordagem parte da caracterização do serviço, identificação de requisitos, análise da arquitetura existente para realizar a definição e dimensionamento da nova arquitetura tecnológica. Com base nisso, são delineados diversos cenários que conjugam características do serviço e correspondente arquitetura tecnológica.

A partir dos cenários identificados, é realizada a modelagem econômica levando em conta os investimentos diretos (CAPEX), custos e despesas operacionais (OPEX) e a receita gerada pelo serviço para calcular a sua viabilidade econômica segundo métodos tradicionais de: NPV, TIR e payback descontado apresentados no item 3.2.3. A modelagem inclui a análise de sensibilidade e cenários para a melhor compreensão das incertezas envolvidas no processo de avaliação. O processo de avaliação técnico-econômica da introdução de IPTV na operadora ACME não utiliza nenhuma ferramenta especial além de processadores de planilhas (Microsoft Excel).

\section{B.1.4 Premissas Gerais}

O período de tempo considerado na avaliação técnico-econômica é de um horizonte de 10 anos, considerando a natureza intensiva de investimento de um serviço dessa natureza e a longevidade do serviço. A modelagem supõe que a operadora realiza a 
implementação da arquitetura tecnológica durante o ano vigente e os serviços são lançados ao mercado durante o Ano 1.

A avaliação assume que a ACME opera em um país fictício com características bastante similares ao Brasil, dividindo sua atuação em cinco grandes regionais que compreendem população de característica urbana.

\section{B.2 MODELAGEM DE SERVIÇOS E TECNOLOGIA}

\section{B.2.1 Definição dos Serviços}

Após a realização de estudos mercadológicos, a equipe da ACME chegou à conclusão de que a oferta de serviços IPTV será composta essencialmente pela categoria de serviços de vídeo do modelo de referência apresentado na Figura 5. A possibilidade da introdução de serviços adicionais tais como: vídeo telefonia, jogos interativos, música, entre outros, deve ser considerada apenas como potencial evolução dos serviços de vídeo. Desta forma, a análise tecnico-econômica em questão tratará essencialmente dos serviços de vídeo.

\section{B.2.1.1 Componentes e funcionalidades do serviço}

Os serviços IPTV Os serviços de vídeo a serem oferecidos pela ACME em adição ao seu portfolio atual incluem:

- Broadcast: total de 200 canais distribuídos conforme ilustrado na Tabela 10. 
Tabela 10 - Quantidade de Canais

\begin{tabular}{lc}
\hline Tipo de Canal & Quantidade \\
\hline Canais Abertos & 30 \\
\hline SDTV & 20 \\
\hline HDTV & 10 \\
\hline Canais Fechados & 150 \\
\hline SDTV & 100 \\
\hline HDTV & 50 \\
\hline Canais Exclusivos & 20 \\
\hline SDTV & 10 \\
\hline HDTV & 10 \\
\hline Total & 200 \\
\hline SDTV & 130 \\
\hline HDTV & 70 \\
\hline
\end{tabular}

\section{- Vídeo Armazenado}

- VOD: 2.000 títulos de duração média de 90 min (30\% em qualidade HDTV)

- PVR: integrado no STB do usuário com capacidade de 10h de gravação (SDTV / HDTV)

No ambiente regulatório local, existem restrições a respeito da oferta de conteúdo na modalidade broadcast por operadoras de telecomunicações. Desta maneira, os cenários utilizados na análise técnico-econômica deverão contemplar a possibilidade da inclusão ou não de conteúdo broadcast na oferta. No caso da oferta limitada a VOD, uma parceria com operadora de TV via satélite seria desejável para complementar a oferta de serviços com canais de programação tradicionais. Uma outra opção seria a comercialização do serviço de VOD como um complemento dos serviços de TV a cabo disponíveis ao mercado. Já existem disponíveis no mercado set-top boxes híbridos possibilitam a oferta de serviços de VOD utilizando IPTV e canais broadcast advindo de satélite ou cabo.

No mercado em que a ACME atua, os provedores de TV por assinatura e TV aberta já estão se movimentando para ofertar conteúdo em qualidade HDTV. Ademais, com o advento da TV Digital aberta, as operadoras de TV aberta já estão contemplando a oferta de conteúdo HDTV no futuro próximo. Desta maneira, além de contemplar a natureza da oferta de conteúdo broadcast e/ou VOD, os cenários de análise deverão 
incluir a possibilidade da oferta de conteúdo apenas em qualidade SDTV e também a oferta de conteúdo em qualidade HDTV.

Além das funcionalidades apresentadas, o serviço deve contar com uma interface amigável com o usuário final que permita a interatividade e traga uma experiência realmente diferenciada em comparação aos serviços de TV paga existentes.

\section{B.2.1.2 Modelo de Precificação}

O serviço será comercializado em conjunto com o acesso à Internet banda larga e serviços de telefonia tradicional. A intenção da ACME é de que o serviço não seja vendido isoladamente.

A partir de pesquisas de mercado realizadas com os concorrentes já atuantes no mercado de TV por assinatura (cabo e satélite) em que a ACME almeja atuar, a equipe de Marketing determinou modalidades de empacotamento e preços sugeridos para a oferta de IPTV. Deve-se lembrar que a ACME será uma nova entrante no mercado, supõe-se que o preço praticado esteja em condição de igualdade ou ligeiramente inferiores aos da concorrência para que possa ter uma oferta competitiva.

Considerando que a determinação dos modelos de precificação não é parte da metodologia e deveriam ser dados de entrada, foram utilizados preços de referência do mercado nacional praticados pelas operadoras de TV por assinatura que oferecem qualidade digital para os serviços broadcast de qualidade SDTV. Para os serviços de qualidade HDTV, foi adotada a premissa de que são $50 \%$ mais caros do que os tradicionais por oferecerem maior qualidade ao usuário final, com base em relações de preço praticadas no mercado internacional. Para os serviços VOD foi considerada como referência de preço os modelos oferecidos de maneira muito embrionária de operadoras de TV paga no mercado local e também o preço de aluguel de títulos em vídeo locadoras.

\footnotetext{
${ }^{6}$ Análises não estão incluídas no escopo dessa metodologia.
} 
- Assinatura (inclui canais abertos e fechados conforme B.2.1.1)

- SDTV: R $\$ 150$ / mês

- SDTV + HDTV: R $\$ 225$ / mês

- Taxa de adesão / instalação:

- SDTV: $R \$ 250$

- SDTV + HDTV: R\$ 375

- Set-top box: a oferta bem sucedida da concorrência vem contemplando a oferta de set-top box em regime de comodato. Entretanto, deseja-se analisar o modelo alternativo em que o usuário compra o set-top box separadamente.

- Preço estimado: SDTV: $\mathrm{R} \$ 500 ; \mathrm{HDTV}: \mathrm{R} \$ 800$;

- Elementos Opcionais: cobrados separadamente

- Canais exclusivos: cobrado por pacote de canais exclusivos conforme o item B.2.1.

- SDTV: R\$ 20 / mês; HDTV: R\$ 30 / mês

- VOD: o assinante tem acesso a uma parcela de conteúdo (20\%) de forma gratuita e o acesso a maior parte do conteúdo é cobrado por título assistido

- SDTV: R\$ 8 / título; HDTV: R\$ 12 / título

- Caso a oferta seja construída apenas com VOD, existe uma taxa de assinatura do serviço - SDTV: R $\$ 30$ / mês; HDTV: R $\$ 45$ / mês

- PVR: integrado ao set-top box e usuário paga tarifa adicional mensal pela sua utilização. Fornecido em regime de comodato e, de forma análoga ao set-top box, deseja-se analisar o modelo de compra separadamente;

- SDTV: R\$ 20 / mês; HDTV: R\$ 30 / mês

- Na modalidade de compra, o preço estimado seria: SDTV: $\mathrm{R} \$ 900$; HDTV: $R \$ 1.300$; 
- Ponto adicional: cobrado separadamente mensalmente e possui taxa de instalação;

- Adicional mensal: SDTV: R\$ 25 / mês; HDTV: R\$ 38 / mês;

- Taxa de instalação: SDTV: R\$ 70; HDTV: R\$ 105;

\section{B.2.1.3 Modelo de Negócios}

A operadora ACME não atuará como produtora nem agregadora de conteúdo. Seu papel será de distribuição de conteúdo. Ela atuará, portanto, nos papéis de provedora de serviço e de rede da cadeia de valor de serviços IPTV.

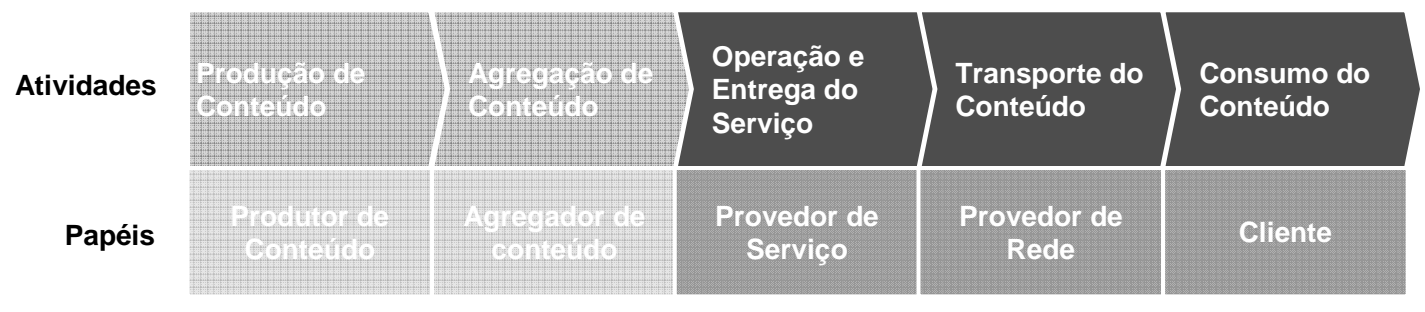

Figura 50 - Posicionamento da ACME na Cadeia de Valor

O modelo de negócios adotado entre a ACME e os produtores/agregadores de conteúdo e seus custos com conteúdo serão da ordem de $35 \%$ da receita líquida. Tais custos foram estimados com base nas análises de demonstrativos de resultados de empresas de TV paga no Brasil.

\section{B.2.1.4 Projeção de assinantes}

O serviço IPTV será oferecido apenas nas regiões urbanas em que a ACME atua, ou seja, nas mesmas áreas em que o serviço de Internet Banda Larga é oferecido. $O$ serviço banda larga é oferecido há cinco anos e estima-se que a operadora ACME consiga atingir aproximadamente 1,5 milhões de assinantes banda larga no longo prazo. O foco da oferta do serviço IPTV será nas regiões metropolitanas, onde as operadoras de TV a cabo possuem forte presença. A densidade demográfica 
estimada para essas regiões de natureza urbana é da ordem de 2.000 domicílios $/ \mathrm{km}^{2}$.

A partir de estudos de mercado, foi determinada a projeção de demanda de assinantes banda larga e assinantes IPTV para a operadora $\mathrm{ACME}^{7}$. Para a servir de subsídio a este trabalho, a projeção de demanda foi realizada com base no modelo de adoção tecnológica de Bass utilizando coeficientes de inovação e imitação calculados para Internet Banda Larga e IPTV (54). A premissa de taxa de churn (representa os assinantes que deixam o serviço) é de aproximadamente $10 \%$ ao ano, estimada a partir de benchmarks de operadoras de TV paga no mercado nacional.

A projeção de demanda para o serviço IPTV compreende três cenários que se distinguem pelo potencial de assinantes IPTV no longo prazo:

- Conservador: 100 mil

- Moderado: 500 mil

- Agressivo: 1 milhão

\footnotetext{
${ }^{7}$ Análises não estão incluídas no escopo dessa metodologia.
} 


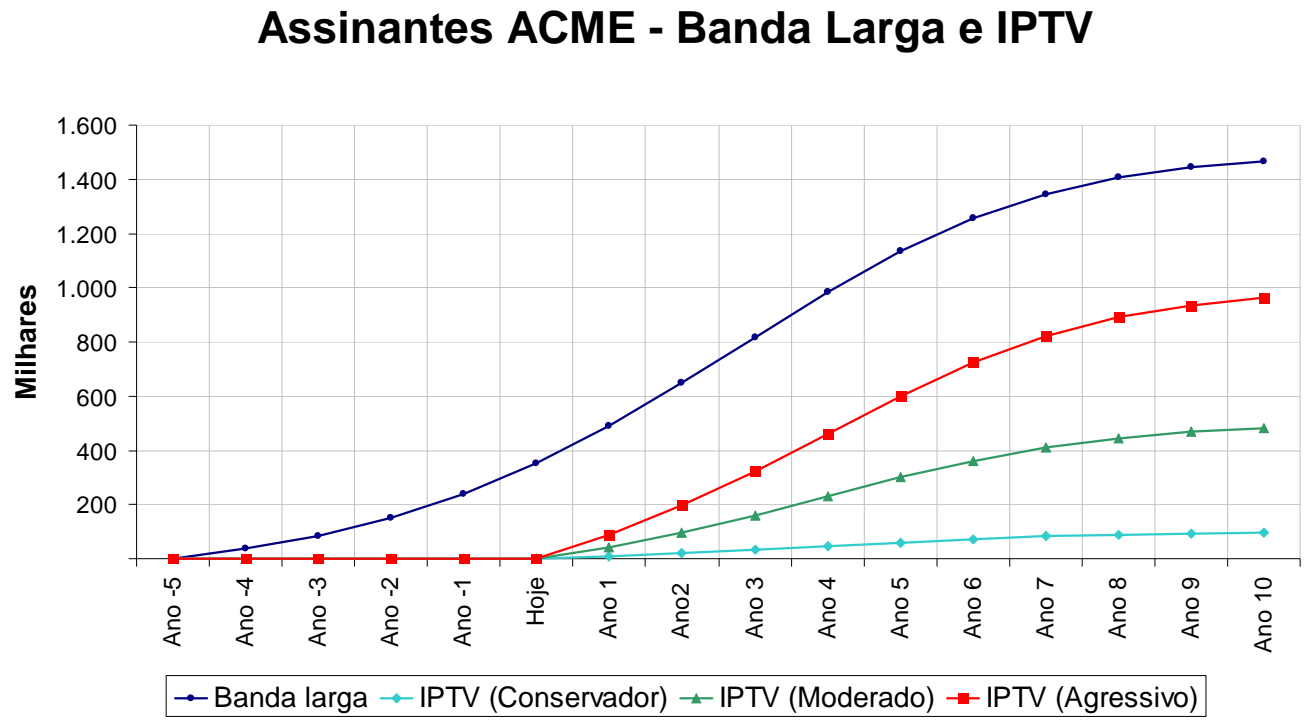

Figura 51 - Evolução de Assinantes Internet Banda Larga e IPTV - ACME

\section{B.2.1.5 Perfil de utilização}

Os cenários de oferta de IPTV da ACME poderão incluir a oferta de conteúdo em SDTV e HDTV, ou seja, é possível que os usuários assinem uma modalidade de serviço diferenciada que os habilita a receberem o conteúdo em HDTV. Tal modalidade de serviços pressupõe que o assinante possua aparelhos de TV que permitam a exibição em formato HDTV.

A penetração de HDTV na base de assinantes e a respectiva quantidade de pontos por domićlio estão apresentadas na Tabela 11, considerando quatro cenários de adoção de HDTV. Além do aumento da penetração de HDTV, a quantidade de pontos por domicílio varia entre os cenários. Nos casos em que a penetração de HDTV é mais alta, assume-se que esta média é maior devido ao perfil mais sofisticado de consumo dos assinantes. 
Tabela 11 - Características dos cenários - SDTV e HDTV

\begin{tabular}{|c|c|c|c|c|}
\hline Perfil HDTV & Sem HDTV & $\begin{array}{c}\text { HDTV } \\
\text { Conservador }\end{array}$ & $\begin{array}{l}\text { HDTV } \\
\text { Moderado } \\
\text { (Cenário } \\
\text { Base) }\end{array}$ & $\begin{array}{c}\text { HDTV } \\
\text { Agressivo }\end{array}$ \\
\hline $\begin{array}{l}\text { Quantidade de } \\
\text { pontos / domicílio }\end{array}$ & $100 \%$ & $100 \%$ & $100 \%$ & $100 \%$ \\
\hline 1 SDTV & $50,0 \%$ & $45,0 \%$ & $35,0 \%$ & $15,0 \%$ \\
\hline 2 SDTV & $28,6 \%$ & $25,7 \%$ & $20,0 \%$ & $8,6 \%$ \\
\hline 3 SDTV & $14,3 \%$ & $12,9 \%$ & $10,0 \%$ & $4,3 \%$ \\
\hline 4 SDTV & $7,1 \%$ & $6,4 \%$ & $5,0 \%$ & $2,1 \%$ \\
\hline 1 HDTV + 1 SDTV & $0,0 \%$ & $6,7 \%$ & $20,0 \%$ & $46,7 \%$ \\
\hline 1 HDTV + 2 SDTV & $0,0 \%$ & $2,5 \%$ & $7,5 \%$ & $17,5 \%$ \\
\hline $2 \mathrm{HDTV}+2 \mathrm{SDTV}$ & $0,0 \%$ & $0,8 \%$ & $2,5 \%$ & $5,8 \%$ \\
\hline $\begin{array}{l}\text { Penetração de } \\
\text { HDTV }(\%)\end{array}$ & $0 \%$ & $10 \%$ & $30 \%$ & $70 \%$ \\
\hline $\begin{array}{l}\text { Média de pontos / } \\
\text { domicílio }\end{array}$ & 1,79 & 1,85 & 1,98 & 2,23 \\
\hline
\end{tabular}

Com relação ao serviço de broadcast e VOD, os parâmetros que norteiam a sua expectativa de adoção estão apresentados na Tabela 12. Foram considerados cinco cenários dos quais dois representam a oferta de broadcast ou VOD de forma mutuamente excludente, e os outros três cenários em que se tem as duas ofertas variando em intensidade de adoção de VOD. A adoção de serviços VOD ainda é recente e as características de utilização podem variar bastante. Para este trabalho, a quantidade de títulos consumidos por assinante foi estimada com base na experiência de operadoras em outros mercados e os parâmetros de simultaneidade foram selecionados com base em estimativas dos fornecedores de tecnologia (18). 
Tabela 12 - Características dos cenários - VOD e broadcast

\begin{tabular}{|c|c|c|c|c|c|}
\hline Perfil VOD & $\begin{array}{c}\text { Apenas } \\
\text { VOD / } \\
\text { Sem } \\
\text { broadcast }\end{array}$ & $\begin{array}{c}\text { Apenas } \\
\text { broadcast/ } \\
\text { Sem VOD }\end{array}$ & $\begin{array}{c}\text { VOD } \\
\text { Conservador }\end{array}$ & $\begin{array}{c}\text { VOD } \\
\text { Moderado } \\
\text { (Cenário } \\
\text { Base) }\end{array}$ & $\begin{array}{c}\text { VOD } \\
\text { Agressivo }\end{array}$ \\
\hline $\begin{array}{l}\text { Penetração } \\
\text { broadcast }\end{array}$ & $0 \%$ & $100 \%$ & $100 \%$ & $100 \%$ & $100 \%$ \\
\hline $\begin{array}{l}\text { Penetração } \\
\text { VOD }\end{array}$ & $100 \%$ & $0 \%$ & $30 \%$ & $70 \%$ & $90 \%$ \\
\hline $\begin{array}{l}\text { Taxa da } \\
\text { simultaneidade } \\
\text { no pico }\end{array}$ & $15 \%$ & $0 \%$ & $5 \%$ & $15 \%$ & $30 \%$ \\
\hline $\begin{array}{l}\text { Títulos } \\
\text { consumidos / } \\
\text { mês }\end{array}$ & 16 & 0 & 8 & 16 & 24 \\
\hline $\begin{array}{l}\text { Porcentagem } \\
\text { de conteúdo } \\
\text { gratuito }\end{array}$ & $60 \%$ & $60 \%$ & $60 \%$ & $60 \%$ & $60 \%$ \\
\hline $\begin{array}{l}\text { Duração média } \\
\text { títulos (min) }\end{array}$ & 90 & 0 & 90 & 90 & 90 \\
\hline $\begin{array}{l}\text { Quantidade de } \\
\text { Títulos }\end{array}$ & 2.000 & 0 & 1.000 & 2.000 & 5.000 \\
\hline SDTV & 1400 & 0 & 700 & 1400 & 3.500 \\
\hline HDTV & 600 & 0 & 300 & 600 & 1.500 \\
\hline
\end{tabular}

Além disso, espera-se a seguinte taxa de adoção para os demais serviços:

- Contratação de pacote canais exclusivos: $30 \%$ da base de assinantes

- Contratação de PVR: $30 \%$ da base de assinantes

\section{B.2.2 Análise de Requisitos}

A partir do entendimento dos serviços que serão oferecidos, foi realizado o mapeamento dos principais requisitos que nortearão a definição da arquitetura tecnológica e estão apresentados na Tabela 13. Os requisitos não funcionais relacionados a desempenho e disponibilidade foram definidos a partir de métricas desenvolvidas pelo DSL Forum (17) para os requisitos de QoE na camada de serviço do modelo de QoE/QoS apresentado no item 2.6.2. 
Tabela 13 - Requisitos de Serviço - ACME

\begin{tabular}{|c|c|c|}
\hline \multirow{2}{*}{$\begin{array}{l}\text { Grupos de } \\
\text { Requisitos }\end{array}$} & \multicolumn{2}{|c|}{ Requisitos } \\
\hline & Funcionais & Não funcionais \\
\hline Funcionalidades & $\begin{array}{l}\text {. Serviços de Vídeo } \\
\text {. Broadcast } \\
\text {.Vídeo Armazenado (VOD / } \\
\text { PVR) } \\
\text {. Vídeo em SDTV e HDTV }\end{array}$ & \\
\hline $\begin{array}{l}\text { Capacidade / } \\
\text { Escalabilidade }\end{array}$ & & $\begin{array}{l}\text { Quantidade de assinantes: } \\
\text { - Vide Figura 51 } \\
\text { Quantidade de canais: } \\
\text { - Vide Tabela } 10 \\
\text {. Adocaão de SDTV / HDTV } \\
\text {-Vide Tabela } 11 \\
\text {. Adoção VOD } \\
\text { - Vide Tabela } 12\end{array}$ \\
\hline Desempenho & $\begin{array}{l}\text {. Existência de mecanismos de } \\
\text { garantia de QoS / QoE } \\
\text { - Controle de Admissão de } \\
\text { vídeo } \\
\text { - Monitoramento / } \\
\text { Gerenciamento do } \\
\text { transporte de vídeo fim-a- } \\
\text { fim }\end{array}$ & $\begin{array}{l}\text { - Qualidade de vídeo / } \\
\text { vídeo } \\
\text { - MOS = } 5 \\
\text {-Sincronização de áudio } \\
\text { / vídeo < } 45 \mathrm{~ms} \\
\text {. Tempos de resposta } \\
\text {-Tempo de inicialização } \\
<10 \mathrm{~s} \\
\text { - Tempo de mudança de } \\
\text { canal < } 2 \mathrm{~s} \\
\text { - Tempo de interações } \\
\text { com interface < } 200 \mathrm{~ms}\end{array}$ \\
\hline $\begin{array}{l}\text { Disponibilidade / } \\
\text { Confiabilidade }\end{array}$ & $\begin{array}{l}\text { Mecanismos de alocação } \\
\text { dinâmica de recursos } \\
\text { Contingência / Redundância } \\
\text { de plataformas tecnológicas } \\
\text {. Mecanismos de verificação e } \\
\text { correção de erros }\end{array}$ & $\begin{array}{l}\text { Disponibilidade de } 99,99 \% \\
\text { (Downtime = 8h } 46 \mathrm{~min} / \\
\text { ano) }\end{array}$ \\
\hline Segurança & $\begin{array}{l}\text { Mecanismos de proteção de } \\
\text { conteúdo } \\
\text { / Mecanismos de Autenticação } \\
\text { / Autorização / Contabilização }\end{array}$ & \\
\hline Gerenciabilidade & $\begin{array}{l}\text { Sistemas de gerenciamento } \\
\text { de falhas e desempenho fim-a- } \\
\text { fim }\end{array}$ & \\
\hline Usabilidade & $\begin{array}{l}\text {. Interface de usuário } \\
\text {. Electronic Program Guide } \\
\text { (EPG) } \\
\text {. Modos de visualização } \rightarrow \\
\text { simples }\end{array}$ & \\
\hline
\end{tabular}




\begin{tabular}{|c|c|c|}
\hline \multirow{2}{*}{$\begin{array}{c}\text { Grupos de } \\
\text { Requisitos }\end{array}$} & \multicolumn{2}{|c|}{ Requisitos } \\
\cline { 2 - 3 } Adaptabilidade & Funcionais & Não funcionais \\
\hline & $\begin{array}{c}\text { Flexibilidade para adição de } \\
\text { novos serviços } \\
- \text { Comunicação (vídeo } \\
\text { telefonia, integração com } \\
\text { telefonia fixa) } \\
\text { - Entretenimento (jogos } \\
\text { online) } \\
\text { - Comércio / Propaganda } \\
\text { direcionada }\end{array}$ \\
\hline
\end{tabular}

\section{B.2.3 Análise da Arquitetura Tecnológica Atual}

\section{B.2.3.1 Levantamento de Informações da Arquitetura Atual}

\section{B.2.3.1.1 Rede}

\section{B.2.3.1.1.1 Serviços Suportados}

A quantidade de assinantes (portas IP instaladas) e o respectivo tráfego gerado para a rede IP para cada um dos serviços IP oferecidos pela ACME estão explicitados na Tabela 14. 
Tabela 14 - Serviços suportados e tráfego gerado

\begin{tabular}{lrr}
\hline Serviço & $\begin{array}{c}\text { Portas } \\
\text { Instaladas }\end{array}$ & $\begin{array}{c}\text { Tráfego } \\
\text { Total (Mbps) }\end{array}$ \\
\hline Acesso Banda Larga & 352.399 & 13.942 \\
\hline $250 \mathrm{kbps}$ & 82.814 & 1.035 \\
\hline $500 \mathrm{kbps}$ & 185.009 & 4.625 \\
\hline $1 \mathrm{Mbps}$ & 52.860 & 2.643 \\
\hline $2 \mathrm{Mbps}$ & 17.620 & 1.762 \\
\hline $4 \mathrm{Mbps}$ & 8.810 & 1.762 \\
\hline 8 Mbps & 5.286 & 2.114 \\
\hline Acesso Banda Estreita & 1.000 .000 & 8.000 \\
\hline Acesso IP Dedicado & 20.000 & 8.000 \\
\hline LAN-to-LAN & 10.000 & 4.000 \\
\hline VPN IP & 20.000 & 8.000 \\
\hline Total & $\mathbf{1 . 4 0 2 . 3 9 9}$ & $\mathbf{4 1 . 9 4 2}$ \\
\hline
\end{tabular}

\section{B.2.3.1.1.2 Núcleo}

A estrutura do núcleo conta com 5 PoPs IP localizados nas 5 regiões em que a ACME está presente, conforme ilustrado na Figura 52. Nos PoPs de núcleo, se situam também os elementos de borda que concentram a inteligência dos serviços e realizam a distribuição de tráfego para a rede de agregação. Os elementos do núcleo IP/MPLS se interconectam utilizando uma rede de transmissão óptica baseada em tecnologia DWDM. 


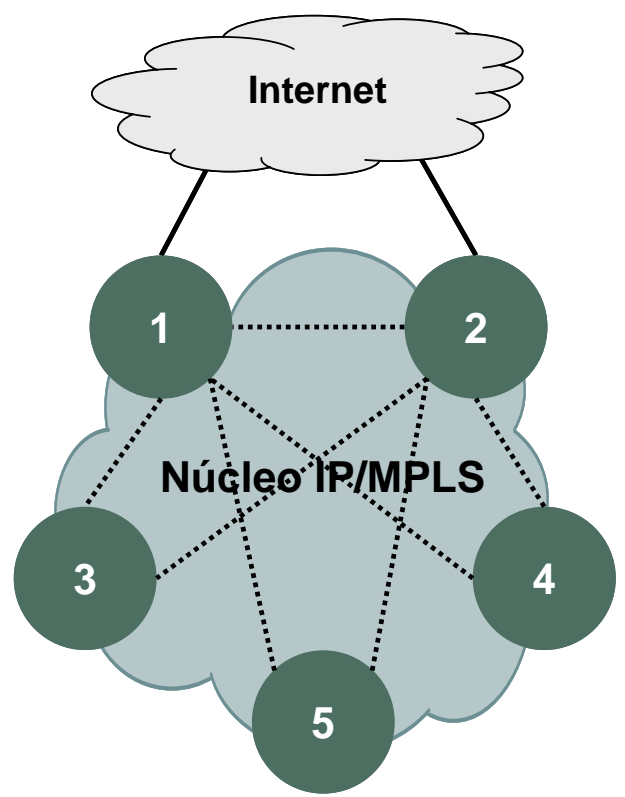

Figura 52 - Topologia do núcleo da Rede IP - ACME

Os PoPs das localidades 1 e 2 concentram a maior parte do tráfego IP, pois possuem a maior quantidade de portas, conforme apresentado na Tabela 15.

Tabela 15 - Distribuição de tráfego

\begin{tabular}{lcc}
\hline Localidade & $\begin{array}{c}\text { Distribuição } \\
\text { de Tráfego (\%) }\end{array}$ & $\begin{array}{c}\text { Tráfego } \\
\text { Total (Mbps) }\end{array}$ \\
\hline Região 1 & $30 \%$ & 12.583 \\
\hline Região 2 & $25 \%$ & 10.485 \\
\hline Região 3 & $20 \%$ & 8.388 \\
\hline Região 4 & $15 \%$ & 6.291 \\
\hline Região 5 & $10 \%$ & 4.194 \\
\hline Total & $\mathbf{1 0 0 \%}$ & $\mathbf{4 1 . 9 4 2}$ \\
\hline
\end{tabular}

Do tráfego total na rede IP, aproximadamente $80 \%$ sai para a Internet (off-net). Os outros 20\% ficam dentro da rede IP da ACME (on-net). Apenas as localidades 1 e 2 realizam interconexão com a Internet, conferindo maior capacidade de processamento de tráfego a estes PoPs, e enlaces de maior capacidade para agregar o tráfego Internet das demais localidades. A saída para a Internet é balanceada entre as duas localidades. 
Tabela 16 - Matriz de tráfego no núcleo da rede

\begin{tabular}{cccccc}
\hline Origem & Destino & $\begin{array}{c}\text { Tráfego } \\
\text { (Mbps) }\end{array}$ & $\begin{array}{c}\text { Capacidade } \\
\text { dos enlaces } \\
\text { (Mbps) }\end{array}$ & $\begin{array}{c}\text { Taxa de } \\
\text { Ocupação } \\
(\%)\end{array}$ & $\begin{array}{c}\text { Ocupação } \\
\text { Máxima } \\
(\%)\end{array}$ \\
\hline 1 & Internet & 16.777 & -- & $56 \%$ & $70 \%$ \\
\hline 1 & 2 & 1.258 & 10.000 & $13 \%$ & $21 \%$ \\
\hline 1 & 3 & 4.781 & 10.000 & $48 \%$ & $51 \%$ \\
\hline 1 & 4 & 3.649 & 10.000 & $36 \%$ & $51 \%$ \\
\hline 1 & 5 & 2.475 & 10.000 & $25 \%$ & $51 \%$ \\
\hline 2 & Internet & 16.777 & -- & $56 \%$ & $70 \%$ \\
\hline 2 & 3 & 4.614 & 10.000 & $46 \%$ & $49 \%$ \\
\hline 2 & 4 & 3.523 & 10.000 & $35 \%$ & $49 \%$ \\
\hline 2 & 5 & 2.391 & 10.000 & $24 \%$ & $49 \%$ \\
\hline
\end{tabular}

O núcleo da rede está construído em uma topologia parcial mesh para interconectar os 5 PoPs visando garantir o nível elevado de disponibilidade da rede. Recentemente, a ACME promoveu a evolução dos enlaces de transmissão DWDM que interconectam o núcleo da rede de capacidade $n \times 2,5$ Gbps para $n \times 10 \mathrm{Gbps}$ visando atender às futuras demandas de tráfego IP. A Tabela 16 apresenta o tráfego em cada um dos enlaces da rede, a capacidade dos enlaces, a taxa de ocupação atual e a taxa de ocupação máxima para garantir as condições de redundância e disponibilidade em caso de falhas. A interconexão com os demais provedores de Internet é realizada através de diversos enlaces dependendo de relações contratuais com tais provedores. 


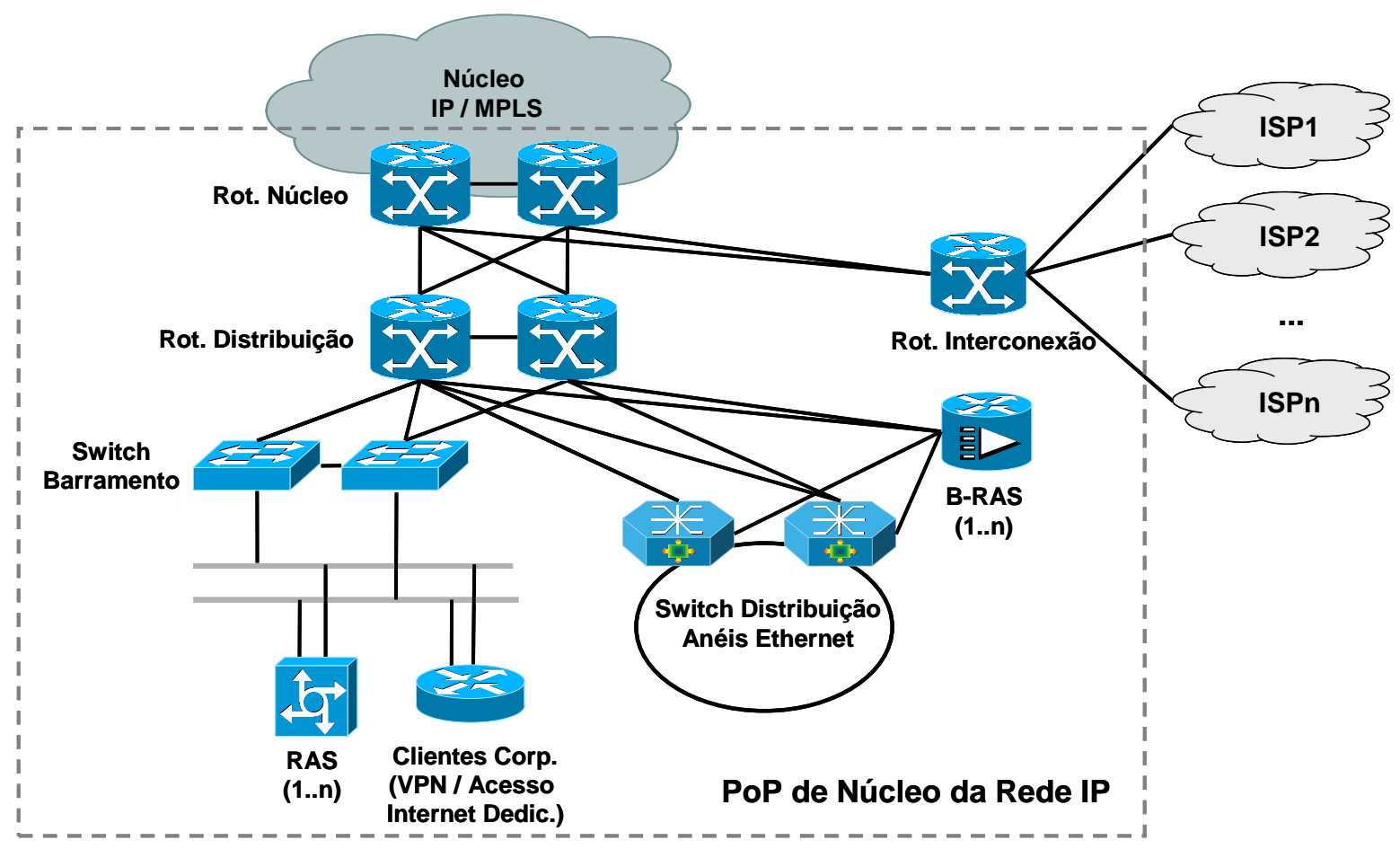

Figura 53 - Estrutura típica de um PoP de núcleo da Rede IP

A topologia típica de um PoP de núcleo da ACME está apresentada na Figura 53. Em cada PoP existem os seguintes elementos:

- Roteadores de núcleo: responsáveis pelo roteamento de pacotes entre os diversos PoPs do núcleo e em direção aos assinantes (tráfego inter-PoP);

- Roteadores de distribuição: responsáveis pelo roteamento de pacotes entre o núcleo e as redes de agregação e acesso;

- Switches do barramento: permitem a conexão dos diversos elementos de rede de borda e acesso nos roteadores de distribuição (principalmente RAS e clientes corporativos);

- Switches/Roteadores de distribuição Ethernet: são os elementos de rede que fazem a distribuição para as redes metropolitanas Ethernet, constituindo os elementos de cabeceira dessas redes;

- B-RAS: concentra o tráfego do serviço de Internet banda larga. Possuem o papel de aplicar políticas do serviço e realizar a gestão dos assinantes;

- RAS: concentram o tráfego para do serviço de Internet discada. Realizam o mesmo papel do B-RAS para acesso discado; 
- Roteadores de acesso de serviços corporativos: elementos de acesso para serviços corporativos (VPN IP / IP Dedicado);

- Roteadores de Interconexão: responsáveis pelo encaminhamento do tráfego para a Internet e outros provedores de telecomunicações.

Visando garantir a disponibilidade da rede, além da topologia parcial mesh, os PoPs de núcleo possuem estrutura redundante. Os roteadores do núcleo, switches de distribuição Ethernet e switches de barramento possuem redundância e trabalham de forma balanceada.

\section{B.2.3.1.1.3 Agregação}

A ACME conta com redes de agregação Ethernet/IP e também ATM. Entretanto, as redes ATM estão em fase final de desativação para transportar o serviço Internet Banda Larga e realizam esse transporte apenas para localidades secundárias. As localidades em que o serviço IPTV será oferecido são, por definição, regiões em que já existem redes de agregação Ethernet/IP. Tais redes possuem capacidade de implementar funcionalidades que requeiram inteligência IP (Camada 3), mas também são capazes de implementar transporte puro Ethernet (Camada 2), sendo consideradas redes ambivalentes Camada 2 / Camada 3 e possuindo também inteligência de controle MPLS. Desta forma, o serviço de Internet banda larga da ACME é implementado em camada 2, utilizando um modelo de agregação de inteligência centralizada no B-RAS, conforme apresentado no item 2.8.1.2. Todas as sessões de assinantes são terminadas no B-RAS que aplica as políticas pertinentes de acordo com os tipos de serviço e assinante. A partir daí, o tráfego é encaminhado ao núcleo da rede e, na seqüência, para a interconexão com outros Internet Service Providers (ISPs). O tráfego do serviço banda larga agregado em cada uma das regiões está apresentado na Tabela 17. 


\begin{tabular}{|c|c|}
\hline Localidade & $\begin{array}{c}\text { Tráfego } \\
\text { Total (Mbps) }\end{array}$ \\
\hline Região 1 & 9.467 \\
\hline Região 2 & 8.240 \\
\hline Região 3 & 5.583 \\
\hline Região 4 & 2.826 \\
\hline Região 5 & 999 \\
\hline Total & 27.114 \\
\hline
\end{tabular}

Apesar do modelo de camada 2 implementado para o serviço banda larga, outros serviços podem ser implementados em camada 3 na rede de agregação, como é o caso do serviço de VPN IP de clientes corporativos.

A transmissão entre os nós da rede de agregação é implementada diretamente sobre fibra óptica apagada na quase totalidade de seus enlaces. Para enlaces que interconectam localidades mais remotas, é utilizada a rede de transmissão SDH para realizar o transporte do tráfego.

Em cada uma das cinco regiões em que a ACME oferece serviços, a topologia das redes de agregação é implementada em anéis $10 \mathrm{Gbps}$ conforme apresentado na Figura 54. Os anéis são compostos por diversos switches/roteadores que além de agregarem o tráfego Internet banda larga, também são utilizados para transportar o tráfego de serviços corporativos (VPN IP, IP Dedicado e LAN-to-LAN). Cada um dos anéis é terminado nos PoPs de núcleo de cada uma das regionais. 


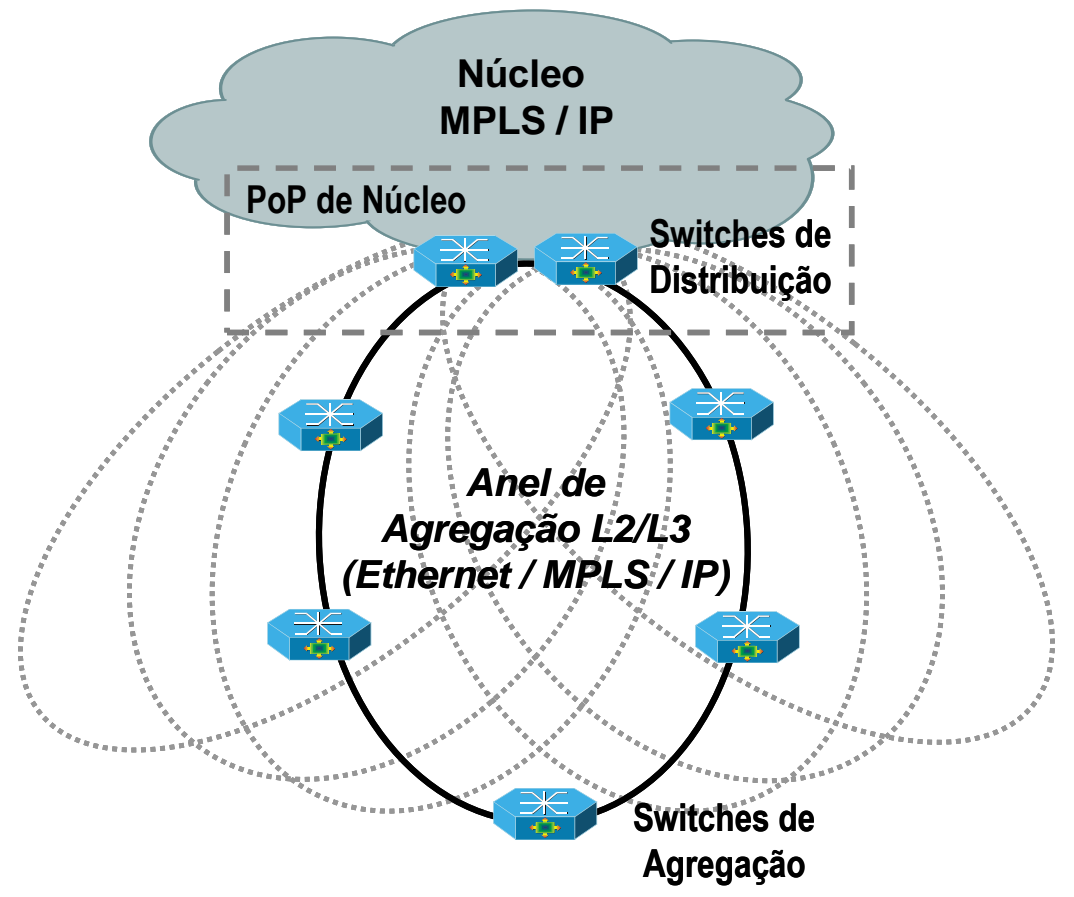

Figura 54 - Topologia típica da rede de agregação - ACME

\section{B.2.3.1.1.4 Acesso}

No acesso, o serviço de Internet Banda Larga é implementado sobre a tecnologia ADSL utilizando a rede de par metálico já existente para a oferta de serviços de telefonia. $\mathrm{Na}$ rede de acesso, existem dois tipos de DSLAMs: baseados em tecnologia ATM ou Ethernet/IP. Da mesma forma que rede de agregação ATM, os DSLAMs ATM estão em processo de desativação e todas as novas implementações são realizadas utilizando DSLAMs com tecnologia Ethernet/IP. Os DSLAMs ATM remanescentes servem as localidades secundárias, onde não será oferecido o serviço IPTV e, portanto, serão desconsiderados nessa análise. 


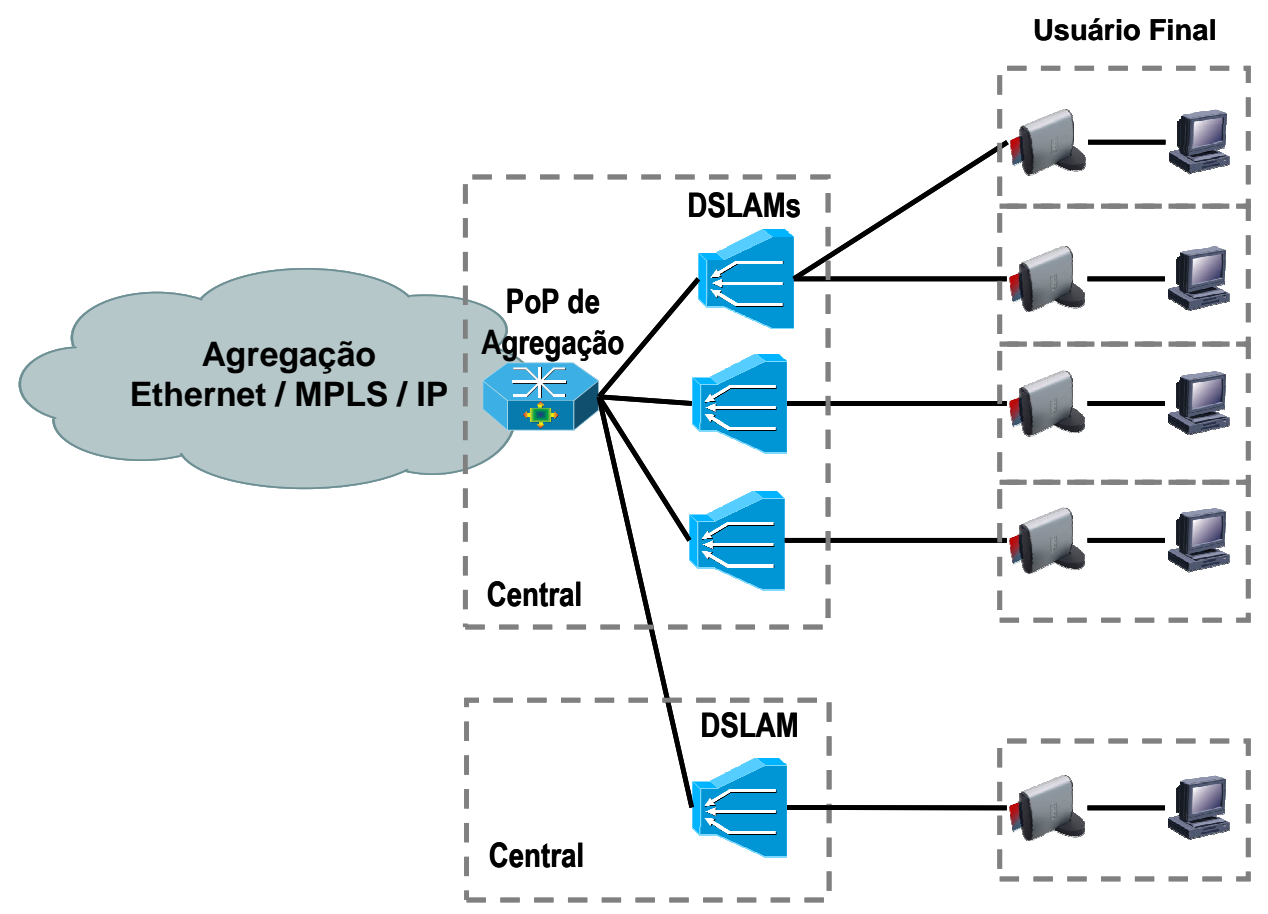

Figura 55 - Topologia da rede de acesso ACME

A topologia da rede corresponde à FTTN discutida no item 2.8.1.3. Os DSLAMs existentes na rede são prediais, ou seja, instalados nos prédios de central, também conhecidos como Central Office (CO). Esses DSLAMs são conectados aos switches/roteadores das redes de agregação Ethernet/IP por meio de conexão em fibra óptica. Em regiões de maior densidade de assinantes, PoPs da rede de agregação e DSLAMs estão no mesmo prédio (ou seja, existe um PoP de agregação no prédio da central), e a conexão entre os DSLAMs e a rede de agregação é realizada no próprio prédio da central. Naquelas localidades de menor densidade, os DSLAMs se interconectam no PoP de agregação mais próximo. A topologia física da rede de acesso está ilustrada nas figuras a seguir. A Figura 55 ilustra a arquitetura macro da rede do ponto de vista lógico, e a Figura 56 ilustra como a rede de acesso se distribui geograficamente e os seus principais elementos. 


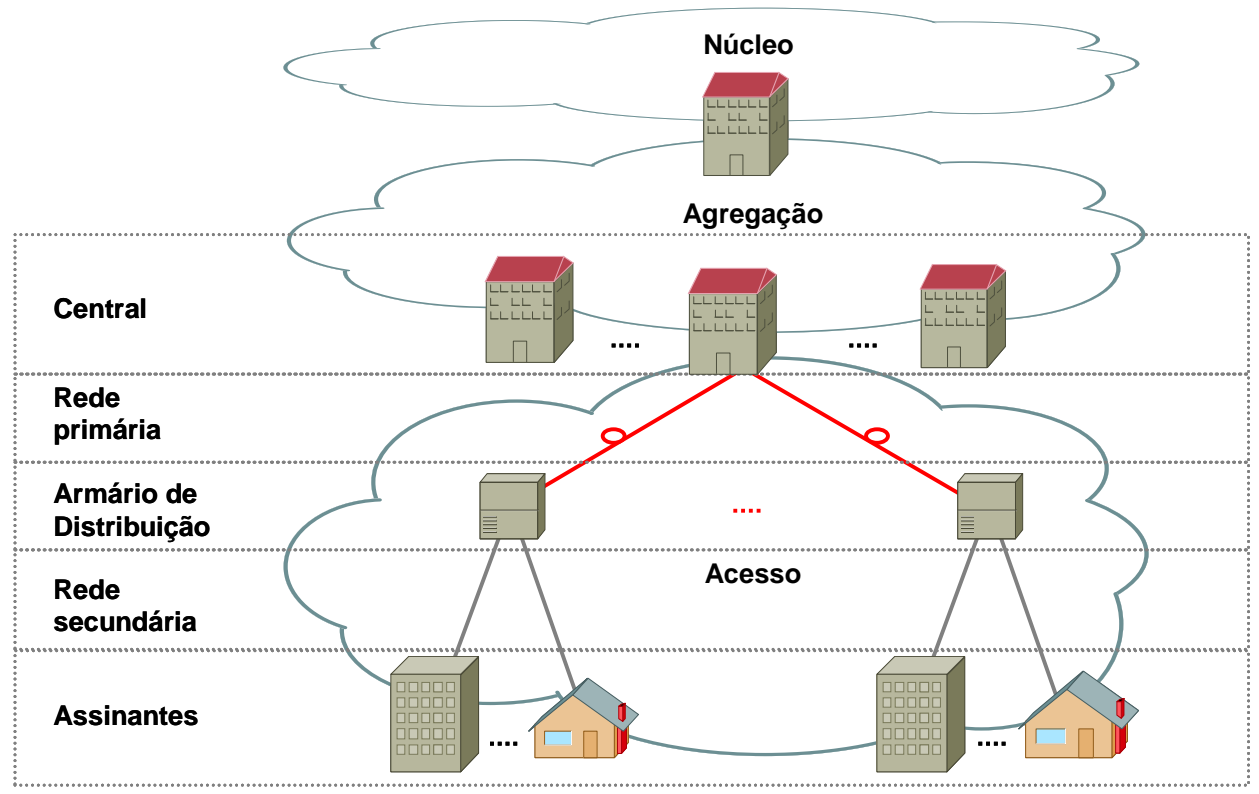

Figura 56 - Distribuição geográfica da rede de acesso - ACME

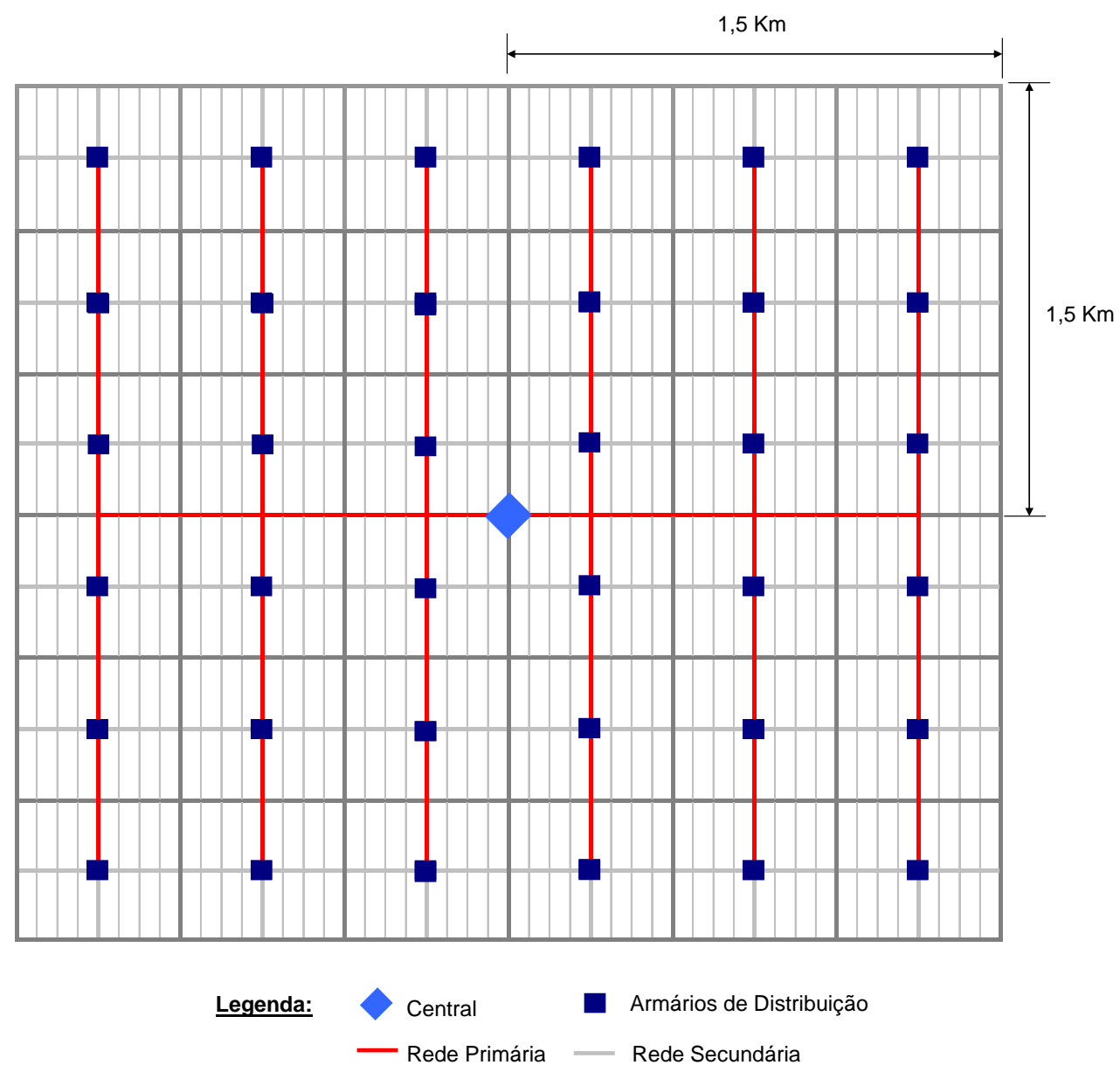

Figura 57 - Topologia da planta externa - ACME 
Um aspecto importante na rede de acesso é a distância entre o DSLAM e o usuário final, ou seja, o comprimento do par metálico que conecta o usuário ao DSLAM. Quanto maior a distância, menor a taxa de transmissão oferecida pela tecnologia DSL (vide Figura 14).

Por simplificação, assume-se que as centrais da ACME nas regiões urbanas onde será oferecido o serviço abrangem áreas uniformes e tem sua região de cobertura definida pelo esquema da Figura 57. Desta forma, as centrais e, por conseqüência, os DSLAMs atendem uma região de aproximadamente $3 \mathrm{~km} \times 3 \mathrm{~km}$ nas regiões urbanas conforme. Tais regiões possuem densidade populacional da ordem de 2.000 domicílios / $\mathrm{km}^{2}$ (31). Cada central de fios abrange em média 18.000 assinantes de telefonia, que estão divididos em 36 armários de distribuição, e cada DSLAM localizado na central atende em média 500 assinantes. Tais parâmetros da rede de acesso nas regiões urbanas foram estimados com base em outras modelagens já realizadas para redes de acesso (31) e também referências de mercado (4).

A conexão entre a central e os armários constitui a rede primária de distribuição e é implementada de forma subterrânea; já a conexão entre os usuários e os armários constitui a rede secundária de distribuição e é implementada de forma aérea.

$\mathrm{Na}$ topologia de rede atual, o comprimento do trecho entre a central e a residência do usuário final atinge distâncias da ordem $2 \mathrm{~km}$, em que é possível oferecer taxas da ordem de 6-8 Mbps ao usuário final de Internet Banda Larga utilizando tecnologia ADSL.

\section{B.2.3.1.1.5 Resumo das Características de rede}

A Tabela 18 apresenta a distribuição de elementos de rede voltados à prestação de serviços banda larga ao longo das cinco regiões de atuação da ACME. 
Tabela 18 - Distribuição de elementos de rede

\begin{tabular}{|c|c|c|c|c|c|c|}
\hline & $\begin{array}{c}\text { Região } \\
1\end{array}$ & $\begin{array}{c}\text { Região } \\
\quad 2\end{array}$ & $\begin{array}{c}\text { Região } \\
3\end{array}$ & $\begin{array}{c}\text { Região } \\
\quad 4\end{array}$ & $\begin{array}{c}\text { Região } \\
\quad 5\end{array}$ & Total \\
\hline \multicolumn{7}{|l|}{ Núcleo } \\
\hline \multicolumn{7}{|l|}{ Roteadores de } \\
\hline Núcleo & 2 & 2 & 2 & 2 & 2 & 10 \\
\hline \multirow{2}{*}{\multicolumn{7}{|c|}{$\begin{array}{l}\text { Roteadores de } \\
\text { Distribuição }\end{array}$}} \\
\hline & 2 & 2 & 2 & 2 & 2 & 10 \\
\hline \multicolumn{7}{|l|}{$\begin{array}{l}\text { Roteadores de } \\
\text { Interconexão }\end{array}$} \\
\hline Interconexão & 2 & 2 & 0 & 0 & 0 & 4 \\
\hline \multicolumn{6}{|l|}{ Switches de } & 10 \\
\hline B-RAS & 3 & 2 & 2 & 2 & 1 & 10 \\
\hline \multicolumn{7}{|l|}{ Agregação } \\
\hline Anéis & 3 & 3 & 3 & 2 & 1 & 12 \\
\hline Nós de agregação & 12 & 10 & 9 & 7 & 5 & 43 \\
\hline $\begin{array}{l}\text { Switches de } \\
\text { distribuição }\end{array}$ & 2 & 2 & 2 & 2 & 2 & 10 \\
\hline $\begin{array}{l}\text { Switches de } \\
\text { agregacãa }\end{array}$ & 10 & 8 & 7 & 5 & 3 & 33 \\
\hline \multicolumn{7}{|l|}{ Acesso } \\
\hline $\begin{array}{l}\text { Nós de acesso / } \\
\text { DSLAMs }\end{array}$ & 211 & 176 & 141 & 106 & 70 & 705 \\
\hline Centrais de Fios & 33 & 28 & 22 & 17 & 11 & 111 \\
\hline $\begin{array}{l}\text { Armários de } \\
\text { distribuicão }\end{array}$ & 1.200 & 1.000 & 800 & 600 & 400 & 4.000 \\
\hline $\begin{array}{l}\text { Assinantes Banda } \\
\text { Larga }\end{array}$ & 105.720 & 88.100 & 70.480 & 52.860 & 35.240 & 352.399 \\
\hline
\end{tabular}

\section{B.2.3.1.2 Gerenciamento}

A ACME conta com um conjunto de ferramentas de OSS/BSS para realizar o gerenciamento dos serviços e da rede IP de maneira fim-a-fim. As classes de ferramentas existentes estão enumeradas a seguir de acordo com as grandes áreas 
do modelo de referência do eTOM apresentado no item 2.9, além das ferramentas que percorrem todas as áreas de maneira fim-a-fim.

- Aprovisionamento

- Aprovisionamento / Configuração: suportam a ativação de novos serviços / clientes.

- Garantia de Qualidade

- Gerência de Falhas: coleta, filtragem, correlação e normalização de alarmes e eventos de falha de rede e serviços, incluindo também os registros de falhas de clientes / serviços e rede, e acompanhamento da resolução de problemas.

- Gerência de Desempenho: coleta, análise e relatórios de desempenho e utilização de rede e serviços;

- Gerência de Testes: suporta e automatiza procedimentos de testes de rede e serviços;

- Service Level Management (SLM): gestão do nível dos serviços prestados;

- Faturamento

- Mediação: coleta de registros de utilização dos recursos de rede e serviços;

- Faturamento (Billing): consolidação dos dados de utilização de serviços por clientes e emissão de faturas.

- Autorização / Autenticação / Contabilização: realizam o controle da utilização de serviços / recursos de rede pelos clientes devidos.

- Suporte e Disponibilidade de Operações

- Inventário: repositório com as informações a respeito dos ativos da rede.

- Ferramentas fim-a-fim

- CRM: mapeia processos de negócio para o cliente de maneira fim-a-fim: desde ordem de serviço até falhas e cobrança. 
- Gestão da Força de Trabalho (Workforce Management): mapeia processos de trabalho de maneira fim-a-fim.

- Gestão de Ordem de Serviço (Order Management): registro e gerenciamento da execução ordens de serviço.

- Enterprise Application Integration (EAI): realizam a integração entre as diversas camadas de rede, serviço e cliente.

\section{B.2.3.2 Levantamento de informações de tendências de evolução}

A evolução da arquitetura tecnológica atual visa suportar a evolução dos serviços prestados atualmente pela rede IP. Os principais motivadores dessa evolução são: crescimento de usuários banda larga e a oferta crescente de maior largura de banda para atender aos requisitos das aplicações multimídia disponíveis na Internet e responder à altura aos movimentos da concorrência na oferta de acesso de Internet banda larga. Atualmente, as operadoras cabo concorrentes da ACME já começam a promover com maior intensidade a oferta de banda larga nas velocidades 2, 4 e 8 Mbps.

A Figura 58 apresenta a evolução esperada do tráfego na rede IP da ACME em virtude do crescimento dos serviços IP. Espera-se que a distribuição do tráfego entre as regionais no futuro seja muito parecida com a atual. Além disso, espera-se que a proporção de tráfego on-net seja maior no futuro (da ordem de 30\%), com a adoção de medidas para trazer maior quantidade de conteúdo para dentro da rede ACME. 


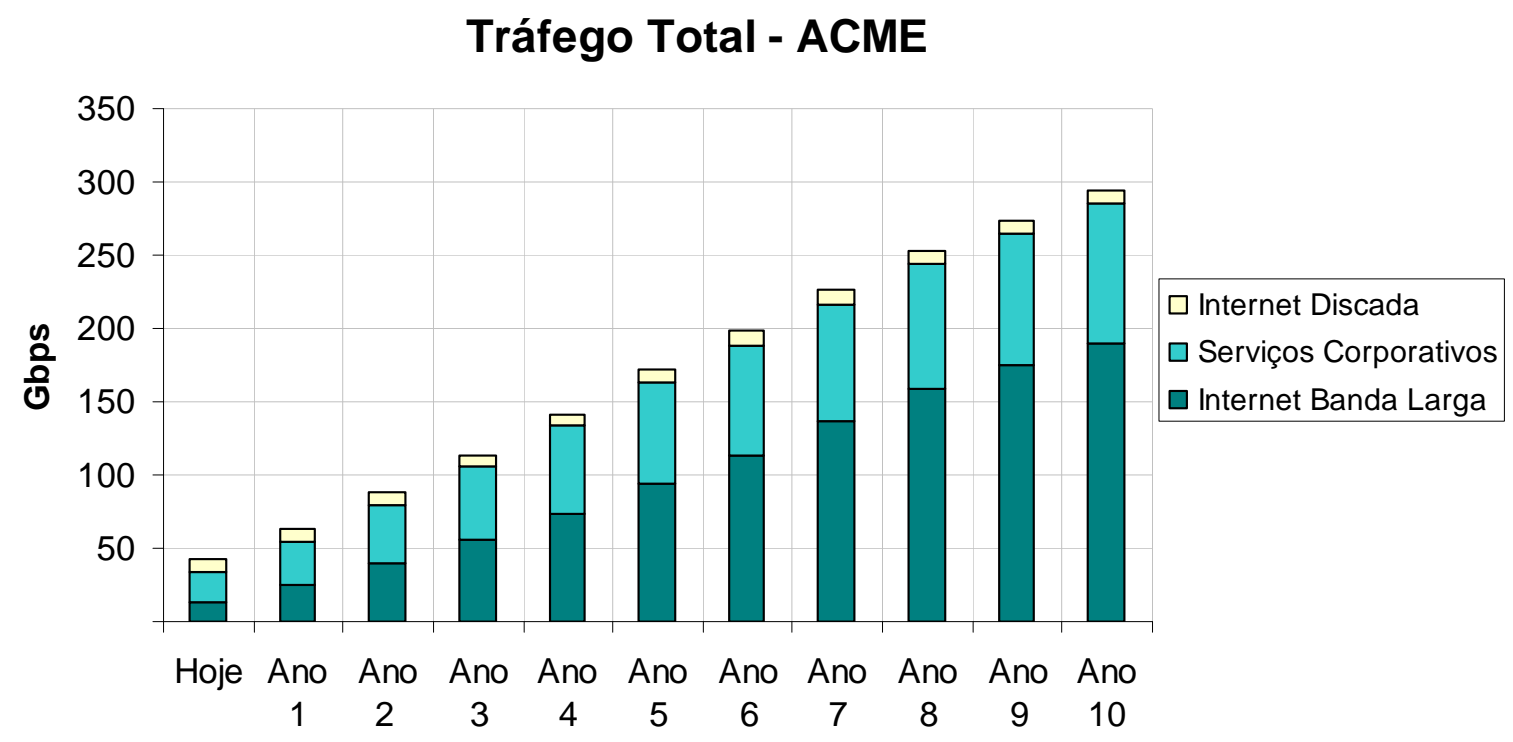

Figura 58 - Projeção de Evolução de Tráfego - ACME

Para suportar tal expectativa de crescimento de serviços IP, a ACME deverá evoluir sua rede de maneira a suportar tal volume de tráfego. A expectativa de evolução do tráfego em cada segmento de rede será apresentada no item B.2.4. Algumas diretrizes de evolução já foram tomadas pela equipe de engenharia com relação à infra-estrutura tecnológica:

- Rede

- Núcleo: já foi realizada a evolução dos enlaces de núcleo para $n \times 10 \mathrm{Gbps}$ visando à escalabilidade futura. A evolução para $40 \mathrm{Gbps}$ no núcleo será considerada oportunamente de acordo com o crescimento do tráfego.

- Agregação: modelo de agregação utiliza Ethernet/IP em topologia de anéis de velocidade de $10 \mathrm{Gbps}$. As redes ATM estão em processo de desativação e todas as novas expansões das redes de agregação deverão ocorrer utilizando Ethernet/IP.

- Acesso: utilização de tecnologia XDSL para a oferta de serviços Internet banda larga, utilizando DSLAMs Ethernet/IP. Os DSLAMs ATM estão em processo de desativação. A evolução do acesso para tecnologias ópticas está sendo considerada e a sua implementação dependerá da evolução da 
demanda e movimentação da concorrência visando à oferta de maior largura de banda ao usuário final.

- Gerenciamento: a arquitetura existente de OSS/BSS é bastante flexível e escalável para suportar novos serviços e se ampara em modelos conceituais tradicionais. Desta forma, a arquitetura deverá ser mantida mesma para suportar a evolução de serviços, sofrendo adaptações à medida do necessário.

\section{B.2.3.3 Análise e Validação das Informações}

A descrição e análise do ambiente atual foram realizadas ao longo dos itens anteriores. Para efeitos da aplicação da metodologia neste caso, supõe-se que todas as informações são válidas e que foram obtidas em entrevistas com as equipe de engenharia e de operações.

\section{B.2.4 Definição e Dimensionamento da Arquitetura Tecnológica}

\section{B.2.4.1 Análise e dimensionamento das alternativas de Arquitetura Tecnológica}

Nesta seção estão apresentadas as principais considerações relacionadas à arquitetura tecnológica incluindo infra-estrutura de: serviço, rede e gerenciamento. Quando da apresentação de valores de dimensionamento, eles correspondem ao cenário base de serviços. As considerações relativas aos cenários alternativos serão realizadas ao longo das análise de sensibilidade e cenários no item B.4. 


\section{B.2.4.1.1 Infra-estrutura de serviço}

\section{B.2.4.1.1.1 Sistemas de Head-end}

Os sistemas de recepção deverão suportar a recepção de 200 canais conforme apresentado na Tabela 10. No SHE será recebido conteúdo para distribuição nacional e também conteúdo local da região em que ele se localiza, e nos VHOs será recebido apenas conteúdo local (canais abertos).

Os equipamentos de recepção nos SHE e VHOs são proporcionais à quantidade de canais recebidos. Os equipamentos relacionados à recepção incluem: conjunto de antenas satélite (incluindo também os splitters e LNBs) e VHF/UHF (incluindo splitters), e receptores (satélite, VHF/UHF e fibra óptica). Os principais blocos da solução relacionados à recepção estão evidenciados na Figura 59.

Para realizar o dimensionamento, foi definida uma grade de canais típica de TV fechada e se obteve a alocação dos canais nos meios de recepção:

- Satélite: 170 canais recebidos a partir de diversos satélites e com codificação diversificada de acordo com o portal Lyngsat (55);

- VHF/UHF: 25 canais abertos recebidos em cada regional;

- Fibra: 5 canais locais recebidos em cada regional; 


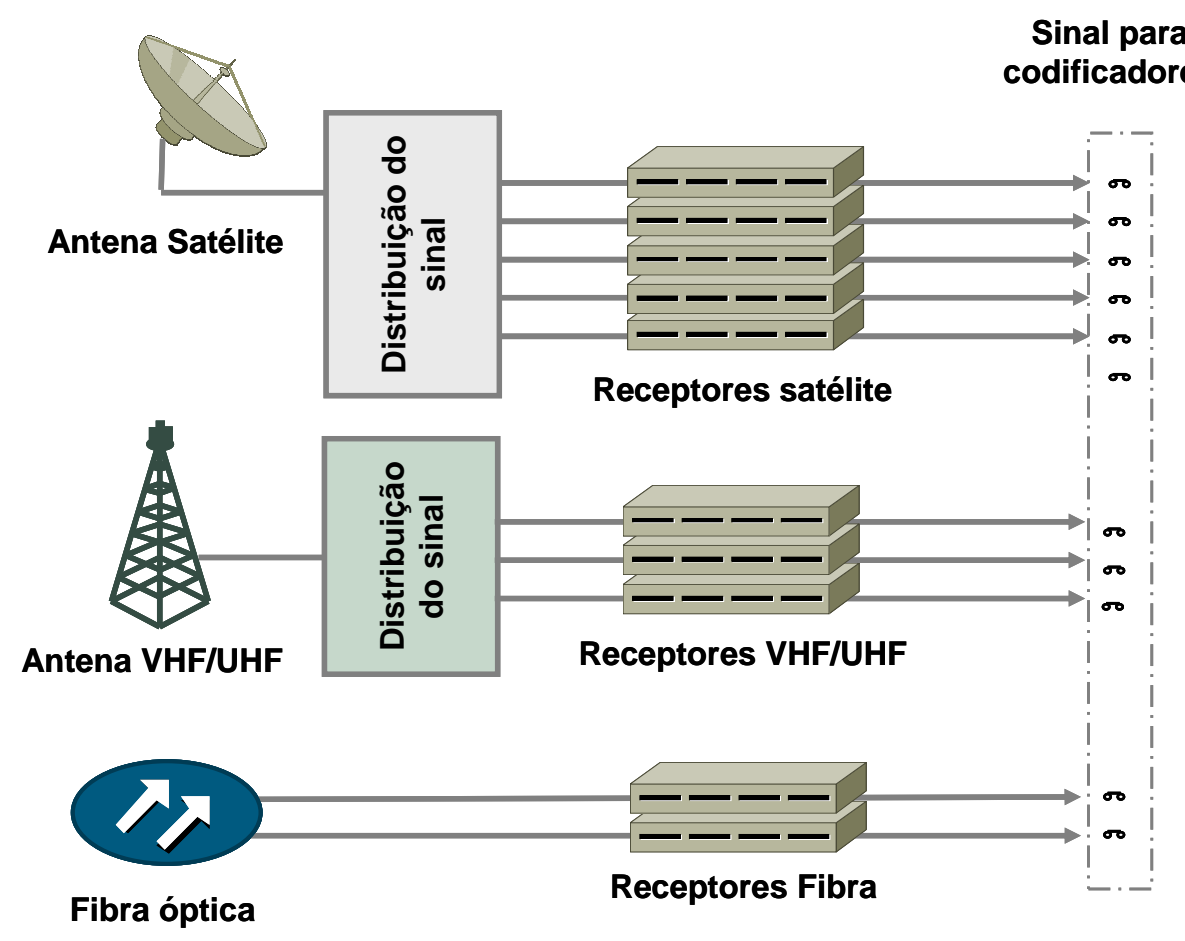

Figura 59 - Sistemas de recepção

A quantidade de equipamentos de recepção necessária em cada localidade no cenário base de serviços está apresentada a seguir:

- SHE: 1 localidade

- Conteúdo de satélite: supõe-se que 6 satélites concentram os 170 canais a partir de uma grade de canais hipotética. Logo, são considerados 7 conjuntos antenas parabólicas banda $\mathrm{C} / \mathrm{Ku}$ de $4,5 \mathrm{~m}$ de diâmetro (6 antenas tradicionais fixas e 1 antena de orientação automática que pode receber canais no lugar de qualquer outra antena ativa em caso de falha). Os conjuntos de antenas incluem LNBs e splitters para distribuir os canais, além de um switch L-Band que realiza a comutação para a antena redundante em caso de falha. Além disso, são necessários 180 IRDs (170 +10 sobressalentes) variados recepcionar os canais satélite;

- Conteúdo VHF/UHF: 6 conjuntos de antenas VHF/UHF single log para receber canais abertos ( 5 antenas fixas e 1 antena de busca que atua pode receber canais no lugar de qualquer antena ativa em caso de falha) incluindo splitters para distribuir os canais; e 28 demoduladores VHF/UHF ( $25+3$ sobressalentes). 
- Conteúdo fibra: 5 receptores baseados em tecnologia de fibra óptica.

- VHO: 4 localidades

- Conteúdo VHF/UHF e via fibra óptica: idem à infra-estrutura para receber canais abertos VHF/UHF no SHE;

Além dos sistemas de recepção, nos SHE e VHO, são necessários equipamentos para realizar o processamento e codificação dos sinais. Os principais blocos da solução relacionados à codificação estão evidenciados na Figura 60 .

Foi selecionado o padrão de codificação MPEG-4 AVC devido a sua grande eficiência de compressão que se traduz em economia significativa de banda e devido à crescente disponibilidade de dispositivos compatíveis no mercado (desde codificadores até set-top boxes). Para efeitos de dimensionamento da infra-estrutura de rede e de armazenamento, considera-se que os codificadores empregados oferecem a compressão de conteúdo nas taxas indicadas na Tabela 19 extraídas a partir das referências de taxa de codificação apresentadas no item 2.7.1.2, e de informações de fornecedores.

Tabela 19 - Taxa de codificação MPEG-4 AVC

\begin{tabular}{cc}
\hline Qualidade & Média \\
\hline SDTV & $1,8 \mathrm{Mbps}$ \\
HDTV & $7,5 \mathrm{Mbps}$ \\
\hline
\end{tabular}




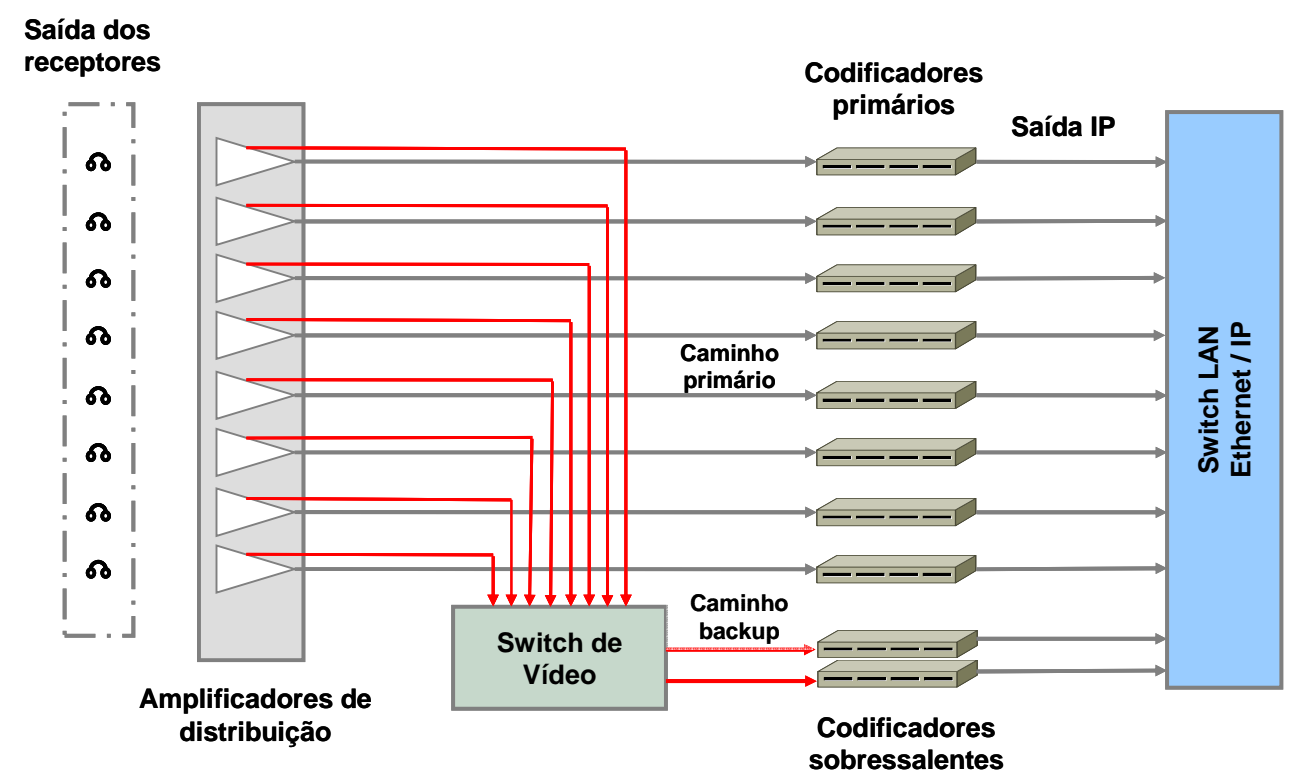

Figura 60 - Sistemas de processamento e codificação

A quantidade de equipamentos necessária em cada localidade no cenário base de serviços está apresentada a seguir:

- SHE: 1 localidade (canais: 130 SDTV / 70 HDTV)

- Codificadores broadcast:

- MPEG-4 SDTV: 130 + 10 sobressalentes;

- MPEG-4 HDTV: 70 + 5 sobressalentes;

- 200 amplificadores de distribuição das saídas dos receptores;

- 1 plataforma de inserção de conteúdo VOD;

- 1 switch de vídeo para realizar a comutação dos canais para codificadores backup em caso de falha;

- 1 switch Gigabit Ethernet para conectar codificadores, plataforma de middleware e DRM à infra-estrutura de rede multisserviço da ACME.

- VHO: 4 localidades (quantidades por localidade)

- Codificadores broadcast (canais: 20 SDTV / 10 HDTV)

- MPEG-4 SDTV: 20 + 2 (redundância);

- MPEG-4 HDTV: 10 + 2 (redundância) 
- 30 amplificadores de distribuição;

- 1 switch de vídeo;

- 1 switch Gigabit Ethernet.

Além do dimensionamento dos equipamentos mencionados, foram identificadas as necessidades de preparação e modificação de infra-estrutura para instalar os equipamentos. As adaptações de infra-estrutura incluem, por exemplo: ar condicionado, instalação elétrica, dutos, bastidores para equipamentos, bases e torres para antenas, entre outros. Tal dimensionamento não será detalhado, pois não é o foco do trabalho, mas foi devidamente considerado no custeio dos blocos da solução.

\section{B.2.4.1.1.2 Middleware}

Considerando que a arquitetura das plataformas varia significativamente de fabricante para fabricante e que o foco desse trabalho não é a especificação detalhada de hardware e software da plataforma de middleware, foram especificados os requisitos que a plataforma deve atender. Assim, é possível realizar uma estimativa de dimensionamento e custo de uma plataforma de middleware.

Os principais requisitos funcionais da plataforma de middleware dimensionada para o caso da ACME:

- Serviços oferecidos: broadcast e VOD;

- Funções para o assinante: EPG;

- Funções de administração do serviço para a operadora: neste caso, o middleware inclui as funções de BSS / OSS relacionadas às plataformas de conteúdo;

- Integração para novos serviços: plataforma customizável visando flexibilidade para adição de novos serviços, tais como, jogos, áudio, integração com telefonia, etc.; 
- Plataforma compatível com componentes da solução de IPTV de outros fabricantes (ex.: set-top box, DRM) e customizável para integração com fabricantes ainda não suportados.

O principal parâmetro quantitativo para a estimativa de custo da plataforma foi a quantidade de assinantes do serviço.

\section{B.2.4.1.1.3 Digital Rights Management}

O dimensionamento da plataforma de DRM foi realizado de maneira similar ao da plataforma de middleware pelas mesmas razões. Desta forma, foram identificados os principais requisitos que a plataforma deveria atender, para que seja possível realizar uma estimativa de dimensionamento e custo.

Os principais requisitos funcionais identificados para o caso da ACME foram:

- Proteção de conteúdo em transporte (broadcast e VOD) e do conteúdo armazenado no PVR;

- Método de autenticação a ser empregado baseado no conceito de virtual smart cards, devido à sua maior simplicidade de gestão operacional;

- Plataforma compatível com componentes da solução de IPTV de outros fabricantes (ex.: set-top box, middleware) e customizável para integração com fabricantes ainda não suportados.

O principal parâmetro quantitativo utilizado para a estimativa de custo da plataforma de DRM foi a quantidade de assinantes. 


\section{B.2.4.1.1.4 Servidores de Vídeo}

Para o dimensionamento dos servidores de vídeo, três arquiteturas foram consideradas:

- Centralizada no SHE: todo o conteúdo de vídeo fica residente no SHE e todas as requisições vão até ele.

- Distribuída no VHO: a injeção de 100\% conteúdo original é feita no SHE. Entretanto, cópias dos títulos mais populares são realizadas para infraestrutura de armazenamento localizada no VHO. Desta forma, $20 \%$ do conteúdo é replicado nos $\mathrm{VHOs,} \mathrm{que} \mathrm{atendem} 80 \%$ das requisições.

- Distribuída no VSO: conceito análogo ao anterior. A diferença é que existe uma cópia de $100 \%$ do conteúdo do SHE em cada VHO e, além disso, cópia do conteúdo mais popular é realizada nos VSO. De forma análoga ao anterior, $20 \%$ do conteúdo é copiado nos VSOs que atendem $80 \%$ das requisições. Apesar da réplica integral do conteúdo em cada VHO, o SHE continua sendo o ponto único de injeção de conteúdo.

A distribuição do conteúdo para mais perto do assinante visa à diminuição de utilização de recursos de rede e aumento de desempenho. A relação custo-benefício que se dá em cada um dos cenários determina qual a melhor abordagem.

Para suportar tal distribuição de conteúdo, a arquitetura de referência de servidores de vídeo utilizada para o dimensionamento conta com módulos de armazenamento / streaming do conteúdo, e módulos de controle. Os módulos de controle são responsáveis por: direcionar qual módulo de armazenamento será acessado; realizar o balanceamento de carga entre as diversas unidades de armazenamento; e realizar a replicação do conteúdo no caso de arquiteturas distribuídas.

Conforme indicado no item 4.2.2.4.1.1.4, para dimensionar os servidores de vídeo em suas diversas arquiteturas de distribuição, foram utilizados os parâmetros de espaço de armazenamento e vazão em cada localidade (considerando overhead de protocolos de rede). Os cálculos foram individualmente para o conteúdo em qualidade SDTV e HDTV e depois os dois resultados foram somados para compor 
os parâmetros necessários para dimensionar adequadamente os servidores de vídeo.

$\mathrm{Na}$ Tabela 20, estão apresentados os parâmetros de dimensionamento de servidores de vídeo para cada um dos tipos de arquitetura, considerando o cenário base de serviços. Nessa tabela, estão indicados o volume de armazenamento e a vazão necessária em cada nó para cada uma das arquiteturas. Foi escolhida região 2 para exemplificar o dimensionamento de maneira mais condensada nas diversas arquiteturas. A coluna que se refere à concentração indica a porcentagem em volume (proporcional à quantidade de títulos) e em vazão (proporcional a acessos simultâneos) que está concentrada naquele nó da infra-estrutura.

Os principais parâmetros para realizar o dimensionamento foram: a quantidade de títulos indicada no item B.2.1.1; a quantidade de assinantes indicada no item B.2.1.4; e perfil de utilização de VOD indicado no item B.2.1.5; e as taxas de codificação apresentadas na Tabela 20. 
Tabela 20 - Dimensionamento - Servidores de Vídeo

\begin{tabular}{|c|c|c|c|c|c|c|c|c|c|c|c|}
\hline Arquiteturas & Concentração & $\begin{array}{c}\text { Ano } \\
1\end{array}$ & $\begin{array}{c}\text { Ano } \\
2\end{array}$ & $\begin{array}{c}\text { Ano } \\
3\end{array}$ & $\begin{array}{c}\text { Ano } \\
4\end{array}$ & $\begin{array}{c}\text { Ano } \\
5\end{array}$ & $\begin{array}{c}\text { Ano } \\
6\end{array}$ & $\begin{array}{c}\text { Ano } \\
7\end{array}$ & $\begin{array}{c}\text { Ano } \\
8\end{array}$ & $\begin{array}{c}\text { Ano } \\
9\end{array}$ & $\begin{array}{c}\text { Ano } \\
10\end{array}$ \\
\hline \multicolumn{12}{|c|}{ Centralizado no SHE } \\
\hline \multicolumn{12}{|c|}{ SHE } \\
\hline Volume(Gbyte) & $100 \%$ & 5,1 & 5,1 & 5,1 & 5,1 & 5,1 & 5,1 & 5,1 & 5,1 & 5,1 & 5,1 \\
\hline Vazão(Gbps) & $100 \%$ & 26,2 & 59,0 & 97,6 & 139,8 & 181,6 & 218,9 & 248,5 & 269,7 & 283,4 & 291,8 \\
\hline \multicolumn{12}{|c|}{ Distribuído no VHO } \\
\hline \multicolumn{12}{|c|}{ SHE } \\
\hline Volume (Gbyte) & $100 \%$ & 5,1 & 5,1 & 5,1 & 5,1 & 5,1 & 5,1 & 5,1 & 5,1 & 5,1 & 5,1 \\
\hline Vazão (Gbps) & $20 \%$ & 5,2 & 11,8 & 19,5 & 28,0 & 36,3 & 43,8 & 49,7 & 53,9 & 56,7 & 58,4 \\
\hline \multicolumn{12}{|l|}{ VHO Região 2} \\
\hline Volume (Gbyte) & $20 \%$ & 1,0 & 1,0 & 1,0 & 1,0 & 1,0 & 1,0 & 1,0 & 1,0 & 1,0 & 1,0 \\
\hline Vazão (Gbps) & $80 \%$ & 5,2 & 11,8 & 19,5 & 28,0 & 36,3 & 43,8 & 49,7 & 53,9 & 56,7 & 58,4 \\
\hline \multicolumn{12}{|c|}{ Distribuído no VSO } \\
\hline \multicolumn{12}{|c|}{ SHE } \\
\hline Volume (Gbyte) & $100 \%$ & 5,1 & 5,1 & 5,1 & 5,1 & 5,1 & 5,1 & 5,1 & 5,1 & 5,1 & 5,1 \\
\hline Vazão (Gbps) & $\mathrm{N} / \mathrm{A}$ & 0,1 & 0,1 & 0,1 & 0,1 & 0,1 & 0,1 & 0,1 & 0,1 & 0,1 & 0,1 \\
\hline \multicolumn{12}{|l|}{ VHO Região2 } \\
\hline Volume (Gbyte) & $100 \%$ & 5,1 & 5,1 & 5,1 & 5,1 & 5,1 & 5,1 & 5,1 & 5,1 & 5,1 & 5,1 \\
\hline Vazão (Gbps) & $20 \%$ & 1,3 & 2,9 & 4,9 & 7,0 & 9,1 & 10,9 & 12,4 & 13,5 & 14,2 & 14,6 \\
\hline \multicolumn{12}{|l|}{ VSO Região2 } \\
\hline Volume (Gbyte) & $20 \%$ & 1,0 & 1,0 & 1,0 & 1,0 & 1,0 & 1,0 & 1,0 & 1,0 & 1,0 & 1,0 \\
\hline Vazão (Gbps) & $80 \%$ & 0,4 & 0,7 & 0,9 & 1,1 & 1,3 & 1,4 & 1,5 & 1,5 & 1,5 & 1,6 \\
\hline
\end{tabular}


Cada uma das arquiteturas se traduz em perfis de tráfego diferenciados para os segmentos de núcleo e agregação da rede IP multisserviço. Na Figura 61, está exemplificado o perfil de tráfego VOD no núcleo para as três arquiteturas no cenário base, e a Figura 62 compara o perfil de tráfego nas redes de agregação nas mesmas condições.

O tráfego no núcleo é significativamente superior na arquitetura centralizada no SHE quando comparado às outras arquiteturas. Quando o conteúdo é distribuído até o VHO, uma boa parte das requisições de assinantes é atendida pelo próprio VHO, diminuindo o tráfego no núcleo. No extremo em que o conteúdo é distribuído até o VSO, o tráfego no núcleo é marginal para suportar apenas a replicação de conteúdo do SHE para os VHO e pode ser feita em horários programados em que o volume de tráfego na rede é menor.

Nas redes de agregação, os perfis de tráfego nas arquiteturas centralizada e distribuída até o VHO são idênticos. Há uma diminuição significativa de tráfego quando o conteúdo está distribuído até o VSO, pois a maior parte das requisições é atendida no próprio VSO. 


\section{Tráfego VOD no Núcleo}

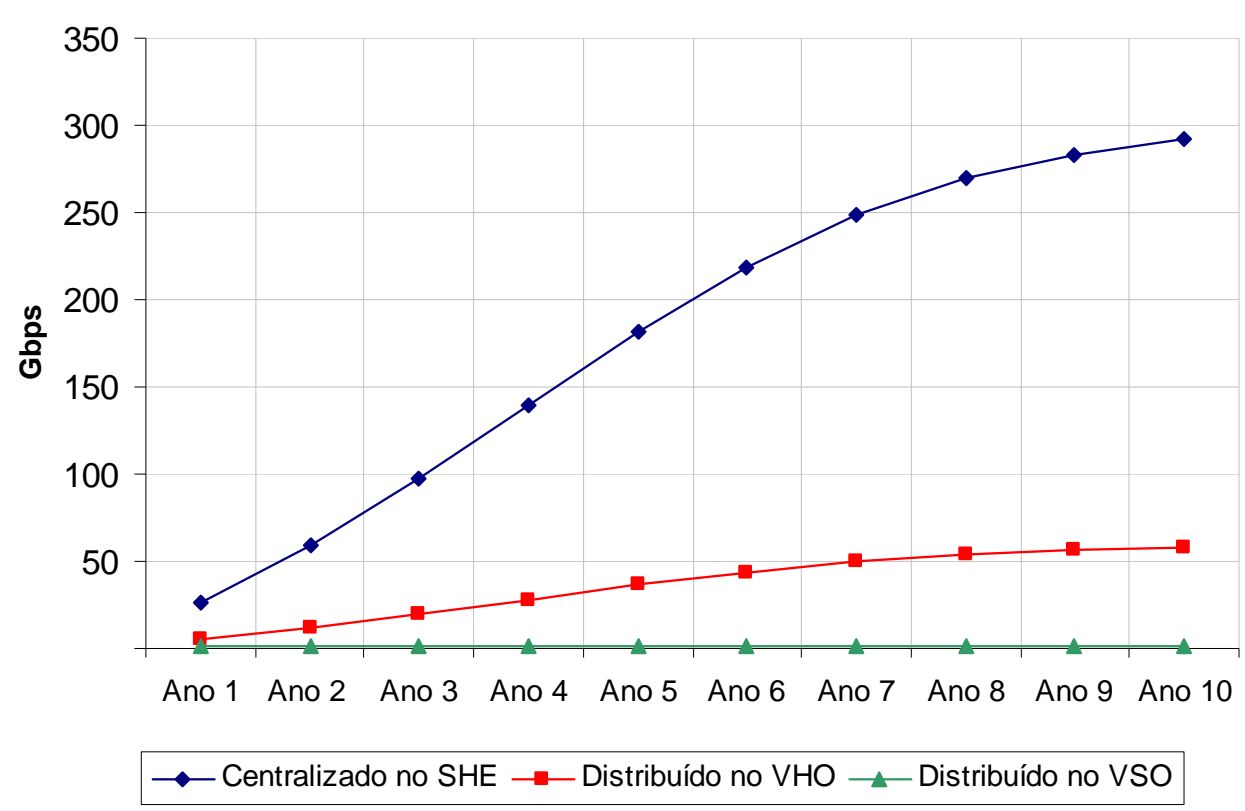

Figura 61 - Perfil de tráfego VOD no núcleo da rede

\section{Tráfego VOD na Agregação}

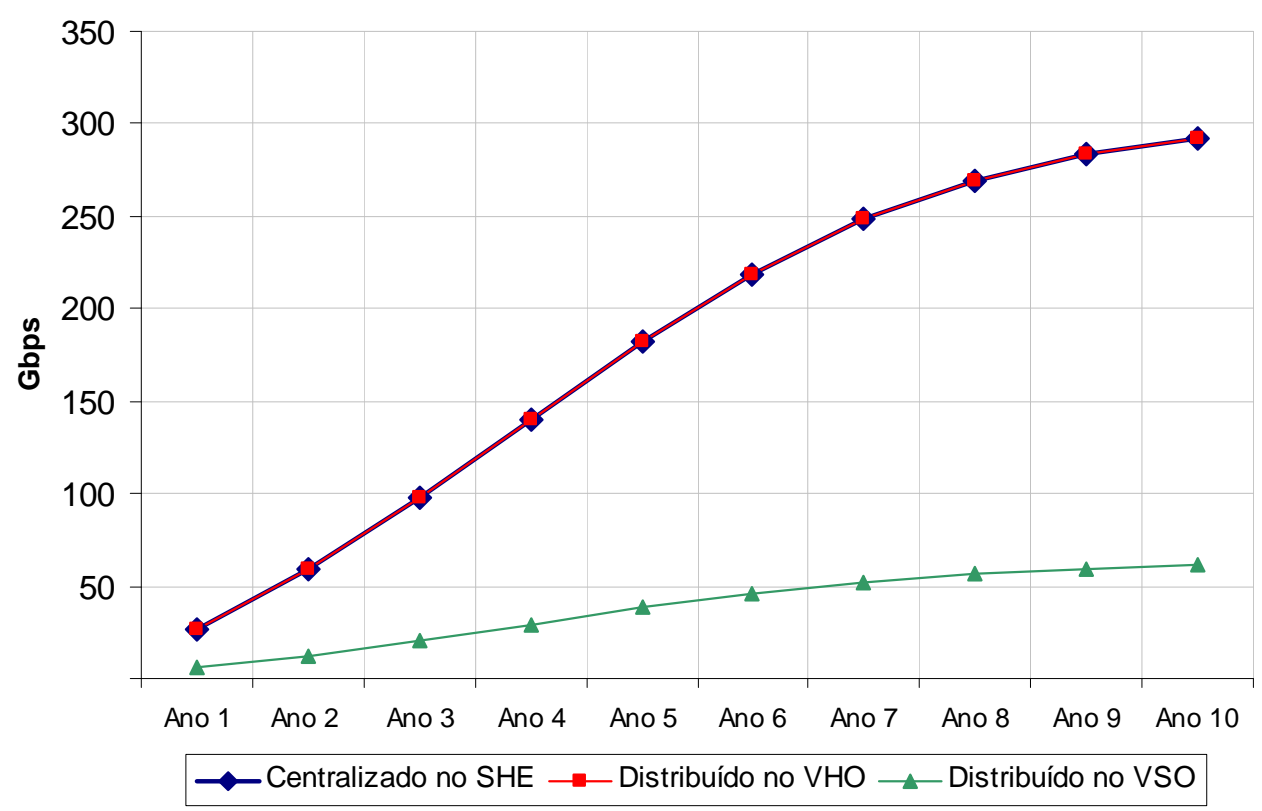

Figura 62 - Perfil de tráfego VOD nas redes de agregação 


\section{B.2.4.1.1.5 Set-top box}

No caso da ACME, para suportar padrões de qualidade de vídeo SDTV e HDTV, foram considerados os dois tipos de set-top boxes no dimensionamento. Além disso, foram considerados set-top boxes que possuem funcionalidade de PVR integrada, e permitem a gravação de até $10 \mathrm{~h}$ de conteúdo de vídeo.

Os set-top boxes considerados são compatíveis com o padrão de codificação MPEG-4 AVC e também com as demais plataformas de serviço: middleware e DRM.

A quantidade de set-top boxes varia diretamente com a quantidade de novos assinantes a cada ano. Além disso, ela varia com a modalidade em que são fornecidos aos assinantes. No caso em que os set-top box são de propriedade da operadora, existe a possibilidade de reaproveitar os equipamentos de assinantes deixam de contratar o serviço IPTV da ACME.

A Figura 63 mostra a quantidade acumulada para cada tipo de set-top box , considerando o cenário base para adoção do serviço, VOD, PVR e que são de propriedade da operadora com taxa de reaproveitamento de $75 \%$ dos assinantes que deixaram a ACME. Na Figura 64, está evidenciada diferença da quantidade de novos set-top boxes a cada ano nas modalidades de propriedade da operadora ou do assinante final, considerando o cenário base do serviço. 


\section{Quantidade acumulada de set-top-boxes}

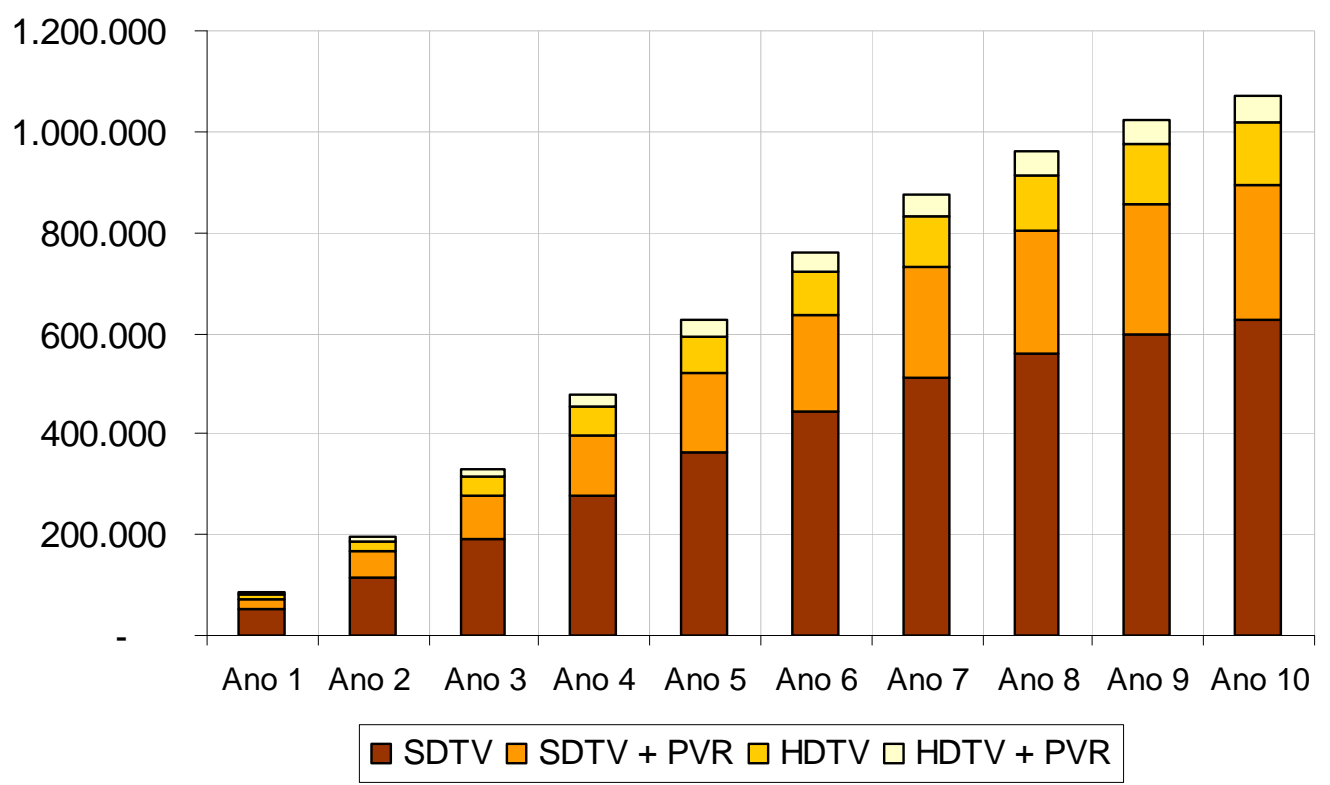

Figura 63 - Quantidade de set-top boxes por tipo

\section{Quantidade de novos set-top-boxes}

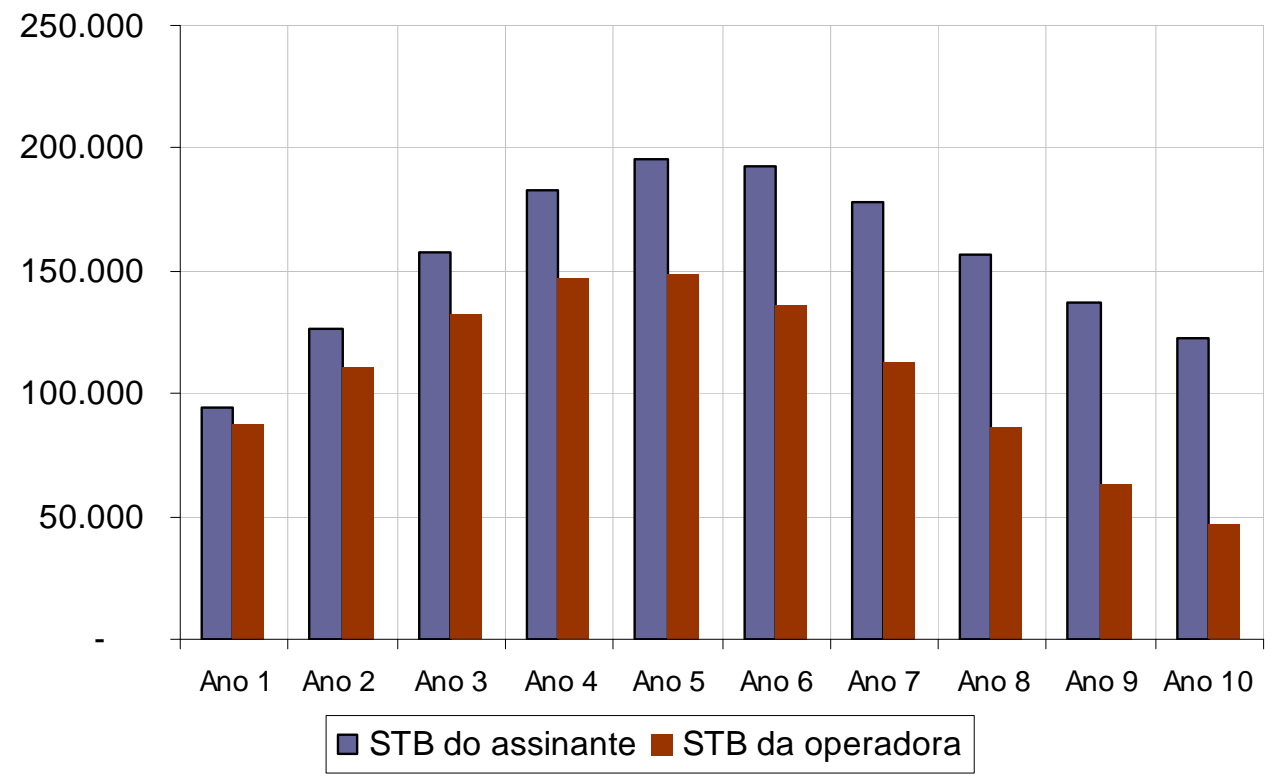

Figura 64 - Quantidade de novos de set-top boxes 


\section{B.2.4.1.2 Infra-estrutura de Rede}

\section{B.2.4.1.2.1 Acesso}

A última milha entre o usuário e o primeiro nó de acesso da rede da ACME deve ser capaz de suportar a largura de banda para que todos os serviços disponíveis ao assinante sejam utilizados simultaneamente. Dessa maneira, pode-se garantir que não exista nenhuma restrição ao serviço do usuário final pelo menos no que diz respeito ao acesso.

$\mathrm{Na}$ Figura 65, foram identificados os perfis de banda necessários no acesso de acordo com as diversas combinações de quantidade de pontos ativos (SDTV e/ou HDTV) por residência simultaneamente. Além do tráfego de vídeo estimado com base nas taxas de codificação apresentadas na Tabela 19 e tomando como base 0 overhead de protocolos de comunicação de aproximadamente $10 \%$, foi considerado que um usuário típico pode ter acesso Internet de velocidades variando de $1 \mathrm{Mbps}$ até $24 \mathrm{Mbps}$ (considerando a perspectiva de longo prazo), e a possibilidade de 2 canais de voz (VolP) utilizando aproximadamente 128Kbps por canal. Tal dimensionamento, leva em conta que cada televisor ativo recebe apenas um canal por vez, graças aos mecanismos de multicast implementados até o nó de acesso combinados com funcionalidades fast leave. 


\section{Largura de banda necessária no Acesso}

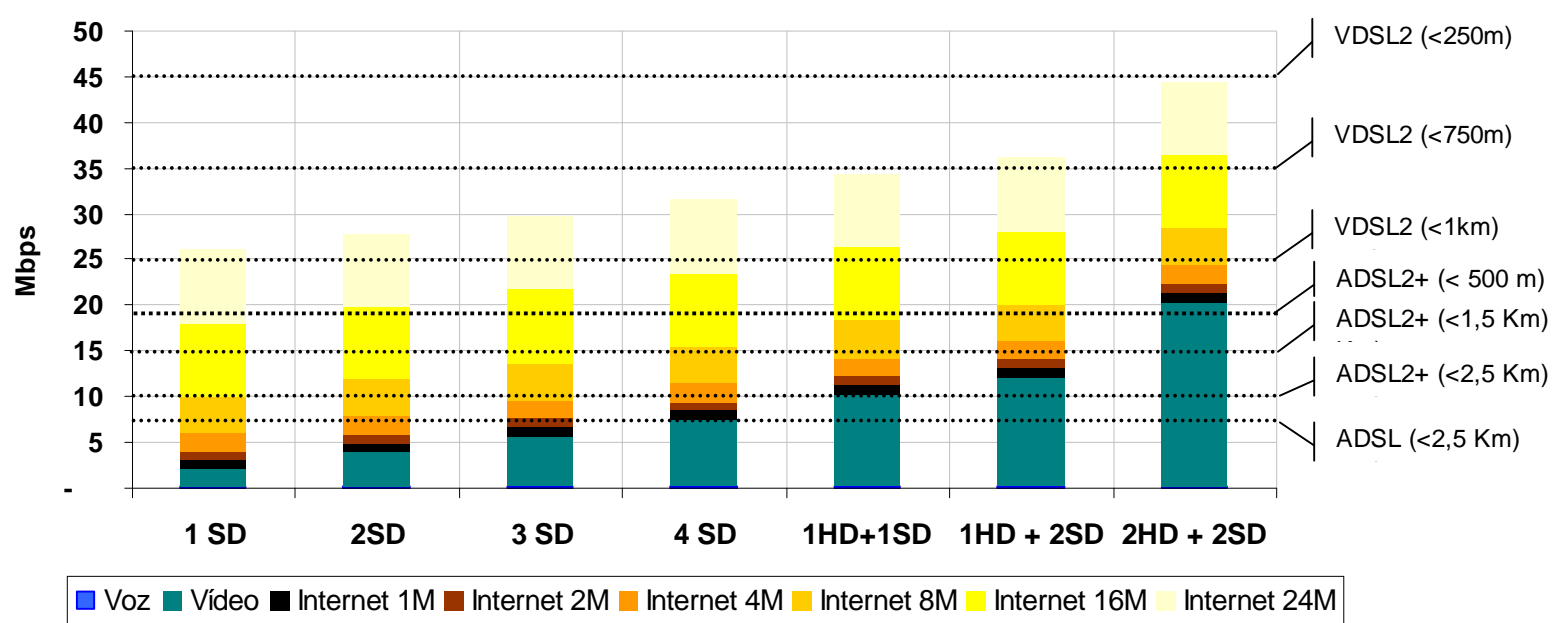

Figura 65 - Largura de banda no acesso por quantidade de pontos

Além da necessidade de banda de cada perfil, foram indicados na Figura 65 os limites de cada tecnologia de acesso baseado em cobre (ADSL, ADSL2+ e VDSL2) de acordo a distância do usuário até o nó de acesso (localizado na central de fios neste caso) e tomando como base as curvas apresentadas na Figura 14. As tecnologias baseadas em fibra óptica não foram explicitadas no gráfico, pois seus limites de banda são significativamente superiores, tais quais suas limitações de distância até o usuário final.

Analisando as necessidades de cada perfil na Figura 65, percebe-se que a tecnologia ADSL atualmente empregada na planta de acesso da ACME é obsoleta para suportar serviços de vídeo. Ela permitiria uma oferta limitada de no máximo 2 pontos SDTV por assinante com margem de segurança adequada.

A tecnologia ADSL2+ é apropriada para oferecer vídeo em qualidade SDTV e pode limitar a oferta de acesso Internet de maiores velocidades: 8Mbps para distâncias de até $1,5 \mathrm{~km}$ da central; e a 4 Mbps a distâncias de até $2,5 \mathrm{~km}$ da central. Eventualmente, poderia ser empregada para oferta de vídeo para assinantes que possuem apenas um ponto em HDTV, e ainda com restrições de distância da central e limitações ao acesso Internet a 2 ou 4 Mbps dependendo da situação.

Já a tecnologia VDSL2 pode ser utilizada para suportar a oferta de vídeo em HDTV devido à maior capacidade de banda. Entretanto, as restrições dessa tecnologia 
estão relacionadas à distância até o usuário final. Para que se obtenha largura de banda significativamente superior ao ADSL2+ (>25 Mbps), o assinante deve estar a distâncias menores do que $1 \mathrm{~km}$ do nó de acesso. Quanto mais perto do nó de acesso, melhor será o desempenho, sendo limitado a capacidade de 45-50Mbps por assinante. Desta forma, é possível oferecer conteúdo em qualidade HDTV, mas a oferta de Internet pode se limitar dependendo da distância do assinante até o nó de acesso, mas não será menor do que 8Mbps.

As tecnologias que utilizam acesso baseado em fibra até o assinante não possuem restrições significativas de banda ou de distância quando comparadas ao caso da ACME, conforme descrito no item 2.8.1.3. Com qualquer dessas tecnologias, seria possível atender a qualquer perfil de tráfego no acesso da ACME. A maior restrição de dessa categoria de tecnologias diz respeito ao elevado custo de implantação de uma nova planta de acesso.

Levando em conta as análises de perfis de assinante e a adequação das diversas tecnologias de acesso, são consideradas as seguintes alternativas para cada tipo de serviço:

- Assinantes SDTV: manutenção da arquitetura FTTN, utilizando ADSL2+;

- Assinantes HDTV: introdução da arquitetura FTTCab, utilizando VDSL2. Entretanto, visando maior escalabilidade futura na oferta de maiores velocidades de acesso e mais pontos de televisão em HDTV, arquiteturas de FTTH também são consideradas como alternativa e foram dimensionadas.

As arquiteturas tecnológicas mencionadas - FTTN, FTTCab e FTTH - para o caso da ACME estão detalhadas a seguir:

- FTTN: manutenção da arquitetura tradicional com a substituição da tecnologia ADSL por ADSL2+ no acesso. Não há necessidade de promover alterações na rede de par metálico. As modificações envolvidas incluem a substituição ou adição de portas ADSL2+ nos DSLAMs já existentes localizados na central e o fornecimento de um modem compatível ao assinante. Essa arquitetura de acesso está ilustrada na Figura 66. 
Central

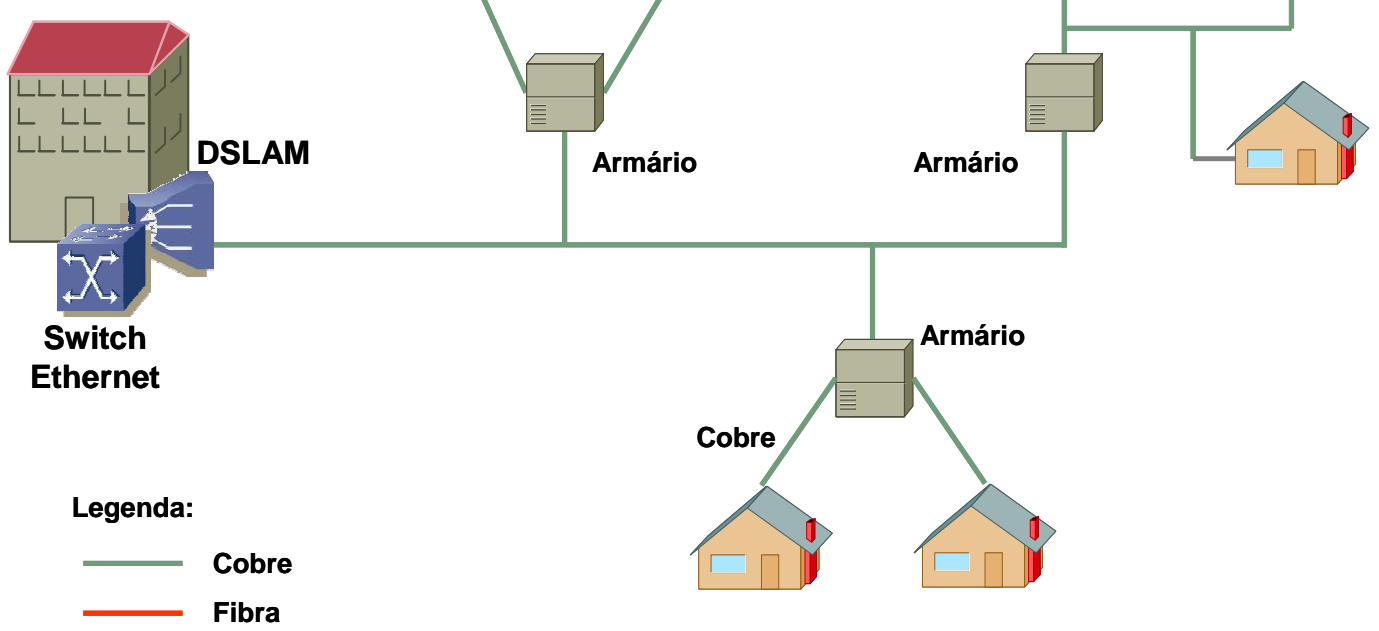

Figura 66 - Rede de Acesso ACME - FTTN: ADSL2+

- FTTCab: nessa arquitetura, a rede de distribuição primária passa a ser implementada em fibra óptica e é adicionado um DSLAM remoto de menor porte (48 a 96 portas) no armário de distribuição, constituindo assim um nó remoto ou remote node $(\mathrm{RN})$. A rede de distribuição secundária de par metálico continua inalterada e a tecnologia utilizada neste trecho da rede é o VDSL2 devido à sua maior largura de banda em curtas distâncias. Essa arquitetura de rede está ilustrada na Figura 67. 


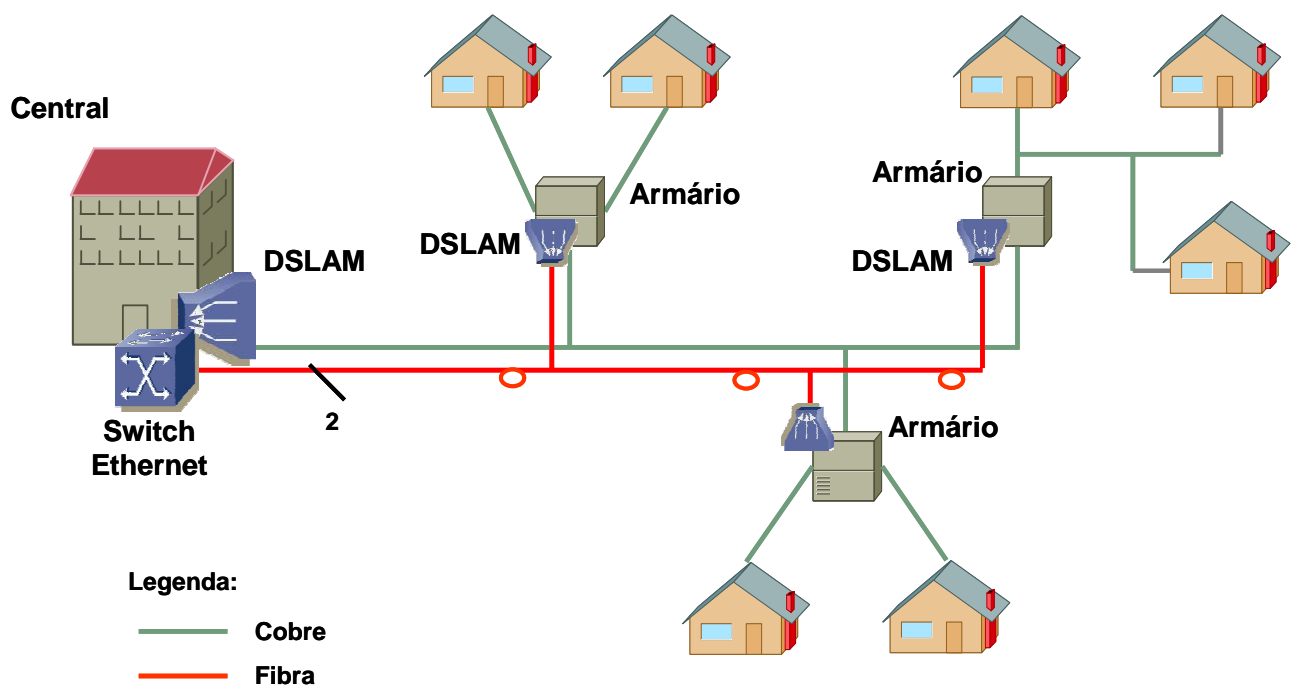

Figura 67 - Rede de Acesso ACME - FTTCab: VDSL2

- FTTH: nessa modalidade de arquitetura, a rede de acesso inteira é implementada em fibra óptica desde a rede de distribuição secundária até a rede primária. Três modalidades são consideradas no caso da ACME:

- PON: neste caso, não existem elementos ativos na rede de distribuição. Existem OLTs na central e apenas elementos passivos (splitters) nos armários que agora constituem RNs. Neste caso, a fibra que interliga o armário (RN) e a central (CO), a fibra é compartilhada, e existe uma fibra dedicada desde o armário (RN) até o assinante. No caso da $A C M E$, dentre as diversas tecnologias PON existentes, foram selecionadas as tecnologias EPON e GPON para avaliação devido à compatibilidade com o modelo de agregação Ethernet e a sua escalabilidade. No caso do EPON taxa de compartilhamento considerada foi de 1:16, visando à oferta de uma capacidade de acesso diferenciada em relação às alternativas de acesso em cobre, resultando em 62,5 Mbps de banda por assinante. No caso do GPON, considerou-se a taxa de compartilhamento de 1:32, podendo oferecer até $78 \mathrm{Mbps}$ ao usuário final. A arquitetura PON está ilustrada na Figura 68. 


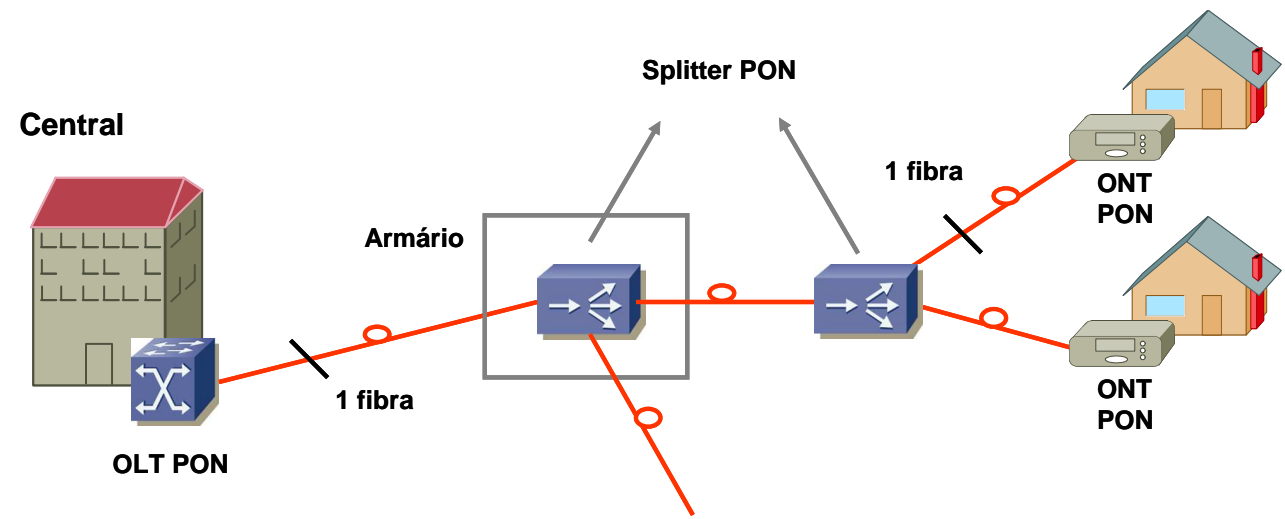

Figura 68 - Rede de Acesso ACME - FTTH: PON

- Ethernet estrela ativa: arquitetura semelhante à PON (rede de fibra compartilhada), mas utilizando elementos ativos no lugar (switches Ethernet de menor porte que conectam o assinante em portas de 100 Mbps) de splitters nos armários de distribuição (RN). Na central, os OLTs constituem switches Ethernet de maior porte - agregam os diversos switches dos RNs em portas 1Gbps. Para tornar comparável o dimensionamento entre essa arquitetura e a arquitetura PON em termos de largura de banda, também foi adotada uma taxa de compartilhamento de 1:16 para cada porta dos OLTs, oferecendo até $62,5 \mathrm{Mbps}$ por assinante.

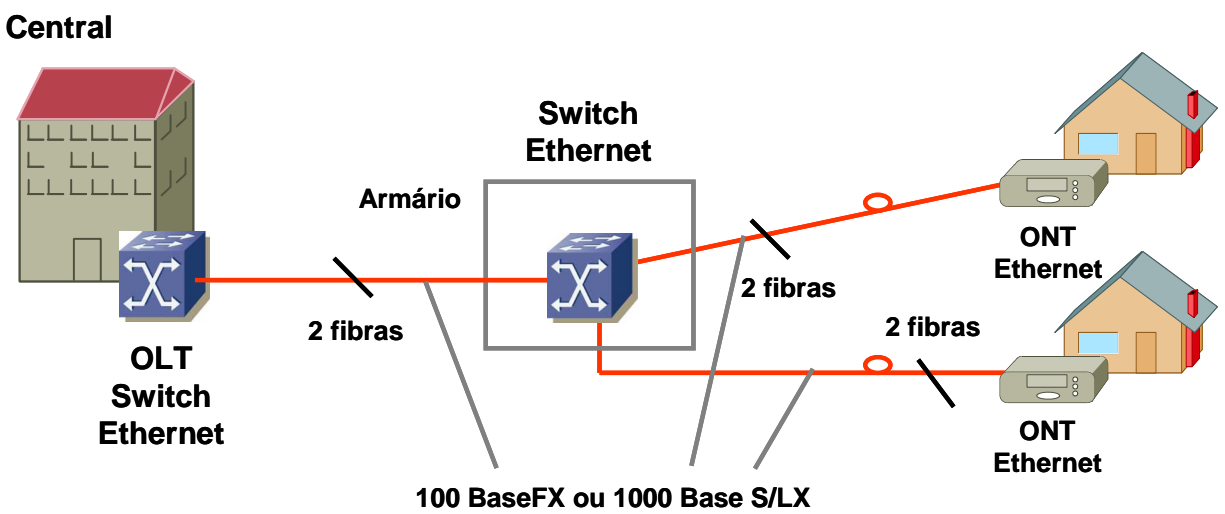

Figura 69 - Rede de Acesso ACME - FTTH: Ethernet estrela ativa

- Ethernet ponto-a-ponto: esta arquitetura difere das outras anteriores, pois a fibra óptica é dedicada para cada assinante desde a central até o seu domicílio. Não existem elementos ativos intermediários nos armários de distribuição (RNs). Existem apenas switches Ethernet estão localizados na central de fios (COs) e a largura de banda para o usuário final é aquela oferecida pela porta do switch dedicada ao assinante, que é de $100 \mathrm{Mbps}$ 
neste caso. Essa alternativa confere grande escalabilidade, pois existe um meio físico dedicado até o assinante permitindo, por exemplo, a evolução da capacidade de banda para 1Gbps, apenas com a substituição das portas switch e terminal do usuário.

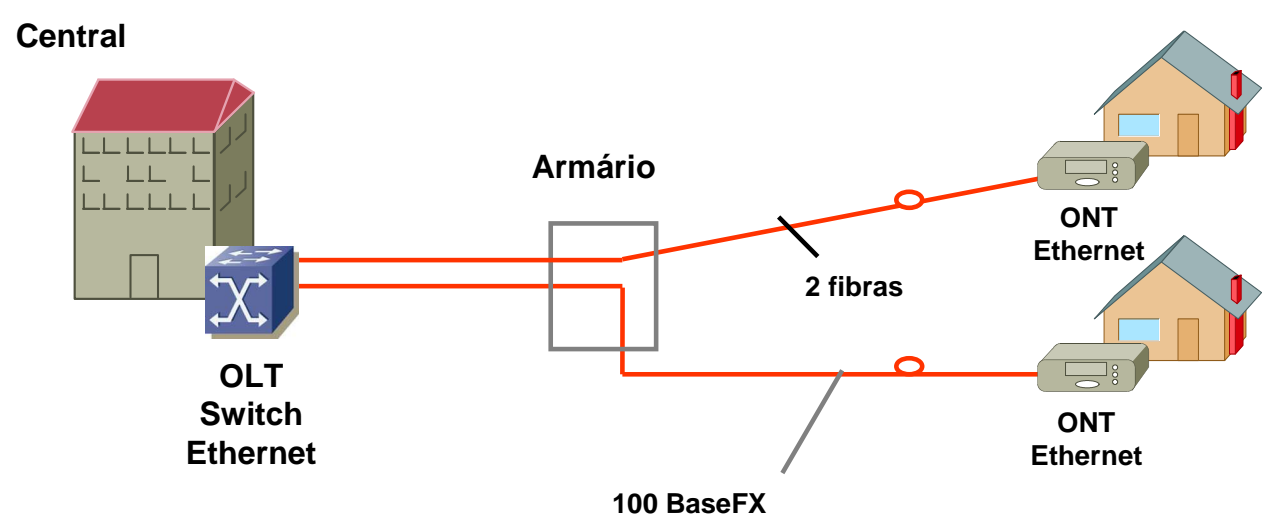

Figura 70 - Rede de Acesso ACME - FTTH: Ethernet ponto-a-ponto

O dimensionamento da rede de acesso para cada uma das alternativas explicitadas foi realizado no nível equivalente a área coberta de uma central de fios ou estação telefônica conforme apresentado na Figura 57. Considera-se que a quantidade de assinantes IPTV na área de uma central é equivalente à penetração do serviço na base de assinantes de telefonia, tendo em vista que uma central atende em média 18.000 assinantes de telefonia.

Para o caso da oferta de conteúdo HDTV que exige mudanças significativas da arquitetura da rede de acesso (FTTCab e FTTH), supõe-se que a evolução da rede se dá gradativamente em unidades equivalentes à área de cobertura de uma central. Além disso, o lançamento de rede de fibra óptica ocorre gradativamente e de forma linear ao longo de quatro anos para cobrir os assinantes potenciais.

Devido a fatores de concentração de riqueza ao longo das áreas em que a ACME oferecerá o serviço, considera-se que os assinantes de conteúdo HDTV estão concentrados geograficamente em regiões delimitadas. No entanto, nas áreas em que se oferece HDTV, supõe-se que uma parcela de aproximadamente $20 \%$ dos usuários ainda serão assinantes do serviço em qualidade SDTV tradicional. Ou seja, mesmo nas áreas em que se oferecem tecnologias de mais alta velocidade através das novas arquiteturas FTTCab e FTTH, ainda existem assinantes servidos pela arquitetura tradicional de rede FTTN, porém evoluída para ADSL2+. 
A premissa para a ocupação da rede de acesso é de no máximo $75 \%$ em todas as arquiteturas consideradas. Ademais, a premissa para dimensionamento das arquiteturas de rede de acesso que envolvem lançamento de fibra óptica (FTTCab e FTTH) é de que a quantidade de homes passed (residências habilitadas com tecnologia de fibra óptica) é de $25 \%$ maior do que o máximo de assinantes IPTV no longo prazo, visando acomodar eventuais flutuações na demanda.

O tráfego em cada um dos nós da rede de acesso, estejam eles na central (CO) ou armários de distribuição (RN), é realizado de acordo com as fórmulas apresentadas no item 4.2.2.4.1.2. A quantidade de portas por tecnologia para o cenário base está apresentada na Tabela 21. 
Tabela 21 - Quantidade de portas instaladas por tecnologia de acesso

\begin{tabular}{cccccccccccc}
\hline & \multicolumn{10}{c}{ Portas (Milhares) } \\
\cline { 2 - 12 } Tecnologia & Ano & Ano & Ano & Ano & Ano & Ano & Ano & Ano & Ano & Ano \\
\hline $\begin{array}{c}\text { FTTN } \\
\text { (ADSL2+) }\end{array}$ & 38 & 85 & 141 & 202 & 262 & 316 & 359 & 390 & 410 & 422 \\
\hline $\begin{array}{c}\text { FTTCab } \\
\text { (VDSL2) }\end{array}$ & 16 & 37 & 60 & 87 & 112 & 136 & 154 & 167 & 176 & 181 \\
\hline Total & 54 & 122 & 202 & 289 & 375 & 452 & 513 & 557 & 585 & 602 \\
\hline
\end{tabular}

Os principais parâmetros relacionados ao dimensionamento da região coberta por uma central em cada uma das arquiteturas estão mostrados Tabela 22. Para quaisquer arquiteturas, existe a necessidade de novos CPEs que foram dimensionados da mesma forma que a quantidade de set-top boxes no item B.2.4.1.1.5. 
Tabela 22 - Dimensionamento Acesso - Cobertura de uma central

\begin{tabular}{|c|c|c|c|c|c|c|c|c|c|c|}
\hline & $\begin{array}{c}\text { Ano } \\
1\end{array}$ & $\begin{array}{c}\text { Ano } \\
2 \\
\end{array}$ & $\begin{array}{c}\text { Ano } \\
3\end{array}$ & $\begin{array}{c}\text { Ano } \\
4 \\
\end{array}$ & $\begin{array}{c}\text { Ano } \\
5\end{array}$ & $\begin{array}{c}\text { Ano } \\
6\end{array}$ & $\begin{array}{c}\text { Ano } \\
7\end{array}$ & $\begin{array}{c}\text { Ano } \\
8 \\
\end{array}$ & $\begin{array}{c}\text { Ano } \\
9 \\
\end{array}$ & $\begin{array}{c}\text { Ano } \\
10 \\
\end{array}$ \\
\hline Assinantes Telefonia & 18.000 & 18.000 & 18.000 & 18.000 & 18.000 & 18.000 & 18.000 & 18.000 & 18.000 & 18.000 \\
\hline Assinantes Banda Larga & 4.407 & 5.832 & 7.364 & 8.873 & 10.221 & 11.310 & 12.109 & 12.650 & 12.994 & 13.204 \\
\hline Assinantes IPTV & 390 & 877 & 1.451 & 2.078 & 2.700 & 3.254 & 3.694 & 4.008 & 4.212 & 4.336 \\
\hline Homes passed & 5.421 & 5.421 & 5.421 & 5.421 & 5.421 & 5.421 & 5.421 & 5.421 & 5.421 & 5.421 \\
\hline
\end{tabular}

\begin{tabular}{|c|c|c|c|c|c|c|c|c|c|c|}
\hline FTTN & & & & & & & & & & \\
\hline Portas ADSL2+ & 520 & 1.169 & 1.935 & 2.770 & 3.600 & 4.339 & 4.926 & 5.344 & 5.616 & 5.782 \\
\hline \multicolumn{11}{|l|}{ FTTCab } \\
\hline Portas OLT & 11 & 24 & 40 & 58 & 75 & 90 & 103 & 111 & 117 & 120 \\
\hline Portas RN (VDSL2) & 520 & 1.169 & 1.935 & 2.770 & 3.600 & 4.339 & 4.926 & 5.344 & 5.616 & 5.782 \\
\hline Cabos Fibra CO/RN (km) & 108 & 108 & 108 & 108 & 108 & 108 & 108 & 108 & 108 & 108 \\
\hline \multicolumn{11}{|l|}{ FTTH } \\
\hline \multicolumn{11}{|l|}{ EPON } \\
\hline Taxa de compartilhamento ( $1: N)$ & 16 & 16 & 16 & 16 & 16 & 16 & 16 & 16 & 16 & 16 \\
\hline Banda por assinante (Mbps) & 62,5 & 62,5 & 62,5 & 62,5 & 62,5 & 62,5 & 62,5 & 62,5 & 62,5 & 62,5 \\
\hline Portas OLT & 32 & 73 & 121 & 173 & 225 & 271 & 308 & 334 & 351 & 361 \\
\hline Portas RN & 520 & 1.169 & 1.935 & 2.770 & 3.600 & 4.339 & 4.926 & 5.344 & 5.616 & 5.782 \\
\hline Fibra CO/RN (km) & 1.080 & 1.080 & 1.080 & 1.080 & 1.080 & 1.080 & 1.080 & 1.080 & 1.080 & 1.080 \\
\hline Fibra RN/Drop (km) & 4.608 & 4.608 & 4.608 & 4.608 & 4.608 & 4.608 & 4.608 & 4.608 & 4.608 & 4.608 \\
\hline Fibra Drop/Assinante $(\mathrm{km})$ & 39 & 88 & 145 & 208 & 270 & 325 & 369 & 401 & 421 & 434 \\
\hline
\end{tabular}




\begin{tabular}{|c|c|c|c|c|c|c|c|c|c|c|}
\hline & $\begin{array}{c}\text { Ano } \\
1 \\
\end{array}$ & $\begin{array}{c}\text { Ano } \\
2 \\
\end{array}$ & $\begin{array}{c}\text { Ano } \\
3\end{array}$ & $\begin{array}{c}\text { Ano } \\
4 \\
\end{array}$ & $\begin{array}{c}\text { Ano } \\
5\end{array}$ & $\begin{array}{c}\text { Ano } \\
6\end{array}$ & $\begin{array}{c}\text { Ano } \\
7\end{array}$ & $\begin{array}{c}\text { Ano } \\
8 \\
\end{array}$ & $\begin{array}{c}\text { Ano } \\
9 \\
\end{array}$ & $\begin{array}{c}\text { Ano } \\
10 \\
\end{array}$ \\
\hline \multicolumn{11}{|l|}{ GPON } \\
\hline Taxa de compartilhamento $(1: N)$ & 32 & 32 & 32 & 32 & 32 & 32 & 32 & 32 & 32 & 32 \\
\hline Banda por assinante (Mbps) & 78 & 78 & 78 & 78 & 78 & 78 & 78 & 78 & 78 & 78 \\
\hline Portas OLT & 16 & 37 & 60 & 87 & 112 & 136 & 154 & 167 & 176 & 181 \\
\hline Portas RN & 520 & 1.169 & 1.935 & 2.770 & 3.600 & 4.339 & 4.926 & 5.344 & 5.616 & 5.782 \\
\hline Fibra CO/RN (km) & 540 & 540 & 540 & 540 & 540 & 540 & 540 & 540 & 540 & 540 \\
\hline Fibra RN/Drop (km) & 4.608 & 4.608 & 4.608 & 4.608 & 4.608 & 4.608 & 4.608 & 4.608 & 4.608 & 4.608 \\
\hline Fibra Drop/Assinante (km) & 39 & 88 & 145 & 208 & 270 & 325 & 369 & 401 & 421 & 434 \\
\hline \multicolumn{11}{|l|}{ Ethernet Estrela ativa } \\
\hline Taxa de compartilhamento (1:N) & 16 & 16 & 16 & 16 & 16 & 16 & 16 & 16 & 16 & 16 \\
\hline Banda por assinante (Mbps) & 62,5 & 62,5 & 62,5 & 62,5 & 62,5 & 62,5 & 62,5 & 62,5 & 62,5 & 62,5 \\
\hline Portas OLT & 32 & 73 & 121 & 173 & 225 & 271 & 308 & 334 & 351 & 361 \\
\hline Portas RN & 520 & 1.169 & 1.935 & 2.770 & 3.600 & 4.339 & 4.926 & 5.344 & 5.616 & 5.782 \\
\hline Fibra CO/RN (km) & 2.160 & 2.160 & 2.160 & 2.160 & 2.160 & 2.160 & 2.160 & 2.160 & 2.160 & 2.160 \\
\hline Fibra RN/Drop (km) & 9.216 & 9.216 & 9.216 & 9.216 & 9.216 & 9.216 & 9.216 & 9.216 & 9.216 & 9.216 \\
\hline Fibra Drop/Assinante (km) & 78 & 175 & 290 & 416 & 540 & 651 & 739 & 802 & 842 & 867 \\
\hline \multicolumn{11}{|l|}{ Ethernet P2P } \\
\hline Taxa de compartilhamento $(1: N)$ & 1 & 1 & 1 & 1 & 1 & 1 & 1 & 1 & 1 & 1 \\
\hline Banda por assinante (Mbps) & 100,0 & 100,0 & 100,0 & 100,0 & 100,0 & 112,0 & 124,0 & 136,0 & 148,0 & 160,0 \\
\hline Portas OLT & 520 & 1.169 & 1.935 & 2.770 & 3.600 & 4.339 & 4.926 & 5.344 & 5.616 & 5.782 \\
\hline Portas RN & 0 & 0 & 0 & 0 & 0 & 0 & 0 & 0 & 0 & 0 \\
\hline Fibra CO/RN (km) & 34.202 & 34.202 & 34.202 & 34.202 & 34.202 & 34.202 & 34.202 & 34.202 & 34.202 & 34.202 \\
\hline Fibra RN/Drop $(\mathrm{km})$ & 9.216 & 9.216 & 9.216 & 9.216 & 9.216 & 9.216 & 9.216 & 9.216 & 9.216 & 9.216 \\
\hline Fibra Drop/Assinante (km) & 78 & 175 & 290 & 416 & 540 & 651 & 739 & 802 & 842 & 867 \\
\hline
\end{tabular}




\section{B.2.4.1.2.2 Agregação}

Uma vez realizado o dimensionamento e a identificação de arquiteturas de acesso, a rede de agregação deve ser analisada. $O$ modelo de agregação considerado para o caso da ACME leva em conta uma rede Ethernet/IP capaz de implementar serviços de camada 2 e 3. Desta forma, é possível aproveitar a capacidade de implementar multicast nativamente nessa rede para a otimização do tráfego de vídeo. Sendo assim, para este caso considera-se que o modelo de agregação de vídeo é realizado com a inteligência distribuída em uma rede IP (camada 3 ) conforme detalhado no item 2.8.1.2.

O modelo de agregação do serviço Internet banda larga continua se valendo da inteligência centralizada no B-RAS, utilizando a rede de agregação como uma rede puramente de transporte camada 2. No entanto, tal modelo pode evoluir para um modelo de inteligência totalmente distribuída, assim como é o caso do serviço de vídeo. Tal evolução do modelo de agregação do serviço banda larga não será detalhada, pois não é o foco deste trabalho.

Para este dimensionamento, considera-se então que, pelo menos em um primeiro momento, a ACME possui um modelo híbrido de agregação: o serviço de vídeo agregado com inteligência distribuída e o serviço de Internet banda larga utilizando inteligência centralizada. No futuro, este modelo híbrido pode evoluir para um modelo distribuído para os dois serviços.

Em termos de arquitetura, com a introdução do serviço de vídeo, a rede de agregação da ACME permanece implementada utilizando a topologia de anéis que são terminados nos PoPs de núcleo. O que varia neste caso, é o dimensionamento e evolução da rede para suportar o volume de tráfego adicional devido ao serviço de vídeo, ou seja, o dimensionamento dos diversos anéis que compõem a rede de agregação. Considera-se que a quantidade de anéis e switches na rede de agregação continua a mesma e o que varia é o tráfego no anel e em cada elemento de rede. Para o dimensionamento do tráfego nas redes de agregação consideram-se as fórmulas apresentadas no item 4.2.2.4.1.2. 
A quantidade de usuários VOD, a taxa de simultaneidade no pico e os modelos de distribuição de conteúdo descritos no item B.2.1.5 são determinantes para o tráfego VOD. Um dos fatores que pode contribuir para otimizar o tráfego de VOD é a alteração da arquitetura de distribuição de conteúdo, introduzindo elementos de armazenamento de conteúdo VOD nos VSO conforme detalhado no item B.2.4.1.1.4. O dimensionamento de tráfego VOD nas redes de agregação para o cenário base está apresentado na Tabela 23.

No caso dos canais de programação broadcast, o mecanismo de multicast tem um papel importante para a otimização do tráfego nas redes de agregação. Considerase que em cada anel da rede de agregação sempre estará sendo trafegado o conteúdo de todos os canais da grade de programação, ou seja, a quantidade de streams equivalentes ao número de canais oferecidos na grade completa. Esta aproximação pode ser adotada neste caso, pois o número de assinantes conectados a cada nó da rede de agregação é bastante superior à quantidade de canais conforme discutido no item 4.2.2.4.1.2. O dimensionamento de tráfego broadcast nas redes de agregação para o cenário base está apresentado na Tabela 24.

Tabela 23 - Tráfego de vídeo na agregação - VOD

\begin{tabular}{lcccccccccc}
\hline & \multicolumn{10}{c}{ Tráfego (Gbps) } \\
\cline { 2 - 13 } Região & Ano & Ano & Ano & Ano & Ano & Ano & Ano & Ano & Ano & Ano \\
\hline 1 & 8 & 18 & 29 & 42 & 54 & 66 & 75 & 81 & 85 & 88 \\
\hline 2 & 7 & 15 & 24 & 35 & 45 & 55 & 62 & 67 & 71 & 73 \\
\hline 3 & 5 & 12 & 20 & 28 & 36 & 44 & 50 & 54 & 57 & 58 \\
\hline 4 & 4 & 9 & 15 & 21 & 27 & 33 & 37 & 40 & 43 & 44 \\
\hline 5 & 3 & 6 & 10 & 14 & 18 & 22 & 25 & 27 & 28 & 29 \\
\hline Total & $\mathbf{2 6}$ & $\mathbf{5 9}$ & $\mathbf{9 8}$ & $\mathbf{1 4 0}$ & $\mathbf{1 8 2}$ & $\mathbf{2 1 9}$ & $\mathbf{2 4 9}$ & $\mathbf{2 7 0}$ & $\mathbf{2 8 3}$ & $\mathbf{2 9 2}$ \\
\hline
\end{tabular}

Tabela 24 - Tráfego de vídeo na agregação - broadcast

\begin{tabular}{lcccccccccc}
\hline & \multicolumn{10}{c}{ Tráfego (Gbps) } \\
\cline { 2 - 12 } Região & Ano & Ano & Ano & Ano & Ano & Ano & Ano & Ano & Ano & Ano \\
\hline 1 & 0,8 & 0,8 & 0,8 & 0,8 & 0,8 & 0,8 & 0,8 & 0,8 & 0,8 & 0,8 \\
\hline 2 & 0,8 & 0,8 & 0,8 & 0,8 & 0,8 & 0,8 & 0,8 & 0,8 & 0,8 & 0,8 \\
\hline 3 & 0,8 & 0,8 & 0,8 & 0,8 & 0,8 & 0,8 & 0,8 & 0,8 & 0,8 & 0,8 \\
\hline 4 & 0,8 & 0,8 & 0,8 & 0,8 & 0,8 & 0,8 & 0,8 & 0,8 & 0,8 & 0,8 \\
\hline 5 & 0,8 & 0,8 & 0,8 & 0,8 & 0,8 & 0,8 & 0,8 & 0,8 & 0,8 & 0,8 \\
\hline Total & $\mathbf{4}$ & $\mathbf{4}$ & $\mathbf{4}$ & $\mathbf{4}$ & $\mathbf{4}$ & $\mathbf{4}$ & $\mathbf{4}$ & $\mathbf{4}$ & $\mathbf{4}$ & $\mathbf{4}$ \\
\hline
\end{tabular}


Considerando o cenário base, o volume de tráfego nas redes de agregação antes e depois da introdução do serviço IPTV está apresentado nas Figura 71. Conforme apresentado, observa-se que o tráfego total nas redes de agregação cresce consideravelmente com a introdução do serviço IPTV devido, principalmente, ao tráfego do serviço VOD.

\section{Tráfego na Agregação - Total}

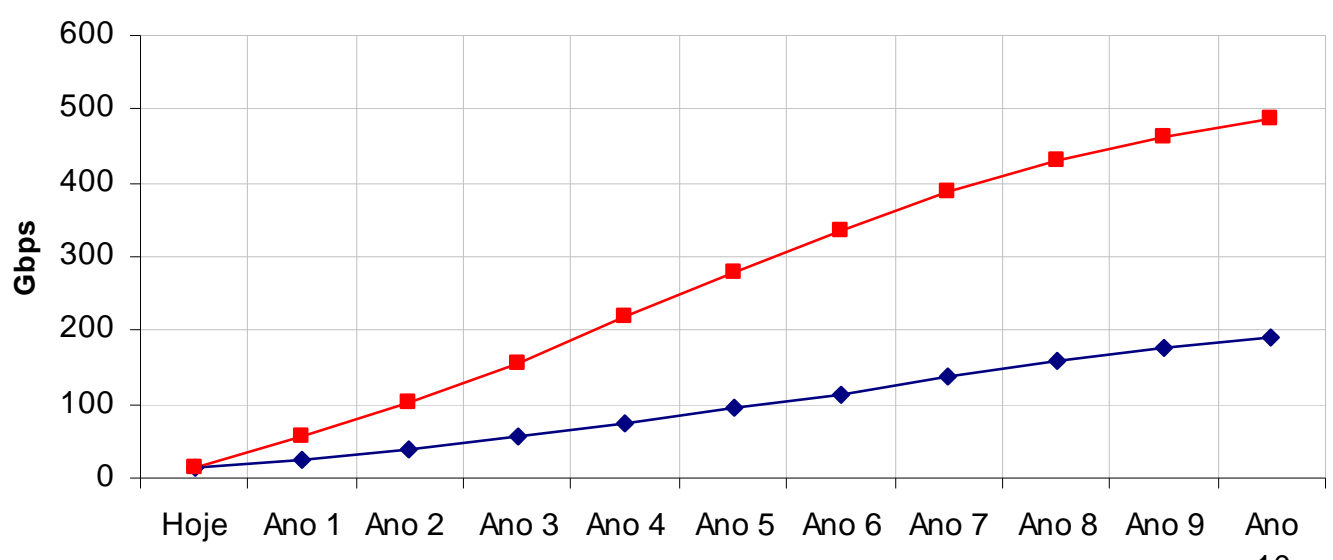

10

Figura 71 - Tráfego total nas redes de agregação

\section{B.2.4.1.2.3 Núcleo}

Da mesma forma que ocorre com os demais segmentos da rede, 0 dimensionamento do núcleo da rede da ACME para suportar o tráfego de vídeo passa pelo entendimento dos principais fluxos de tráfego de vídeo. Para o dimensionamento do tráfego no núcleo da rede utilizam-se as diretrizes do item 4.2.2.4.1.2.

O tráfego relacionado ao conteúdo VOD varia de acordo com a quantidade de assinantes do serviço, taxa de simultaneidade no pico e o modelo de distribuição de conteúdo descrito no item 4.2.2.4.1.1.4. Tão maior será o impacto do tráfego VOD no 
núcleo quanto mais concentrado o conteúdo estiver no SHE. Desta maneira, o tráfego no núcleo devido ao VOD é proporcional à quantidade de requisições de exibição de conteúdo VOD realizadas em cada $\mathrm{VHO}$ e que necessitam transmitir o conteúdo a partir do SHE, ocupando assim recursos do núcleo da rede. Para o cenário base, em que maior parte das requisições são atendidas pelo VHO e apenas uma parcela das requisições necessita buscar conteúdo no núcleo, a matriz de tráfego relacionada ao conteúdo VOD está apresentada na Tabela 25.

$\mathrm{Na}$ análise do tráfego relacionado aos canais de conteúdo broadcast deve-se tomar em conta a otimização trazida pelos mecanismos de multicast. Considerando que o núcleo da rede IP também conta com mecanismo de multicast habilitado, apenas um stream por canal de conteúdo broadcast nacional é transmitido para cada $\mathrm{VHO}$ a partir do SHE, onde o conteúdo nacional é recebido para ser distribuído. Esta aproximação pode ser adotada neste caso, pois o número de assinantes conectados a cada nó do núcleo da rede é bastante superior à quantidade de canais conforme discutido no item 4.2.2.4.1.2. A matriz de tráfego relacionada ao conteúdo broadcast está apresentada na Tabela 26.

Tabela 25 - Matriz de tráfego de vídeo - VOD

\begin{tabular}{|c|c|c|c|c|c|c|c|c|c|c|c|}
\hline \multirow{2}{*}{ 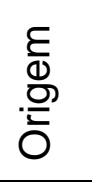 } & \multirow{2}{*}{$\begin{array}{l}\stackrel{.}{.} \\
\stackrel{\bar{D}}{\Phi} \\
\stackrel{0}{0}\end{array}$} & \multicolumn{10}{|c|}{ Tráfego (Mbps) } \\
\hline & & $\begin{array}{c}\text { Ano } \\
1\end{array}$ & $\begin{array}{c}\text { Ano } \\
2\end{array}$ & $\begin{array}{c}\text { Ano } \\
3\end{array}$ & $\begin{array}{c}\text { Ano } \\
4\end{array}$ & $\begin{array}{c}\text { Ano } \\
5\end{array}$ & $\begin{array}{c}\text { Ano } \\
6\end{array}$ & $\begin{array}{c}\text { Ano } \\
7\end{array}$ & $\begin{array}{c}\text { Ano } \\
8\end{array}$ & $\begin{array}{c}\text { Ano } \\
9\end{array}$ & $\begin{array}{c}\text { Ano } \\
10\end{array}$ \\
\hline 1 & 1 & 1,6 & 3,5 & 5,9 & 8,4 & 10,9 & 13,1 & 14,9 & 16,2 & 17,0 & 17,5 \\
\hline 1 & 2 & 1,3 & 2,9 & 4,9 & 7,0 & 9,1 & 10,9 & 12,4 & 13,5 & 14,2 & 14,6 \\
\hline 1 & 3 & 1,0 & 2,4 & 3,9 & 5,6 & 7,3 & 8,8 & 9,9 & 10,8 & 11,3 & 11,7 \\
\hline 1 & 4 & 0,8 & 1,8 & 2,9 & 4,2 & 5,4 & 6,6 & 7,5 & 8,1 & 8,5 & 8,8 \\
\hline 1 & 5 & 0,5 & 1,2 & 2,0 & 2,8 & 3,6 & 4,4 & 5,0 & 5,4 & 5,7 & 5,8 \\
\hline Tot: & & 5,2 & 11,8 & 19,5 & 28,0 & 36,3 & 43,8 & 49,7 & 53,9 & 56,7 & 58,4 \\
\hline
\end{tabular}


Tabela 26 - Matriz de tráfego de vídeo - broadcast

\begin{tabular}{|c|c|c|c|c|c|c|c|c|c|c|c|}
\hline \multirow{2}{*}{ 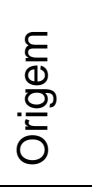 } & \multirow{2}{*}{ 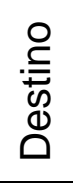 } & \multicolumn{10}{|c|}{ Tráfego (Mbps) } \\
\hline & & $\begin{array}{c}\text { Ano } \\
1 \\
\end{array}$ & $\begin{array}{c}\text { Ano } \\
2 \\
\end{array}$ & $\begin{array}{c}\text { Ano } \\
3\end{array}$ & $\begin{array}{c}\text { Ano } \\
4\end{array}$ & $\begin{array}{c}\text { Ano } \\
5 \\
\end{array}$ & $\begin{array}{c}\text { Ano } \\
6 \\
\end{array}$ & $\begin{array}{c}\text { Ano } \\
7 \\
\end{array}$ & $\begin{array}{c}\text { Ano } \\
8 \\
\end{array}$ & $\begin{array}{c}\text { Ano } \\
9 \\
\end{array}$ & $\begin{array}{c}\text { Ano } \\
10 \\
\end{array}$ \\
\hline 1 & 1 & 0,8 & 0,8 & 0,8 & 0,8 & 0,8 & 0,8 & 0,8 & 0,8 & 0,8 & 0,8 \\
\hline 1 & 2 & 0,8 & 0,8 & 0,8 & 0,8 & 0,8 & 0,8 & 0,8 & 0,8 & 0,8 & 0,8 \\
\hline 1 & 3 & 0,8 & 0,8 & 0,8 & 0,8 & 0,8 & 0,8 & 0,8 & 0,8 & 0,8 & 0,8 \\
\hline 1 & 4 & 0,8 & 0,8 & 0,8 & 0,8 & 0,8 & 0,8 & 0,8 & 0,8 & 0,8 & 0,8 \\
\hline 1 & 5 & 0,8 & 0,8 & 0,8 & 0,8 & 0,8 & 0,8 & 0,8 & 0,8 & 0,8 & 0,8 \\
\hline Tota & & 4 & 4 & 4 & 4 & 4 & 4 & 4 & 4 & 4 & 4 \\
\hline
\end{tabular}

Quando comparadas às parcelas de tráfego VOD e broadcast, percebe-se que o tráfego VOD é responsável pela maior parte do tráfego IPTV no núcleo também. Somando as duas parcelas de tráfego, é possível obter o tráfego na rede devido ao serviço IPTV. A Figura 72 mostra o tráfego total no núcleo antes e depois da introdução do serviço IPTV. Apesar de significativo, o impacto no núcleo não é tão grande quanto na agregação para o cenário base, pois já considera que uma boa parcela do conteúdo VOD é acessado diretamente no VHO, sem a necessidade de passar pelo núcleo para chegar ao SHE. 
Tráfego no Núcleo

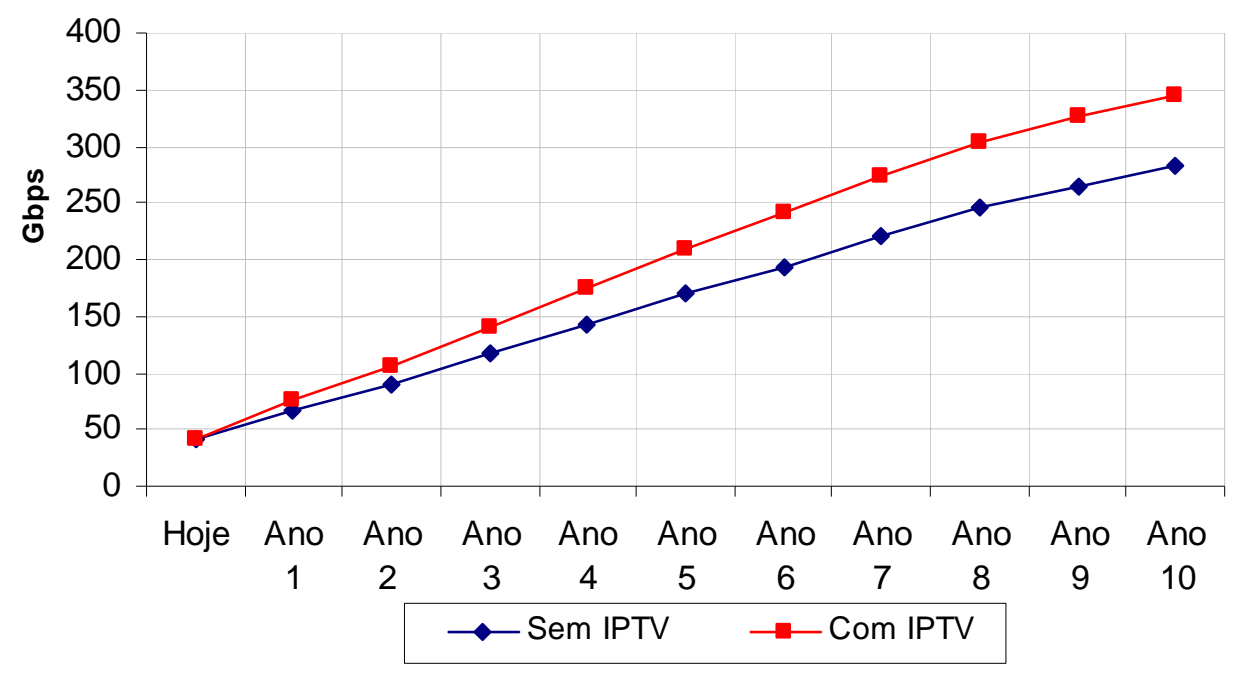

Figura 72 - Tráfego total no núcleo da rede

\section{B.2.4.1.3 Infra-estrutura de Gerenciamento}

A implementação das soluções de OSS/BSS variam bastante de acordo com cada fornecedor. Levando isso em consideração e que a especificação detalhada de software e hardware das plataformas de OSS/BSS não é o foco deste trabalho, foram identificados os principais requisitos que tal infra-estrutura deve ter de maneira a suportar o serviço IPTV e a arquitetura tecnológica até aqui delineados.

Para este caso, supõe-se os sistemas de OSS/BSS devem oferecer funcionalidades de gerenciamento complementares que podem ser mapeadas sobre o modelo de operações do eTOM conforme delineado no item 2.9. As funções necessárias são cobertas por duas categorias de sistemas:

- Middleware: funções relacionadas à plataforma de conteúdo (principalmente relacionadas ao aprovisionamento e faturamento do serviço);

- Gestão de Falhas e Desempenho integrado: a adoção de um sistema de monitoramento fim-a-fim de qualidade de vídeo que permeie desde a camada de rede até a camada do serviço (vídeo), e que cubra desde o set-top box até o head-end. Tal sistema se utiliza de agentes de medição distribuídos que 
verificam a qualidade do vídeo transportado ao longo da rede e coletam diversas métricas relacionadas ao desempenho do serviço.

Além das categorias de sistemas mencionados, se faz necessária a criação de uma estrutura de Video Operations Center (VOC) para suportar a operação contínua do serviço. A integração das novas plataformas de gerenciamento ao ambiente existente também foram consideradas neste caso.

\section{B.3 MODELAGEM ECONÔMICA}

Conforme descrito no item 4.2.3 a modelagem econômica do caso da ACME passa pela elaboração dos modelos de: receita, custos e investimentos que se conjugam na elaboração do fluxo de caixa associado ao serviço IPTV e na obtenção dos indicadores econômicos de VPL, TIR e período de payback conforme detalhado no item 4.2.3.

Para cada um dos cenários delineados no item 5.1.3, é realizada a modelagem econômica do serviço, visando identificar sua viabilidade e atratividade em comparação com os demais.

As principais premissas econômicas utiliza as neste caso são:

- Moeda corrente: Real $(\mathrm{R} \$)$;

- Taxa de inflação: $5 \%$;

- Taxa real de juros de títulos do governo: $10 \%$ ao ano;

- Taxa de câmbio: US $\$ 1,00=R \$ 2,00$;

- Imposto de Renda: 34\% sobre o resultado;

- Imposto sobre vendas: $20 \%$ sobre a receita bruta. 


\section{B.3.1 Receitas}

O cálculo de receitas foi obtido através da aplicação do modelo de precificação detalhado do serviço à projeção de assinantes e seu perfil de utilização detalhados nos itens B.2.1.4 e B.2.1.5, respectivamente. Os resultados estão apresentados na Figura 45.

As principais fontes de receita identificadas são:

- Receita de serviços: inclui a assinatura básica; pontos adicionais; instalação; canais exclusivos e VOD;

- Receita de equipamentos: apenas quando existe a venda dos set-top boxes ao assinante;

Conforme apresentado na Figura 45, verifica-se que o serviço de broadcast TV constitui a base de sustentação de receitas do serviço IPTV no cenário base, incluindo a assinatura básica, pontos adicionais e canais exclusivos. O serviço de VOD, por sua vez, corresponde a uma parcela menos relevante da receita.

\section{B.3.2 Custos e Despesas Operacionais}

As principais fontes de custos e despesas operacionais, também conhecidas como OPEX, relacionadas ao serviço IPTV da ACME se dividem em:

- Custos de Serviços Prestados: incluem os custos diretamente relacionados à oferta de IPTV. Neste caso foram considerados os custos relacionados a conteúdo, e custos de operação e manutenção.

- Custos de equipamentos: custo dos set-top boxes revendidos aos assinantes. Quando o set-top box é fornecido em regime de comodato e pertence à operadora, ele é considerado um investimento.

- Despesas de comercialização: despesas relacionadas a vendas, marketing e provisão para devedores duvidosos. 
- Despesas Gerais e Administrativas: despesas gerais com a administração do serviço.

A Figura 46 mostra a estimativa de Custos e Despesas operacionais relacionadas aos serviços IPTV da ACME no cenário base.

Os custos dos serviços prestados foram estimados conforme os critérios descritos a seguir:

- Conteúdo: os custos relacionados ao conteúdo foram calculados com base em benchmarks de custos de operadoras de TV paga no mercado local com a aquisição de conteúdo. Foi utilizada a premissa de $35 \%$ sobre a receita líquida auferida com conteúdo broadcast e VOD.

- Operação e Manutenção (O\&M): inclui todas as atividades relacionadas ao dia-a-dia de operação e manutenção do serviço. Para o caso da ACME, os custos de O\&M foram considerados nas seguintes categorias:

- Redes e sistemas: estimativa de custos realizada utilizando-se uma porcentagem dos investimentos acumulados ao logo do tempo para cada categoria de investimento explicitado no item B.3.3. A estimativa dos custos de O\&M foi feita partindo do princípio que os custos incorridos com os serviços IPTV são incrementais aos custos para a operação dos serviços IP atualmente em operação, pois todos os serviços se utilizam de uma infra-estrutura de rede comum. A Tabela 27 apresenta as principais premissas utilizadas para a estimativa desses custos e que foram adaptadas de resultados obtidos no projeto Ecosys (28) relacionado à análise técnico-econômica de serviços banda larga. Além disso, foi considerado o incremento de pessoal para suportar a operação do serviço na quantidade de: 5 técnicos no SHE e 3 técnicos nos VHOs de cada uma das regiões. 
Tabela 27 - Premissas de Operação e Manutenção de Rede e Sistemas

\begin{tabular}{lc}
\hline Categoria de custo & $\begin{array}{c}\text { Porcentagem do } \\
\text { Investimento } \\
\text { Acumulado }\end{array}$ \\
\hline Plataformas de Serviço & $5 \%$ \\
\hline Núcleo & $5 \%$ \\
\hline Agregação & $5 \%$ \\
\hline Acesso & $5 \%$ \\
\hline $\begin{array}{l}\text { Elementos ativos } \\
\text { (switches / DSLAMs) }\end{array}$ & $0,5 \%$ \\
\hline $\begin{array}{l}\text { Elementos passivos } \\
\text { (fibra óptica / splitters) }\end{array}$ & \\
\hline
\end{tabular}

- Clientes: atividades de manutenção associadas aos clientes incluindo instalação e desinstalação do serviço, e as visitas de assistência técnica quando da ocorrência de problemas. As principais premissas de quantidade de visitas a clientes estão apresentadas na Tabela 28.

Tabela 28 - Premissas de manutenção relacionada ao cliente

\begin{tabular}{lc}
\hline \multicolumn{1}{c}{$\begin{array}{c}\text { Categorias de } \\
\text { custo }\end{array}$} & $\begin{array}{c}\text { Quantidade de visitas } \\
\text { Quantidade de novos } \\
\text { assinantes }\end{array}$ \\
\hline Instalação & $\begin{array}{c}\text { Quantidade de desconexões } \\
\text { Desinstalação }\end{array}$ \\
\hline Assistência técnica & $\begin{array}{c}5 \% \text { da base de assinantes } \\
\text { por mês }\end{array}$ \\
\hline
\end{tabular}

As despesas de comercialização e as despesas gerais e administrativas foram estimadas com base em uma porcentagem da receita do serviço utilizando benchmarks de operadoras de TV paga do mercado nacional. Considerando que deve-se levar em consideração apenas as despesas incrementais, foram utilizadas as seguintes premissas para estimar tais categorias de despesas:

- Despesa de comercialização: $5 \%$ da receita líquida (média dos benchmarks $=7 \%$ ). Assumiu-se que as despesas de comercialização incrementais são da mesma ordem de grandeza das absolutas encontradas em operadoras de TV paga. 
- Despesas gerais e administrativas: $5 \%$ da receita líquida (médias dos benchmarks $=19 \%)$. Assumiu-se que as despesas gerais incrementais em termos de percentual de receita são significativamente menores do que os benchmarks, pois já existe uma operação de telefonia e banda larga estabelecida para suportar diversos serviços.

\section{B.3.3 Investimentos}

As categorias de investimento, também conhecidas como CAPEX, consideradas no caso da ACME dizem respeito às categorias de infra-estrutura tecnológica apresentadas em detalhe no dimensionamento da arquitetura tecnológica do item 5.1.2.4 e estão listadas a seguir:

- Serviço: sistemas de head-end (recepção e processamento de sinais), middleware, DRM, servidores de vídeo e set-top boxes;

- Rede: núcleo, agregação e acesso;

- Gerenciamento: monitoramento de qualidade de vídeo fim-a-fim, monitoramento de rede, e sistemas de gerenciamento (OSS/BSS) para infraestrutura de serviço.

A mensuração do investimento em cada componente tecnológico foi feita através de cotações junto a diversos fornecedores de tecnologia, preços de referência de mercado e parâmetros de dimensionamento explicitados no item 5.1.2.4. Considerou-se a queda dos preços de referência associados a cada componente da solução ao longo do tempo devido aos ganhos de escala e a conseqüente redução de custos da tecnologia.

Foi considerado que os investimentos associados à IPTV são sempre incrementais, pois sua implementação parte de uma rede IP já em funcionamento. Desta forma, os investimentos mensurados correspondem única e exclusivamente ao serviço IPTV. Para tanto, nas esferas de núcleo e agregação da rede, os investimentos foram proporcionalizados à largura de banda utilizada pelo serviço IPTV. No caso do acesso, como a infra-estrutura não varia conforme a banda, mas sim com o número de assinantes, uma porta de acesso pode servir a tantos serviços quanto se queira 
oferecer sobre ela. Considera-se neste caso que a ACME pode oferecer três serviços utilizando a infra-estrutura de acesso, a saber: Internet Banda larga, Voz e Vídeo. Entretanto, os serviços que demandam a evolução da arquitetura acesso são o IPTV e Internet banda larga devido às suas necessidades de banda conforme apresentado na Figura 65. Ainda com base nos perfis de utilização da Figura 65, pode-se considerar que a banda requerida pelos dois serviços é da mesma ordem de magnitude e, portanto, metade dos investimentos do acesso é atribuído ao serviço IPTV. A outra metade deve ser atribuída ao serviço de Internet Banda larga.

\section{Investimentos Totais}

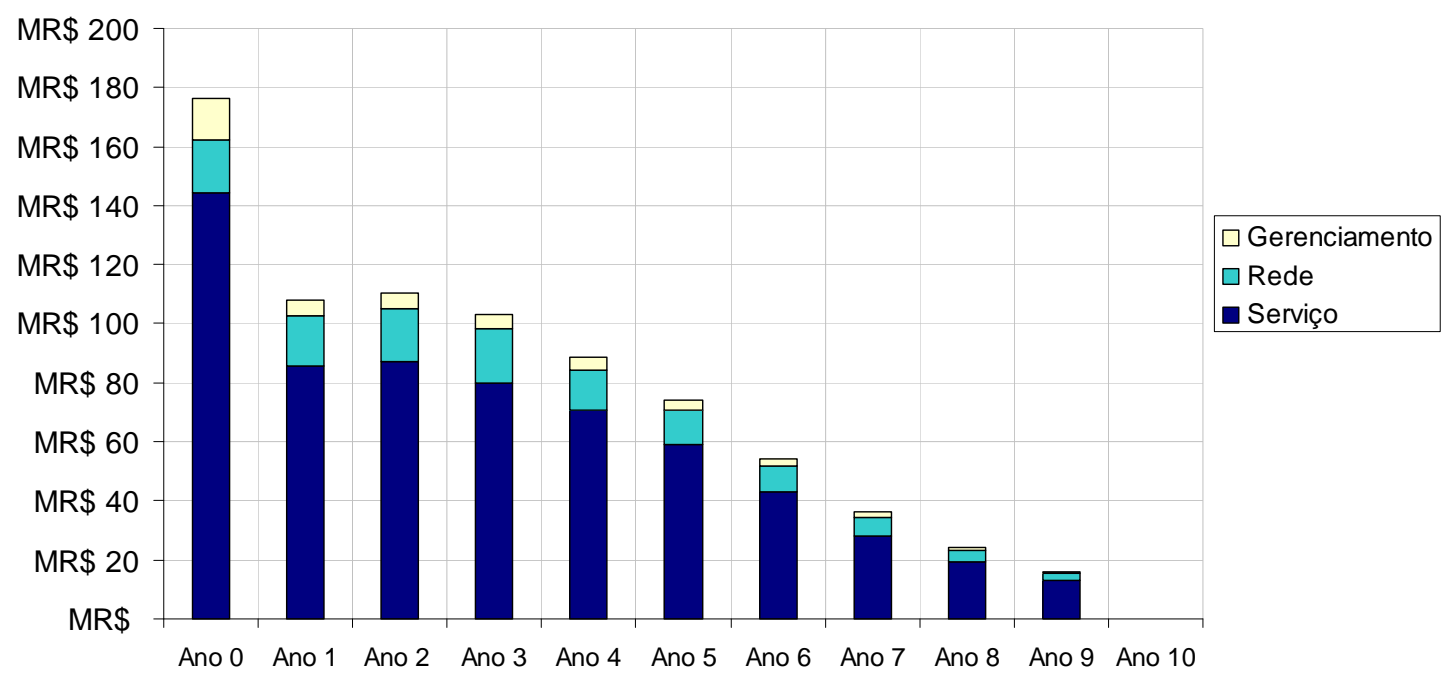

Figura 73 - Investimentos - serviço IPTV (grandes blocos)

Os resultados da estimativa dos investimentos totais estão apresentados na Figura 73 de acordo com os grandes blocos de infra-estrutura. Nota-se que a infra-estrutura de serviço corresponde à maior parte dos investimentos relacionados à IPTV. A seguir estão apresentados os detalhes de cada uma das componentes de investimento relacionada ao serviço IPTV. A Figura 47 apresenta os investimentos associado a cada componente em um gráfico consolidado para que se tenha a noção da proporção entre todas as suas componentes. 


\section{Investimentos - Infra-estrutura de Serviço}

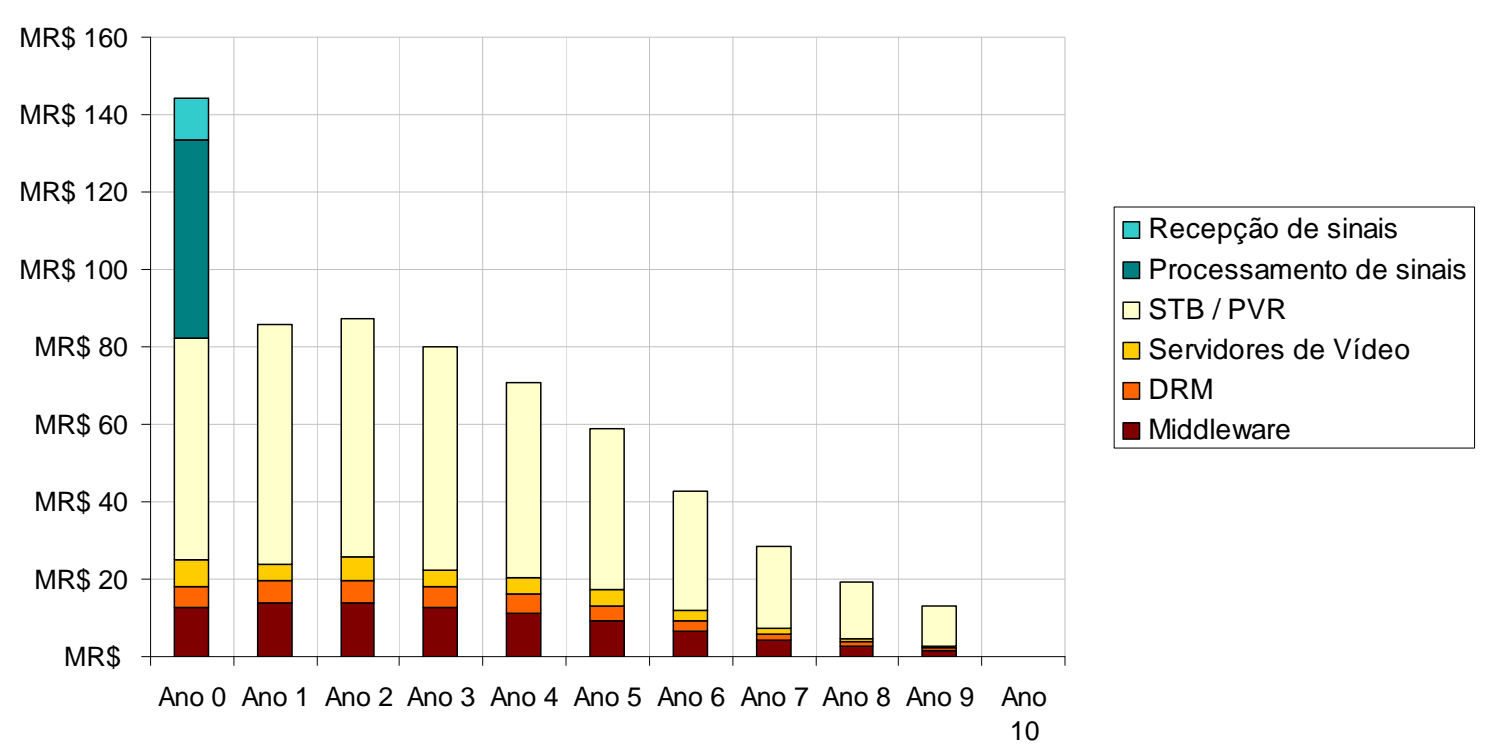

Figura 74 - Investimentos em Plataforma de Serviço - serviço IPTV

Há que se notar que, no cenário base da $\mathrm{ACME}$, os set-top boxes compõem uma parte significativa dos investimentos em infra-estrutura de serviço conforme explicita o gráfico da Figura 74. Isto ocorre porque neste cenário, os usuários recebem o settop box em regime de comodato. 


\section{Investimentos - Infra-estrutura de Rede}

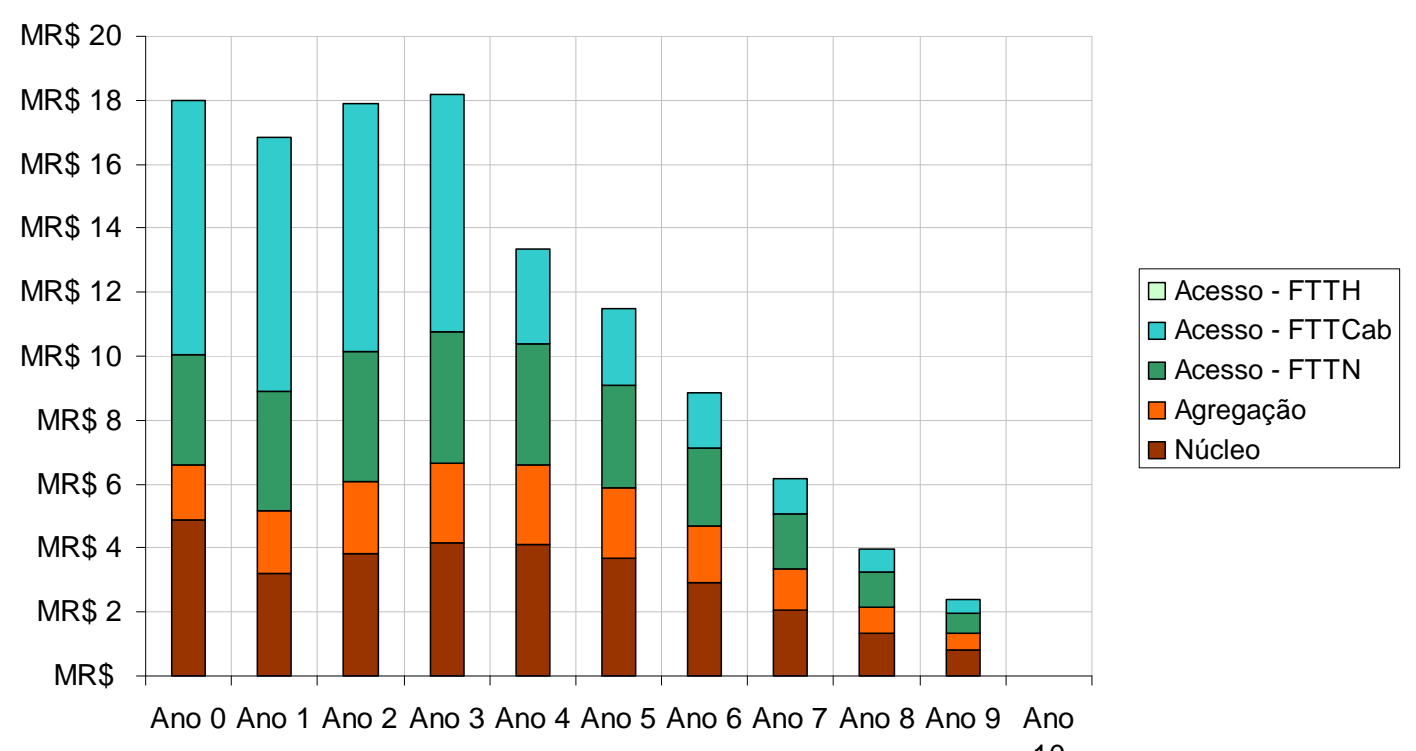

Figura 75 - Investimentos em Rede - serviço IPTV

Dos investimentos em rede apresentados na Figura 75, os investimentos em acesso são aqueles mais significativos devido à necessidade de substituição completa de elementos de acesso. Pode-se notar que, apesar de uma menor parte das portas se valerem de uma arquitetura FTTCab conforme apresentado na Tabela 21, os investimentos nessa arquitetura são relevantes quando comparados aos investimentos nas portas instaladas na arquitetura FTTN. Tal porte desse investimento se deve ao fato de que existe uma substituição da rede primária de acesso de par metálico por uma rede óptica, exigindo maiores investimentos. 


\section{Investimentos - Infra-estrutura de Gerenciamento}

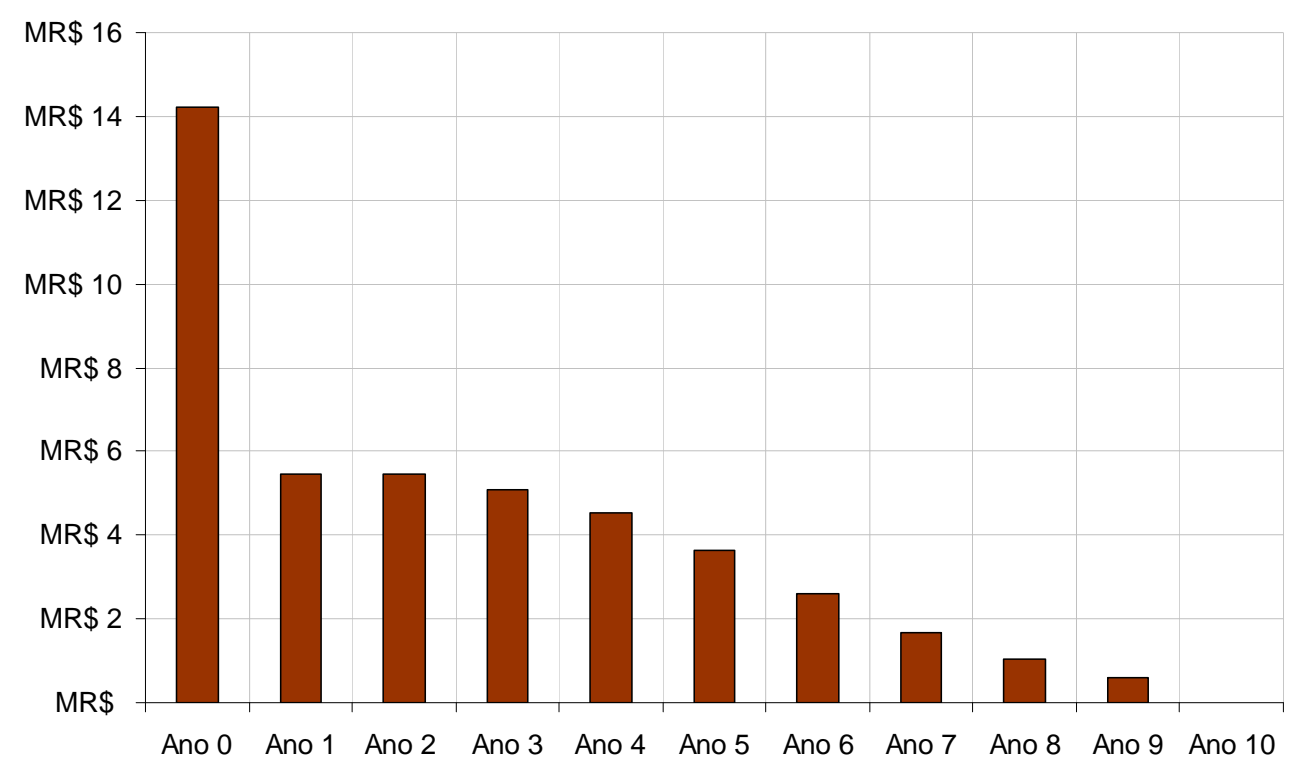

Figura 76 - Investimentos em Rede - serviço IPTV

A Figura 76 apresenta os investimentos associados à infra-estrutura de gerenciamento. Tais investimentos incluem desde a criação de um VOC, sistemas de monitoramento fim-a-fim da qualidade de vídeo, até o gerenciamento completo de assinantes e integração desses sistemas com sistemas já existentes.

\section{B.3.4 Fluxo de Caixa}

As demais dimensões de receita, custos e despesas operacionais, e investimentos são conjugadas conforme explicitado no 3.2.1 para se obter o Fluxo de Caixa associado à introdução dos serviços IPTV. Para tais cálculos, foram utilizados parâmetros de alíquotas de imposto local e assume-se que a depreciação dos ativos acontece ao longo de 5 anos de maneira linear. Além disso, todos os cálculos de receitas e custo não incluem o efeito da inflação. Desta forma, os fluxos de caixa estão expressos em valores reais.

Para descontar o fluxo de caixa a valor presente, a taxa de desconto real empregada foi de $15 \%$ considerando o Real $(R \$)$ como moeda de referência. Esta é considerada 
a considerada a TMA do projeto conforme discutido no item 3.2.2. A taxa de desconto foi determinada a partir do custo médio ponderado de capital (WACC) típico de uma empresa de telecomunicações brasileira conforme calculado no estudo de Bragança (53). Os valores de WACC lá apresentados foram devidamente adaptados para serem utilizados em Reais $(R \$)$, pois estavam expressos tendo como base o dólar (US\$) como moeda de referência. A variação de capital de giro foi estimada com base em percentual da receita e dos seus custos e despesas.

A Tabela 29 mostra os principais resultados financeiros até obtenção do Fluxo de Caixa, que serve de base para calcular os diversos indicadores econômicos. $\mathrm{Na}$ Figura 49, estão apresentados o fluxos de caixa relacionados ao serviço IPTV. 
Tabela 29 - Cálculo do Fluxo de Caixa do Projeto

\begin{tabular}{|c|c|c|c|c|c|c|c|c|c|c|c|c|}
\hline & Milhões de $\mathrm{R} \$$ & $\begin{array}{c}\text { Ano } \\
0\end{array}$ & $\begin{array}{c}\text { Ano } \\
1\end{array}$ & $\begin{array}{c}\text { Ano } \\
2\end{array}$ & $\begin{array}{c}\text { Ano } \\
3\end{array}$ & $\begin{array}{c}\text { Ano } \\
4\end{array}$ & $\begin{array}{c}\text { Ano } \\
5\end{array}$ & $\begin{array}{c}\text { Ano } \\
6\end{array}$ & $\begin{array}{c}\text { Ano } \\
7\end{array}$ & $\begin{array}{c}\text { Ano } \\
8\end{array}$ & $\begin{array}{c}\text { Ano } \\
9\end{array}$ & $\begin{array}{c}\text { Ano } \\
10\end{array}$ \\
\hline 1 & Receita Bruta & - & 80,7 & 230,2 & 409,6 & 610,5 & 817,0 & $1.008,8$ & $1.168,6$ & $1.288,0$ & $1.369,1$ & $1.420,0$ \\
\hline 2 & Impostos sobre vendas & - & 16,1 & 46,0 & 81,9 & 122,1 & 163,4 & 201,8 & 233,7 & 257,6 & 273,8 & 284,0 \\
\hline 3 & Receita Líquida (1 - 2) & - & 64,6 & 184,2 & 327,6 & 488,4 & 653,6 & 807,1 & 934,8 & $1.030,4$ & $1.095,3$ & $1.136,0$ \\
\hline 4 & $\begin{array}{l}\text { Custos e Despesas } \\
\text { Operacionais }(5+6)\end{array}$ & - & 33,9 & 89,4 & 156,0 & 230,3 & 306,5 & 377,3 & 436,3 & 480,4 & 510,4 & 529,3 \\
\hline 5 & $\begin{array}{l}\text { Custo dos serviços } \\
\text { Prestados }\end{array}$ & - & 27,5 & 71,0 & 123,2 & 181,4 & 241,1 & 296,6 & 342,8 & 377,4 & 400,9 & 415,6 \\
\hline 6 & $\begin{array}{l}\text { Despesas de } \\
\text { comercialização, gerais } \\
\text { e administrativas }\end{array}$ & - & 6,5 & 18,4 & 32,8 & 48,8 & 65,4 & 80,7 & 93,5 & 103,0 & 109,5 & 113,6 \\
\hline 7 & Depreciação & - & 35,3 & 56,9 & 79,0 & 99,6 & 132,2 & 107,8 & 93,4 & 76,2 & 58,7 & 40,9 \\
\hline 8 & $\begin{array}{l}\text { Resultado antes de Juros e } \\
\text { Impostos }(3-4-7)\end{array}$ & - & $-4,6$ & 37,9 & 92,7 & 158,5 & 214,9 & 321,9 & 405,1 & 473,8 & 526,2 & 565,8 \\
\hline 9 & Imposto de Renda & - & - & 12,9 & 31,5 & 53,9 & 73,1 & 109,5 & 137,7 & 161,1 & 178,9 & 192,4 \\
\hline 10 & $\begin{array}{l}\text { Variação de Capital de } \\
\text { Giro }\end{array}$ & - & 2,6 & 4,3 & 4,9 & 5,3 & 5,8 & 3,9 & 3,4 & 2,3 & 1,4 & 0,7 \\
\hline 11 & Investimentos & 176,3 & 108,0 & 110,5 & 103,3 & 88,7 & 74,1 & 54,3 & 36,2 & 24,3 & 15,9 & - \\
\hline 12 & $\begin{array}{l}\text { Fluxo de Caixa } \\
(8+7-11-12)\end{array}$ & $-176,3$ & $-79,9$ & $-32,9$ & 32,0 & 110,2 & 194,1 & 262,1 & 321,3 & 362,3 & 388,7 & 413,7 \\
\hline
\end{tabular}




\section{B.4 ANÁLISE DE SENSIBILIDADE E CENÁRIOS}

Os resultados para o cenário base foram apresentados ao longo dos itens 5.1.2.4 e 5.1.3. Neste item, serão sumarizadas as principais conclusões extraídas do cenário base e também serão realizadas comparações entre os diversos cenários apresentados na Tabela 8.

\section{B.4.1 Cenário base}

Conforme observado, o cenário base da introdução de serviços IPTV na ACME se mostra como uma alternativa viável tanto do ponto de vista tecnológico quanto econômico. Seus principais resultados foram apresentados ao longo da descrição da aplicação da metodologia no item 5.1 e complementado com informações deste anexo. A seguir serão discutidas as variações dos resultados de acordo com os diversos cenários.

\section{B.4.2 Nível de adoção do serviço}

O fluxo de caixa descontado acumulado para os cenários de adoção conservadora ou agressiva do serviço estão apresentados na Figura 77. Além disso, os principais indicadores econômicos estão apresentados na Tabela 30. 


\section{FC Descontado - Acumulado}

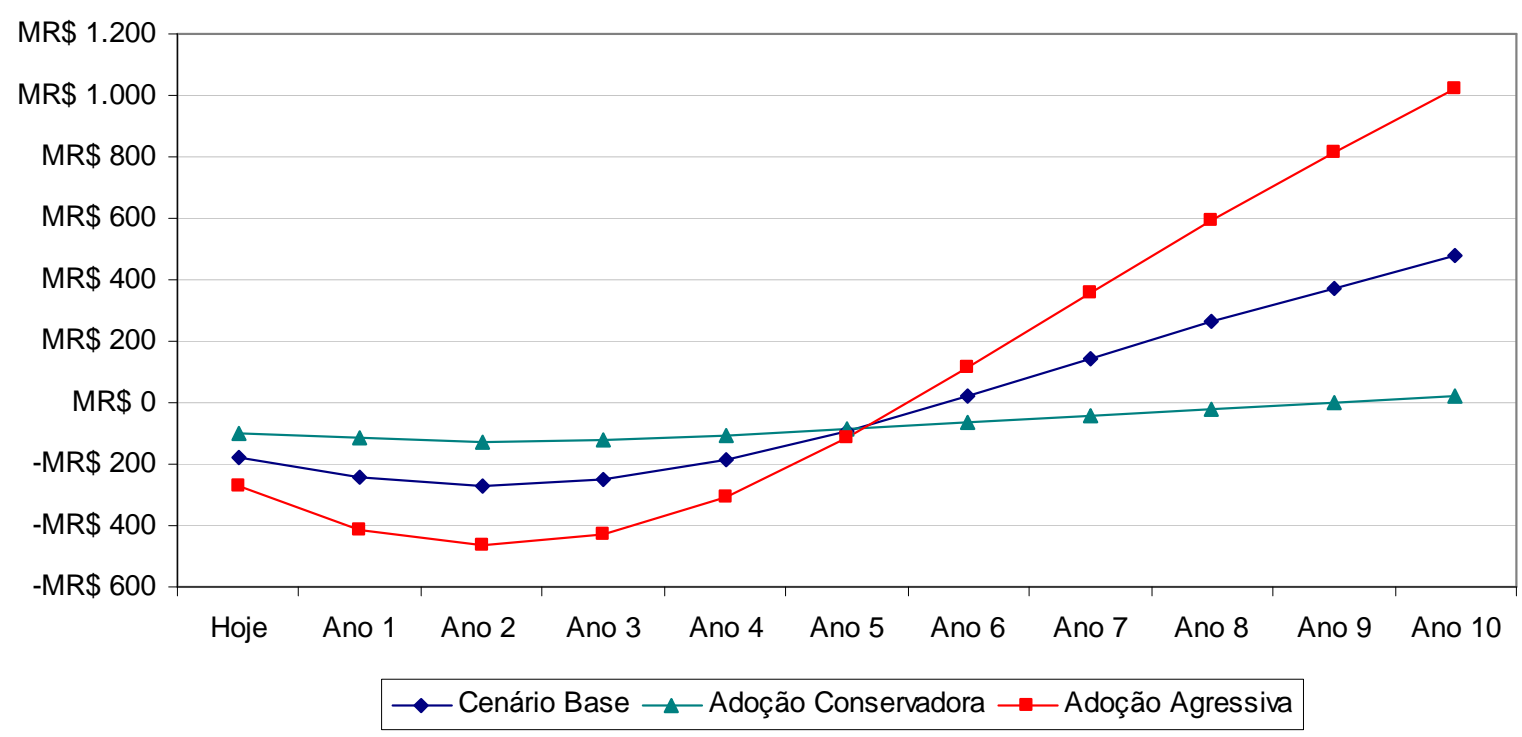

Figura 77 - Fluxo de Caixa Acumulado - cenários de adoção do serviço

Tabela 30 - Indicadores econômicos - cenários de adoção do serviço

\begin{tabular}{lccc}
\hline Indicador & $\begin{array}{c}\text { Adoção } \\
\text { Conservadora }\end{array}$ & $\begin{array}{c}\text { Adoção } \\
\text { Moderada } \\
\text { (Cenário base) }\end{array}$ & $\begin{array}{c}\text { Adoção } \\
\text { Agressiva }\end{array}$ \\
\hline VPL & MR $\$ 23$ & MR $\$ 475$ & MR $\$ 1.021$ \\
\hline TIR & $18 \%$ & $35 \%$ & $38 \%$ \\
\hline $\begin{array}{l}\text { Payback } \\
\text { Descontado (anos) }\end{array}$ & 8,9 & 5,8 & 5,5 \\
\hline
\end{tabular}

Todos os dois cenários alternativos continuam satisfazendo a viabilidade econômica ao longo dos 10 anos com VPL>0 e TIR > TMA. Entretanto, a adoção do serviço em menor escala dificulta a recuperação dos investimentos realizados alongando o período de recuperação de investimento para 9 anos. Apesar do pico negativo de caixa acumulado mais intenso no cenário em que a adoção é massiva, a recuperação dos investimentos ocorre de maneira rápida, diminuindo o tempo de recuperação para 5,5 anos. 


\section{Investimento por assinante}

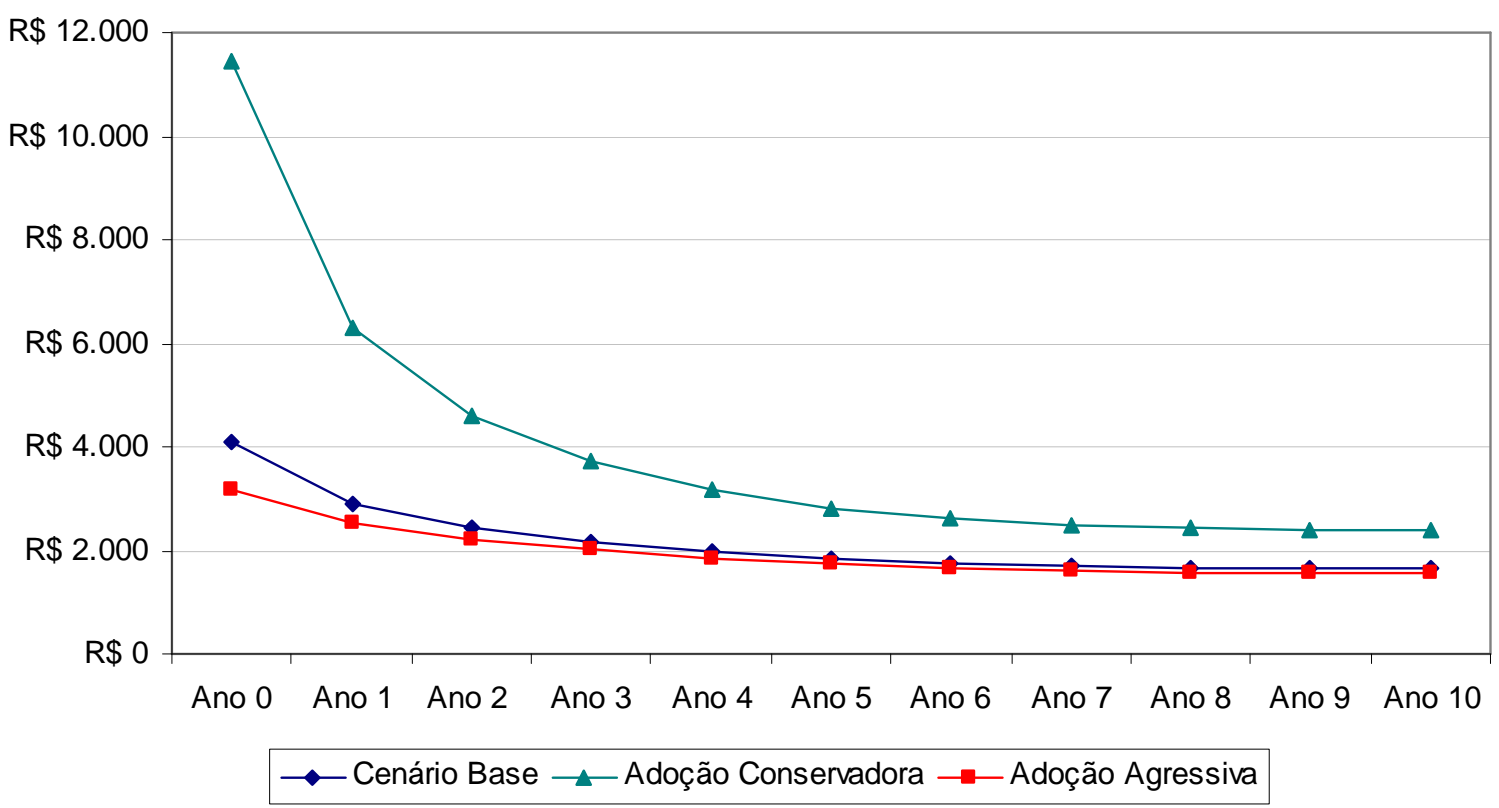

Figura 78 - Investimento por assinante - cenários de adoção do serviço

O fator da escala é bastante relevante neste caso e se reflete diretamente no investimento médio por assinante apresentado na Figura 78. No caso de uma adoção tímida do serviço, não há escala suficiente para diluir os investimentos realizados no instante inicial, principalmente relacionados à infra-estrutura de processamento e recepção de sinais necessária ao serviço de broadcast conforme evidenciado na Figura 79. A inexistência de uma condição de escala mínima dificulta a recuperação dos investimentos, tornando a implementação menos atrativa nestas condições. 


\section{Investimento médio por assinante}

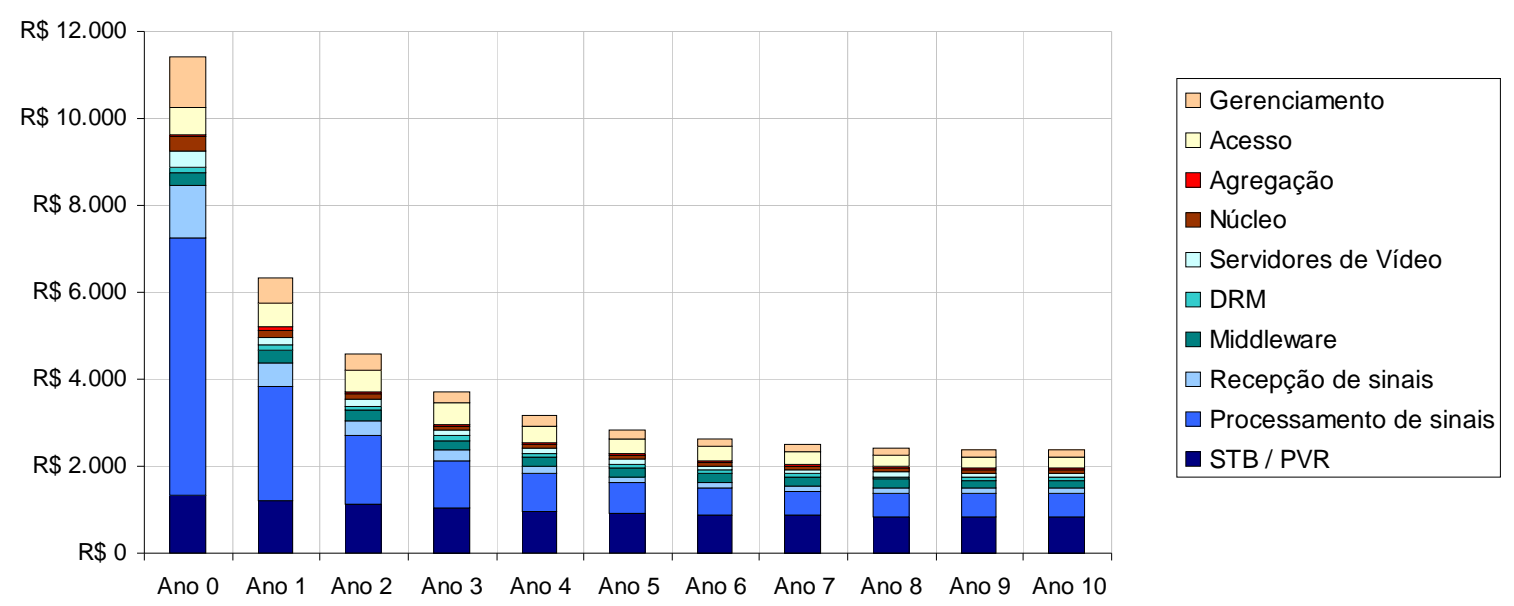

Figura 79 - Investimento por assinante - adoção conservadora

Não se verifica ganhos expressivos de escala quando da adoção massiva do serviço, denotando que o volume de assinantes do cenário base já favorecia bastante a implementação do serviço neste quesito. Desta forma, o tempo de recuperação de investimento fica bastante próximo do cenário base. Entretanto, a geração de valor é substancialmente maior no caso em que a adoção do serviço é massiva, o que é refletido em seu VPL bastante superior aos outros cenários.

\section{B.4.3 Adoção de HDTV / SDTV}

Os resultados do fluxo de caixa acumulado para os cenários de variação de perfil de adoção de HDTV estão apresentados na Figura 80 e os principais indicadores na Tabela 31. Os parâmetros que norteiam tais cenários estão apresentados na Tabela 11. 


\section{FC Descontado - Acumulado}

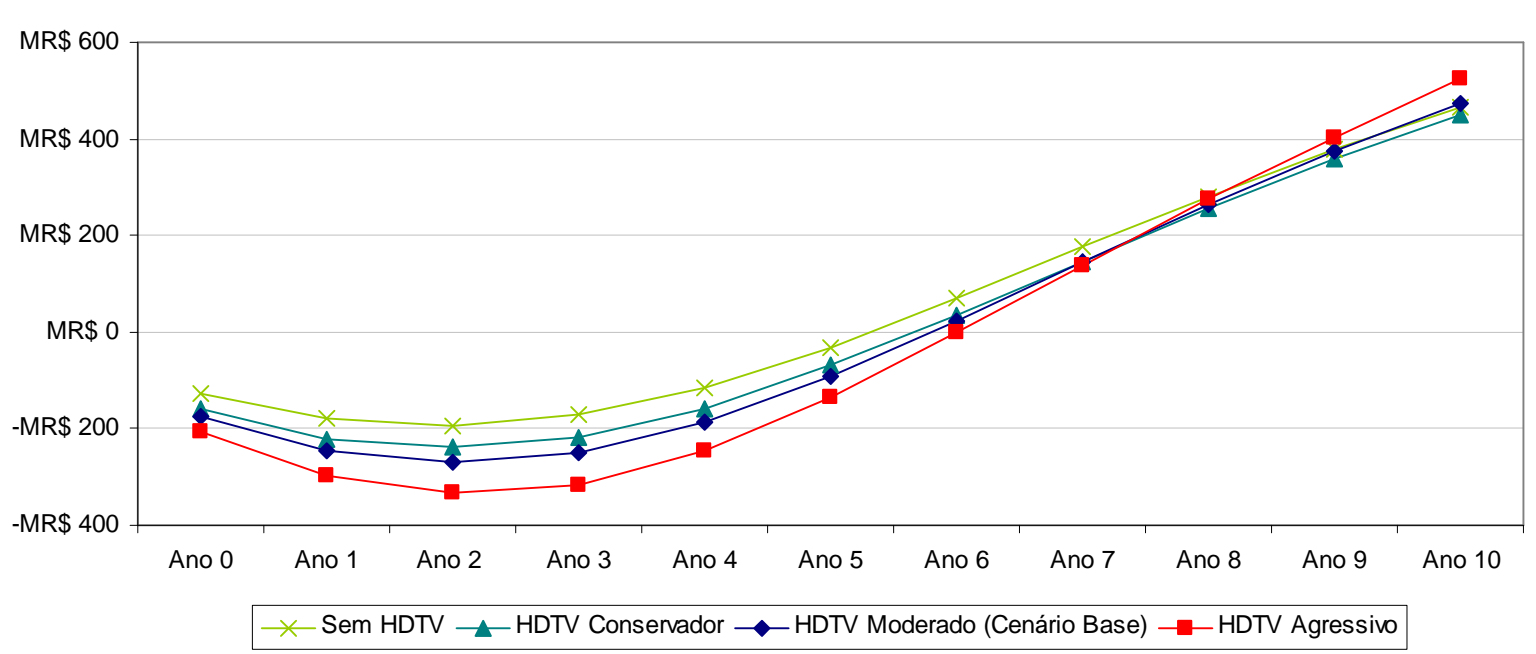

Figura 80 - Fluxo de Caixa Acumulado - cenários de adoção de HDTV

Tabela 31 - Indicadores econômicos - cenários de adoção de HDTV

\begin{tabular}{lcccc}
\hline Indicador & $\begin{array}{c}\text { Sem } \\
\text { HDTV }\end{array}$ & $\begin{array}{c}\text { Adoção HDTV } \\
\text { Conservadora }\end{array}$ & $\begin{array}{c}\text { Adoção } \\
\text { HDTV } \\
\text { Moderada } \\
\text { (Cenário } \\
\text { Base) }\end{array}$ & $\begin{array}{c}\text { Adoção } \\
\text { HDTV } \\
\text { Agressiva }\end{array}$ \\
\hline VPL & MR $\$ 467$ & $\mathrm{MR} \$ 451$ & $\mathrm{MR} \$ 475$ & $\mathrm{MR} \$ 523$ \\
\hline TIR & $40 \%$ & $36 \%$ & $35 \%$ & $33 \%$ \\
\hline $\begin{array}{l}\text { Payback } \\
\begin{array}{l}\text { Descontado } \\
\text { (anos) }\end{array}\end{array}$ & 5,3 & 5,7 & & \\
\hline
\end{tabular}

Verifica-se que os diversos cenários são viáveis do ponto de vista econômico, pois satisfazem às condições de VPL > 0 e TIR > TMA. Verifica-se também que não há diferenças significativas no perfil de fluxo de caixa descontado face à variação dos parâmetros relacionados à penetração de HDTV na base de assinantes conforme mostra a Figura 80. O tempo de recuperação de investimento é muito próximo para todos os cenários, variando de 5,3 onde não existe transmissão de conteúdo em HDTV a 6 no cenário onde existe consumo massivo deste serviço. 


\section{Investimento médio por assinante - Ano 10}

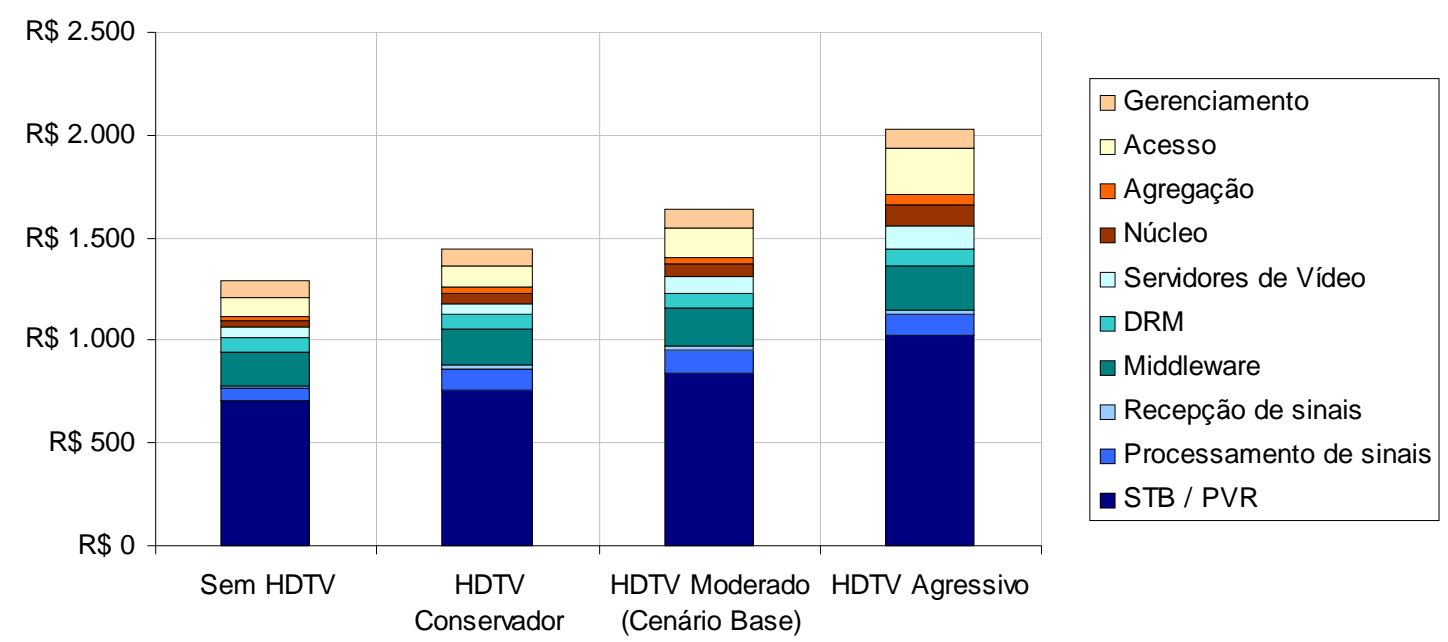

Figura 81 - Investimento por assinante - cenários de adoção de HDTV

\section{Receita média por assinante (por mês)}

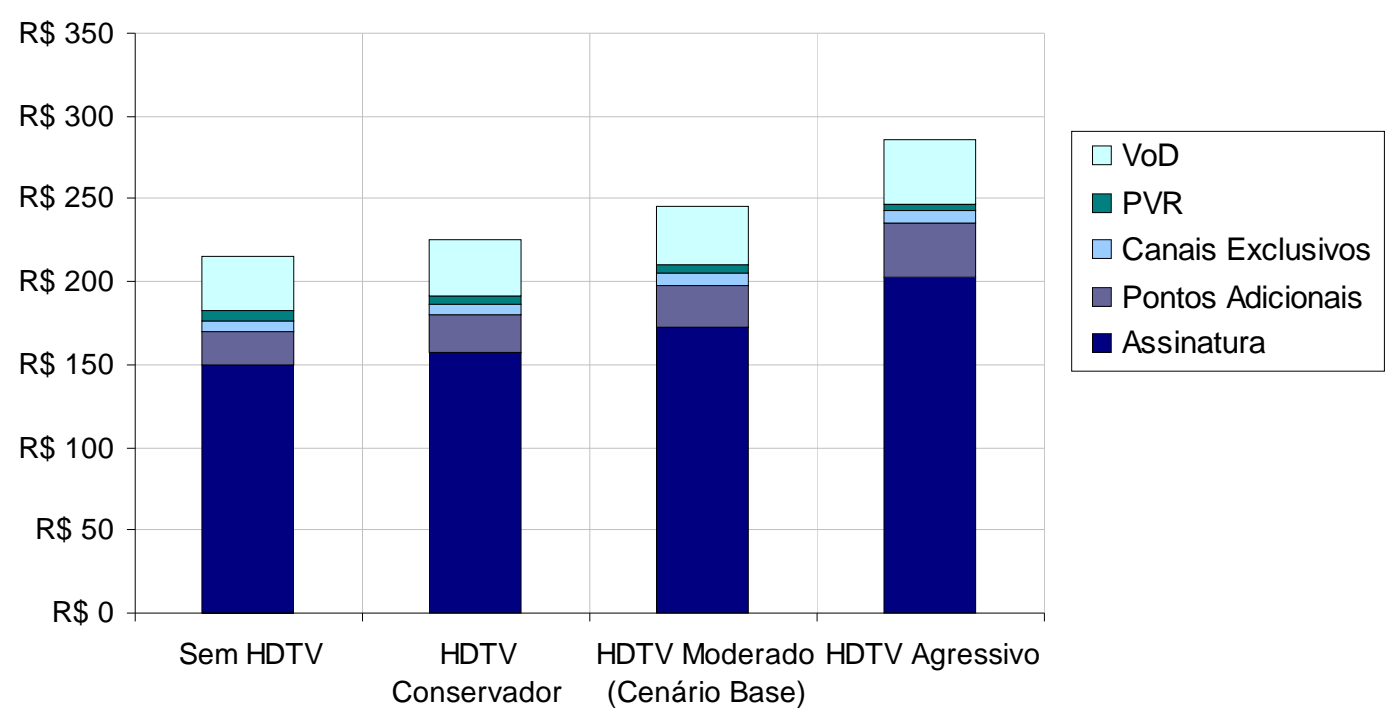

Figura 82 - Receita por Assinante - cenários de adoção de HDTV

Os perfis de receita e investimento por assinante para os diversos cenários estão apresentados na Figura 81 e na Figura 82, respectivamente. Verifica-se o aumento investimento requerido por assinante com a maior adoção de HDTV é significativo. $O$ aumento de investimento para o cenário de adoção agressiva é de $41 \%$ em relação ao cenário conservador. Tal aumento de investimentos está associado aos seguintes componentes: 
- Set-top box: os set-top boxes preparados para receber conteúdo em HDTV são mais caros;

- Servidores de vídeo: maior necessidade de investimento em servidores de vídeo para armazenar e dar vazão às requisições de conteúdo VOD em qualidade HDTV;

- Rede: maior necessidade de investimento em rede para suportar o acréscimo de banda do conteúdo HDTV. O investimento na agregação e núcleo é proporcional ao acréscimo de tráfego HDTV, especialmente devido ao tráfego VOD. No acesso, os investimentos são mais vultosos devido à evolução da arquitetura de acesso para uma arquitetura FTTCab para atender aos usuários que fazem uso de conteúdo em alta definição.

Em contrapartida, a receita associada aos assinantes que possuem HDTV é maior para o modelo de precificação e níveis de preço definidos para o caso da ACME, promovendo a recuperação desse investimento de uma maneira equilibrada. No longo prazo, tal recuperação se mostra eficiente e implicando em maior valor gerado para a ACME nos caso de maior adoção de HDTV com VPL superior aos demais cenários.

\section{B.4.4 Adoção de VOD / broadcast}

A Figura 83 apresenta os resultados do fluxo de caixa acumulado para os cenários de variação de perfil de adoção de broadcast e VOD, e a Tabela 32 contém os principais indicadores econômicos associados a esses cenários. Os parâmetros que norteiam tais cenários estão indicados na Tabela 12. 


\section{FC Descontado - Acumulado}

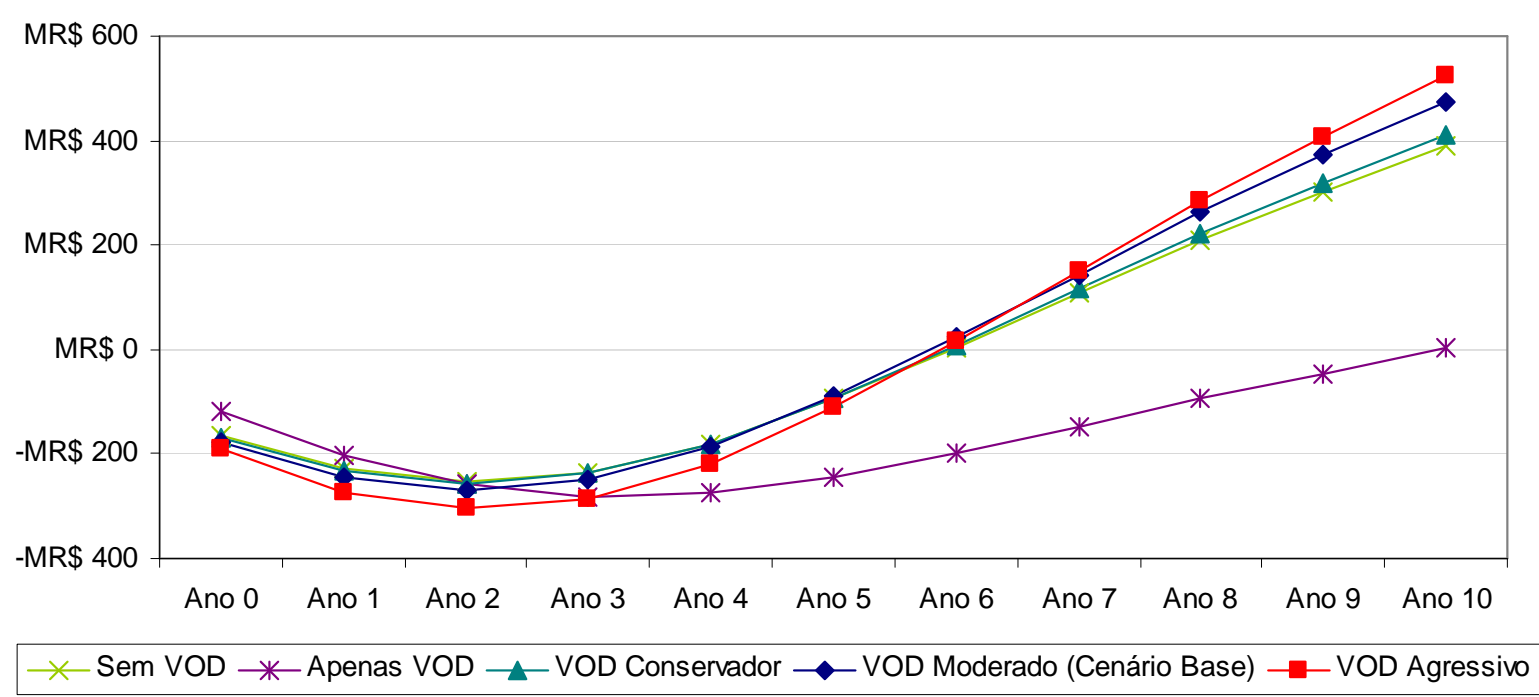

Figura 83 - Fluxo de Caixa Acumulado - cenários de adoção de VOD

Tabela 32 - Indicadores econômicos - cenários de adoção de VOD

\begin{tabular}{|c|c|c|c|c|c|}
\hline Indicador & $\begin{array}{l}\text { Apenas } \\
\text { VOD }\end{array}$ & Sem VOD & $\begin{array}{l}\text { Adoção VOD } \\
\text { Conservadora }\end{array}$ & $\begin{array}{c}\text { Adoção } \\
\text { Moderada } \\
\text { (Cenário } \\
\text { Base) }\end{array}$ & $\begin{array}{l}\text { Adoção } \\
\text { VOD } \\
\text { Agressiva }\end{array}$ \\
\hline VPL & $\mathrm{MR} \$ 1$ & MR\$ 391 & $\mathrm{MR} \$ 411$ & MR \$ 475 & $\mathrm{MR} \$ 523$ \\
\hline TIR & $15 \%$ & $33 \%$ & $34 \%$ & $35 \%$ & $34 \%$ \\
\hline $\begin{array}{l}\text { Payback } \\
\text { Descontado } \\
\text { (anos) }\end{array}$ & 10,0 & 6,0 & 5,9 & 5,8 & 5,9 \\
\hline
\end{tabular}

Todo os cenários de adoção de VOD e broadcast se apresentam como viáveis economicamente no período de 10 anos satisfazendo $V P L>0$ e $T I R>T M A$, com exceção do cenário em que se oferta apenas VOD (fica no limiar de viabilidade). 


\section{Investimento médio por assinante - Ano 10}

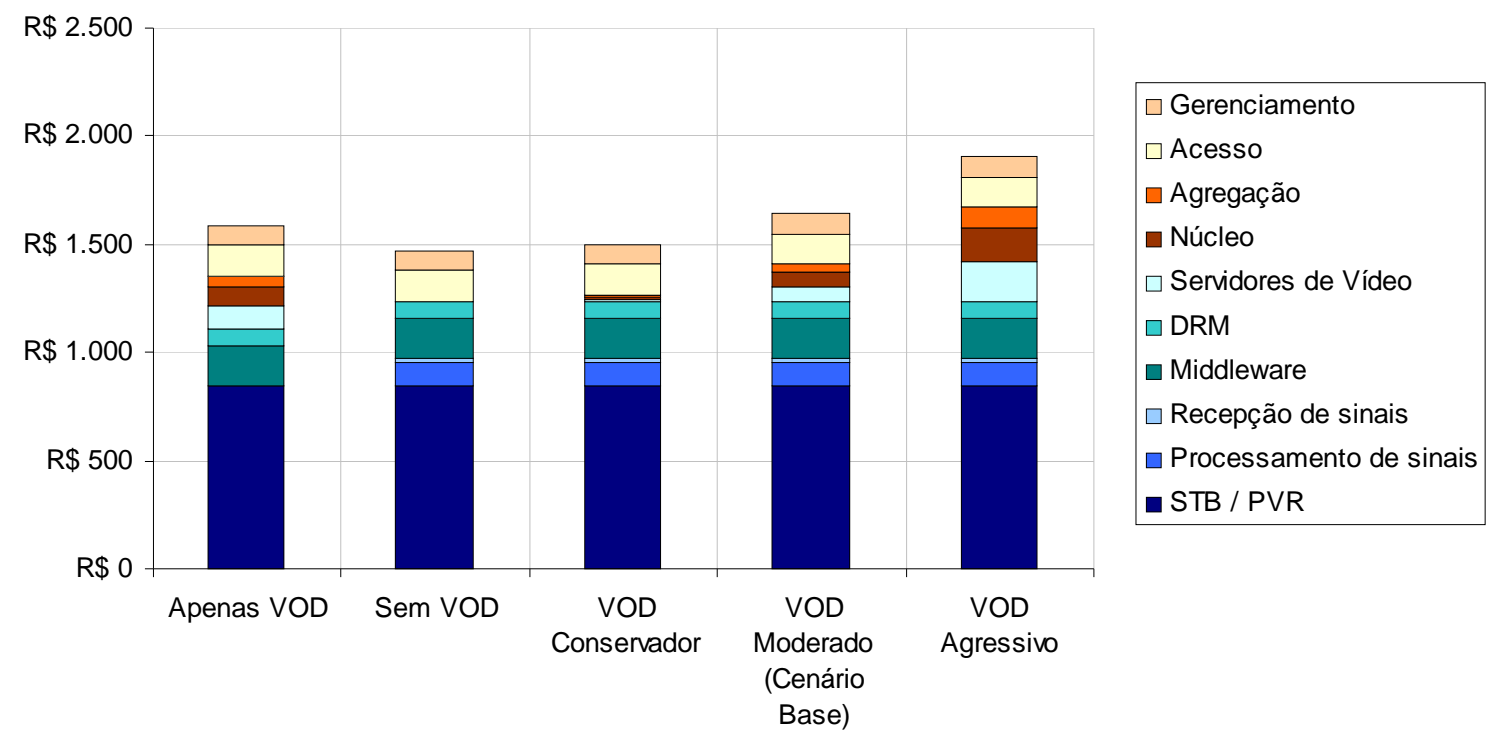

Figura 84 - Investimento por assinante - cenários de adoção de VOD

\section{Receita média por assinante (por mês)}

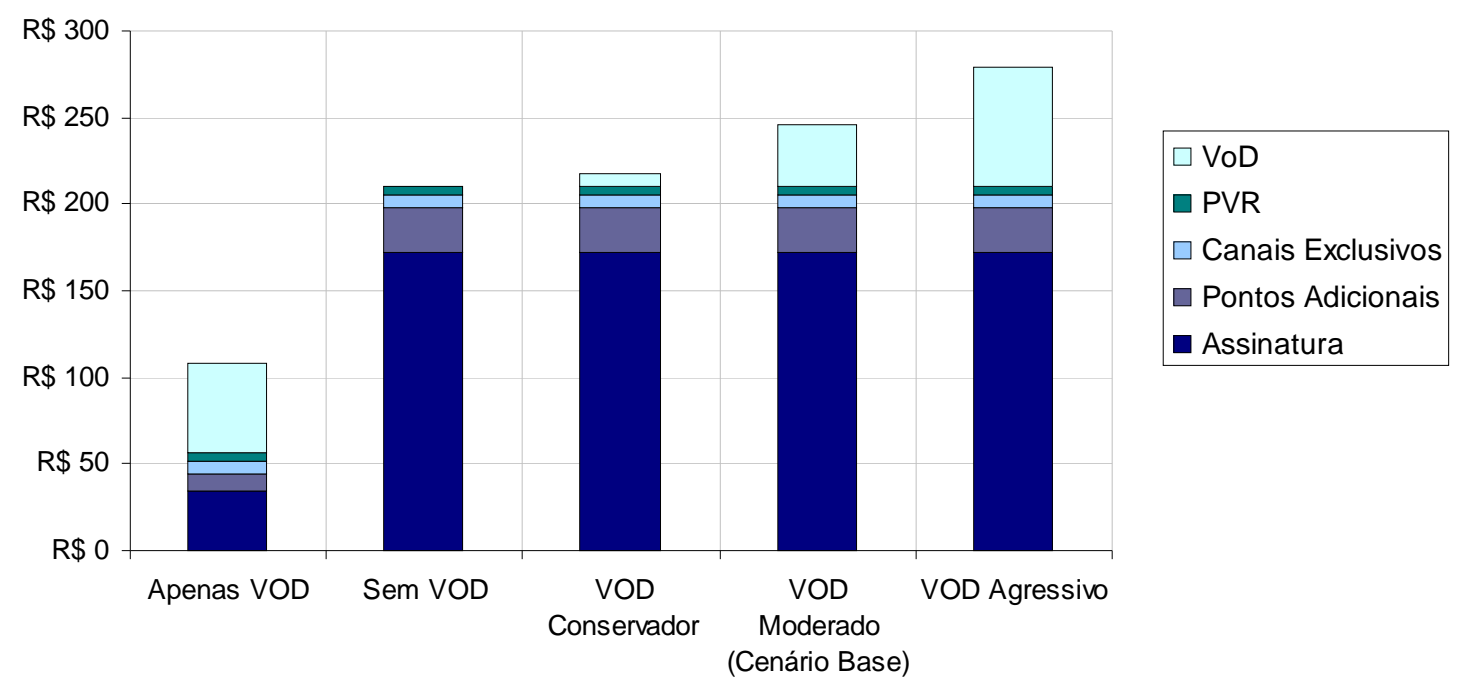

Figura 85 - Receita por Assinante - cenários de adoção de VOD

Nos três cenários viáveis não se verifica uma variação acentuada dos perfis de fluxo de caixa. A geração de valor é crescente com a maior oferta e consumo de VOD 
neste caso, pois apresenta VPL crescente. Nos três cenários, o período de recuperação de investimento é muito próximo, situando-se ao redor de 6 anos.

Os investimentos em VOD são ligeiramente superiores quando se tem uma adoção maior do serviço, conforme pode ser notado na Figura 84. No cenário mais agressivo, os investimentos são $16 \%$ maiores quando comparados ao cenário conservador. O aumento de investimento aqui referido está relacionado aos seguintes itens:

- Servidores de vídeo: necessidade de maior capacidade de armazenamento para conteúdo adicional nos cenários mais avançados e maior vazão para atender às requisições de uma quantidade maior de assinantes.

- Rede: dimensionamento de rede para atender ao aumento do tráfego de VOD. Este aumento se dá especialmente na agregação e no núcleo, pois a arquitetura de acesso não varia com estes cenários.

Em contrapartida, existe também um acréscimo de receita da receita do serviço devido ao consumo mais acentuado de títulos VOD pelos assinantes conforme mostra a Figura 85. Da mesma forma que ocorre com a oferta de HDTV, tais efeitos se compensam de maneira que existe maior geração de valor no longo prazo ainda que o investimento com a oferta de VOD mais intensiva seja maior.

No caso da oferta exclusiva de VOD sem broadcast, o projeto não é economicamente atrativo pois fica no limiar de viabilidade com VPL próximo de zero. Conforme evidenciado na Figura 85, sem a oferta de broadcast, a receita associada ao serviço diminui substancialmente. Conforme as regras de precificação apresentadas no item B.2.1.5 o valor da assinatura é bastante inferior quando se considera o serviço VOD isoladamente. Por outro lado, não ocorre uma redução de investimentos em mesma proporção como se pode observar na Figura 84.

Para que o serviço de VOD puro apresentasse condições de viabilidade similares aos outros cenários, a composição de receitas deveria ser tal que ficasse próxima dos demais patamares apresentados. Isso poderia ser conseguido, por exemplo, cobrando um valor de assinatura mais alto do usuário e oferecendo um conjunto interessante de títulos VOD que possam ser visualizados sem limitações e sem custo adicional ao assinante. Há que se notar que os parâmetros de simultaneidade de acesso devem ser ajustados para refletir essa condição de consumo mais intenso 
e podem ocasionar aumento de investimentos em rede e servidores de vídeo como notado nos cenários de adoção crescente.

Uma alternativa para viabilizar este cenário de oferta exclusiva de VOD seria no sentido de diminuir o investimento por assinante, por exemplo, fazendo com que o set-top box seja comprado ao invés de ser oferecido em regime de comodato. Desta maneira, o investimento poderia ser reduzido em até $50 \%$. As discussões a respeito dos efeitos da modalidade de compra ou comodato do set-top box estão apresentadas no item B.4.5.

\section{B.4.5 Modalidade de oferta do set-top box}

O fluxo de caixa acumulado para o cenário que considera a compra do set-top box pelo usuário ao invés do fornecimento do equipamento em regime de comodato sem custo para o usuário está apresentado na Figura 86 , e os principais indicadores econômicos na Tabela 33.

\section{FC Descontado - Acumulado}

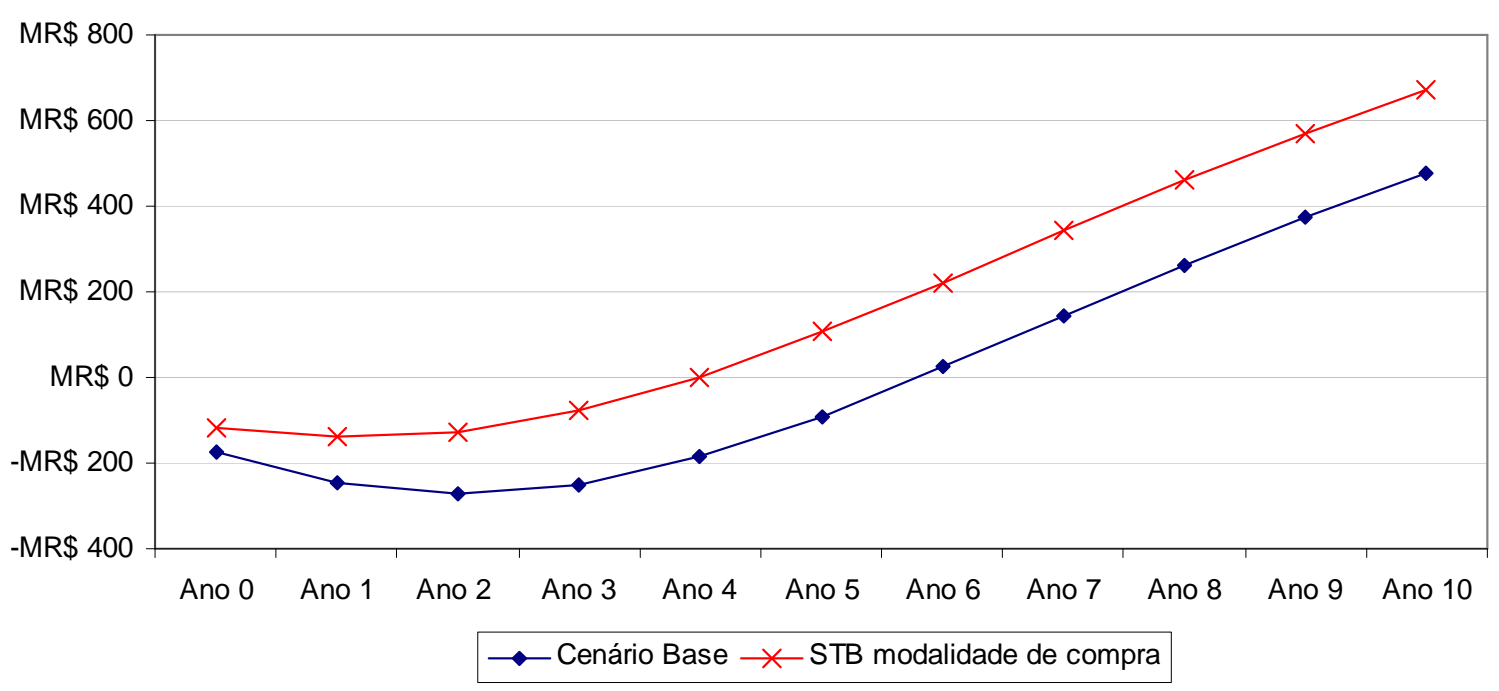

Figura 86 - Fluxo de Caixa Acumulado - cenários de oferta set-top box 
Tabela 33 - Indicadores econômicos - cenários de oferta set-top box

\begin{tabular}{lcc}
\hline Indicador & $\begin{array}{c}\text { Set-top box em } \\
\text { comodato } \\
\text { (Cenário Base) }\end{array}$ & $\begin{array}{c}\text { Set-top box na } \\
\text { modalidade de } \\
\text { compra }\end{array}$ \\
\hline VPL & MR $\$ 475$ & MR $\$ 670$ \\
\hline TIR & $35 \%$ & $55 \%$ \\
\hline Payback & & 4,0 \\
\hline Descontado (anos) & 5,8 & \\
\hline
\end{tabular}

O cenário em que o assinante compra o set-top box fica significativamente mais atrativo do ponto de vista econômico. Neste cenário, o valor gerado ao longo de dez anos é elevado para MR $\$ 670$, a TIR para 55\%, o período de recuperação de investimento é reduzido para 4 anos e o ponto de mínimo do fluxo de caixa fica bastante suavizado.

\section{Investimento médio por assinante}

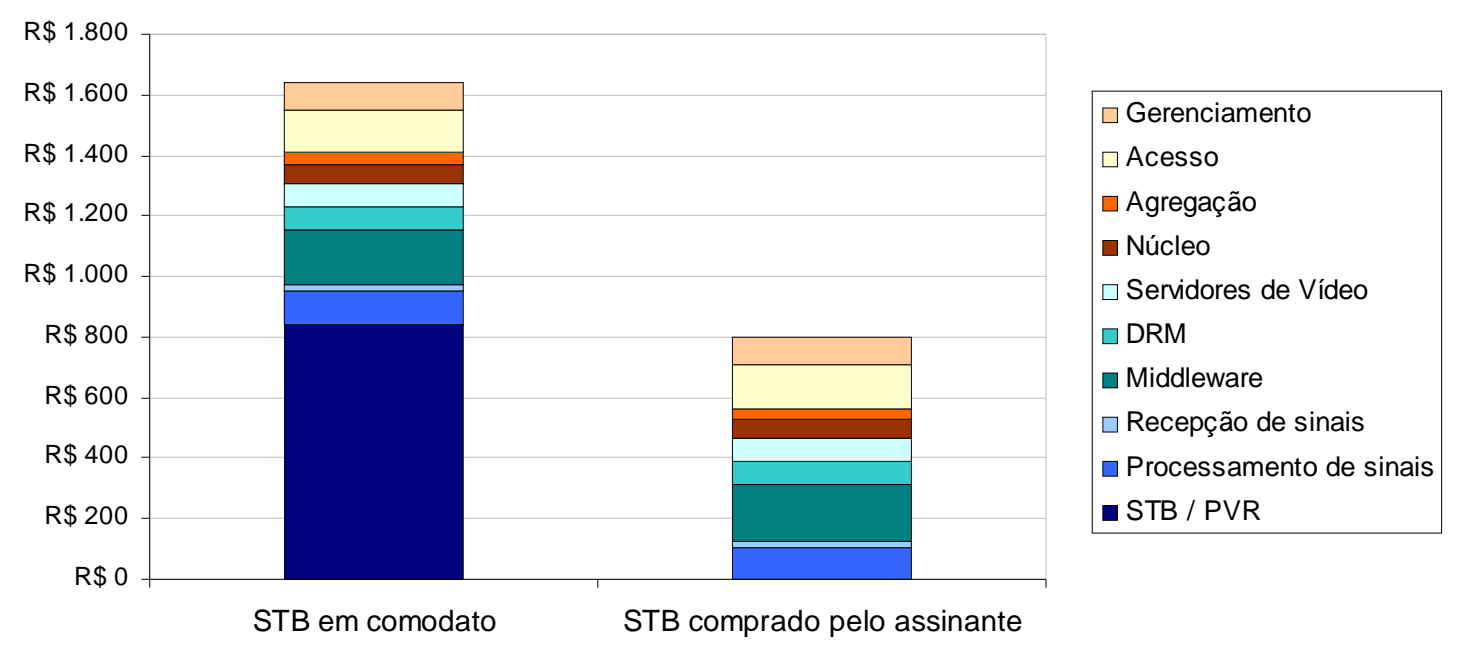

Figura 87 - Investimento por assinante - cenários de oferta set-top box

A razão disso é eliminação do set-top box como uma componente dos investimentos conforme pode ser observado na Figura 87. O nível de investimento por assinante fica reduzido a aproximadamente $50 \%$ de seu valor, beneficiando o resultado econômico.

Conforme constatado, a modalidade como o set-top box é fornecido ao usuário final faz bastante diferença do ponto de vista econômico. Neste caso, foram simulados dois extremos em que ou a operadora paga integralmente o set-top box ou o usuário 
paga pelo equipamento. Entretanto, modalidades intermediárias podem ser exercitadas visando melhorar as condições de viabilidade do serviço e também não onerar demasiadamente o usuário. Uma dessas modalidades é o caso em que a operadora subsidia parte do equipamento, e o usuário paga pelo restante. Outra modalidade é o aluguel do equipamento em que o usuário paga prestações mensais pelo equipamento, remunerando a operadora por ele.

Neste caso, considera-se que a operadora fornece o set-top box em regime de comodato por razões históricas do mercado, pois as operadoras de TV paga no mercado em que a ACME atua assim o fazem e qualquer outra modalidade poderia inibir a adoção do serviço em um primeiro momento. Entretanto, maneiras alternativas poderiam ser exploradas visando à obtenção de uma melhor condição de viabilidade.

\section{B.4.6 Arquitetura de distribuição de conteúdo}

A comparação dos cenários de distribuição de conteúdo leva em conta três alternativas: conteúdo centralizado no SHE, distribuído nos VHOs (cenário base) e distribuído nos VSOs, conforme detalhado no item B.2.4.1.1.4. Os resultados de fluxo de caixa acumulado e principais indicadores econômicos estão apresentado na Figura 88 e Tabela 34, respectivamente. 
FC Descontado - Acumulado

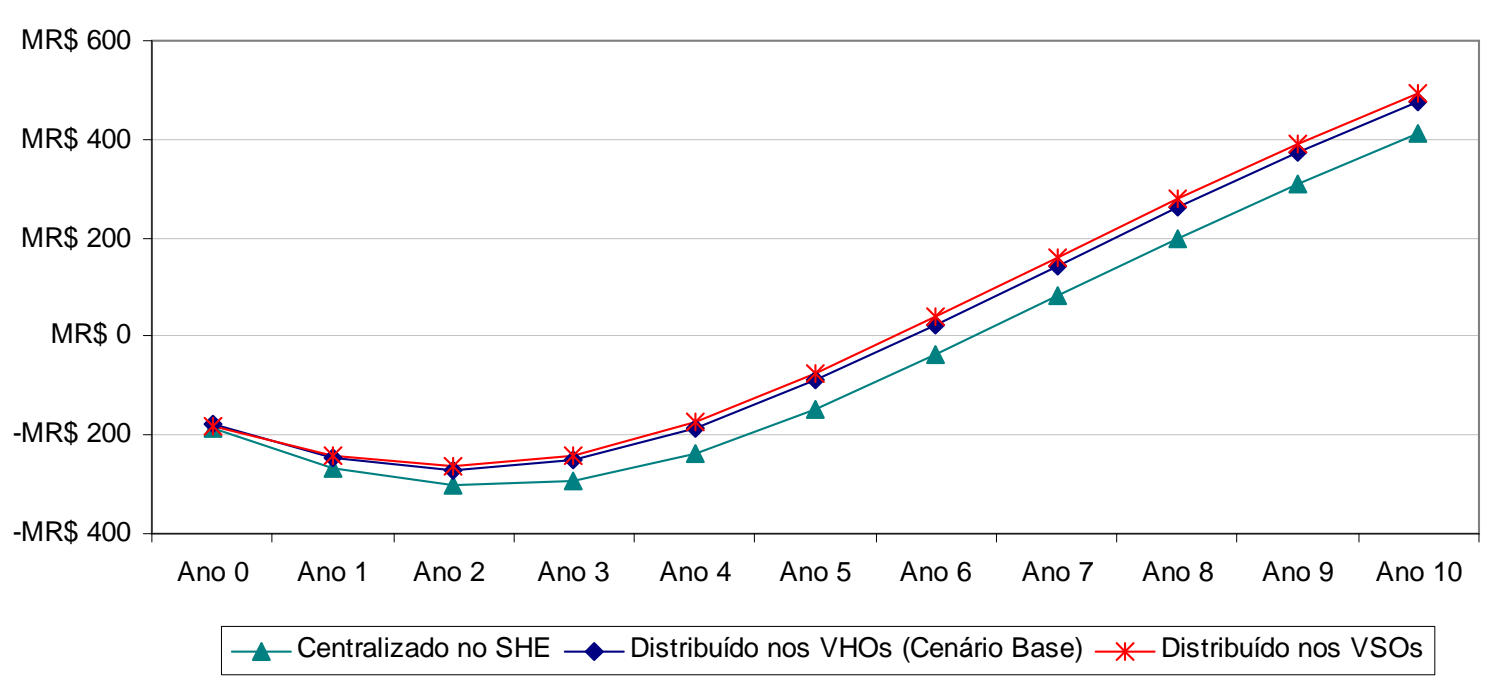

Figura 88 - Fluxo de Caixa Acumulado - cenários de distribuição de conteúdo

Tabela 34 - Indicadores econômicos - cenários de distribuição de conteúdo

\begin{tabular}{lccc}
\hline \multicolumn{1}{c}{ Indicador } & $\begin{array}{c}\text { Centralizado } \\
\text { no SHE }\end{array}$ & $\begin{array}{c}\text { Distribuído nos } \\
\text { VHOs } \\
\text { (Cenário Base) }\end{array}$ & $\begin{array}{c}\text { Distribuído nos } \\
\text { VSOs }\end{array}$ \\
\hline VPL & MR $\$ 411$ & MR\$ 475 & MR\$ 492 \\
\hline TIR & $31 \%$ & $35 \%$ & $36 \%$ \\
\hline Payback & & & \\
Descontado (anos) & 6,3 & 5,8 & 5,7 \\
\hline
\end{tabular}

Conforme se pode observar, os cenários possuem resultados muito próximos entre si e todos apresentam viabilidade econômica satisfazendo os critérios de VPL $>0$ e TIR > TMA. 


\section{Investimento médio por assinante Rede e Servidores de Vídeo}

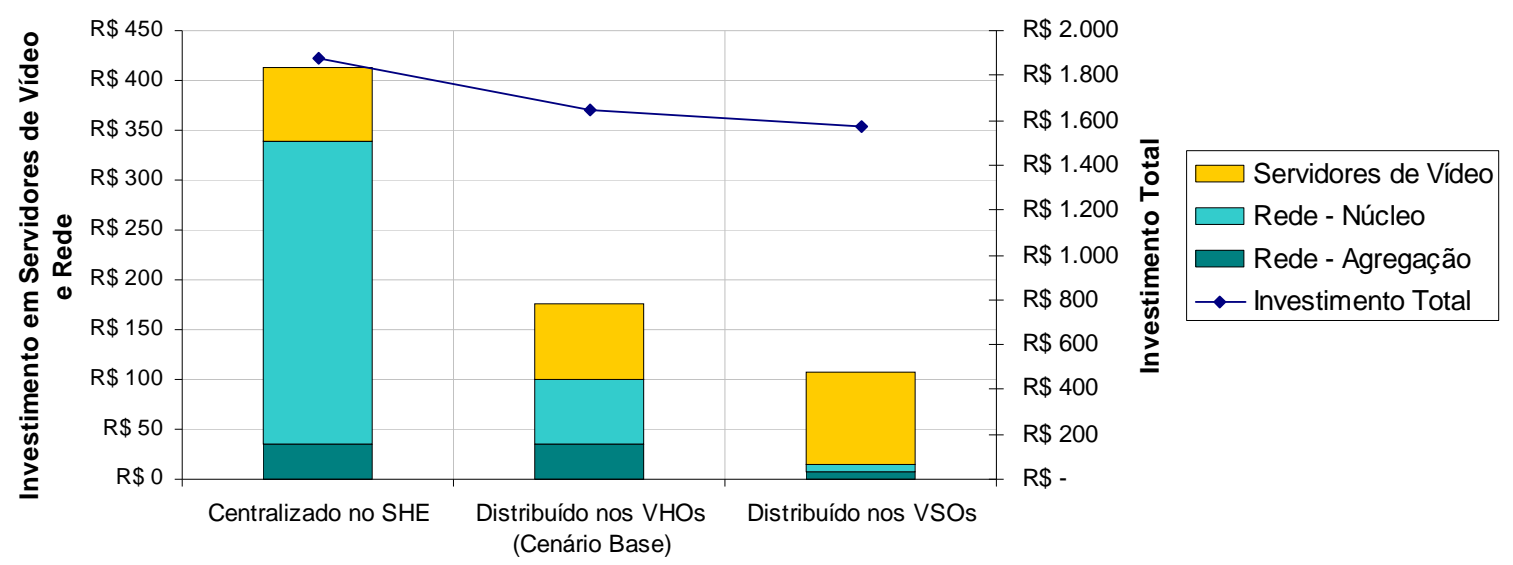

Figura 89 - Investimento por assinante - cenários de distribuição de conteúdo

Ainda assim, nota-se uma diminuição do valor gerado e uma ligeira postergação no tempo de recuperação de investimento no caso de centralização no SHE devido ao aumento do investimento neste cenário. Tal incremento de investimento está associado ao núcleo da rede e ocorre devido ao aumento do tráfego neste segmento de rede, pois todas as requisições de conteúdo são atendidas pelo SHE e cada fluxo de tráfego VOD trafega pelo núcleo para chegar aos VHOs. A Figura 89 mostra o investimento médio por assinante em sua totalidade e também as componentes de rede e servidores de vídeo em maior destaque, onde se pode perceber tal incremento de investimento.

No cenário da distribuição total do conteúdo para o VSO, percebe-se que existe um aumento simbólico do valor gerado. Tal incremento se deve à ligeira diminuição do investimento neste cenário. Devido à necessidade de unidades de armazenamento nos VSOs, existe um aumento de investimento em servidores de vídeo que é compensada pela redução de investimentos em rede de agregação e núcleo. Como existem cópias do conteúdo mais acessado nos VSOs, o tráfego da agregação é diminuído substancialmente. O investimento no núcleo também é reduzido dado que existe uma cópia de todo o conteúdo nos VHOs e, assim, as requisições não atendidas nos VSOs são atendidas integralmente nos VHOs. Desta forma, o tráfego no núcleo da rede devido ao tráfego VOD é apenas relacionado à cópia das matrizes 
de conteúdo do SHE para o VHO, e não devido ao atendimento de requisições de assinantes.

Comparando os diversos cenários, percebe-se que as situações de maior distribuição de conteúdo no caso da ACME levam à otimização do investimento total, pois a necessidade de investimento adicional em unidades de armazenamento é superada pela economia de recursos de rede. Ainda que seja uma redução pouco expressiva face aos outros investimentos associados ao serviço, ela deve ser tomada em consideração.

Nota-se também que a maior parte dos ganhos é capturada quando da distribuição do conteúdo para o VHO - situação descrita no cenário base - devido aos custos mais elevados de transporte no núcleo em comparação com o segmento agregação e também devido à relação dos custos de rede versus servidor de vídeo.

Deve-se ressaltar que o maior nível de distribuição da solução pode levar ao incremento da complexidade operacional, incorrendo em eventual aumento de custos operacionais que não foi mensurado nesta análise. Desta forma, considerando que os ganhos com a solução de distribuição do conteúdo para os VSOs não é tão significativo nesse caso, esta alternativa deve ser analisada de forma criteriosa levando em conta os aspectos econômicos, operacionais e também fatores tecnológicos relacionados à melhoria de desempenho da solução de IPTV quando da disponibilização do conteúdo mais próximo ao assinante. Tal alternativa poderia ser adotada de maneira caso a caso em regiões selecionadas como, por exemplo, em VSOs que concentram maior quantidade de assinantes.

\section{B.4.7 Tecnologia de rede de acesso}

Os cenário de tecnologia de acesso compreendem a utilização de arquiteturas inteiramente baseadas em fibra óptica (FTTH) no lugar da arquitetura mista de fibra e par metálico (FTTCab) para atender assinantes de conteúdo de alta definição devido à maior necessidade de largura de banda. A Figura 90 mostra os resultados de fluxo de caixa acumulado para cada cenário e a Tabela 35 os principais indicadores econômicos. 


\section{FC Descontado - Acumulado}

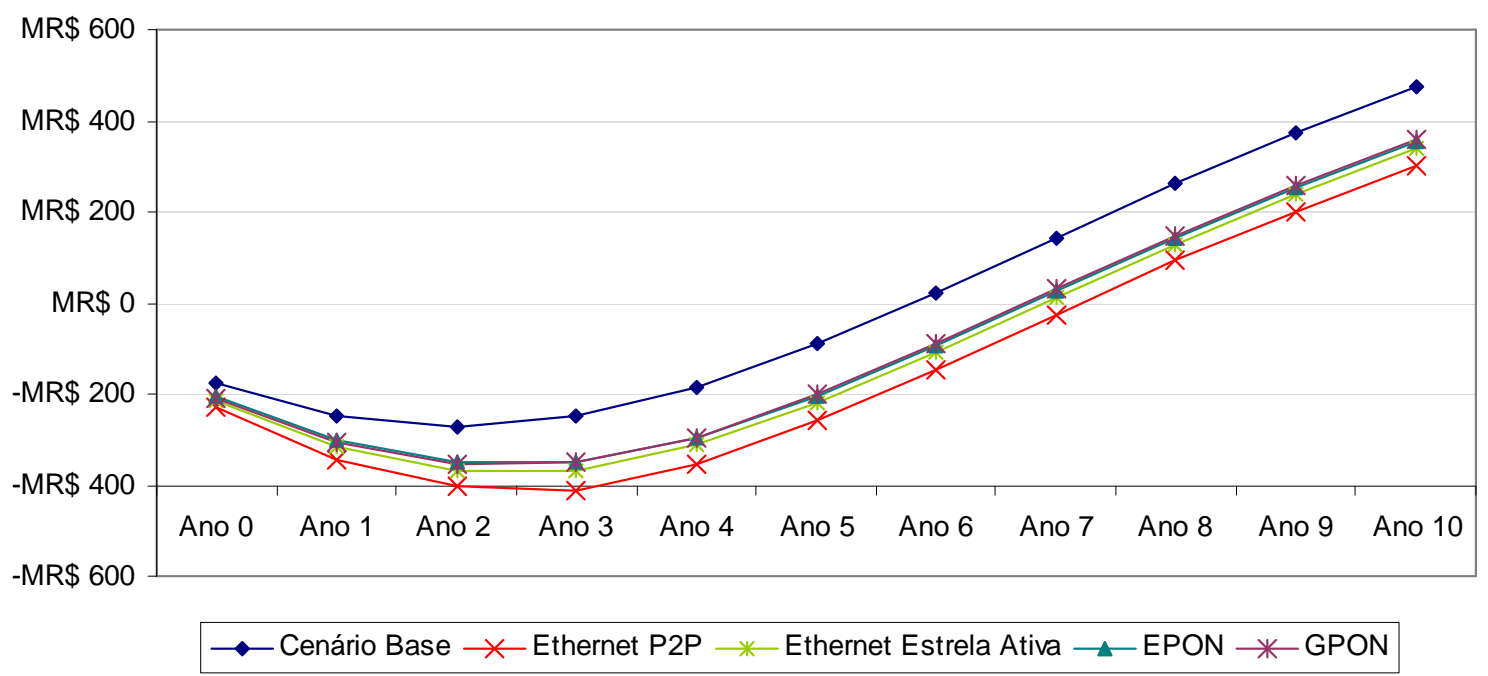

Figura 90 - Fluxo de Caixa Acumulado - cenários de tecnologia de acesso

Tabela 35 - Indicadores econômicos - cenários de tecnologia de acesso

\begin{tabular}{lccccc}
\hline Indicador & $\begin{array}{c}\text { Cenário } \\
\text { Base }\end{array}$ & $\begin{array}{c}\text { Ethernet } \\
\text { Ponto-a- } \\
\text { ponto }\end{array}$ & $\begin{array}{c}\text { Ethernet } \\
\text { Estrela } \\
\text { Ativa }\end{array}$ & EPON & GPON \\
\hline VPL & $\mathrm{MR} \$ 475$ & $\mathrm{MR} \$ 303$ & $\mathrm{MR} \$ 342$ & $\mathrm{MR} \$ 355$ & $\mathrm{MR} \$ 359$ \\
\hline TIR & $35 \%$ & $25 \%$ & $27 \%$ & $28 \%$ & $28 \%$ \\
\hline $\begin{array}{l}\text { Payback } \\
\begin{array}{l}\text { Descontado } \\
\text { (anos) }\end{array}\end{array}$ & 5,8 & 7,2 & & & \\
\hline
\end{tabular}

A introdução de fibra-óptica até a residência do assinante introduz um impacto negativo na viabilidade econômica do projeto. Em todos os cenários alternativos ao cenário base, existe uma diminuição do valor gerado, da TIR e aumento do tempo para recuperação do investimento, que é postergado em no mínimo 1 ano. Este efeito negativo do ponto de vista econômico se dá em virtude dos investimentos vultosos das arquiteturas totalmente baseadas em fibra sem a alteração do volume de receitas para remunerar esse investimento. 


\section{Investimento médio por assinante}

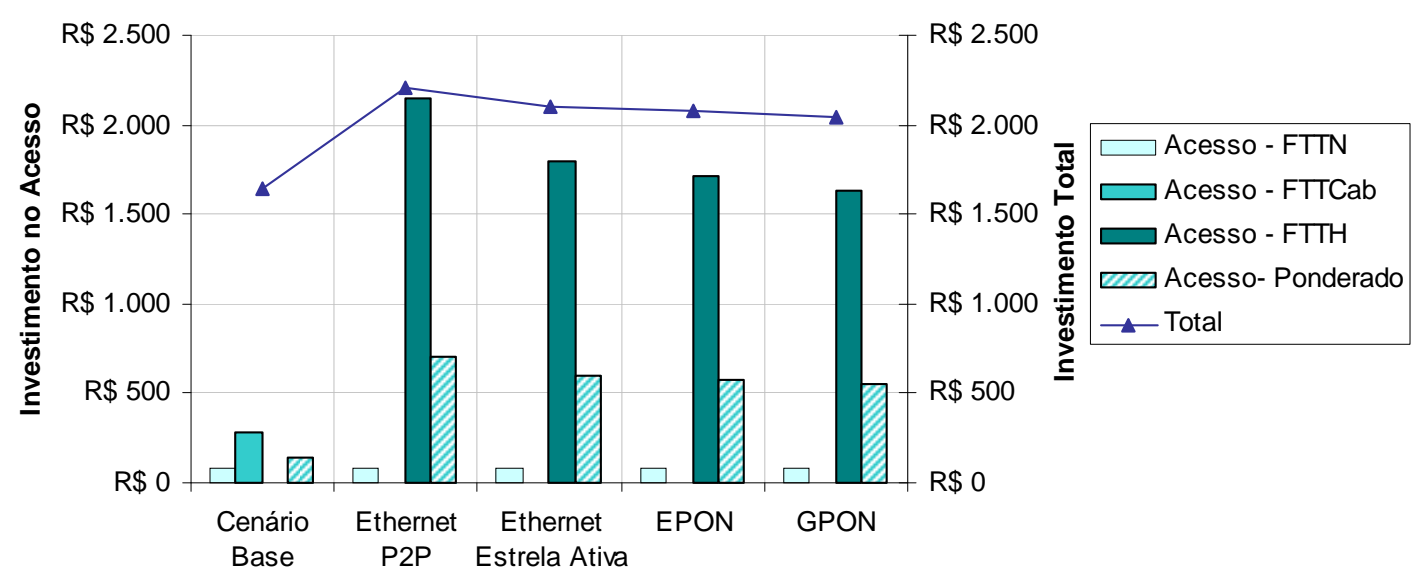

Figura 91 - Investimento por assinante - cenários de tecnologia de acesso

O gráfico de barras da Figura 91 mostra o investimento médio no acesso para assinantes conectados usando FTTN, FTTCab, FTTH e o valor ponderado entre as tecnologias de acesso considerando todos usuários. O gráfico de linha da mesma figura indica o investimento médio por assinante considerando os demais componentes da solução IPTV.

Em todos os três cenários, percebe-se o aumento significativo do investimento ponderado no acesso, que é motivado pelo alto investimento por assinante nas arquiteturas FTTH. O investimento dos assinantes FTTCab no cenário base é substituído pelo investimento em FTTH nos cenários alternativos, elevando bastante o investimento ponderado.

Comparando as arquiteturas ente $\mathrm{si}$, nota-se que a ordem de magnitude dos investimentos em FTTH é bastante similar para as três situações consideradas: Ethernet P2P, Ethernet estrela ativa e PON (EPON e GPON). Entretanto, o investimento é menor nos casos das arquiteturas de estrela ativa e PON respectivamente, devido ao compartilhamento de fibras na rede de distribuição primária para servir diversos assinantes conforme discutido no item B.3.2.

Considerando as arquiteturas compartilhadas, as PON apresentam menor nível de investimento devido ao menor custo da solução passiva em comparação com a solução baseada em elementos ativos nos armários de distribuição. Além disso, a 
arquitetura de estrela ativa pode levar à maior complexidade operacional, pois a manutenção dos elementos ativos distribuídos nos armários torna-se menos eficiente do que nas outras arquiteturas em que os elementos ativos estão concentrados na central. Das duas tecnologias PON consideradas, a tecnologia GPON apresentou menor nível de investimento. Entretanto, há que se considerar que existem perspectivas de evolução da tecnologia EPON de velocidades de 1 Gbps para $10 \mathrm{Gbps}$, o que poderá trazer redução de custo médio por assinante em sua arquitetura.

Apesar da diferença quantitativa nos investimentos que favorece as arquiteturas PON em detrimento da Ethernet ponto-a-ponto em aproximadamente 30\% considerando os investimentos ao longo de todo período de avaliação, outros aspectos qualitativos devem ser levados em conta na hora da decisão de qual a melhor arquitetura a ser perseguida.

Um dos fatores importantes a considerar é que apesar dos maiores investimentos, a arquitetura ponto-a-ponto oferece maior flexibilidade e escalabilidade pensando no longo prazo, pois existe uma fibra dedicada para cada assinante desde a central até seu domicílio. Por exemplo, na arquitetura ponto-a-ponto, a evolução do acesso de 100 Mbps para 1Gbps ao usuário final pode ocorrer de forma menos traumática, alterando apenas os elementos ativos sem interferir na rede de fibra óptica. $O$ conceito de rede ponto-a-ponto é o mesmo empregado na rede de par metálico e que permitiu sua utilização até os dias de hoje desde a oferta de telefonia básica em seus primórdios até a Internet de alta velocidade nos dias mais recentes.

Além dos aspectos de arquitetura mais adequada, a evolução para uma rede óptica de maneira fim-a-fim deve ser pensada de forma integrada a partir da oferta de serviços que possam contribuir para remunerar tal infra-estrutura de maneira mais eficiente. Exemplos desses serviços incluem desde Internet banda larga de alta velocidade (ex.: $16 \mathrm{Mbps}$, 24Mbps, 50Mbps) até serviços de valor adicionado que podem ser agregados à plataforma de IPTV (vídeo telefonia e jogos multiplayer online). Conforme discutido no item B.3.3, deve-se considerar que do investimento associado ao acesso, $50 \%$ foi alocado ao serviço IPTV no caso ACME. Os $50 \%$ restantes deveriam ser alocados ao serviço de banda larga de velocidades mais altas. Desta forma, o investimento efetivo para implementar essa arquitetura é duas vezes maior do que os valores apresentados. 
Outro fator importante na evolução de rede de acesso é a janela de tempo em que será implementada. Nos cenários aqui apresentados, ela foi pensada para acontecer desde o primeiro momento visando atender assinantes HDTV. De maneira alternativa, a evolução do acesso pode ocorrer em etapas, estendendo ao máximo a vida útil da rede de par metálico utilizando a arquitetura de FTTCab considerada no cenário base. No curto prazo, a oferta de HDTV aconteceria utilizando FTTCab e no longo prazo seria evoluída para uma arquitetura FTTH levando a fibra do armário para a casa do assinante.

\section{B.4.8 Preço do serviço}

O preço é uma das características fundamentais associadas à viabilidade econômica do serviço. Desta forma, foram realizadas simulações a fim de capturar a influência da variação do preço. Os resultados estão apresentados na Figura 92 e na Tabela 36.

\section{FC Descontado - Acumulado}

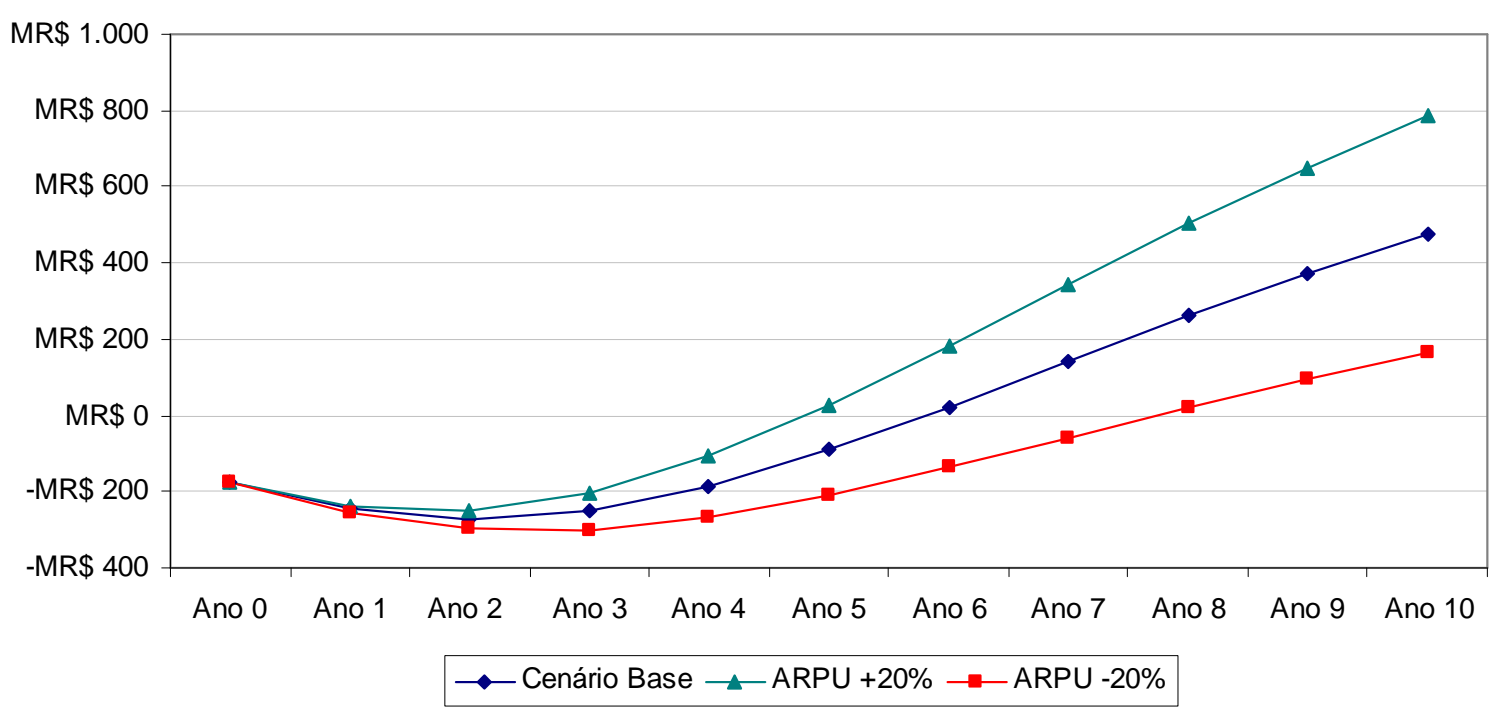

Figura 92 - Fluxo de Caixa Acumulado - cenários de preço do serviço 
Tabela 36 - Indicadores econômicos - cenários de preço do serviço

\begin{tabular}{lccc}
\hline \multicolumn{1}{c}{ Indicador } & ARPU - 20\% & Cenário Base & ARPU + 20\% \\
\hline VPL & MR \$ 163 & MR\$ 475 & MR\$ 785 \\
\hline TIR & $23 \%$ & $35 \%$ & $45 \%$ \\
\hline $\begin{array}{l}\text { Payback } \\
\begin{array}{l}\text { Descontado } \\
\text { (anos) }\end{array}\end{array}$ & & & \\
\hline
\end{tabular}

A variação do preço do serviço foi capturada na variação da ARPU associada ao assinante e observa-se que existe uma grande sensibilidade na viabilidade econômica do serviço. Para uma variação da ordem de $20 \%$ na receita do assinante, o perfil de fluxo de caixa varia bastante. Com um aumento de $20 \%$ na receita, o VPL aumenta em $65 \%$ e com o decréscimo de receita em mesma proporção, o VPL também diminui em $66 \%$. O tempo para recuperação do investimento também é significativamente alongado com a diminuição da receita, demorando aproximadamente 2 anos a mais. Tal influência do nível de preço se deve ao seu efeito cumulativo e multiplicador da receita devido à natureza recorrente do serviço.

Além de satisfazer às expectativas do assinante, o nível de preço adequado é fundamental para a rentabilidade do serviço no horizonte de tempo determinado. A rentabilidade do serviço fica bastante vulnerável a qualquer variação do preço, por exemplo, relacionada a guerras de preço promovidas pela concorrência, indicando que a estratégia de baixo preço é potencialmente perigosa. Em contrapartida, a estratégia da diferenciação pela riqueza de conteúdo, experiência oferecida ao usuário e a adição de novos serviços são opções para diminuir a susceptibilidade do serviço ao fator preço.

\section{B.4.9 Custos de conteúdo}

Conforme ilustrado no item B.3.2, os custos associados com a aquisição de conteúdo são os mais representativos da estrutura de custos e despesas operacionais. Desta forma, foram realizadas simulações para avaliar os efeitos de sua variação. Os resultados estão apresentados na Figura 93 e Tabela 37. 


\section{FC Descontado - Acumulado}

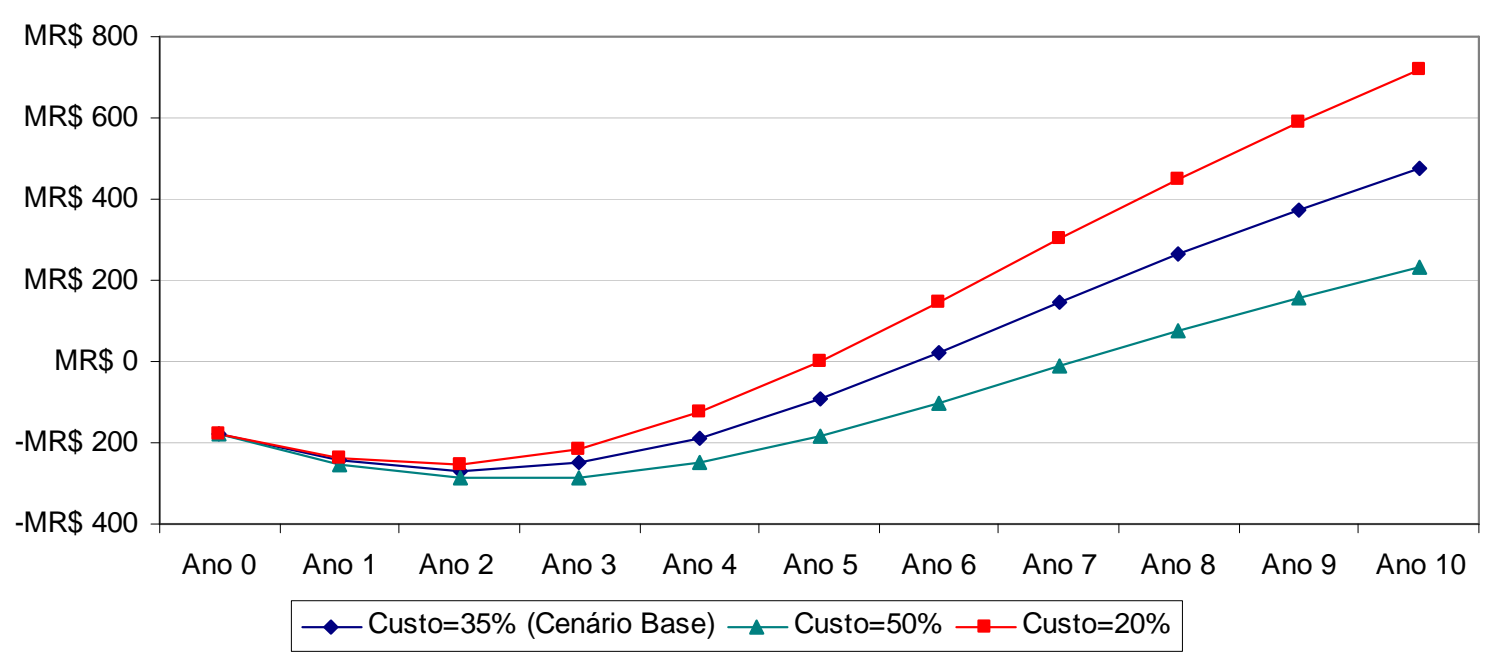

Figura 93 - Fluxo de Caixa Acumulado - cenários de custo de conteúdo

Tabela 37 - Indicadores econômicos - cenários de custo de conteúdo

\begin{tabular}{lccc}
\hline Indicador & Custos = 20\% & $\begin{array}{c}\text { Custos = 35\% } \\
\text { (Cenário Base) }\end{array}$ & Custos = 50\% \\
\hline VPL & MR $\$ 719$ & MR\$ 475 & MR $\$ 230$ \\
\hline TIR & $43 \%$ & $35 \%$ & $26 \%$ \\
\hline $\begin{array}{l}\text { Payback } \\
\text { Descontado }\end{array}$ & 5,0 & 5,8 & 7,2 \\
\hline
\end{tabular}

O custo com conteúdo foi estimado a partir de benchmarks de operadoras pagas no cenário local como sendo $35 \%$ da receita líquida. Foram realizadas simulações variando este patamar para $20 \%$ e $50 \%$ a fim de verificar seus efeitos. O tempo para recuperação do investimento é retardado em mais de um ano quando do aumento de custos de programação para um patamar de $50 \%$ da receita.

Nota-se que o serviço é bastante sensível ao custo de conteúdo, pois o VPL varia em torno de $50 \%$ quando sujeito a tal variação de entrada. Desta forma, os acordos com provedores de conteúdo de maneira a minimizar tais custos possuem fundamental importância na viabilidade econômica do serviço. 


\section{B.4.10 Investimento na infra-estrutura tecnológica}

Conforme evidenciado até aqui, o perfil de investimentos associado ao serviço tem um fator determinante em sua atratividade econômica. Desta forma, foram realizadas simulações para avaliar os efeitos de sua variação. Os resultados estão apresentados na Figura 94 e na Tabela 38.

\section{FC Descontado - Acumulado}

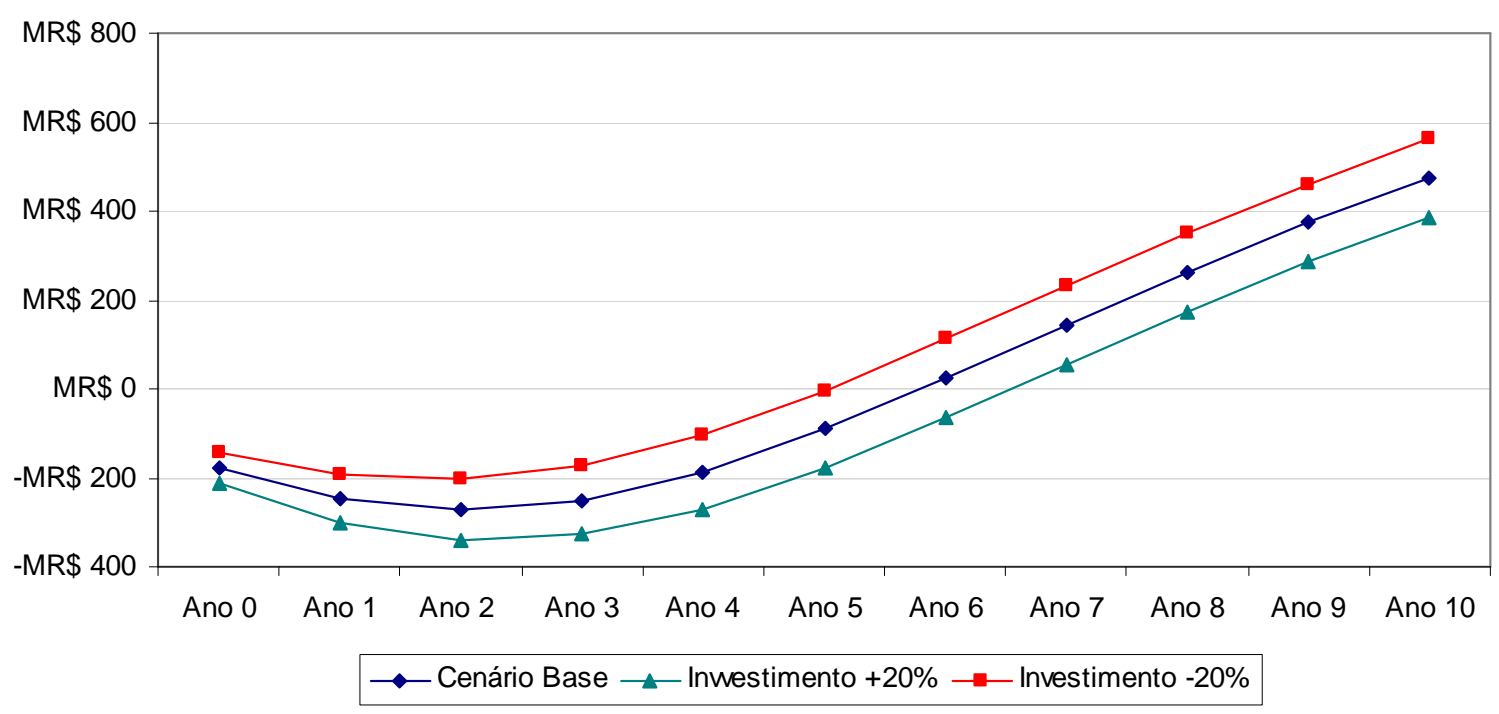

Figura 94 - Fluxo de Caixa Acumulado - cenários de investimento

Tabela 38 - Indicadores econômicos - cenários de investimento

\begin{tabular}{lccc}
\hline Indicador & $\begin{array}{c}\text { Investimento } \\
\mathbf{- 2 0 \%}\end{array}$ & Cenário Base & $\begin{array}{c}\text { Investimento } \\
\mathbf{+ 2 0} \%\end{array}$ \\
\hline VPL & $\mathrm{MR} \$ 563$ & $\mathrm{MR} \$ 475$ & $\mathrm{MR} \$ 387$ \\
\hline TIR & $42 \%$ & $35 \%$ & $29 \%$ \\
\hline $\begin{array}{l}\text { Payback } \\
\text { Descontado }\end{array}$ & 5,0 & 5,8 & 6,5 \\
\hline
\end{tabular}

Analisando os resultados, nota-se que e houver uma variação dos investimentos em mesma proporção do que na receita do serviço, o perfil de fluxo de caixa varia em menor intensidade. O VPL dos cenários alternativos apresenta uma variação da ordem de $20 \%$ com a variação de $20 \%$ no nível de investimentos. Com menor nível 
de investimentos, o período de sua recuperação diminui em meio ano e com o maior nível de investimentos, este período é dilatado em um ano.

Ainda que não seja tão significativo, existe um efeito benéfico na atratividade do serviço devido à queda do custo de tecnologia associado à infra-estrutura a IPTV, seja por força de melhores condições contratuais ou pela diminuição intrínseca do custo da tecnologia oriundos do aumento da escala de adoção de serviços IPTV no mundo.

\section{B.4.11 Taxa de desconto}

Além dos cenários anteriores, foi realizada a simulação para capturar o efeito da taxa de desconto na atratividade econômica do projeto. A taxa de desconto utilizada como base para as demais simulações foi de $15 \%$. Neste caso, foram realizadas simulações para taxas de desconto de $10 \%$ e $20 \%$. Os resultados estão apresentados na Figura 95 e na Tabela 39.

\section{FC Descontado - Acumulado}

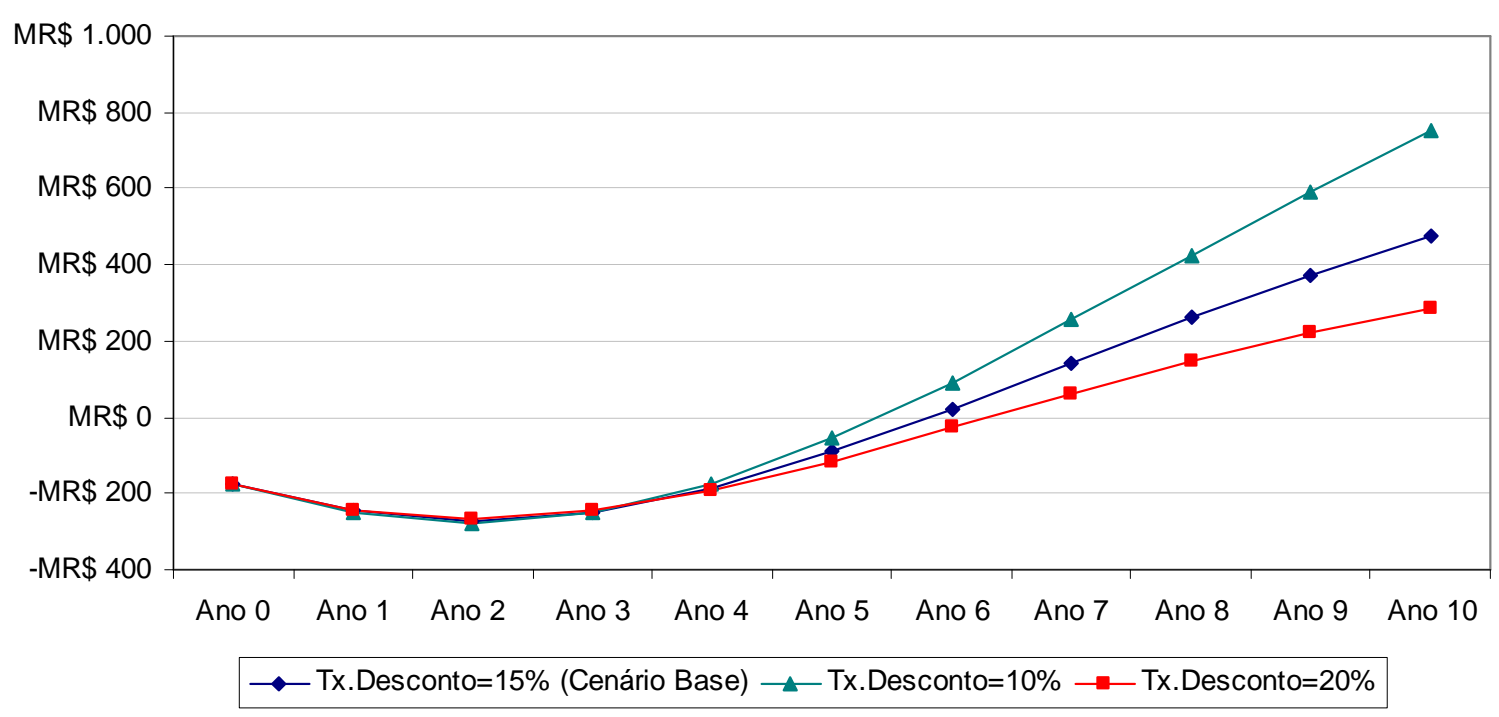

Figura 95 - Fluxo de Caixa Acumulado - cenários de taxa de desconto 
Tabela 39 - Indicadores econômicos - cenários de taxa de desconto

\begin{tabular}{lccc}
\hline Indicador & $\begin{array}{c}\text { Taxa de } \\
\text { desconto }=\mathbf{1 0} \%\end{array}$ & $\begin{array}{c}\text { Taxa de } \\
\text { desconto }=\mathbf{1 5} \% \\
\text { (cenário base) }\end{array}$ & $\begin{array}{c}\text { Taxa de } \\
\text { desconto = 20\% }\end{array}$ \\
\hline VPL & MR $\$ 750$ & MR\$ 475 & MR\$ 288 \\
\hline TIR & $35 \%$ & $35 \%$ & $35 \%$ \\
\hline Payback & & 5,8 & 6,3 \\
\hline Descontado & 5,4 & 5,8 & \\
\hline
\end{tabular}

A partir dos resultados da simulação percebe-se que existe grande sensibilidade à taxa de desconto no que diz respeito ao valor gerado ao longo do tempo. O VPL aumenta cerca de $60 \%$ com a diminuição de $5 \%$ na taxa de desconto e diminui $40 \%$ com o aumento da taxa na mesma quantidade. Entretanto, o tempo para recuperação do investimento fica muito próximo nos diversos cenários.

Este comportamento se deve às características do fluxo de caixa que possui nível de investimento elevado durante os primeiros anos para suportar os novos assinantes, e possui aumento significativo de receita no longo prazo.

Desta forma, ainda que fosse exigido um maior retorno do projeto (refletido em uma taxa de desconto maior), o tempo de recuperação do investimento varia muito pouco, passando de 5,8 para 6,3 anos, ainda que a geração de riqueza varie significativamente devido ao aumento de receita associado ao serviço no longo prazo. 